\title{
Effects of Milk Processing on the Milk Fat Globule Membrane Constituents
}

\author{
A Thesis \\ presented to the
}

Faculty of California Polytechnic State University,

San Luis Obispo

In Partial Fulfillment of the Requirements for the Degree

Master of Science in Agriculture, with Specialization in Dairy Products Technology

By

Xiomara E. Elías-Argote, 
(C)2011

Xiomara E. Elías-Argote

ALL RIGHTS RESERVED 


\section{COMMITTEE MEMBERSHIP}

TITLE: $\quad$ Effect of Milk Processing on the Milk Fat Globule Membrane Constituents

AUTHOR: $\quad$ Xiomara Elizabeth Elías-Argote

DATE SUBMITTED: $\quad$ Monday, July $18^{\text {th }}, 2011$

COMMITTEE CHAIR:

Rafael Jiménez-Flores, Ph.D., Professor

COMMITTEE MEMBER:

Margaret Rice, Ph.D., Professor

COMMITTEE MEMBER:

Chad Immoos, Ph.D., Associate Professor 
"We don't receive wisdom; we must discover it for ourselves after a journey that no one can take for us or spare us"

\section{-Marcel Proust}




\section{ACKNOWLEDGEMENTS}

Abraham Lincoln once stated, "I am a success today because I had a friend who believed in me and I didn't have the heart to let him down..." In my case, I am presenting this thesis because I had professors, friends, and family members who supported me throughout my journey, and without them, I would have not crossed the finish line.

I want to acknowledge the role of my committee members: Dr. Rice, Dr. Immoos, and Dr. Jiménez-Flores, who gave me their advice, guidance, and time, and who shared their knowledge for the completion of this thesis. This work is also the result of a collaborative effort between departments, and therefore, I want to thank Dr. Carrol and Dr. Tomanek for their support and mentorship. Marcus Zuzow was a key factor and the catalyst to complete proteomic analysis, and I will always be grateful for all the assistance I got from Dr. Tomanek's group. All of these people shaped my thesis and contributed to the final work, but we must remember, "Science may set limits to knowledge, but should not set limits to imagination" (Bertrand Russell). And the latter was kept alive with the help of my friends at DPTC, hometown, and my family.

To all of you who touched my life during my master program, I thank and dedicate this work but do not leave without saying, "give the best of yourself: go there to win, or die trying to win.” ¡Gracias! 


\section{ABSTRACT \\ Effects of Milk Processing on the Milk Fat Globule Membrane Constituents \\ Xiomara E. Elías-Argote}

The milk fat globule membrane (MFGM) is avidly studied by many groups of scientists around the world due to its unprecedented nutritional and functional properties; however, limited research has been performed on the effects of milk processing on the chemical changes of the MFGM. Thus, this study highlights the changes that lipids and proteins undergo from the time milk leaves cow's udders. Cooling $\left(4^{\circ} \mathrm{C}\right)$ was included along with subsequent pasteurization by different traditional thermal processes and cold pasteurization by pulse light ultra violet treatment. Cooling milk to $4{ }^{\circ} \mathrm{C}$ had a measureable effect on the MFGM composition, resulting in protein alterations, particularly to butyrophilin and adipophilin. Thermal treatments disturbed the native structures of molecules and increased the adsorption of milk and whey proteins on the globules, especially $\alpha$-lactalbumin and $\beta$-lactoglobulin. As the heat intensity increased, the aggregation of fat globules became more pronounced due to protein interactions. Intrinsic MFGM proteins also varied in relative abundance during the processing steps. The concentrations of polar lipids did not change during processing, with the exception of phosphatidylserine, which decreased during the cooling and thermal treatments. Cold pasteurization (UV treatment) had a minimal effect on fat globules and MFGM proteins. Since the MFGM promises to deliver nutritional effects and more when included in food products, currently HTST pasteurization was shown to be the best method to process milk and obtain MFGM isolates for further supplementation.

Keywords: milk fat globule membrane (MFGM), proteomics, thermal treatment, milk processing, UV-light treatment. 


\section{TABLE OF CONTENTS}

LIST OF TABLES $\quad$ xv

LIST OF FIGURES xiv

I. INTRODUCTION

II. LITERATURE REVIEW

A. Brief Outline ..................................................................................................... 5

B. Origin and Function of the Milk Fat Globule Membrane ........................................ 5

C. Composition and Structure of the MFGM.......................................................... 10

1. Lipids of the Milk Fat Globule Membrane .................................................... 14
a) Phospholipids
b) Sphingolipids 19

2. Milk Fat Globule Membrane Proteins ............................................................. 23

a) Butyrophilin 26

b) Xanthine Oxidase 27

c) Adipophilin 29

d) Glycoprotein PAS6 and PAS7 30

e) Mucins 31

f) Lactoferrin 32

g) Cluster of Differentiation (CD36) 33

h) Fatty acid-binding protein (FABP) 34

D. Health Benefits of the Milk Fat Globule Membrane .............................................. 34

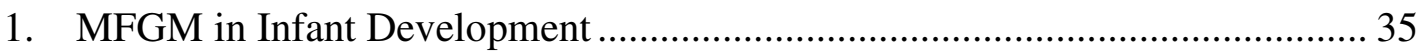

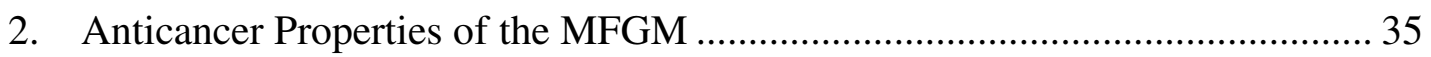

3. Antimicrobial and Antiviral Properties of the MFGM ................................. 36

E. Biochemical Properties of the MFGM in Food Products .................................... 38

1. Emulsifying and stabilizing properties of MFGM ...................................... 38

2. Potential delivery systems derived from MFGM....................................... 39 
3. Application of MFGM Components in Food Systems .................................. 39

F. Sources of the Milk Fat Globule Membrane: a Novel Dairy Product .................... 41

G. Isolation and Purification of the MFGM ........................................................ 43

1. Laboratory Production of MFGM.................................................................. 43

2. Commercial Production of MFGM............................................................. 45

a) Microfiltration 45

b) Ultrafiltration $\quad 46$

c) Purification through Aggregation 47

H. Physical and Chemical Effects of Processing on Fat Globules and MFGM.......... 48

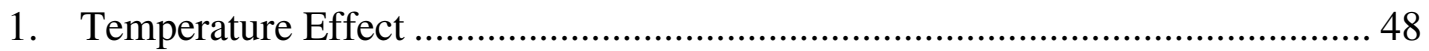

a) Cool Temperatures 48

b) Thermal Temperatures $\quad 50$

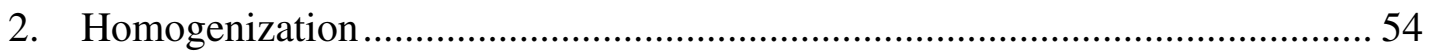

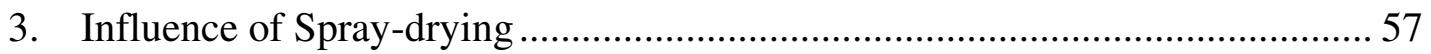

I. Cold Pasteurization-UV Pulsed Light Treatment ..................................................... 58

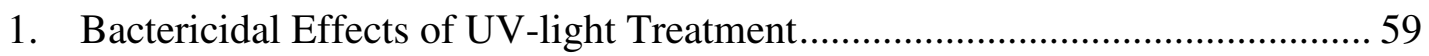

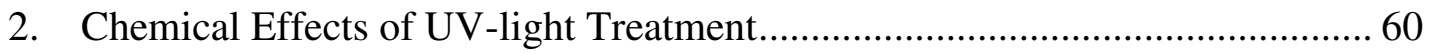

J. Methodology to Monitor the Biological Activity of the MFGM............................. 61

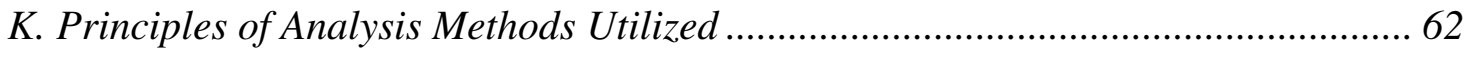

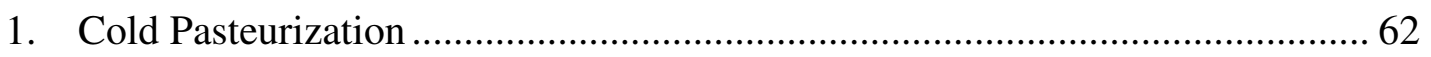

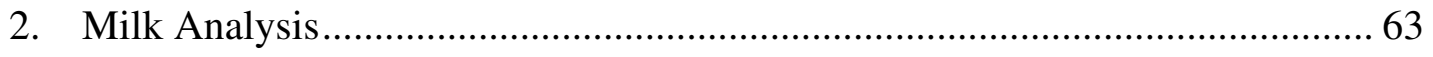

a) Analysis of Milk Lipids 63

b) Fourier Transform Infrared (FTIR) Milk Analysis 65

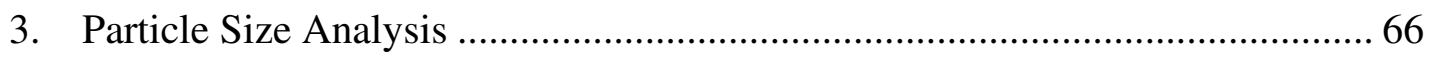

4. Sodium Dodecyl Sulfate Polyacrylamide Electrophoresis (SDS-PAGE) ......... 67

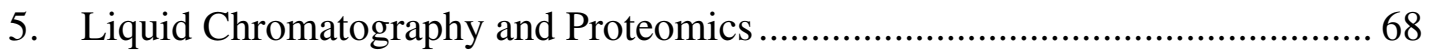




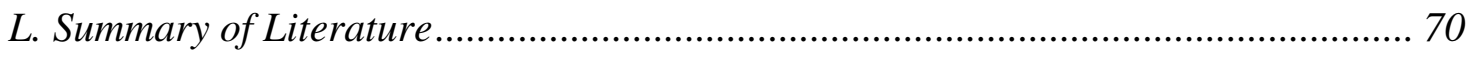

M. Justification for Present Research.................................................................... 71

III. MATERIALS AND METHODS

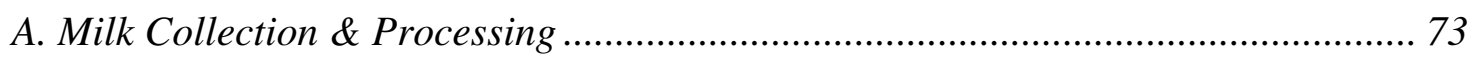

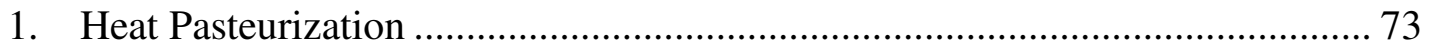

2. Cold Pasteurization- Pulsed UV Light............................................................... 74

a) Microbial Reduction in Milk 74

b) Milk Processing 75

B. Physical Properties of the Milk Fat Globule Membrane …………….................... 75

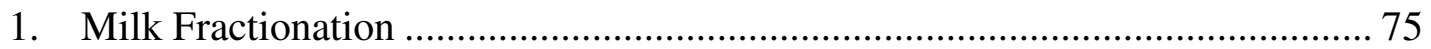

2. Milk Fat Globule Size Distribution................................................................. 76

C. Chemical Composition of Processed Milk …………………………………....... 77

1. Evaluation of Milk Composition …………………......................................... 77

2. Fat Extraction-Mojonnier............................................................................ 78

3. Determination of Phospholipids in the MFGM ………………....................... 79

a) Phospholipid Solid Phase Extraction (SPE) 79

b) Phospholipid Separation \& Quantification 80

4. Measurements of S-S and SH group levels........................................................ 82

D. Milk Fat Globule Membrane Extraction................................................................. 83

E. MFGM Protein Profile from One Dimensional Analysis....................................... 85

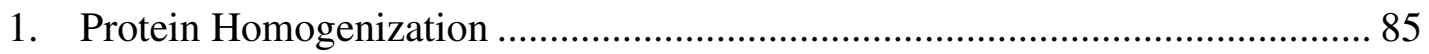

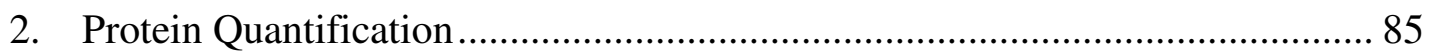

3. Sodium Dodecyl-Sulfate Polyacrylamide Gel Electrophoresis .......................... 86

4. Protein Densitometry \& Statistical Analysis .................................................... 87

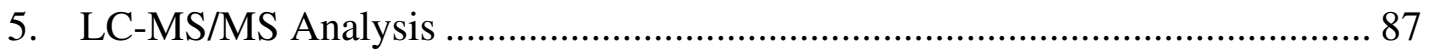


6. Database Searching and Criteria for Protein Identification 88

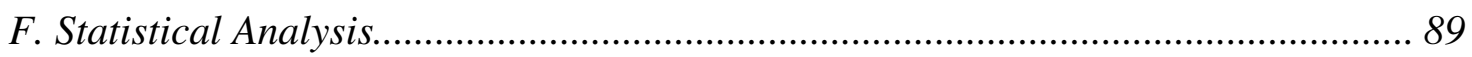

G. MFGM Protein Profile from Two-Dimensional Analysis..................................... 89

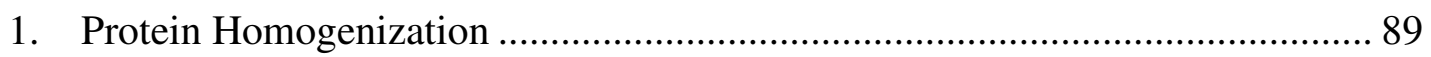

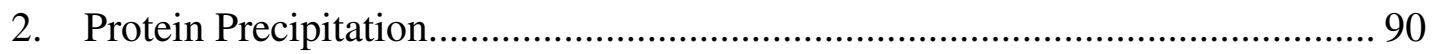

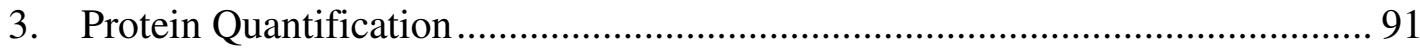

4. Isoelectric Focusing (IEF)-First Dimension ........................................... 92

5. SDS-PAGE-Second Dimension............................................................. 92

6. Sensitive Stepwise Colloidal Staining ...................................................... 93

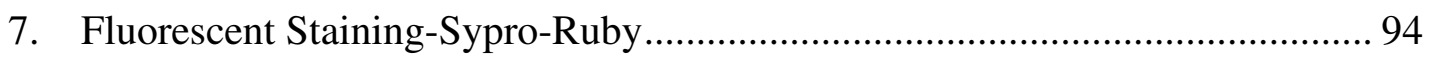

8. 2-DE Gel Image \& Statistical Analysis ...................................................... 95

9. Protein Excision \& Digestion from SDS-PAGE ....................................... 95

10. Mass Spectrometry- Protein Identification with MALDI-TOF ........................ 97

\section{RESULTS}

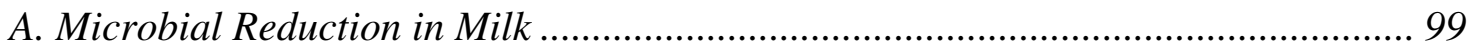

B. Fat Globule Size Distribution in Milk Processing ........................................... 102

C. Chemical Composition of Milk during Milk Processing .................................... 107

1. Milk Composition by FTIR Analysis .................................................... 107

2. Isolation of Milk Fat Globule Membrane .................................................. 108

3. Changes in the Amount of Protein in the Milk Fat Globule Membrane.......... 110

4. Changes in the Phospholipid of the Milk Fat Globule Membrane ................. 110

5. Changes in the Sulfhydryl (SH) \& Disulfide SS Groups............................. 117

D. Protein Profile from One Dimensional Gels Coupled with LC/MS..................... 118

1. Milk Fat Globule Membrane Protein Profile ............................................... 118 
2. MFGM Protein Quantification by SDS-PAGE Densitometry 120

3. MFGM Protein Identification through LC/MS

E. MFGM Protein Profile from 2-Dimensional Gel Coupled with MALDI-TOF ...... 133

1. Visualization of MFGM Proteins with Fluorescent Dye .................................... 133

2. Visualization of MFGM Protein with Coomassie Blue.................................... 134

3. MFGM Protein Variation during Milk Processing ………….......................... 135

4. Identification of MFGM Proteins during Milk Processing ............................... 137

$\begin{array}{ll}\text { V. DISCUSSION } & 146\end{array}$

A. Effects of Milk Processing on the Physical Properties of the MFGM .................. 146

B. Effects of Milk Processing on the Chemical Composition of the MFGM .............. 148

1. Changes in Milk Composition ……………………….............................. 148

2. Effects on MFGM Isolates \& Protein .............................................................. 149

3. Effects on the Phospholipid Profile of the MFG …………………………...... 151

4. Changes in the Sulfhydryl (SH) and Disulfide (SS) Groups .......................... 154

C. Effects of Milk Processing on the MFGM Proteins from 1DE Perspectives ......... 155

1. Quantification of Protein Variation during Milk Processing ........................... 155

2. Identification of Proteins that Change in Milk Processing .............................. 157

a) Proteins in Globlal Composition 157

b) Proteins Identification in Molecular Weight Regions 165

D. Effects of Milk Processing on the MFGM Proteins from 2DE Perspectives ......... 167

VI. CONCLUSIONS \& LIMITATIONS

VII. DIRECTIONS FOR FUTURE RESEARCH

$\begin{array}{ll}\text { VIII. REFERENCES } & 171\end{array}$

$\begin{array}{ll}\text { IX. APPENDIX } & 200\end{array}$

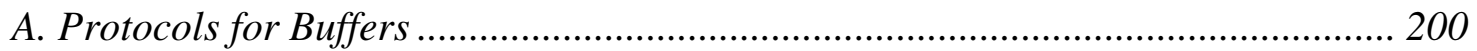




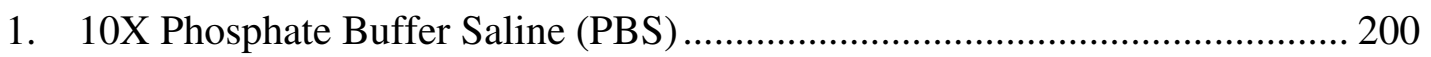

2. Formic Acid Buffer .................................................................................... 200

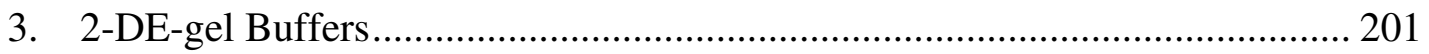

a) Homogenization Buffer 201

b) Immobilized pH Gradient (IPG) Rehydration Buffer 201

c) Equilibration Buffer 202

d) 10X SDS-PAGE Running Buffer 202

e) Molecular Weight Standards for 2-D gels 202

f) Agarose (0.8\%) 202

g) $10 \% \mathrm{TCA} /$ Acetone 203

h) Bromophenol Blue (0.1\%) 203

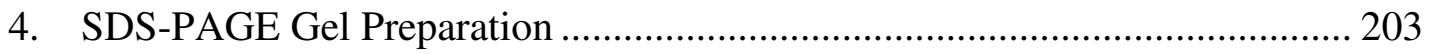

5. Sensitive Colloidal Staining Solution ........................................................ 204

6. Protein Extraction Buffers for MALDI-TOF................................................... 204

a) Destaining Buffer (25mM NH $\mathrm{m}_{4} \mathrm{HCO}_{3} / 50 \%$ acetonitrile) 204

b) Analyte Solution (0.1\% TFA/ Acetonitrile 2:1) 204

c) Promega Mass Spectrometry Grade Porcine Trypsin Gold 205

d) Mass Spectrometry Peptide Standard 205

e) Matrix Solution (0.2mg HCCA/mL 0.1\%TFA/ Acetonitrile) 205

f) Wash Buffer (10mM Ammonium Phosphate in 0.1\%TFA) 206

g) Recrystalization Buffer (Ethanol/acetone/0.1\% TFA, 6:3:1 v/v/v) 206

h) Tris-glycine buffer 206

i) Tris-glycine/8M urea/ 17mM SDS buffer 206

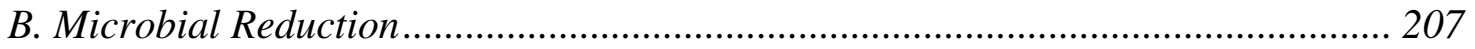

C. MFGM Extraction ............................................................................................. 207

D. MFGM Protein Quantification ................................................................. 208

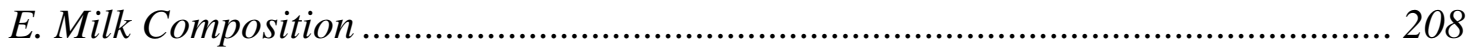

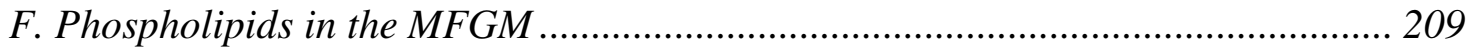

G. SH \& SS Quantification ............................................................................ 211 
H. Particle Size Analysis ..................................................................................... 212

J. 1DE \& Mass Tandem Spectrometry.............................................................. 214

K. Two-Dimensional Statistical Data from Delta2D ............................................ 231 


\section{LIST OF TABLES}

Table 1. Factors that affect the composition and structure of the MFGM (Adapted from Ward et al. 2006, and Evers, 2004a)...................................................... 13

Table 2. Composition of milk lipids and their distribution among the milk fat globule (MFG) core, the milk fat globule membrane (MFGM), and the skim milk (adapted from Jiménez-Flores and Brisson, 2008; Michalski et al., 2006; Jensen, 2002) 16

Table 3. Nutritional aspects of polar lipids of the MFGM (adapted from Dewettinck et al., 2008; Jiménez-Flores and Brisson, 2008; Rombaut et al., 2006). 19

Table 4. MFGM Protein classification using proteomics techniques (adapted from Reinhardt and Lippolis, 2006).

Table 5. Health benefits of MFGM components (adapted from Dewettinck et al., 2008; Fong et al., 2007; Jiménez-Flores and Brisson, 2008; Michalski and Caroline, 2006 ; Riccio, 2004; Pan et al., 2006; Spitsberg, 2005). 24

Table 6. Phospholipid and protein composition in dairy products (adapted from Dewettinck et al., 2008; Fong et al., 2007; Jiménez-Flores, 2009; Morin et al., 2006). 41

Table 7. Biochemical reactions of side chain groups of amino acid residues linked in the peptide chain (I) of proteins at high temperature (Adapted from Walstra et al. 2006). 51

Table 8. Parameters that describe the fat globule size distribution in milk. 103

Table 9. Parameters that describe the fat globule size distribution in $40 \%$ cream. 105

Table 10. Parameters calculated from the size distributions of fat globules in skim milk. 107 
Table 11. Fat, lactose, total solid, and protein content of milk during milk processing. 108

Table 12. Linear equations of phospholipid standards and respective retention time $\left(\mathrm{T}_{\mathrm{R}}\right)$

Table 13. Phospholipid content in fat globules........................................................... 115

Table 14. Relative abundance of MFGM proteins during milk processing.................. 120

Table 15. MFGM proteins identified by LC-MS/MS upon milk processing. ................ 122

Table 16. Proteins identified in region I ( higher than $150 \mathrm{kDa}$ ) of MFGM isolates through $\mathrm{LC} / \mathrm{MS}$

Table 17. Proteins identified in region II (higher than 55 and less than $150 \mathrm{kDa}$ )

of MFGM isolates through LC/MS.

Table 18. Proteins identified in region III (higher than 35 and less than $55 \mathrm{kDa}$ )

of MFGM isolates through LC/MS.

Table 19. Proteins identified in region IV (less than $35 \mathrm{kDa}$ ) of MFGM isolates through LC/MS.

Table 20. Identified proteins in the proteome map from $4{ }^{\circ} \mathrm{C}$ milk sample versus the Fresh milk sample that vary during milk processing.

Table 21. Identified proteins in the proteome map from Batch milk sample versus the Fresh milk sample that vary during milk processing.

Table 22. Identified proteins in the proteome map from HTST milk sample versus the Fresh milk sample that vary during milk processing.

Table 23. Identified proteins in the proteome map from UHT milk sample versus the Fresh milk sample that vary during milk processing. 145 
Table 24. Microbial reduction in heat and cold pasteurization. Aerobic and coliforms petrifilms were incubated for 48 and 24 hrs respectively...... 207

Table 25. Microbial reduction in UV pulsed light treatment. Aerobic and coliform petrifilms were incubated for 48 and $24 \mathrm{hrs}$ respectively.

Table 26. MFGM material (pellet) from samples................................................... 207

Table 27. Effect of milk processing on MFGM proteins........................................ 208

Table 28. Milk composition for each independent trial........................................... 208

Table 29. Phospholipid content ${ }^{+}$indicated as mg of phospholipid per gram of milk ..... 209

Table 30. Polar lipids quantification in milk during processing (trials II \& III). .......... 209

Table 31. Polar lipid quantification in milk during processing (trials II, III, and IV)... 210

Table 32. Phospholipids in total lipids (mg/100 g total lipids).................................. 210

Table 33. Polar lipids quantification in cream during processing (trials II \& III)......... 211

Table 34. Effect of heat treatment on the amounts of free and total sulfhdryl (SH) and disulfide (SS) groups in the milk fat globule membrane.

Table 35. Quantification of MFGM proteins by SDS-PAGE densitometry.................. 213

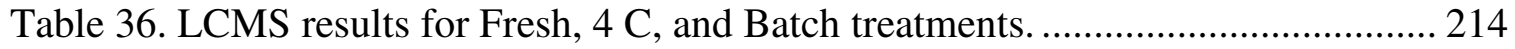

Table 37.B. LC/MS results for HTST, UHT, and UV treatment .............................. 218

Table 38. Functional classification of MFGM proteins ........................................... 223

Table 39. ANOVA-2 results utilizing Delta2D for all treatments against Fresh milk as a control $(\mathrm{p}<0.01)$ 231

Table 40. ANOVA-2 results utilizing Delta2D for each treatment against Fresh milk as a control $(\mathrm{p}<0.01)$. 231 


\section{LIST OF FIGURES}

Figure 1. Milk Processing in the dairy industry. Upon collection, milk is transferred to a storage unit at $4{ }^{\circ} \mathrm{C}$ where it awaits pasteurization for further processing (Adapted from Dairy Processing Handbook).

Figure 2. Pathway of milk fat synthesis regulation in bovine mammary glands. This model incorporates the most recent information in milk droplet secretion and enzymes involved in milk fat synthesis (Taken from Bionaz et al., 2008)

Figure 3. Schematic representation of the structure of the milk fat globule membrane (Taken from Lopez et al. 2011).

Figure 4. Schematic representation of the different types of lipids seen in the milk fat globule membrane (Nelson and Cox, 2000). 15

Figure 5. Glycerophospholipid structure showing the glycerol backbone with two fatty acids (top). Different alcohol substituents that form polar lipid derivatives at the second alcohol via a phosphoester linkage (bottom table) (Nelson and Cox, 2000).

Figure 6. Basic structure of sphingolipids, which are composed of a sphingosine base link to a fatty acid on its amide group and a headgroup (R) on its hydroxyl group (Top). Most common phosphosphingolipids and glycosphingolipid headgroups (bottom table) (Nelson and Cox, 2000). 20

Figure 7. Functions of sphingomyelin and metabolites as well as factors that can modulate sphingolipid metabolism and cell regulation (Adapted from Vesper et al. 1999).

Figure 8. Milk fat globule isolation in a laboratory and pilot plant setting. MFGM proteins can be purified using a four-step procedure: Step 1. cream (fat 
globule) isolation; Step 2. washing of globules; step 3. Disruption of globules, and step 4. Membrane collection (Dewettinck et al., 2008). 44

Figure 9. Fat globule in raw milk (left, 7000x) with no change on surface and thermally treated globule (right; $63{ }^{\circ} \mathrm{C}, 30 \mathrm{~min}, 6000 \mathrm{x}$ ) exhibiting deposits of casein proteins. Images captured with scanning electron microscopy (Adapted from Bermudez-Aguirre, D. et al. 2008)

Figure 10. Changes in the MFGM and fat globules as a function of thermal treatment in creams. A) Schematic representation of native fat globules or at low heat, and B) after high heat treatment, which adsops aqueous phase proteins, especially whey proteins (Taken from Gassi et al., 2008).

Figure 11. Effects of homogenization on milk fat globules. Native fat globules lack adsorption of casein micelles and whey protein. Upon homogenization, serum proteins and casein attached to the interphase of fat droplets (top) and MFGM fragments are desorbed (bottom) (Adapted from Michalski and Januel, 2006). 56

Figure 12. Milk Collection and Processing... 73

Figure 13. Analysis of milk phospholipids involves fat extraction from milk, isolation of PL from other simple lipids via solid phase extraction (SPE), and separation and quantification of the different phospholipid classes via HPLC. 80

Figure 14. Milk fat separation upon churning and centrifugation. Left. Actual conical tube containing cream layers. Right. Schematic representation. The buttermilk, which contains MFGM proteins, was isolated for the next step in MFGM purification 84 
Figure 15. Aerobic bacterial counts in pasteurized and UV pulsed light treated milk. The volume is shown in $\mathrm{ml}$, and the irradiation time is in seconds (s). Each second delivers three Joules $/ \mathrm{cm}^{2}$. Counts after $48 \mathrm{hrs}$ of incubation at $37{ }^{\circ} \mathrm{C} \ldots . . .99$

Figure 16. Coliform counts in pasteurized and UV pulsed light treated milk. The volume is shown in $\mathrm{ml}$, and the irradiation time is in seconds (s). Each second delivers three Joules $/ \mathrm{cm}^{2}$. A $22 \%$ reduction is observed in the $7 \mathrm{ml} / 9 \mathrm{sec} \mathrm{UV}$ pulsed treated sample. Counts after $24 \mathrm{hrs}$ of incubation at $37^{\circ} \mathrm{C}$. 100

Figure 17. Microbial reduction in aerobic bacteria in UV pulsed treated milk. The volume is shown in $\mathrm{ml}$, and the irradiation time is in seconds (s). Each second delivers three Joules $/ \mathrm{cm}^{2}$. Counts after $48 \mathrm{hrs}$ of incubation at $37^{\circ} \mathrm{C}$. Statistically significant difference in samples is denoted by $(\mathrm{p}<0.0001) \ldots . . . .101$

Figure 18. Microbial reduction in coliforms in UV pulsed treated milk. The volume is shown in $\mathrm{ml}$, and the irradiation time is in seconds (s). Each second delivers three Joules $/ \mathrm{cm}^{2}$. Counts after $24 \mathrm{hrs}$ of incubation at $37^{\circ} \mathrm{C}$ 102

Figure 19. Milk fat globule (MFG) size distribution (volume \%) in milk as a function of particle diameter $(\mu \mathrm{m})$. Data for Trial II. Similar results were observed with the other trials (I, III, and IV). Values are average of tree measurements 103

Figure 20. Fat globule (FG) size distribution of $40 \%$ cream as a function of particle diameter $(\mu \mathrm{m})$. Data are shown for Trial IV. Similar results observed for other trials.

Figure 21. Fat globule (FG) size distribution in skim milk showing residual fat globules aggregates and normal size fat globules. 106 
Figure 22. MFGM isolates of samples collected during milk processing. Values represent the mean weight of dry membrane material of four independent experiments, expressed as mg of MFGM (pellet upon ultracentrifugation) per liter of milk. Samples with different subscript are statistically significant different $(\mathrm{p}<0.0001)$ 109

Figure 23. Final MFGM material isolated from milk following a modified protocol by Patton et al. (1986). From left to right: Fresh, UHT, and UV MFGM pellets.

Figure 24. Effect of milk processing on the amount of protein in the milk fat globule membrane. Values represent the mean of three independent experiments, expressed as $\mathrm{mg}$ of protein per $100 \mathrm{mg}$ of MFGM pellet. Samples with different subscript are statistically significant different ( $\mathrm{p}<0.0001 ; \mathrm{n}=3$ experiments; $\mathrm{n}=3$ measurement).

Figure 25. Normal-phase high performance liquid chromatography (HPLC) coupled with charged aerosol detector (CAD) chromatogram of phospholipid standards to quantify the PL from the MFGM, phosphatidylethanolamine (PE), phosphatidylinositol (PI), phosphatidylserine (PS), phosphatidylcholine (PC) and sphingomyelin (SM) with three peaks.

Figure 26. Normal-phase liquid chromatography (LC) coupled with charged aerosol detector (CAD) chromatograms of (Black) PL standards and (Blue) $4{ }^{\circ} \mathrm{C}$ sample. PE, phosphatidylethanolamine; PI, phosphatidylinositol; PS, phosphatidylserine; PC, phosphatidylcholine; SM, sphingomyelin; NL, neutral lipids; PA, phosphatidic acid. 
Figure 27. Polar lipid concentration (mg of PL per g of total lipids) in the milk fat globules. The PL means of two independent experiments are presented with the standard error of mean $(\mathrm{s} / \bullet \mathrm{N})$

Figure 28. Concentration of PI and PS (mg of PL per $\mathrm{g}$ of total lipid) in the milk fat globules. These PLs are found in lower amounts in the MFGM. The means of two independent experiments are presented with the standard error of mean $(\mathrm{s} / \bullet \mathrm{N})$.

Figure 29. Phospholipid content of milk fat globules presented as percentage of the total phospholipids. The PL means of three independent experiments is presented with standard error of mean $(\mathrm{s} / \bullet \mathrm{N})$.

Figure 30. Global representation of phospholipids in treated samples for three independent trials (II, III, and IV). PL content is presented as mean of three HPLC measurements (mg PL per g of fat).

Figure 31. Effect of milk processing on the free and total sulfhydryl (SH) and disulfide (SS) groups of milk fat globule membrane protein 118

Figure 32. Sodium dodecyl sulfate-PAGE pattern (4-12\% gradient Bis-Tris NuPAGE gel) of milk fat globule membrane material isolated from different fractions of milk processing. 1\&8) Novex Sharp Standards, 2) Fresh, 3) $4{ }^{\circ} \mathrm{C}$, 4) Batch, 5) HTST, 6) UHT, and 7) UV. 119

Figure 33. Percentage of identified proteins in each milk treatment from the 102 total characterized proteins identified by LC-MS

Figure 34. Representative 2-DE map of Batch (left) and high temperature short time (HTST) pasteurization treatments dyed with fluorescent dye, Sypro-Ruby. 
A total of $100 \mu \mathrm{g}$ of protein was loaded and stained with a 1:5 dilution of the dye.

Figure 35. Representative 2-DE map of MFGM proteins during milk processing.

A $12.5 \%$ SDS-PAGE stained w sensitive colloidal. A) Fresh, B) $4{ }^{\circ} \mathrm{C}$,

C) Batch, D) HTST, E) UHT, and F) UV.

Figure 36. Protein expression change during milk processing. 2DE gels were compared using a statistical program. Each treatment was compared against the Fresh sample, and the change in protein expression is indicated as a percentage (Delta2D, $\mathrm{p}<0.01)$ 136

Figure 37. Protein expression change during milk processing. 2DE gels were compared using a statistical program. All the treatments were compared against the Fresh sample (6 Treat), without UHT (5 Treat), and no heat application (Fresh, $4{ }^{\circ} \mathrm{C}, \mathrm{UV}$ ). The change in protein expression is indicated as a percentage.

Figure 38. Proteome map (Delta 2D) depicting 104 spots from the $4{ }^{\circ} \mathrm{C}$ milk sample versus the Fresh milk sample (control). The proteome map represents average pixel volumes for each protein spot. Labeled spots showed changes in abundance in response to cold storage temperature (two-way ANOVA, $\mathrm{p}<0.01$, total spots 305). 138

Figure 39. Proteome map (Delta 2D) depicting 175 spots from Batch milk sample versus the Fresh milk sample (control). The proteome map represents average pixel volumes for each protein spot. Labeled spots showed changes in abundance in response to thermal treatment $\left(65^{\circ} \mathrm{C}, 30 \mathrm{~m}\right.$; two-way ANOVA, $\mathrm{p}<0.01$, total spots 344$)$. 141 
Figure 40. Proteome map (Delta 2D) depicting 128 spots from high temperature short time (HTST) milk sample versus the Fresh milk sample (control). The proteome map represents average pixel volumes for each protein spot. Labeled spots showed changes in abundance in response to thermal treatment $\left(72{ }^{\circ} \mathrm{C}, 16 \mathrm{~s}\right.$; two-way ANOVA, $\mathrm{p}<0.01$, total spots 350$)$.

Figure 41. Proteome map (Delta 2D) depicting 186 spots from ultra high temperature (UHT) milk sample versus the Fresh milk sample (control). The proteome map represents average pixel volumes for each protein spot. Labeled spots showed changes in abundance in response to high thermal treatment $\left(121^{\circ} \mathrm{C}, 3 \mathrm{~m}\right.$; two-way ANOVA , p < 0.01, total spots 277$)$.

Figure 42. Proteome map (Delta 2D) depicting 116 spots from cold pasteurization (pulsed ultraviolet, UV) milk sample versus the Fresh milk sample (control). The proteome map represents average pixel volumes for each protein spot. Labeled spots showed changes in abundance in response to thermal treatment (1.0 Joules/ $\mathrm{cm}^{2} /$ pulse; two-way ANOVA, $\mathrm{p}<0.01$, total spots 344$)$. 146

Figure 43. Fluctuation of milk and whey proteins in the MFGM during milk processing. Results obtained from SDS-PAGE densitometry $(\mathrm{p}<0.0001$, three independent trials, and three replicates)..... 155

Figure 44. Fluctuation of the main MFGM proteins during milk processing. Results obtained from SDS-PAGE densitometry $(\mathrm{p}<0.0001$, three independent trials, and three replicates). 156 
Figure 45. Fluctuation of MFGM proteins during milk processing. Results obtained from SDS-PAGE densitometry. $X$ unidentified protein band $(\mathrm{p}<0.0001$, three independent trials, and three replicates)

Figure 46. Functional category assignments for identified proteins. A total of 13 categories were assigned based on information in Uniprot and NCBI. 158

Figure 47. Variation of proteins involved in lipid tranport/metabolism during milk processing. BTN (Frag), Butyrophilin (Fragment); AUP-1, Ancient ubiquitous protein 1; LS, Lanosterol synthase; 17-b HSDH, 17-beta hydroxysteroid dehydrogenase; S-4-a-C-3-D, Sterol-4-alpha-carboxylate 3dehydrogenase, decarboxylating; CYB5R3, CYB5R3 protein; LPAAT, Lysophosphatidic acid acyltransferase, zeta; AP E, Apolipoprotein E; LPL, Lipoprotein lipase; FABP (brain), Fatty acid-binding protein, brain 159

Figure 48. Variation of proteins involved in immunity \& defense during milk processing. ANX-A1, Annexin A1; IGK, IGK protein; GDCA, Glycosylation-dependent cell adhesion molecule 1; CD14, Monocyte differentiation antigen CD14; Ig ( ), Immunoglobulin light chain, lambda gene cluster; LPO, Lactoperoxidase. 160

Figure 49. Variation of proteins involved in membrane protein trafficking during milk processing. YKT6, Synaptobrevin homolog YKT6; ADP-RF, ADPribosylation factor 1; STX3, STX3 protein; Rab-13, Ras-related protein Rab-13; R-ras, Related RAS viral (R-ras) oncogene homolog; Rab-5C, Ras-related protein Rab-5C; RAB35, RAB35 protein; Rab-8A, Ras-related protein Rab-8A. 
Figure 50. Variation in proteins involved in G-mediated cell signaling during milk processing. Ras-related C3, Ras-related C3 botulinum toxin substrate 1; Rap-1A, Ras-related protein Rap-1A; ADP-RF15, ADP-ribosylation factor-like protein 15; CDC42, CDC42 protein; NRAS, NRAS protein; RhoC, Rho-related GTP-binding protein RhoC; GNB G(i) a-1, Guanine nucleotide-binding protein G(i) subunit alpha-1

Figure 51. Variation of proteins involved in protein synthesis, binding, and/ or folding during milk processing. $15 \mathrm{kDa}$ SP, $15 \mathrm{kDa}$ selenoprotein; Cofilin 1, Cofilin 1 (Non-muscle); HSC, 71 kDa, Heat shock cognate 71 kDa protein; RRL, Ribonucleotide reductase large subunit; HIST2H2BE, HIST2H2BE protein; Ankyrin, Ankyrin repeat domain 22; EF 1-a 1, Elongation factor 1-alpha 1; DCK , DCK protein. 163

Figure 52. Variation in proteins involved in homeostatic regulation during milk processing. cGMP II PK, cGMP-dependant type II protein kinase; PP1201, PP1201 protein; SDR-1, Dehydrogenase/reductase (SDR family) member 1; ANX A5, Annexin A5; SA, Serum albumin 164

Figure 53. Protein identified in region I (> $150 \mathrm{kDa})$. Molecular weight is shown in parenthesis. cGMP-PK (87), cGMP-dependant type II protein kinase; LP (81), Lactoperoxidase; Acyl-CoA Syn (78), Acyl-CoA synthetase long-chain family member 1; Na-DPTP, Sodium-dependent phosphate transport protein 2B; SA (69), Serum albumin; MA-b-LG (20), Major allergen beta-lactoglobulin; GDCAM-1 (17), Glycosylation-dependent cell adhesion molecule 1; FABP (15), Fatty acid-binding protein. 165 
Figure 54. Protein identified in region II ( $>55$ and $<150 \mathrm{kDa})$. Molecular weight is shown in parenthesis. GNBP-2 (37), Guanine nucleotide-binding protein G(I)/G(S)/G(T) subunit beta-2; cGMP-KP (87), cGMP-dependant type II protein kinase; LS (83), Lanosterol synthase; ACR (55), Acetylcholine receptor subunit epsilon; 5'-Nase (63), 5'-nucleotidase; Na+/Glu T (73), $\mathrm{Na}+$ glucose cotransporter; BTN (F, 14), Butyrophilin (Fragment).... 166

Figure 55. Proteins identified in region III ( $>35$ and $<55 \mathrm{kDa})$. Molecular weight is shown in parenthesis. GNBP-11 (42), Guanine nucleotide-binding protein subunit alpha-11; S-4-a-CD (40), Sterol-4-alpha-carboxylate 3-dehydrogenase; GNAI2 (40), GNAI2 protein; CD14 (40), CD14 protein; ANX-A2 (39), Annexin A2; ANX-A1 (39), Annexin A1; 17-b-HSD (38), 17-beta hydroxysteroid dehydrogenase; CYB5R3 , CYB5R3 protein; STX3, STX3 protein. 167

Figure 56. Milk processing effects on milk fat globules and milk fat globule membrane proteins. Globules are smaller in Fresh milk, and as processing proceeds, some triacylglycerides are released in cooling as well MFGM membrane. Thermal treatment enhances rearrangements between proteins and lipids of the membrane and promotes aggregation of globules and vesicle formation. Casein micelles and whey proteins are the main proteins that are adsorbed to the globule surface

Figure 57. Fat globule (FG) size distribution of $40 \%$ cream as a function of particle diameter $(\mu \mathrm{m})$. Data for Trial III 212

Figure 58. Fat globule (FG) size distribution of $40 \%$ cream as a function of particle diameter $(\mu \mathrm{m})$. Data for Trial II. 
xxvii 


\section{INTRODUCTION}

With consumers becoming more health-conscious, the demand for food products that deliver nutritional and functional benefits has increased. In the dairy industry, the interest in the milk fat globule membrane (MFGM) is no exception. This milk component was initially described in the 1970's and 1980's as the membrane that surrounds fat globules in milk, preventing coalescence and rancidity of lipids (Keenan et al., 1971; Mather and Keenan, 1975; Jarasch et al., 1977; Mather and Keenan, 1998; Patton, 2004; Singh, 2006; Dewettinck et al., 2008). In the last two decades, the nutraceutical properties of the MFGM have been explored (Argov et al., 2008a; Spitsberg, 2005). In fact, anticancer and antihypercholesterolemic activities, antimicrobial and antiviral properties such as inhibition of the ulcer-forming bacterium Helicobacter pylori and rotavirus, and suppression of diseases such as multiple sclerosis have been ascribed to the MFGM. In addition, in clinical studies, complementing infant food with MFGM and micronutrients leads to more copper and vitamin B12 uptake by infants (Lonnerdal et al., 2006). Also, MFGM complementation has reduced the incidence and prevalence of diarrhea in infants (Zavaleta et al., 2006). Contemporary research and innovation in the MFGM has been in the pharmaceutical field where liposome formation for the delivery of drugs, vitamins, and nutrients is being designed and tested (Bezelgues et al., 2009; Thompson and Singh, 2006).

The manufacture of butter and cheese generate by-products that have not found a place in the market or that are underutilized commercially although they have high nutritional and functional potential. In this category are buttermilk and butter serum, which have unprecedented nutritional and functional properties that could be capitalized upon when incorporated in innovative food products. The presence of the MFGM in these 
food or dairy products promises to deliver more than nutritional benefits by including nutraceuticals for health and well-being; however, there is still a lot to know, test, prove and develop about this component of milk.

Buttermilk originates during cream churning where the fat globules are destabilized with subsequent agglomeration and coalescence, displacing the MFGM and water-soluble components from cream into the aqueous phase. This by-product, known as sweet buttermilk, is the main commercial source of MFGM, which has a low cost but currently very limited market (Jiménez-Flores and Brisson, 2008; Jiménez-Flores and HigueraCiapara, 2009; Lopez et al., 2010b). A second source is butter serum, which is popular in countries where butter is made from very high fat content cream (plastic cream), and there is very little traditional buttermilk production. Currently, in the US industry, sweet buttermilk is mainly used in food products such as ice cream and bakery goods, with very limited use as surface-active ingredient (Dewettinck et al., 2008; Jinjarak et al., 2006; Sodini et al., 2006). In fact, in 2007 the use of buttermilk in the United States was mainly for baking to improve flavor and texture, representing $79.9 \%$ of the 49.8 million pounds of dry buttermilk sold. The dairy industry also utilized buttermilk (13.9\%) in products such as ice cream, recombined milk, and cheese, and about 3.4\% was used for prepared dry mixes (American Dairy Products Institute, 2007). In 2008, 1,644 billion pounds of butter were produced in the United States, generating approximately the same amount of buttermilk (United States Department of Agriculture). We could be using this product to complement food and obtain the health benefits ascribed to MFGM constituents such as proteins and phospholipids (PL), which are present in concentrations of 32.9 and 2.03 grams per 100 grams of dry buttermilk, respectively (Jiménez-Flores and Brisson, 2008). 
The genesis of PL characterization in milk started in the 1960's (Smith and Jack, 1959; Sprecher et al., 1965; Webb et al., 1974). More recently, with the use of novel technologies, their physicochemical properties have been exploited, highlighting the emulsification and anti-foaming properties of MFGM. These lipids have been associated with enhanced health, especially those phospholipids present in specific animal tissues such as sphingomyelin and phosphatidylcholine, cerebrosides and gangliosides (considered important glycolipids). In fact, PL and their metabolites have important biological roles such as cell and membrane communication, myelination in the central nervous system, and as membrane receptors. Sources with high concentrations of PL such as the MFGM should be considered of high value by food technologists and efforts need to be made to include them in food products that not only to deliver essential nutrients but functional compounds.

Despite all the health benefits offered by the milk fat globule membrane, little effort has been given by the technological community to incorporate MFGM constituents into food products, and the MFGM still remains the least understood component of nature's most nutritious food: milk (Argov et al., 2008a). With the latest techniques in biology, chemistry and physics, proteomics, genomics, glycomics (Tao et al., 2008) and other reliably objective physical and chemical tools the complex biological structure and interaction of fat globules and MFGM can be characterized in situ or with very little destructive manipulation and, thereby, provide knowledge of the native components that benefit mammalian neonates.

This thesis gives a current view on the relevant discoveries that place the MFGM in a unique position for food and dairy products applications, and presents findings on the chemical, biochemical, and physical changes of the MFGM as a result of milk processing 
throughout collection, storage, and pasteurization, as depicted in Figure 1. In addition, a revolutionary technology in cold pasteurization, pulsed UV-light, is introduced and compared with conventional heat pasteurization. Since heat pasteurization has high capital and operational costs, light treatment may become an alternate pasteurization technique for the dairy industry due to its efficiency and fast results in deactivating microorganisms, especially foodborne pathogens. However, little information is available about its effects on the conformational changes in proteins or the production of byproducts that could be carcinogenic or affect consumer acceptance.

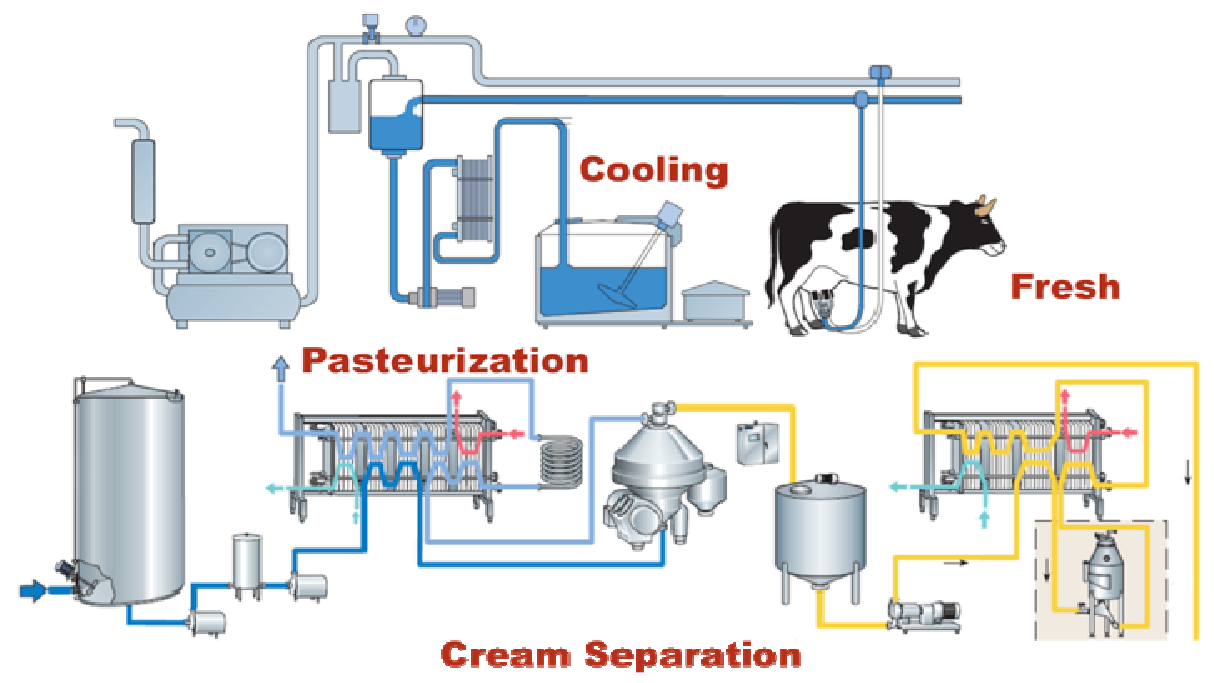

Figure 1. Milk Processing in the dairy industry. Upon collection, milk is transferred to a storage unit at $4^{\circ} \mathrm{C}$ where it awaits pasteurization for further processing (Adapted from Dairy Processing Handbook). 


\section{LITERATURE REVIEW}

\section{A. Brief Outline}

This review highlights the chemical, biochemical, and nutritional characteristics of the milk fat globule membrane as well as its dairy sources. It attempts to give an overview of the origin, composition, structure, health benefits, and technical aspects of the MFGM that have been identified for this novel ingredient as a potential nutraceutical. In addition, the effect of milk processing such as temperature, pressure, and irradiation on the structure and composition of the MFGM will be discussed as well as current methodologies for further noninvasive investigation. These facts are offered as a basic platform from which readers can find ideas and inspiration for furthering the knowledge and application of this milk component and resource.

\section{B. Origin and Function of the Milk Fat Globule Membrane}

Milk lipids are mainly composed of triacylglycerols (TAG) that accumulate within the bilayer of the rough endoplasmic reticulum (rER) of epithelial cells of the mammary glands where they start their journey towards the apical membrane (Nielsen et al., 1999; Bionaz and Loor, 2008). However, freeze-fracture electron microscopy further pinpointed that lipid droplets developed alongside the rER membrane. Regardless of the lipid droplet biogenesis, a membrane known as the milk fat globule membrane (MFGM) surrounds the lipids. This trilayer membrane acts as an emulsifier and prevents coalescence of fat droplets and lipase activity (Dewettinck et al., 2008).

Newly-formed triacylglycerols are first assembled into microdroplets (Bionaz and Loor, 2008), which range in diameter from less than $0.5 \mu \mathrm{m}$ to more than $4 \mu \mathrm{m}$, at the basal membrane of the secretory mammary cells (Keenan et al., 1971). A monolayer, 
consisting of polar phospholipids and proteins, surrounds the assembled triacylglycerols, which do not form part of this monolayer (Wooding and Kemp, 1975). As the microdroplets migrate through the cytoplasm, they coalesce to form bigger droplets called cytoplasmic lipid droplets (CLD). This formation is promoted by calcium and by ganglioside mediation (Mather and Keenan, 1998; Keenan and Mather, 2006; JiménezFlores and Brisson, 2008). CLD accumulation may be promoted by decreased lipid storage in mammary adipocyte tissue (Russell et al., 2007). The CLDs then approach the apical surface, probably assisted by GTP-binding proteins (Spitsberg and Gorewit, 1997), are gradually enveloped in the membrane, and bud out of the secretory cells (Keenan and Mather, 2006; Mather, 2000; Dewettinck et al., 2008). It has been hypothesized that migration is assisted by microtubules; however, current research is inconclusive (Keenan and Mather, 2006). The apical membrane that surrounds MFG may represent a line of defense against pathogens at the mucosal surface of the mammary glands, so proteins associated with host defense may be associated with the MFGM (Smolenski et al., 2006).

During the enveloping process, a distance of 10 to $20 \mathrm{~nm}$ is kept between the outer surface of the droplet and the cytoplasmic face of the plasma membrane, which appears to be filled with electron-dense material when observed in micrographs. The origin of such material is still unknown (Keenan and Mather, 2006; Dewettinck et al., 2008). The formation of secretory vesicles that pick up microdroplets has also been suggested for milk fat globule (MFG) excretion, but cytochemical evidence favors the plasma membrane envelopment mechanism (Mather and Keenan, 1998; Keenan and Mather, 2006). In fact, butyrophilin, an integral MFG protein, plays a role in globule secretion because it is highly expressed on the apical membrane and concentrated at budding locations (Robenek et al., 2006a; Keenan and Mather, 2006; Mather and Keenan, 1998; 
Dewettinck et al., 2008). Molecular data suggest that butyrophilin, xanthine oxidase (XO), and the lipid droplet surface protein, adipophilin (ADPH) play a tripartite role in milk fat secretion according to their relative mRNA abundance (Bionaz and Loor, 2008). However, evidence from freeze-fracture replica immunolabelling (FRIL) has revealed the location of these proteins and contradicts the former hypothesis suggesting that milk lipid secretion is solely mediated by butyrophilin (McManaman et al., 2007). Despite this controversy, Bionaz et al. (2008) consolidated recent and detailed data on milk fat synthesis during lactation and introduced a pathway based on genomic data that depicts the role of proteins involved in fatty acid synthesis as well as milk droplet excretion (Figure 2).

In the secreted milk, lipid globule diameter ranges from $0.15 \mu \mathrm{m}$ to more than $15 \mu \mathrm{m}$ with slight variation in their fatty acid composition between small (1 to $3 \mu \mathrm{m})$ and large (6 $\mu \mathrm{m})$ globules (Michalski and Januel, 2006a; Fauquant et al., 2005). According to Fauquant et al. (2007), small MFG, ranging between $2.3 \mu \mathrm{m}$ to $8.0 \mu \mathrm{m}$, have no significant difference in their phospholipid and sterol content. Later studies indicate that small milk fat globules $(1.6 \mu \mathrm{m})$ contain almost three times more polar lipid, lower amounts of phosphatidylcholine and sphingomyelin, and larger curvature than large fat globules $(6.6 \mu \mathrm{m})$. The latter ones are especially enriched in phosphatidylcholine. In addition, the fatty acid composition in small globules was enriched in C12:0, C14:0, C16:0, C18:1 trans, and C18:2 (Lopez et al., 2010a). Avalli and Contarini (2005) reported higher polar lipid content in cream obtained from natural creaming as supposed to cream from centrifugation, highlighting that such observations were due to the presence of small fat globules. Lopez et al. (2010a) attributed the variation in PL in different globule size to the mechanism of fat globule secretion or to the rearrangement in 
the MFGM post-secretion from the mammary secretory cell and hypothesized that the greater curvature fat globules may exclude choline-containing polar lipids.

The fat globule size depends on many factors such as cow breed and lactation stage. In fact, fat globules from Jersey cows are larger than those from Friesian cows, with average diameters of $4.5 \mu \mathrm{m}$ and $3.5 \mu \mathrm{m}$, respectively (Singh, 2006). Argov et al. (2008) speculated that the distribution in diameter might imply a different role than just fat delivery to neonates (Kemsley, 2008). In fact, membrane vesicles consisting of phospholipids and proteins, with 30-100nm and 100-1000nm diameters, respectively known as exosomes and microvesicles, have been observed in milk without association of triglycerides and cholesterol (Silanikove et al., 2006; Argov et al., 2008b). Their genesis and functions are unknown, but they have been associated with immunoregulation and antitumoral activities (Silanikove et al., 2006). Admyre et al. (2007) identified these vesicles as exosomes that have the capacity to influence immune responses in human breast milk. Argov et al. (2008) have designated them as lactosomes in human milk whereas Silanikove and Shapiro (2007) called them whey membrane particles (WMP) in bovine milk. 


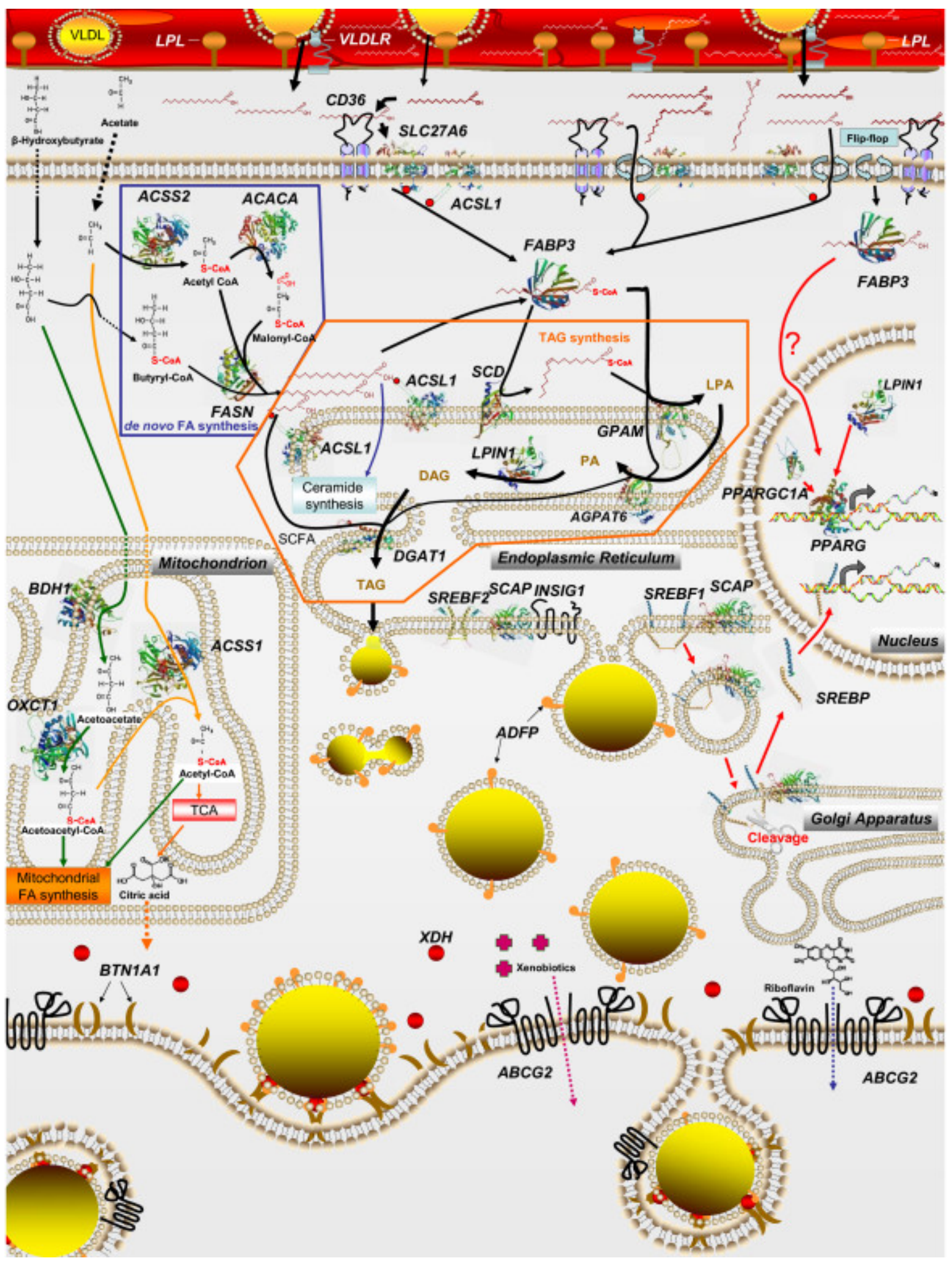

Figure 2. Pathway of milk fat synthesis regulation in bovine mammary glands. This model incorporates the most recent information in milk droplet secretion and enzymes involved in milk fat synthesis (Taken from Bionaz et al., 2008) 
In approximately $1 \%$ of bovine fat globules, some cytoplasm will be entrapped between the bilayer membrane and the fat droplet surface, which forms a crescent or "signet "(Wooding et al., 1970). Keenan and Mather (2006) support the original suggestion by Patton (2004) that crescents might be a pathway for the introduction of hormones or other bioactive molecules in milk. Knowledge about their molecular formation may help us decipher the mechanism that controls milk fat secretion, which is still an area of speculation. Also, there is a lot of emphasis on post-secretion modification of the MFGM, which may be the origin of membrane fragments seen in skim-milk; however, the extent of this event is uncertain (Mather and Keenan, 1998; Mather, 2000; Keenan and Mather, 2006; Singh, 2006). In fact, mechanical treatments like heating, homogenization, aeration, and agitation may enhance MFGM release into the serum phase (Rombaut et al., 2006a; Evers, 2004a).

\section{Composition and Structure of the MFGM}

The MFGM is a complex structure. It is $10-50 \mathrm{~nm}$ thick and contains phospholipids, sphingolipids, and specific membrane proteins (Figure 3). Phospholipids and proteins account for over $90 \%$ of the membrane's dry weight (Singh, 2006). Some of the proteins are an integral part of the membrane such as xanthine oxidase and adipophilin, and others are peripheral or loosely attached within the trilayer membrane including butyrophilin and glycosylated proteins respectively (Dewettinck et al., 2008; Lopez et al., 2008).

Recent studies with trypsin and pronase E shows that butyrophilin may be located on the exterior of the MFGM as well as adipophilin, and xanthine oxidase may have a dual position within the membrane (Vanderghem et al., 2011).

The first membrane, derived from the rER, is a monolayer containing phospholipids and proteins that is in direct contact with the intracellular lipid core (Vanderghem et al., 
2011). The second membrane is a bilayer containing glycosylated and non-glycosylated proteins, glycerophospholipids and sphingolipids, enzymes, cholesterol, and other minor components. Between the inner membrane and the bilayer, there is electron-dense coat rich in proteins (Lopez et al., 2008; Rombaut et al., 2006a). A glycocalyx forms a fourth layer, which acts as a source of specific bacterial and viral ligands and varies during lactation (Spitsberg and Gorewit, 1997; Wilson et al., 2008; Evers, 2004a). Interactions among milk constituents and other molecules occur mainly on this outer surface (Vanderghem et al., 2011). The structural composition of the oligossacharides in glygoproteins is designed as an innate protection to clear out unwanted pathogens from the gastrointestinal tract of the newborn offspring, especially those of human milk (Wilson et al., 2008). Studies have shown that the MFGM is not a continuous membrane (Kobylka and Carraway, 1973), and even some membrane material is destroyed during secretion leaving only the inner layer on parts of the fat globules (Robenek et al., 2006b; Vanderghem et al., 2011). 
Milk fat globule membrane:

a trilayer structure with a lateral organisation of polar lipids

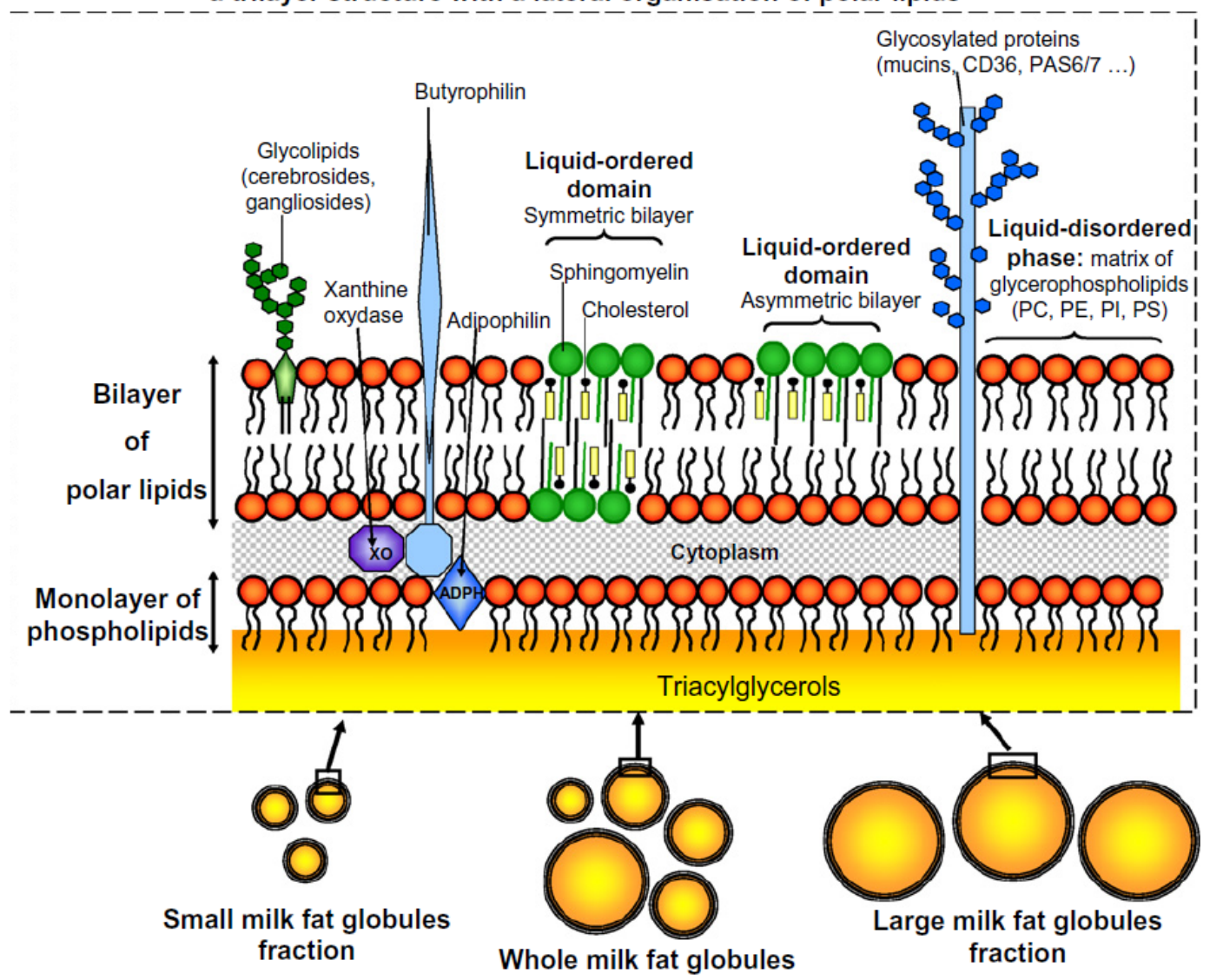

Figure 3. Schematic representation of the structure of the milk fat globule membrane (Taken from Lopez et al. 2011).

The gross composition of the MFGM, reported in literature, differs as a result of isolation, purification, and techniques used in analysis (Keenan and Mather, 2006; Dewettinck et al., 2008; Evers, 2004a). Furthermore, the composition can be altered by physiological, chemical/enzymatic, and physical/mechanical factors (Evers, 2004b). The latter includes cooling, drying, separation, agitation, heating, and homogenization (Dewettinck et al., 2008; Lopez et al., 2008; Jiménez-Flores and Brisson, 2008; Michalski and Januel, 2006a). With respect to physiological factors, Lopez et al. (2008) observed large differences in the fatty acid (FA) composition of the phospholipids in the milk from cows fed a regular diet and a diet rich in polyunsaturated FA. 
Table 1. Factors that affect the composition and structure of the MFGM (Adapted from Ward et al. 2006, and Evers, 2004a).

\begin{tabular}{|c|c|c|}
\hline Factor & Effect & Reference \\
\hline $\begin{array}{l}\text { Chemical/Enzymatic } \\
\text { Processing origin }\end{array}$ & $\begin{array}{l}\text { Loss of membrane components, adsorption } \\
\text { of milk plasma components }\end{array}$ & \\
\hline Bacterial origin & $\begin{array}{l}\text { Production of lipases, phospholipases, } \\
\text { proteinases, or glycosidic hyrolyases may } \\
\text { change MFGM }\end{array}$ & $\begin{array}{l}\text { (McPherson and Kitchen, 1983; Erwin } \\
\text { and Randolph, 1975; Evers, 2004a) }\end{array}$ \\
\hline $\begin{array}{l}\text { Physiological } \\
\text { Diet, breed, stage of } \\
\text { lactation }\end{array}$ & $\begin{array}{l}\text { Affect amount of membrane material, fat } \\
\text { size distribution, and relative distribution } \\
\text { of membrane components }\end{array}$ & $\begin{array}{l}\text { (Mondy and Keenan, 1993; Ye et al., } \\
\text { 2002; Murgiano et al., 2009; Reinhardt } \\
\text { and Lippolis, 2008; Lopez et al., 2008) }\end{array}$ \\
\hline \multicolumn{3}{|l|}{$\begin{array}{l}\text { Physical/Mechanical } \\
\text { (handling \&processing) }\end{array}$} \\
\hline Air bubbles & Loss of membrane material & (Walstra and Jenness, 1984) \\
\hline Ageing & Effects depend on temperature & Little is known \\
\hline Cooling & $\begin{array}{l}\text { Loss of copper, } \\
\text { loss of phospholipids, } \\
\text { absoption of proteins }\end{array}$ & $\begin{array}{l}\text { (Anderson } \text { et al., 1972; Dickow et al., } \\
\text { 2011; Patton et al., 1980; Baumrucker } \\
\text { and Keenan, 1973) }\end{array}$ \\
\hline Pumping, stirring, agitation & $\begin{array}{l}\text { Depends on the degree of air incorporated. } \\
\text { High shear forces are required to change } \\
\text { the MFGM in the absence of air }\end{array}$ & $\begin{array}{l}\text { (Mulder and Walstra, 1974; Stannard, } \\
\text { 1975) }\end{array}$ \\
\hline \multirow[t]{3}{*}{ Homogenization } & $\begin{array}{l}\text { Adsorption of serum protein, rupture of } \\
\text { membrane }\end{array}$ & $\begin{array}{l}\text { (Anderson } \text { et al., 1972; Cano-Ruiz and } \\
\text { Richter, 1997; Mondy and Keenan, } \\
\text { 1993; Lee and Sherbon, 2002; Ye } \text { et al., } \\
\text { 2004a) }\end{array}$ \\
\hline & Formation of PL or membrane vesicles & (Michalski et al., 2002) \\
\hline & $\begin{array}{l}\text { Redistribution of protein and lipids in } \\
\text { globules }\end{array}$ & (Keenan et al., 1983) \\
\hline Heating & $\begin{array}{l}\text { Adsorption of copper, whey proteins \& } \\
\text { caseins }\end{array}$ & $\begin{array}{l}\text { (Koops and Tarassuk, 1959; Greenbank } \\
\text { and Pallansch, 1961; Corredig and }\end{array}$ \\
\hline & $\begin{array}{l}\text { Aggregation of BTN and XO, } \\
\text { loss of PAS } 6 / 7 \text { and phospholipids }\end{array}$ & $\begin{array}{l}\text { Dalgleish, 1996; Sharma and Dalgleish, } \\
\text { 1993; Kim and Jiménez-Flores, 1995; } \\
\text { Houlihan } \text { et al., 1992; Sharma and } \\
\text { Dalgleish, 1994; Lee and Sherbon, } \\
\text { 2002; Ye et al., 2002; Ye et al., 2004b; } \\
\text { Garcia-Amezquita } \text { et al., 2009) }\end{array}$ \\
\hline Spray-Drying & $\begin{array}{l}\text { Reduce globule size and increase surface } \\
\text { area for adsorption of serum proteins }\end{array}$ & $\begin{array}{l}\text { (Landstrom et al., 2000; Ye et al., } \\
\text { 2007) }\end{array}$ \\
\hline
\end{tabular}

A diet rich in polyunsaturated FA resulted in a significant decrease in saturated fatty acid content in milk, which enhances milk's nutritional quality, especially for people with coronary heart disease risks (Lopez et al., 2008; Jensen, 2002). Enzymatic changes are due to microbial growth from both the cow's udder and the external environment (Evers, 
2004a), and according to Erwin and Randolph (1975), mastitis milk has lower amounts of phospholipid, higher levels of cholesterol, and changes in enzyme activity such as xanthine oxidase. Table 1 summarizes the factors that affect the structure and composition of MFGM, effects, and respective references. El-Loly (2011) has recently published the latest review on the MFGM, which includes composition, properties, and factors that affect MFGM constituents.

\section{Lipids of the Milk Fat Globule Membrane}

Polar lipids, such as glycerophospholipids and sphingolipids, constitute less than $1 \%$ of the MFG total lipids; nevertheless, they function as intracellular signaling molecules, provide a framework structure, and have nutritional and functional properties such as emulsification (Jiménez-Flores and Brisson, 2008; Lopez et al., 2008). Research has also found a relationship between polar lipid consumption and enhanced health (Spitsberg, 2005). Polar lipids are amphiphilic molecules comprised of a hydrophobic tail and a hydrophilic head. Their morphology is influenced by the presence of water (Fedotova and Lencki, 2008). On the MFGM, they are distributed heterogeneously and present in different percentages (Lopez et al., 2008; Dewettinck et al., 2008; Jiménez-Flores and Brisson, 2008).

These phospholipids contain high levels of unsaturated long-chain fatty acids (FA) such as palmitic, stearic, and tricosanoic acids (Sánchez-Juanes et al., 2009; Singh, 2006; Carrasco-Pancorbo et al., 2009). No difference has been observed in the FA composition of MFGM phospholipids regardless of season (Fauquant et al., 2005); however, changes have been observed during lactation, especially an increase in medium-chain fatty acids and a decrease in polyunsaturated fatty acids (18, 20, and 22 carbons) as lactation progressed (Bitman and Wood, 1990). During milk processing, polar lipids migrate to 
aqueous phases such as skimmed milk, buttermilk, and butterserum, making these products good sources for further purification, especially butterserum, which was enriched in sphingomyelin (Rombaut et al., 2006c).

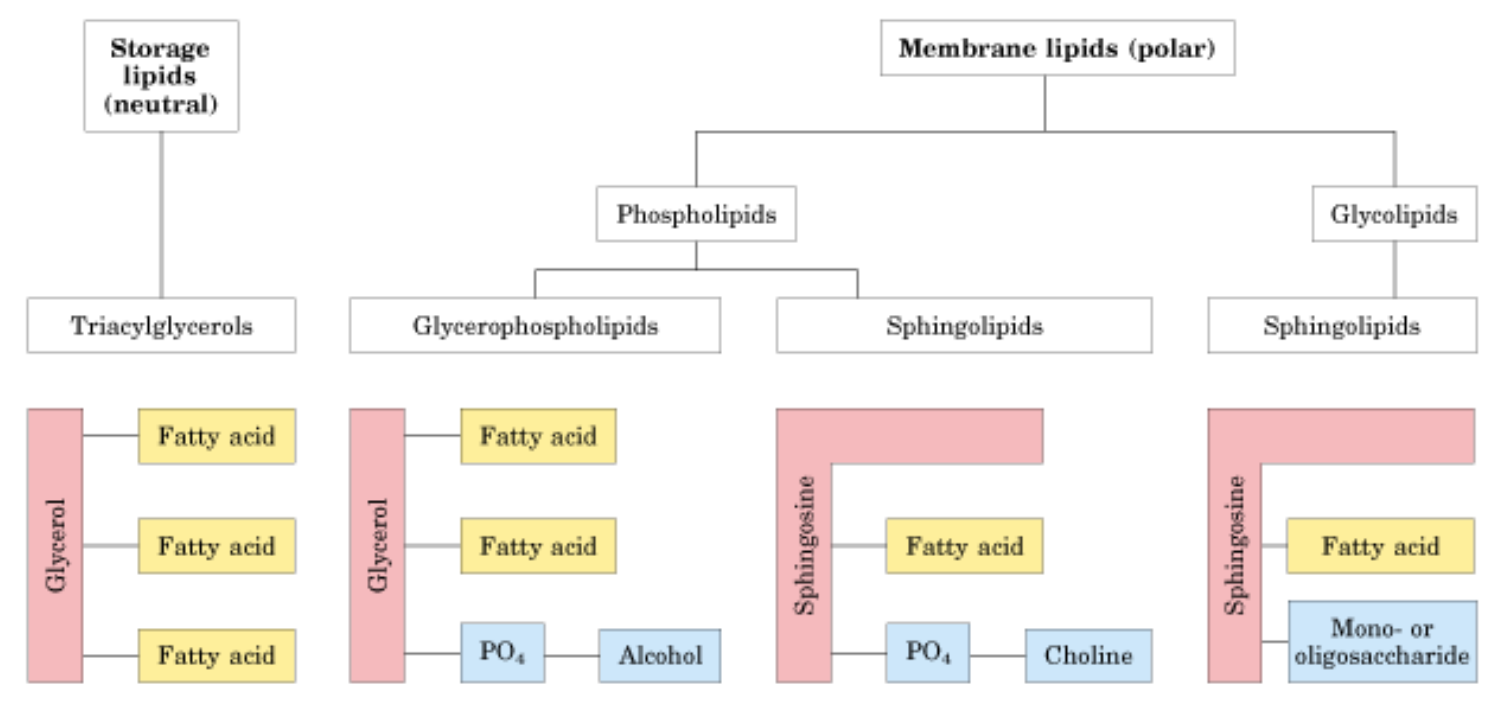

Figure 4. Schematic representation of the different types of lipids seen in the milk fat globule membrane (Nelson and Cox, 2000).

Other lipids such as triglycerides (TG), diglycerides, monoglycerides, sterols, and sterol esters are mainly present in the milk fat globule core and function as energy storage (Table 2). Among these, triglycerides represent about $60 \%$ of the neutral lipids in the milk fat globules, and cholesterol accounts for $90 \%$ of the total sterols in milk fat globules (Mather, 2000; Keenan and Mather, 2006; Dewettinck et al., 2008; Rombaut et $a l ., 2006 \mathrm{c})$. Figure 4 classifies the different types of lipids found in the MFGM. Recently, bioactive sterols such as lanosterol, lathosterol, demosterol, stigmasterol, and $\beta$-sitosterol were identified (Fauquant et al., 2007). Other constituents are hexoses, hexosamines, and sialic acids, which are associated exclusively with proteins and glycosphingolipids (Keenan and Mather, 2006). Small globules contain more medium-chain fatty acids and less stearic acid within the triglyceride core (Fauquant et al., 2005). 
Table 2. Composition of milk lipids and their distribution among the milk fat globule (MFG) core, the milk fat globule membrane (MFGM), and the skim milk (adapted from Jiménez-Flores and Brisson, 2008; Michalski et al., 2006; Jensen, 2002)

\begin{tabular}{|c|c|c|c|c|}
\hline \multirow[b]{2}{*}{ Lipid Class } & \multirow{2}{*}{$\begin{array}{c}\text { Content in total } \\
\text { Fat }(\mathrm{g} / \mathrm{kg})\end{array}$} & \multicolumn{3}{|c|}{ Fraction in (\%) } \\
\hline & & Globule core & MFGM & Skim phase \\
\hline \multicolumn{5}{|l|}{ Neutral glycerides } \\
\hline Triacylglycerol & $958-983$ & 100 & & \\
\hline Diacylglycerol & $2.8-22.5$ & • 90 & $\cdot 10$ & ? \\
\hline Mono-acylglycerol & $0.3-3.8$ & Traces & Traces & Traces \\
\hline Free fatty acids & $1.0-4.4$ & 60 & $\cdot 10$ & 30 \\
\hline Phospholipids $^{\dagger}$ & $2.0-11.1$ & - & 65 & 35 \\
\hline Small globule $(3 \mu \mathrm{m})^{a}$ & & & $28.4^{\ddagger}$ & \\
\hline Large globule $(6 \mu \mathrm{m})$ & & & $36.9^{\ddagger}$ & \\
\hline Cerebrosides & 1.0 & - & 70 & 30 \\
\hline Gangliosides & 0.1 & - & - 70 & - 30 \\
\hline Sterols & & 80 & 10 & 10 \\
\hline Cholesterol & $3.0-4.6$ & & & \\
\hline Cholesteryl ester & $\bullet 0.2$ & & & \\
\hline Carotenoids + Vit. A & 0.02 & • 95 & - 5 & Traces \\
\hline
\end{tabular}

"PL in the MFGM pellet

${ }^{a}$ Small globules tend to contain more sphingomyelin

${ }^{*} \mathrm{PL} \%$ in total lipids of the MFGM from microfiltrated globules

\section{a) Phospholipids}

Glycerophospholipids have a glycerol backbone with two fatty acids attached on positions $s n-1$ and $s n-2$. The third hydroxyl group has a phosphate group esterified to an organic compound such as choline or serine (Rombaut et al., 2006c) as observed in Figure 5. Phosphatidylcholine (PC) represents up to $35 \%$ of the total phospholipids and is a major constituent of cell membranes, which provides structure and maintains the permeability barrier (Dewettinck et al., 2008; Jiménez-Flores and Higuera-Ciapara, 2009). Depending on the water concentration and temperature, PC can take on up to four morphologies including lamellar crystalline $\left(L_{c}\right)$, laminar $\beta^{\prime}\left(L_{\beta}\right)$, laminar $\alpha\left(L_{\alpha}\right)$, and oblique $\beta^{\prime}\left(P_{\beta}\right)$ (Fedotova and Lencki, 2008). 


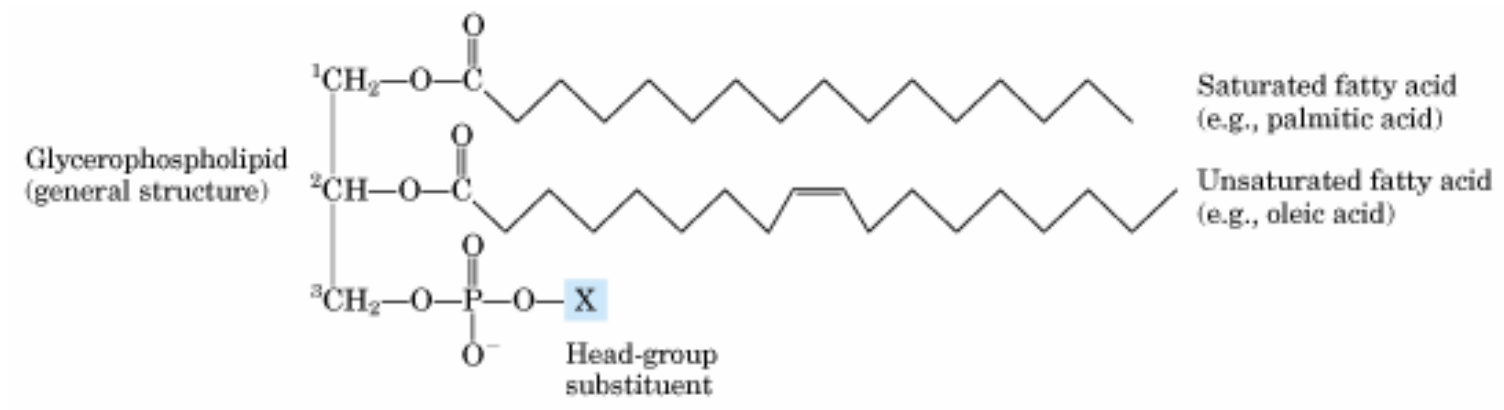

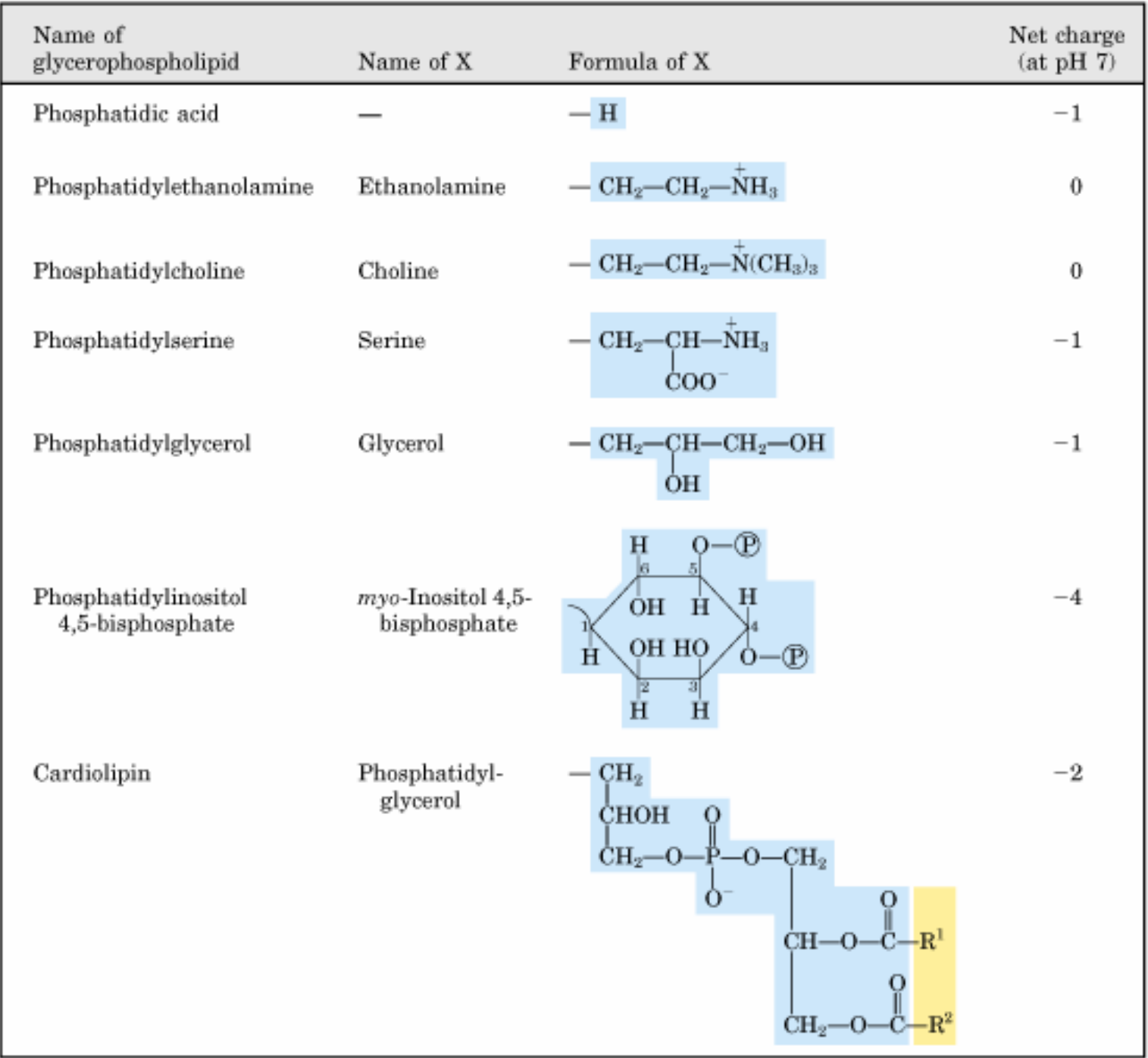

Figure 5. Glycerophospholipid structure showing the glycerol backbone with two fatty acids (top). Different alcohol substituents that form polar lipid derivatives at the second alcohol via a phosphoester linkage (bottom table) (Nelson and Cox, 2000).

Phosphatidylethanolamine (PE) makes up to $30 \%$ of the total phospholipids in

MFGM and is mainly found in nerve tissue and brain, accounting for approximately half 
of the phospholipid content in the latter. In fact, PE is implicated in optimal brain development and boosting memory (Zeisel, 2006). PE derived from MFGM is highly unsaturated (68\%) with high levels of C18:1 and C18:2 and less C14:0 and C16:0 compared to PE from whole milk (Sánchez-Juanes et al., 2009). Phosphatidylinositol (PI) and phosphatidylserine (PS) are anionic phospholipid present in lower amounts in the MFGM. PI acts as a substrate for several enzymes involved in cell signaling and can be phosphorylated to form phosphatidylinositol phosphate (PIP). PS is a negatively charged component of cell and blood platelets that assist in blood coagulation. In addition, PS may reduce the risk of dementia and cognitive dysfunction in the elderly, as presented in Table 3 (Dewettinck et al., 2008). The distribution of these phospholipids is asymmetrical throughout the MFGM (Deeth, 1997). PE, PS, and PI are concentrated in the inner surface whereas PC, sphingomyelin (SM), and glycosphingolipids such as cerebrosides and gangliosides are observed in the bilayer membrane (Deeth, 1997; Lopez et al., 2008).

In the market, sour and sweet buttermilk and quark-skimmed cheese are the highest polar lipid-containing products (Jiménez-Flores and Brisson, 2008). With all the health benefits and biological roles that phospholipids and sphingolipids have, it will be beneficial to fortify food with these low-price products; however, it is important for the food technologist to know the structure of these molecules and understand their chemistry. Phospholipids are good emulsifiers but differ in properties. PC and PE tend to stabilize water-in-oil emulsions due to their low hydrophilic-lipophilic balance (HLB) value while SM, PI, and PS tend to form oil-in-water emulsions (Fedotova and Lencki, 2008; Fedotova and Lencki, 2010). As Jiménez-Flores and Brisson (2008) stated, it is essential to understand the biological mechanism of nutritional delivery to incorporate 
MFGM constituents into foods, so food scientists can formulate products that preserve the optimal structure of these lipids and deliver the proper nutrition and functionality.

Table 3. Nutritional aspects of polar lipids of the MFGM (adapted from Dewettinck et al., 2008; Jiménez-Flores and Brisson, 2008; Rombaut et al., 2006).

\begin{tabular}{|c|c|c|}
\hline Component & PL \%* & Nutritional Aspects \\
\hline \multirow{9}{*}{$\begin{array}{l}\text { Sphingolipids and } \\
\text { metabolites }\end{array}$} & \multirow{9}{*}{$18.0-34.1^{\mathrm{a}}$} & $\begin{array}{l}\text { Reduction of the number of aberrant crypt foci and } \\
\text { adenocarcinomas }\end{array}$ \\
\hline & & Shift in tumor type (malignant $\Rightarrow$ benign) \\
\hline & & Anticholesterolemic, especially from dairy origin \\
\hline & & $\begin{array}{l}\text { Protection of the liver from fat- and cholesterol induced } \\
\text { steatosis }\end{array}$ \\
\hline & & Suppression of gastrointestinal pathogens \\
\hline & & Neonatal gut maturation \\
\hline & & Myelination of the developing central nervous system \\
\hline & & Endogenous modulators of vascular function \\
\hline & & $\begin{array}{l}\text { Associated with age-related diseases and the development of } \\
\text { Alzheimer }\end{array}$ \\
\hline Sphingosine1-phosphate & & Mitogenic \\
\hline \multirow[t]{4}{*}{ Phosphatidylcholine (PC) } & $19.2-37.3$ & $\begin{array}{l}\text { Support liver recovery from toxic chemical attack or viral } \\
\text { damage }\end{array}$ \\
\hline & & Protects the human GI mucosa against toxic attack \\
\hline & & Reduction of necrotizing enterocolitis \\
\hline & & Alleviates orotic acid-induced fatty liver \\
\hline \multirow{2}{*}{$\begin{array}{l}\text { Lysophosphatidylcholine } \\
\text { (lysoPC) }\end{array}$} & 2 & Bacteriostatic and bactericidal capacity \\
\hline & & Strong gastroprotective role in the duodenal mucosa \\
\hline \multirow{2}{*}{$\begin{array}{l}\text { Phosphatidylethanolamine } \\
\text { (PE) }\end{array}$} & $19.8-42.0$ & Maintains hemostasis \\
\hline & & Brain development \& boost memory \\
\hline \multirow[t]{3}{*}{ Phosphatidylinositol (PI) } & $5-11 \%$ & Substrate in cell signaling \\
\hline & & Promotes plasma cholesterol transport and metabolism \\
\hline & & Restore normal memory on a variety of tasks \\
\hline \multirow[t]{2}{*}{ Phosphatidylserine (PS) } & $1.9-10.5$ & Positive effects on Alzheimer patients \\
\hline & & Improve exercise capacity of exercising humans \\
\hline
\end{tabular}

* Relative phospholipid content (g per $100 \mathrm{~g}$ of polar lipid including sphingomyelin)

a Sphingomyelin content

\section{b) Sphingolipids}

Sphingolipids are highly bioactive molecules characterized by a sphingoid base, which is a long-chain aliphatic amine (12-22 carbon atoms) (Rombaut et al., 2006c). Attachment of a fatty acid via a hydroxyl group forms a ceramide that is the basic unit for the formation of a sphingophospholipid such as sphingomyelin and lactosylceramide (Figure 6). The difference in headgroups as well as the length and saturation of the fatty 
acid and sphingoid chains have contributed to the identification of more than 400 sphingolipids (Duan, 2011).

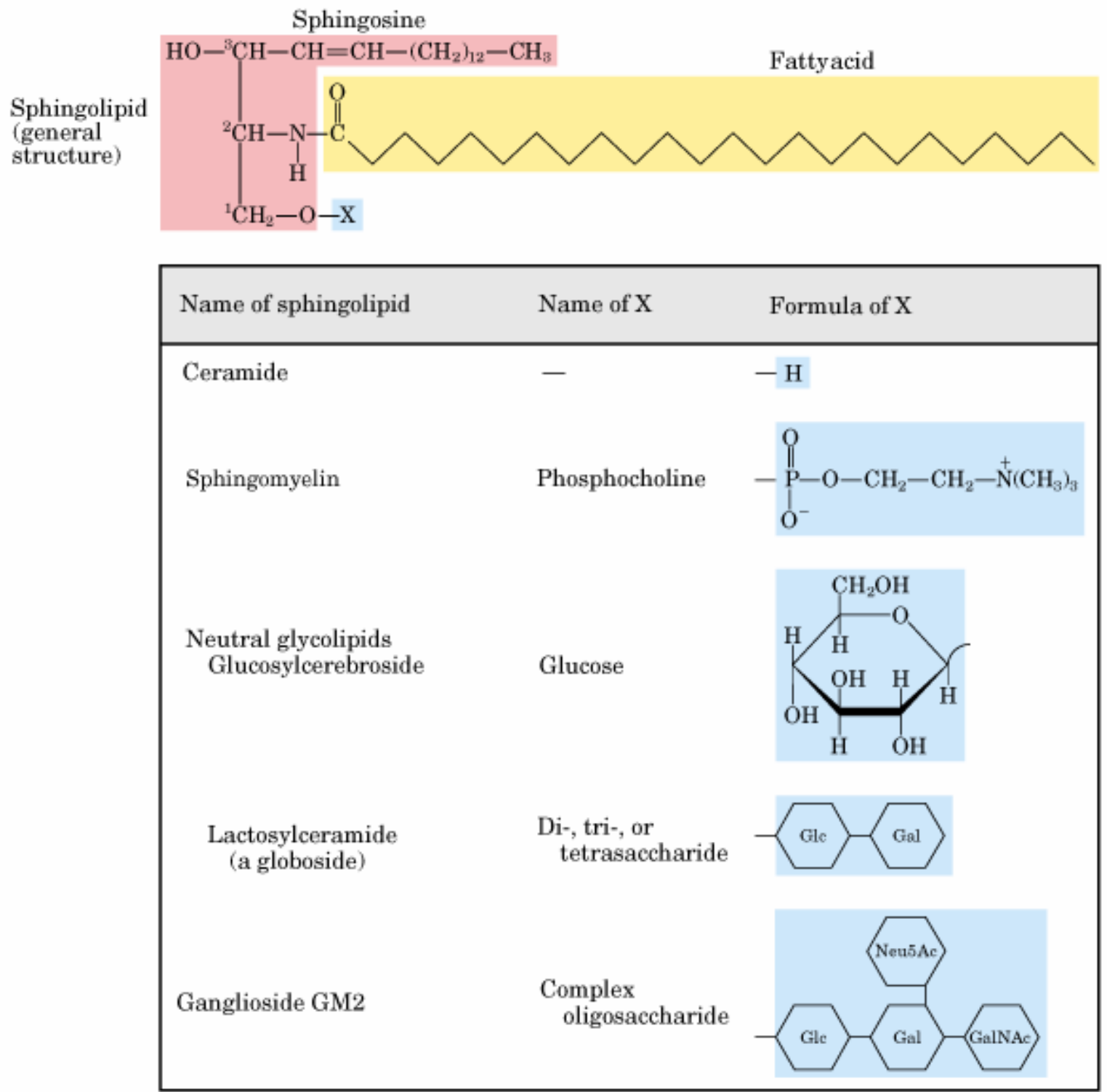

Figure 6. Basic structure of sphingolipids, which are composed of a sphingosine base link to a fatty acid on its amide group and a headgroup (R) on its hydroxyl group (Top). Most common phosphosphingolipids and glycosphingolipid headgroups (bottom table) (Nelson and Cox, 2000).

Sphingomyelin (SM) is the most abundant sphingolipid (Duan, 2011) and constitutes up to one third of the MFGM polar lipid fraction (Dewettinck et al., 2008). It is composed of a phosphorylcholine headgroup and a fatty acid linked to the amide nitrogen 
of the sphingoid long chain base. The high degree of saturation of the acyl chains facilitates complex formation with cholesterol (Figure 3) (Avalli and Contarini, 2005; Duan). This liquid-ordered state, also known as a lipid raft, affects membrane structure and function (Vesper et al., 1999; Duan, 2011; Lopez et al., 2010b). Lipid rafts are rigid domains implicated in cellular processes like signal transduction, endocytosis, and cholesterol trafficking (Lopez et al., 2008; Lopez et al., 2010b; Dewettinck et al., 2008). Other sphingoloipids present in lower percentages in the MFGM are glucosylceramide, lactosylceramide, and gangliosides. Galactosylceramide, ganglioside, and SM have only been identified in mammalian tissue but not in plant tissue (Duan, 2011).

The metabolism of dietary and membrane sphingolipids, which mainly takes place in the middle region of the small intestine, generates ceramide, sphingosine, sphingosine-1phosphate, and ceramide-1-phosphate (Duan and Nilsson, 2009; Duan, 2011). Among these intermediate products, ceramide is the most important because other sphingolipids can be derived from it (Duan, 2011). These molecules act as bioactive lipid messengers that influence cellular functions such as growth, differentiation, apoptosis, response of mucosal cells to pathogens, and have anticancer activities, especially in colorectal, liver, and gastric cancer (Figure 7) (Duan, 2011). Foods high in sphingolipids are eggs and soybeans with over $2,200 \mu \mathrm{mol} / \mathrm{kg}$ and dairy products such as cream and cheese with over $1,300 \mu \mathrm{mol} / \mathrm{kg}$ (Yeh, 1984). For infants the only source of sphingolipids is milk, which has approximately $160 \mu \mathrm{mol} / \mathrm{kg}$ (Yeh, 1984; Duan, 2011). 


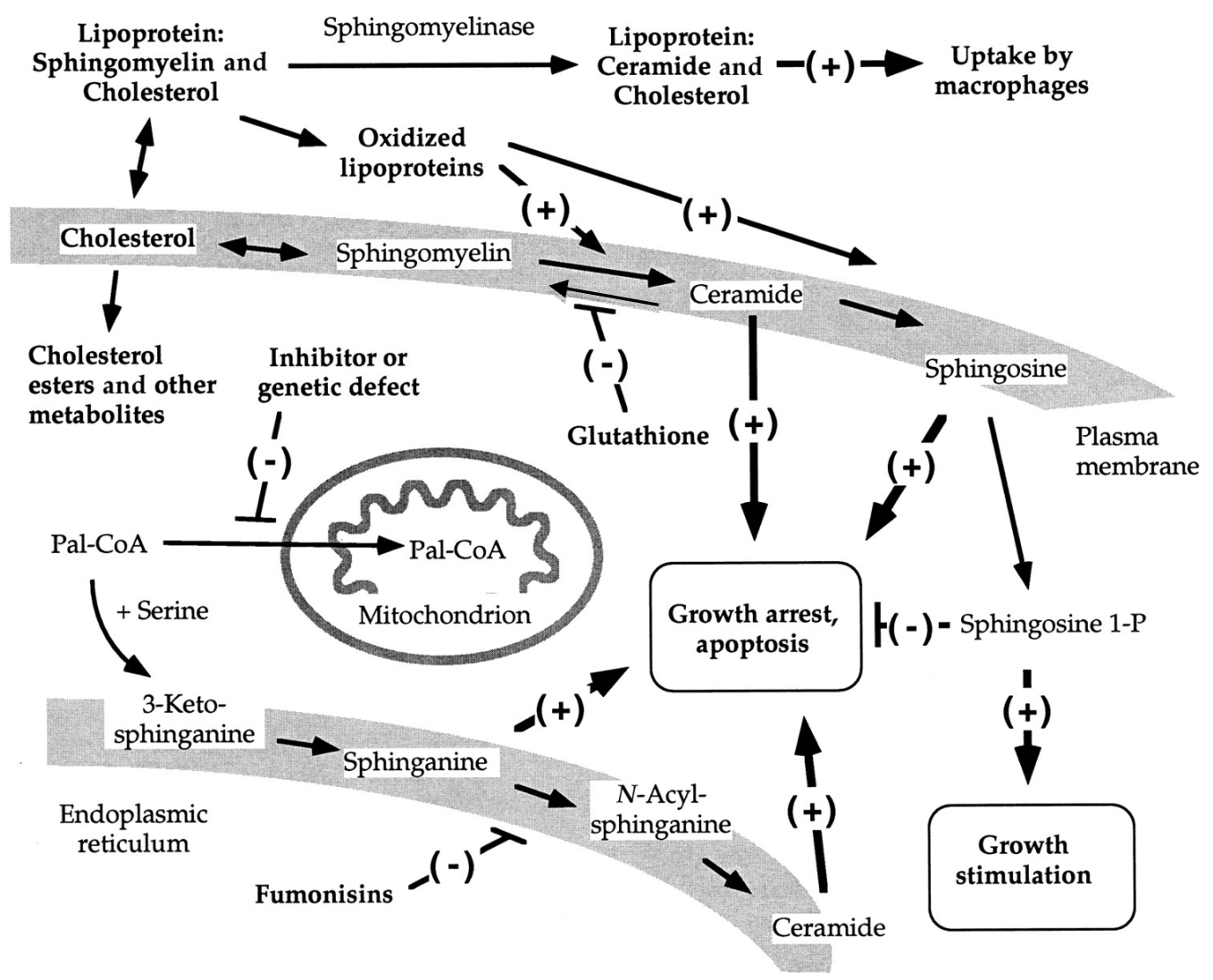

Figure 7. Functions of sphingomyelin and metabolites as well as factors that can modulate sphingolipid metabolism and cell regulation (Adapted from Vesper et al. 1999).

Sphingomyelin is primarily located in the outer membrane of the MFGM and is present in higher percentages in milk derived from cows fed with unsaturated fatty acids due to the presence of smaller globules and consequently more surface area (Lopez et al., 2008). Some studies indicate that starter cultures may contribute to the amount of PL, especially sphingomyelin, present in dairy products and by-products (Umemoto and Sato, 1973; Morin et al., 2006); however, another research group found similar sphingolipid concentrations in the raw material and the final fermented product, indicating that starter cultures do not contribute to SM in dairy foods (Ahn and Schroeder, 2002). In the contrary, they degrade some phospholipids, and thereby, explain the presence of phosphatidic acid in fermented foods. 
SM has been shown to reduce aberrant crypt foci and the appearance of colon adenocarcinoma (Schmelz et al., 1996; Snow et al., 2010), to influence neonatal gut maturation (Duan, 2011; Duan and Nilsson, 2009), and to contribute to myelination of the developing rat central nervous system (Yeh, 1984; Dewettinck et al., 2008). Rats fed with milk sphingolipids had a significant reduction in plasma cholesterol levels and liver triacylglycerols (Nyberg et al., 2000; Watanabe et al., 2010). Sphingomyelin derived from dairy seems to be more efficient in reducing cholesterol levels than egg SM (Noh and Koo, 2004). The ceramide fraction of milk polar lipids had similar results in diabetes/obese model mice; it decreased the level of cholesterol and TAG in the liver and total cholesterol in the plasma (Watanabe et al., 2010).

\section{Milk Fat Globule Membrane Proteins}

MFGM proteins constitute $1-2 \%$ of the total bovine milk protein, and depending on the milk source and how it is processed, 25-70\% of the MFGM may be polypeptides, ranging in molecular weight (MW) from 15,000 to 240,000 Da (Dewettinck et al., 2008; Jiménez-Flores and Higuera-Ciapara, 2009; Riccio, 2004; Ye et al., 2002). Indeed, Murgiano et al. (2009) detected differences between Chianina and Holstein cattle in the amount of proteins associated with mammary gland development, lipid droplet formation, and host defense mechanisms. A detailed description and suggested nomenclature of the known and major MFGM proteins are presented by Mather (2000). Using proteomic techniques, Reinhardt and Lippolis (2006) identified 120 proteins, which were grouped into seven categories as seen in Table 4; however, studies by Fong and Norris have demonstrated eight predominant proteins in the MFGM: butyrophilin, adipophilin (ADPH), xanthine oxidase, cluster of differentiation 36, fatty acid-binding protein (FABP), lactadherin, mucin 1, and mucin 15 (Fong and Norris, 2009). 
Table 4. MFGM Protein classification using proteomics techniques (adapted from Reinhardt and Lippolis, 2006).

\begin{tabular}{ll}
\hline \multicolumn{1}{c}{ Protein Functionality } & \% \\
\hline Membrane/protein trafficking & 23 \\
Cell signaling & 23 \\
Fat transport and/or metabolism & 11 \\
Transport & 9 \\
Protein synthesis, binding \&/or folding & 7 \\
Immune functions & 4 \\
Milk proteins: $\alpha$-and -casein & 2 \\
Unknown function & 21 \\
\hline
\end{tabular}

Early studies demonstrated in-vitro intrinsic phosphorylation of butyrophilin and fatty acid binding protein (FABP) (Spitsberg and Gorewit, 1997). In fact, there have been detected about 28 enzymes in the MFGM including some protein kinases, oxidases, 5'nucleotidase, adenosine triphosphatase, and phosphodiesterase (Reinhardt and Lippolis, 2006; Keenan and Mather, 2006). Half of these enzymes belong to the hydrolase class, and the most abundant enzymes are alkaline phosphatase and xanthine oxidase (Jarasch et al., 1977; Singh, 2006). The purpose of some enzymes is still unclear. It has been hypothesized that they might originate from the cytoplasmic crescents, making them transient MFGM proteins (Keenan and Mather, 2006; Mather and Keenan, 1998). The biological role of the MFGM-associated enzymes has been focused on their damaging effects, which makes their presence undesirable in dairy products because they might cause off-flavors or affect processing properties (Keenan and Mather, 2006). One fourth of the identified proteins still have unknown functions. Table 5 presents the health benefits attributed to MFGM proteins and components.

Table 5. Health benefits of MFGM components (adapted from Dewettinck et al., 2008; Fong et al., 2007; Jiménez-Flores and Brisson, 2008; Michalski and Caroline, 2006 ; Riccio, 2004; Pan et al., 2006; Spitsberg, 2005).

\begin{tabular}{clc}
\hline & \multicolumn{1}{c}{ MW } \\
Proteins & $($ Kg/mol) & Reported Heath Benefits/Functions \\
\hline Mucin 1 (MUC1) $\dagger$ & 160 & Antiviral action/Anti Rotavirus especially in neonates \\
\hline
\end{tabular}




\begin{tabular}{|c|c|c|}
\hline Mucin 15 (MUC15 or PAS III) $\dagger$ & $94-100$ & Antiviral action \\
\hline Butyrophilin (BTN) $\dagger$ & 66 & Suppression of multiple sclerosis \\
\hline Xanthine oxidase (XO) & $150-155$ & Bactericidal agent \\
\hline $\begin{array}{l}\text { Cluster of differentiation } \\
(\text { CD36 or PAS IV) } \dagger\end{array}$ & 78 & Glycoproteins that act as receptors due to high sugar content \\
\hline $\begin{array}{l}\text { Fatty acid binding protein } \\
\text { (FABP) }\end{array}$ & 15 & $\begin{array}{l}\text { Cell growth inhibitor } \\
\text { Anti-cancer factor (FABP as selenium carrier) }\end{array}$ \\
\hline BRCA1 and BRCA2 & 210 & Inhibition of breast cancer \\
\hline Lactadherin (PAS 6/7) $\dagger$ & $43-59$ & $\begin{array}{l}\text { Role of epithelialization, cell polarization, cell movement } \\
\text { and rearrangement, neurite outgrowth, synaptic activity in } \\
\text { the central nervous system, protection against viral infection } \\
\text { in the gut. Phospholipid binding }\end{array}$ \\
\hline Adipophilin (ADPH) & 52 & Milk synthesis \\
\hline \multicolumn{3}{|l|}{ Other components* } \\
\hline$\beta$-Glucoronidase inhibitor & & Inhibition of colon cancer \\
\hline Helicobacter pylori inhibitor & & Prevention of gastric diseases \\
\hline Cholesterolemia-lowering factor & & Anti-cholesterol activity \\
\hline Vitamin E and carotenoids & & Anti-oxidants \\
\hline Phosphoproteins & & Source of organic phosphorus and Ca-phosphate \\
\hline
\end{tabular}

$\dagger$ Glycosylated protein

* Phospholipids described in Table 4

As mentioned before, the protein content also varies throughout the cow's lactation phase (Ye et al., 2002). Two of the major proteins in the MFGM, xanthine oxidoreductase (XOR) and the mammary gland specific butyrophilin (BTN), fluctuate during the 300-day lactation period. They are high during the early and late stages compared with the mid-lactation. Despite the change in protein concentration, the fat globule size was not influenced, and the molar ratio (4:1, BTN:XOR) between these proteins remained the same throughout, suggesting a close interaction (Ye et al., 2002; Keenan and Mather, 2006; Singh, 2006). Further studies by Reinhardt and Lippolis (2008) characterized changes in the bovine MFGM proteome during transition from colostrum to mature milk. From day one (colostrum) to day seven (milk), 26 proteins were upregulated and 19 proteins were downregulated. Some of the most important MFGM proteins, including those regulated during the transition period, are discussed below. Among the upregulated proteins, mucin-1 and mucin-15 had the highest expression change with a 7-fold increase in mature milk (Reinhardt and Lippolis, 2008). 


\section{a) Butyrophilin}

Butyrophilin (BTN) is a glycosylated protein that is mainly found in the apical side of epithelial cells, in budding fat droplets, and in the inner coat of the MFGM (Franke et al., 1981). Recent data also localizes BTN on the cytoplasmic side of the lipid monolayer (McManaman et al., 2007). Mather and Jack (1993) were the first ones to hypothesize that BTN has multiple origins, from the apical membrane and from intracellular sources. It is the most abundant protein of the MFGM, constituting about $40 \%$ by weight of the total MFGM proteins in milk from Holstein cows and approximately 20\% from Jersey milk (Singh, 2006; Jiménez-Flores and Higuera-Ciapara, 2009). Its apparent molecular weight is 62-67 kDa with a 5\% carbohydrate content (Mather and Jacks, 1993; Singh, 2006). Fatty acids are also covalently bound to butyrophilin, which merits its name from the Greek butyros and philos, signifying "affinity for butter" (Keenan and Mather, 2006); palmitic, stearic, and oleic acid are the predominant protein-bound fatty acids in both BTN and XOR (Singh, 2006). Butyrophilin is part of the immunoglobulin (Ig) superfamily of adhesive and receptor proteins. Indeed, its $\mathrm{N}$-terminus has two Ig-like folds, and the C-terminus comprises a B30.2 domain, which is predicted to have two Ig folds that function as a protein-binding domain (Keenan and Mather, 2006; Mather, 2000; Mather and Jacks, 1993).

Butyrophilin is highly expressed during lactation and forms complexes with XO to envelop the nascent fat globule via adipophilin (Keenan and Mather, 2006). Freezefracture localization studies have shown that milk fat secretion is controlled by interactions between butyrophilin present in plasma membrane and in the secretory granule phospholipid monolayer (Robenek et al., 2006a). Jeong et al. (2009) provides

evidence that the cytoplasmic domain of butyrophilin binds to xanthine reductase as it 
was originally hypothesized. In addition, it has been suggested that BTN transfers phosphorus groups to tyrosine residues in proteins, activating them and playing a critical role in controlling the physiological activity of proteins in the secretory cells and within the MFGM. The gene controlling the expression of the BTN gene (BTN1A1) is described in detail in Bionaz and Loor (2008).

To date, the consumption of BTN continues to be a controversial topic due to its association with multiple sclerosis (MS), an autoimmune-mediated inflammatory disease that affects the central nervous system (Dewettinck et al., 2008; Rutter, 2006; Mather, 1999). Some research suggests that dairy products exacerbate symptoms or even produce the disease because BTN resembles a polypeptide named myelin oligodendrocyte glycoprotein (MOG), a putative auto-antigen that induces experimental autoimmune encephalomyelitis (EAE). This disease has clinical symptoms similar to human MS (Dewettinck et al., 2008; Riccio, 2004); however, in other experiments, mice treated with BTN, either before or after MOG injections, did not show clinical manifestations of EAE (Dewettinck et al., 2008). Mather and Linington (1999) have modified BTN to suppress an autoimmune response, which can also be used to screen for MS susceptibility. BTN has also been associated with autism due its resemblance with neurospecific antibodies; however, its etiopathogenesis is unknown (Riccio, 2004). Until the role of BTN with respect to MS and autism is elucidated, dairy products should be included in our daily diet to receive its health benefit, as the etiology of these diseases is a combination of genetic susceptibility and environmental factors (Rutter, 2006).

\section{b) Xanthine Oxidase}

Xanthine oxidoreductase (XOR) is a member of the moldyl hydroxylase family, which is widely expressed in tissues but has higher activity in bovine milk as compared 
to goat, sheep, and human milk (Silanikove and Shapiro, 2007). Moreover, XOR is highly expressed during pregnancy and parturition (Keenan and Mather, 2006). It can be present as xanthine dehydrogenase (XD) and converted to xanthine oxidase (XO) by proteolysis or formation of disulphide bonds (Mather, 2000; Silanikove and Shapiro, 2007; Spitsberg and Gorewit, 1998). It has been shown that plasmin activity is responsible for this interconversion, and the low-oxygen and low-enzyme environment of the inner-membrane decreases the conversion to $\mathrm{XO}$, resulting in a mixed population of enzymes.

$\mathrm{XD}$ is distributed in the CLD monolayer, with a non-enzymatic role in fat globule secretion (McManaman et al., 2007; Silanikove and Shapiro, 2007). Vanderghem et al. (2011) recently demonstrated that XO may be located both peripherally and within the MFGM. XD is not very stable in solution and reverts slowly to XO at pH 7.5 (Spitsberg and Gorewit, 1998). The active molecule is a homodimer with monomeric molecular masses of $150 \mathrm{kDa}$, which accounts for up to $20 \%$ of the coat proteins where XOR binds with high affinity to the carboxyl end of BTN. Each subunit contains one molybdenum, one flavin adenine dinucleotide, and two nonidentical iron-sulfur redox centers (Martin et al., 2004; Keenan and Mather, 2006; Mather, 2000).

During MFGM isolation, XOR disperses in the supernatant but remains tightly bound to the membrane, and can be isolated using high salt and non-ionic detergents (Keenan and Mather, 2006; Mather, 2000). Keenan and Mather (2006) have proposed that the $\mathrm{XDH} / \mathrm{BTN}$ complex associates with other proteins to mediate interactions between the lipid core and the membrane. Besides purine catabolism, XOR generates reactive oxygen species (ROS) and reactive nitrogen species (RNS) such as nitric oxide (NO) and peroxynitrite that act as antimicrobial agents in the neonatal gut. Silanikove and Shapiro 
(2007) concluded that XD is a source of freely available extra-membrane protein that plays an essential role in the development of innate immunity (Martin et al., 2004; Jiménez-Flores and Higuera-Ciapara, 2009). Specifically, 33\% of the free XD is found in the outer surface of the MFGM, $46.7 \%$ in solution, and $20.5 \%$ in the outer surface of exosomes. This form may also affect the physicochemical oxidative properties of milk, especially during storage (Silanikove and Shapiro, 2007).

\section{c) Adipophilin}

Adipophilin, also known as adipocyte differentiation-related protein (ADRP), is ubiquitously expressed in the presence of long chain free fatty acids, especially in the mammary glands and in differentiating pre-adipocytes (Chang and Chan, 2007). It is one of the five members of the perilipin family (Brasaemle, 2007), and ADPH is the human homolog. These proteins localize on the monolayer and bilayer that surround MFG (McManaman et al., 2007). Clusters of ADRP have been observed in the cytoplasmic leaflet of the rough endoplasmic reticulum where lipid droplet biogenesis might take place. According to Robenek et al. (2006b), adipophilin is involved in the growth of lipid droplets, which are enclosed within endoplasmic reticulum (ER) cups. Immunofluorescence evidence by Russell et al. (2007) suggests that ADPR mediates lipid droplet accumulation in differentiating epithelial cells. In fact, its expression may be one of the factors that initiate lipid droplet accumulation (Russell et al., 2007).

During preadipocyte differentiation, adipophilin is highly expressed, and the protein embeds itself in the periphery of the intracellular lipid droplets. As adipocytes mature, ADRP is replaced by proteins known as perilipins; however, this mechanism is absent in the epithelial cells of the mammary glands (Nielsen et al., 1999; Dewettinck et al., 2008). Perilipins are proteins localized in the periphery of intracellular lipid droplets and are 
essential for droplet formation as well as lipolysis, but recent molecular evidence suggests that its role in mammary lipid droplet formation is not significant (Bionaz and Loor, 2008).

In the fat globules, adipophilin associates with the XOR/BTN complex and facilitates the envelopment of the globules with plasma membrane during milk fat droplet secretion (Nielsen et al., 1999). Proteomic data shows that these three proteins are upregulated individually during the transition period from colostrum to mature milk, indicating an early developmental shift in milk fat transport (Reinhardt and Lippolis, 2008). When the membrane is disrupted, adipophilin remains attached in the MFGM-associated coat material (Keenan and Mather, 2006). The apparent molecular weight of adipophilin is 52 $\mathrm{kDa}$, but calculations from the cDNA result in a lower molecular mass, suggesting posttranslational modification, especially acylation (Nielsen et al., 1999). Also, differences in mass and pI may be due to close associations with fatty acids, especially myristate, palmitate, stearate, and oleate (Mather, 2000; Vanderghem et al., 2008).

\section{d) Glycoprotein PAS6 and PAS7}

Early studies by Welsch et al. (1990) demonstrated the presence of glycoproteins in true ruminants. It was postulated that such glycosylation plays a role in the guts of the newborns (Welsch et al., 1990). In 1992, Kim et al. characterized two main glycoproteins in the MFGM, PAS6 and PAS7. The name is derived from the staining technique, periodic acid Schiff glycoprotein (PAS), which is used to identify protein with sugars. Their respective molecular masses are $50 \mathrm{kDa}$ and $47 \mathrm{kDa}$, and their polypeptide core are identical, suggesting that the difference in molecular weight is due to the $\mathrm{N}$-linked carbohydrate moieties. Three glycosylation sites have been detected in PAS6 while PAS7 only includes two sites (Kim et al., 1992; Hvarregaard et al., 1996). These molecules are 
loosely attached to the MFGM and can be removed with salt treatment such as $\mathrm{MgCl}_{2}$ (Singh, 2006; Mather, 2000).

The human homologue, known as lactadherin, has been shown to bind to rotavirus and protect the gastrointestinal tract of newborn infants from infection (Keenan and Mather, 2006). Studies have demonstrated that this protein plays a crucial role in vascular endothelial growth factor (VEGF)-dependent neovascularization, inducing the growth of new blood vessels in-vitro and in-vivo (Silvestre et al., 2005). Later studies showed that alterations in lactadherin production/function might contribute to the initiation or progression of Alzheimer's disease (Boddaert et al., 2007). The mouse homologue, milk fat globule factor-E8 (MFG-E8), has been involved in regulation of apoptotic neurons, and disruption in such mechanism may lead to neurodegenerative diseases (Fuller and Van Eldik, 2008; Elliott and Ravichandran, 2010). A mutation in this protein has also been implicated in atherosclerosis (Ait-Oufella et al., 2007). The bovine PAS-6/7 has been associated with lipid binding, specifically to phosphatidylserine, -inositol, -glycerol and phosphatidic acid. Such binding had a higher affinity towards MFGM polar lipids as supposed to a pure polar lipid fraction (Andersen et al., 1997).

\section{e) Mucins}

Mucins are highly glycosylated proteins that might work as receptors on the surface of cells, especially epithelial cells, where they may inhibit adhesion of intestinal bacteria to host epithelial cell receptors by acting as competitive inhibitors (Wilson et al., 2008; Parker et al., 2010). The predominant mucin in bovine MFGM is related to the human mucin (MUC1), and because of allelic polymorphism, MUC 1 appears as a diffuse band from pooled milk with molecular weight ranging from 160 to $200 \mathrm{kDa}$. Wilson et al. 
(2008) demonstrated that bovine and human MUC1 differs in their glycosylation, which implies a different protection against pathogens.

MUC 1 is incorporated onto the MFGM during the budding and release of lipid droplets at the cell surface (Mather, 2000), and milk processing such as cooling and stirring may contribute to its release from fat globules (Peterson et al., 1998). In vitro studies indicate that these glycosylated proteins prevent binding of $H$. pylori to mucosal cells (Peterson et al., 1998). In addition, Parker et al., (2010) determined that MUC inhibits bacterial binding to human intestinal cells, especially Gram (-) enteric bacteria such as E. coli and B. subtilis compared to Gram (+) bacteria. Another glycosylated protein, MUC15 has also been characterized and shown to be present in the bovine MFGM as well as in nonfat containing fractions such as skim milk and whey. Its molecular weight is about $130 \mathrm{kDa}$, from which 65\% represent the glycans (Pallesen et al., 2007). Both MUC can be used as prophylactic molecules to prevent illness caused by enteric pathogens by inhibiting bacteria's ability to adhere to intestinal epithelial cells or displacing bacteria from cells after microbial binding has occurred (Parker et al., 2010); however, care must be taken during MFGM isolation as these proteins, especially MUC 1 , are readily dissociated from the fat globules into skim milk when milk is cooled and agitated (Singh, 2006).

\section{f) Lactoferrin}

Lactoferrin is an iron-binding protein with varying degrees of glycosylation depending on the state of lactation and exhibiting a high degree of homology with transferrin. The actual concentration in milk differs in response to inflammation or infection (Farrell Jr et al., 2004; Baumrucker et al., 2006), but a decline has been observed during lactation (Reinhardt and Lippolis, 2008). When fully saturated with $\mathrm{Fe}^{3+}$, 
lactoferrin is known as hololactoferrin whereas the iron deficient molecule is called apolactoferrin. The iron-lactoferrin is resistant to proteolysis (Baumrucker et al., 2006), and iron dissociates only below pH 3.5 (Farrell Jr et al., 2004). Its first recognized biological function was binding to the outer membrane of gram (-) bacteria and causing the release of polysaccharides (Farrell Jr et al., 2004). In breast milk, a major portion of iron is bound to lactoferrin, which has a specific receptor on the membrane of the small intestine of infants (Suzuki et al., 2005).

Currently, lactoferrin is associated with antimicrobial activities due its iron-binding capacity, inhibition/modulation of cytokine activity by neutrophils, promotion of growth of epithelial cells, anti-inflammatory responses, and prevention of apoptosis (Baumrucker et al., 2006; Pan et al., 2006). Due to these biological activities, lactoferrin is purified in commercial scale and even included in infant formula (Arla, 2011) since milk processing has little effect on lactoferrin structure (Sánchez et al., 1992), and research has shown that MFGM fractions incorporated in food or supplements exert health-promoting properties (Lonnerdal et al., 2006; Zavaleta et al., 2006; Arla, 2011).

\section{g) Cluster of Differentiation (CD36)}

CD36 has been identified in the MFGM, playing a role in milk fat excretion. It is a glycoprotein with an apparent molecular weight of $77 \mathrm{kDa}$ containing about $24 \%$ carbohydrate (Singh, 2006). Genomic data indicates that CD36 also plays a role in fatty acid (FA) synthesis by importing FA from blood into milk fat globules. Indeed, its expression level increases during lactation, and CD36 may be the most important regulator in endothelial long-chain fatty acid transport (Bionaz and Loor, 2008). 


\section{h) Fatty acid-binding protein (FABP)}

FAB proteins are well known for their role in fatty acid transport and lipid metabolism; however, recent studies have linked FAB proteins with cellular proliferation

and differentiation, and cell growth inhibition including breast cancer cells (Spitsberg and Gorewit, 2002; Jiménez-Flores and Higuera-Ciapara, 2009). Studies by Spitsberg et al., (1995) indicate that FABP associate with CD36, a protein involved in fatty acid import (Bionaz and Loor, 2008), and are under hormonal regulation as shown by a correlation between level of FABP phosphorylation within the MFGM and the level of milk production (Spitsberg et al., 1995). Further research indicated that FABP associated with the cytoplasmic domain of CD36 (Spitsberg and Gorewit, 2002).

\section{Health Benefits of the Milk Fat Globule Membrane}

Progress in the knowledge of the composition and role of milk fat globule membrane components has led to the realization that some MFGM constituents possess biological properties beyond their nutritional significance. Spitsberg (2005), in his review, refers to the MFGM as a nutraceutical with nutritional and pharmaceutical potential. In fact, the MFGM has antimicrobial proteins, illness suppressors, micronutrient-binding proteins that bind compounds such as iron, zinc, copper, folate, and vitamin B1, and other components with anti-carcinogenic properties as seen in Table 5. Indeed, Wat et al. (2009) supplemented bovine PL to mice fed a high-fat diet, resulting in a reduction in liver weight, total liver lipid, and serum lipid levels, which might be of therapeutic benefit in humans with non-alcoholic fatty liver disease, especially obese and diabetic patients (Wat et al., 2009). 


\section{MFGM in Infant Development}

In a clinical study, Lonnerdal et al. (2006) complemented infant food with bovine MFGM and micronutrients to evaluate its effect on children's growth, nutrition, and morbidity. In a double-blind study with 6-11 month-old-infants $(\mathrm{n}=550)$, fortification of food was beneficial for the copper and vitamin B12 status among the subjects, which enhance growth and normal function of the brain and nervous system, respectively (Lonnerdal et al., 2006). This fortifying complementary food was introduced in the market by Arla as LACPRODAN MFGM-10 (Arla Foods Ingredients, Denmark). It is rich in lactoferrin and phospholipids resembling human milk. The latter has more sphingomyelin and lactoferrin $(95-130 \mathrm{mg} / \mathrm{L}$ and $1.7-7 \mathrm{~g} / \mathrm{L}$, respectively) as compared to cow's milk (25 mg/L and 20-200 mg/L, respectively) (Arla, 2011).

In 2008, another clinical study was launched by the Umeá University in Sweden to determine the effects of MFGM-enriched formula with reduced energy and protein content on the growth and development of newborns (NCT00624689). Breast-fed and formula-fed infants usually differ in their growth pattern, risk for obesity and cardiovascular disease, neurological development and morbidity in infections (Timby, 2011). The study will conclude in 2016 , but scientists expect to see minimal differences between breast-fed and formula-fed infants due to the bioactive compounds in the MFGM.

\section{Anticancer Properties of the MFGM}

Many scientists have proposed the use of MFGM as a food supplement due to its effects on cancer cell growth (Spitsberg, 2005; Jiménez-Flores and Higuera-Ciapara, 2009; Jiménez-Flores and Brisson, 2008). In fact, the fatty acid binding protein (FABP) 
has been found to inhibit the growth of some breast cancer cell lines in vitro at very low concentrations (Spitsberg et al., 1995; Spitsberg and Gorewit, 2002). The breast-ovarian cancer susceptibility (BRCA1 and BRCA2) proteins, which regulate lipid synthesis via an interaction with acetyl-CoA carboxylase (Moreau et al., 2006b), have also been identified in the MFGM (Spitsberg and Gorewit, 1999; Vissac et al., 2002). These proteins inhibit the growth of various cell types and influence cellular proliferation and differentiation. Mutations on these genes may be responsible for a significant number of breast and ovarian cancers, and it is speculated that BRCA1 exerts its tumor suppressor function through a lipogenic mechanism (Moreau et al., 2006b). According to Spitsberg (2005), a MFGM-supplement will work by the consumption of MFGM material and subsequent release of peptides that can be absorbed in the digestive tract. The absorbed peptides can then exert their inhibitory action on cells undergoing carcinogenic transformation.

In addition, several lipids found in the MFGM can act as intracellular signaling molecules. Sphingomyelin has been shown to possess anti-cancer properties (Table 3). Its metabolites, sphingosine and ceramide, mediate numerous imperative cell functions including regulating cell growth, development and differentiation. Studies have shown sphingomyelin to be effective in suppressing colon tumors and increasing the efficacy of chemotherapy (Lemonnier et al., 2003; Modrak et al., 2002). Recently, it was shown that an ingredient rich in bovine PL from the MFGM prevented intestinal cancer in rats (Snow et al., 2010).

\section{Antimicrobial and Antiviral Properties of the MFGM}

Milk and colostrum contain several antimicrobial factors, especially low-abundance proteins in colostrum, which are transferred from the mother to the neonate and 
contribute to the protection against infectious diseases (Yamada et al., 2002; Affolter et al., 2010). For many species, the milk-derived antimicrobial system is crucial for survival of the neonate in early lactation. The components of the MFGM are involved with antiinfection or anti-adhesion processes, and hence with protection of the neonate from various viral and bacterial infections (Lopez et al., 2008). Currently there is evidence that the protective effect of milk on viral infections is a complex mechanism involving MFGM components, which include glycosylated proteins (Wilson et al., 2008). Zavaleta et al. (2006) tested the antimicrobial and antiviral properties of bovine MFGM on the incidence and duration of diarrhea in infants. In a double-blind study with 6-11 month old infants, MFGM fortification reduced diarrhea incidence and prevalence.

The antimicrobial and antiviral activities of proteins and lipids are currently receiving increasing interest, especially in the context of the preparation of infant formula and medical food. A review by Pan et al. (2006) summarized the current knowledge of the protein lactoferrin, most comprehensively studied for its beneficial immunological, antimicrobial and anticarcinogenic properties. This review examined the potential mechanism of lactoferrin as a powerful inhibitor of viral infection. Bovine lactoferrin was found to be more effective against viral infections than human lactoferrin. Isaacs et al. (1995) conducted an in vitro study in which fatty acids and monoglycerides were added to infant formula. They found that fatty acids and monoglycerides with chain lengths varying from 8 to 12 carbons were more antiviral and antibacterial than long chain monoglycerides (Isaacs et al., 1995). On the other hand, Sánchez-Juanes et al. (2009) failed to observe binding between individual PL and E. coli in in-vitro studies; therefore, they discard the idea that PLs may block the adhesion of pathogen to the gastrointestinal tract. 


\section{E. Biochemical Properties of the MFGM in Food Products}

\section{Emulsifying and stabilizing properties of MFGM}

MFGM is the native emulsifier in milk. The food industry recognizes the amphiphilic nature of the components in MFGM, phospholipids and glycoproteins, all of which are found in buttermilk powder and are excellent emulsifying agents (Kanno et al., 1991; Corredig and Dalgleish, 1997a; Roesch et al., 2004). The water distribution properties of the MFGM (either purified or in dairy ingredients) aid in thickening formulations and foaming of processed foods. However, the liability is lipid oxidation, causing the powder to go rancid in approximately six months. The major advantages of using buttermilk solids in functional food systems pertain to their significant antioxidant activity and buffering capacity (Wong and Kitts, 2003) and to their high phospholipid content, and their suppressive effect on certain pathogens (Jiménez-Flores and Higuera-Ciapara, 2009; Evers, 2004a).

MFGM components have also been used to stabilize emulsions and enhance the absorption of fat-soluble nutrients such as vitamin $\mathrm{D}_{3}$ and vitamin $\mathrm{A}$. It has been speculated that MFGM-stabilized microdispersions interact with bile salts and enzymes. Indeed, Bezelgues et al. (2009) utilized micelles (monolayers) stabilized with MFGM components to evaluate the capacity of liposoluble compounds to be incorporated into mixed micelles during digestion. Emulsions stabilized with MFGM had a 2-fold accumulation of tocopherol and lycopene when compared to emulsions stabilized with milk proteins, suggesting a nutritional application as absorption promoters of liposoluble nutrients in low-fat food products. Many researchers are starting to see that the value of buttermilk extends beyond emulsification to include the benefits of the MFGM components. 


\section{Potential delivery systems derived from MFGM}

The rich content of phospholipids (PL) in the MFGM, and their unique chemical composition, facilitates the use of its constituents in the formation of liposomes, which are used in the pharmaceutical and cosmetic industries (Singh, 2006; Thompson and Singh, 2006). These are vesicles formed through the self-assembly of amphiphilic molecules such as PL, creating bilayers with an aqueous core. During their formation, hydrophobic molecules can be incorporated into the bilayer while hydrophilic molecules comprise the core (Singh, 2006). In the food industry, liposomes can be utilized to protect sensitive ingredients or to increase the efficacy of additives (Thompson and Singh, 2006); however, the popular methodologies to make liposomes are not feasible on a large scale due to kinetics and the use of detergents and solvents. Furthermore, the current PL sources, soy and egg, have high purification costs and a different composition to those PL from milk. Thus utilization of low-cost sources such as buttermilk or butter serum could alleviate the restrictions of liposome production. Thompson and Singh (2006) have successfully used microfluidization, which uses high pressure to force fluid into microchannels to overcome the limitations of other techniques (Thompson and Singh, 2006). This method can generate a large volume of liposomes in a reproducible manner without promoting oxidation, and the inclusion of MFGM phospholipids increases liposome dispersion and stability (Thompson and Singh, 2006).

\section{Application of MFGM Components in Food Systems}

MFGM components have been incorporated into food systems mainly as buttermilk (Vanderghem et al., 2010). The use of condensed sweet cream buttermilk at low levels of supplementation improved the yield of pizza cheese without affecting compositional, 
rheological or sensory properties (Govindasamy-Lucey et al., 2006). Buttermilk, originating from raw or pasteurized cream was also integrated into casein matrixes to simulate cheese, resulting in increased yield due to the water-holding capacity of phospholipids (Morin et al., 2008). Fedotova et al. (2008) fortified butter with MFGM phospholipids, which stabilized crystal morphology; however, at elevated levels their addition caused a coalescence of the aqueous phase, creating water pockets that may affect sensory properties. A subsequent study by the same group showed that addition of PL increases butter hardness and reduces the tendency to oil-off at elevated temperatures. The optimal butter product contained a blend of 60-80\% globule fat (Fedotova and Lencki, 2010). Recently, Vanderghem et al. (2010) has summarized the effect of the addition of buttermilk on the physico-chemical and technofunctional properties of food products.

Another dairy product of interest is the milk produced during the first week of lactation, known as colostrum, which is free of caseins and rich in immunoglobulins and MFGM proteins (Affolter et al., 2010). One of the main proteins present is lactoferrin, which is correlated with beneficial immunological, antimicrobial, and anticarcinogenic properties. Some current nutraceutical formulations utilize lactoferrin for the treatment of various ailments, including cardiovascular disease (Mao et al., 2007). Methods have been developed for the processing of colostrum to diminish the microbial load and obtain a stable and available product, which may be added to a variety of foods (Scammell, 2001). In addition, milk oligosaccharides from human milk are linked to intestinal protection from pathogens (Wilson et al., 2008), and their potential use in infant formula is being considered, especially for premature infants who are susceptible to necrotizing enterocolitis (Kemsley, 2008). 


\section{F. Sources of the Milk Fat Globule Membrane: a Novel Dairy Product}

The industrial and potential health benefit properties of the MFGM components have led to its isolation and concentration from dairy products. The commercial source is sweet buttermilk, which is the aqueous phase resulting from butter churning that contains proteins, lactose, MFGM, and other minor constituents (Sodini et al., 2006; Rombaut et al., 2006a). Compared to skim milk and whole milk, buttermilk has seven times more phospholipids on a dry basis $(0.28 \mathrm{~g}$ per $100 \mathrm{~g}$ versus $2.03 \mathrm{~g}$ per $100 \mathrm{~g}$, respectively) (Sodini et al., 2006). Despite its high content of MFGM components and low cost, buttermilk has very limited commercial value (Jiménez-Flores and Brisson, 2008; Jiménez-Flores and Higuera-Ciapara, 2009; Singh, 2006). There are also other sources of buttermilk such as cultured (sour) and whey buttermilk, derived from churning of cultured cream and whey cream; however, they do not have high demand in the industry. Sodini et al. (2006) analyzed buttermilk's functional properties including protein solubility, viscosity, emulsification, and foaming and compared them to skim milk and whey. The fat content was higher in buttermilk, but the presence of MFGM components imparted greater emulsification and lower foaming capacity to sweet, sour, and especially whey buttermilk as compared to skim milk and whey. The functional properties of the buttermilk were $\mathrm{pH}$-dependent with the exception of whey buttermilk, whose functionality makes it ideal for low pH foods (Sodini et al., 2006).

Table 6. Phospholipid and protein composition in dairy products (adapted from Dewettinck et al., 2008; Fong et al., 2007; Jiménez-Flores, 2009; Morin et al., 2006).

\begin{tabular}{|c|c|c|c|c|}
\hline \multirow[b]{2}{*}{ Product } & \multicolumn{2}{|c|}{ Phospholipids (g/100g) } & \multicolumn{2}{|c|}{ Protein Percentage in } \\
\hline & Wet basis & Dry basis & Product & Dry \\
\hline Raw milk & 0.035 & 0.28 & 3.3 & - \\
\hline Skim milk & 0.02 & 0.28 & 3.41 & 7.55 \\
\hline Cream & 0.19 & 0.40 & 3.16 & - \\
\hline Isolated MFGM & 0.65 & $6.5^{*}$ & 1.8 & $60 *$ \\
\hline
\end{tabular}




\begin{tabular}{lllll}
\hline Butter & 0.19 & 0.23 & 0.85 & - \\
Sweet Buttermilk & 0.16 & 2.03 & 3.31 & $32.95^{*}$ \\
Butterserum & 1.25 & 11.54 & - & - \\
Fresh acid buttermilk $^{\mathrm{a}}$ & 0.31 & 1.86 & 3.31 & - \\
Acid buttermilk whey & 0.10 & 1.84 & 0.99 & $84.7^{*}$ \\
Whey buttermilk powder (WBP) $^{*}$ & - & $14.81^{*}$ & - & $47.39^{*}$ \\
SPE-WBP* & & $60.59^{*}$ & & $72.69^{*}$ \\
Cheddar cheese & 0.15 & 0.25 & - & 24.89 \\
Cheddar cheese whey & 0.02 & 0.26 & 3.49 & 35.2 \\
\hline
\end{tabular}

${ }^{\ddagger}$ Average from several sources and laboratory data.

*Numbers from corresponding author's laboratory data

${ }^{\text {a }}$ Sour buttermilk

${ }^{\mathrm{b}}$ Solid phase extracted (SPE) whey buttermilk powder (WBP)

Besides sweet buttermilk, other sources such as sour and whey buttermilk have been characterized as denoted in Table 6. Among them, butter serum offers the highest concentration of phospholipids on a dry basis and has promise to become a potential source of MFGM (Rombaut et al., 2006a). However, in any of these sources, other milk proteins 'dilute' the concentration of MFGM components. Thus, much research has been undertaken to adapt filtration techniques such as microfiltration and ultrafiltration to concentrate or purify MFGM without the use of chemical solvents. At the same time, the effects of homogenization and heat treatment on the native structure of the MFGM and the potential implications these may impart on product functionality and nutrition need to be evaluated.

Another source of MFGM is butter serum, a by-product of anhydrous milk fat production. It can be made by either separation of butter upon melting and centrifugation, or homogenization of $75 \%$ cream until phase inversion is induced, creating butter serum (Rombaut et al., 2006b). The phospholipid content in this fraction is five times higher than that of buttermilk (11.54g per $100 \mathrm{~g}$ on dry basis, see Table 1$)$. Two more MFGM-enriched milk fractions are whey protein concentrate (WPC) and buttermilk protein concentrate (BMP), which have been characterized in terms of their protein composition (Affolter et al., 2010). Affolter et al. (2009) found 244 proteins in 
WPC and 133 in BMP, from which 28 in these two fractions can be accounted for in the research performed by Reinhardt et al. (2006). Nevertheless, the main problem with MFGM purification is the presence of caseins and whey proteins, which has triggered the quest for novel purification techniques involving membranes.

\section{G. Isolation and Purification of the MFGM}

\section{Laboratory Production of MFGM}

The yield and composition of the MFGM, as mentioned previously, depends on the technique utilized for its isolation from cream, buttermilk, or whole milk. Loosely bound proteins and especially the amount of skim milk proteins, varies in the final MFGM fraction (Singh, 2006; Keenan and Mather, 2006). Also, the concentration of triacylglycerols differs due to cross-contamination from the globule core (Keenan and Mather, 2006; Mather, 2000). On micro- and macro-scales, MFGM proteins are purified using a common four-step procedure that involves cream separation, cream wash, globule disruption, and membrane collection (Mather, 2000; Dewettinck et al., 2008).

The fat globules are first isolated out of the milk by centrifugation with a physiological buffer layer that also washes the fat globules, eliminating the second step and increasing yield of MFGM material (Patton and Huston, 1986). Alternatively after centrifugation, the globules can be washed two or three times with buffers (Anderson and Brooker, 1974; Basch et al., 1985; Keenan and Mather, 2006); nevertheless, some membrane disruption and loss of at least $16 \%$ of the membrane proteins occurs (Anderson and Brooker, 1974). In addition, cream washing affects the densities of the lipoportein complexes (Houlihan et al., 1992). To minimize MFGM loss, a milk salt buffer or sucrose is usually added to increase the density of serum (Singh, 2006). Then, 
the globules are disrupted by either churning (agitation), cycles of freezing and thawing, treatment with detergents, or by suspension in polar and aprotic solvents (Keenan and Mather, 2006). This step may lead to loss of proteins such as XOR or BTN due to their dispersion in the salt/detergent phase. Once the membrane is disrupted, the proteins can be collected by ultra-centrifugation, protein precipitation at low $\mathrm{pH}$, or induction of aggregation with ammonium sulfate followed by centrifugation (Singh, 2006; Keenan and Mather, 2006). The pathways used to isolate MFGM in a laboratory setting or in a pilot plant are detailed and compared in Figure 8.

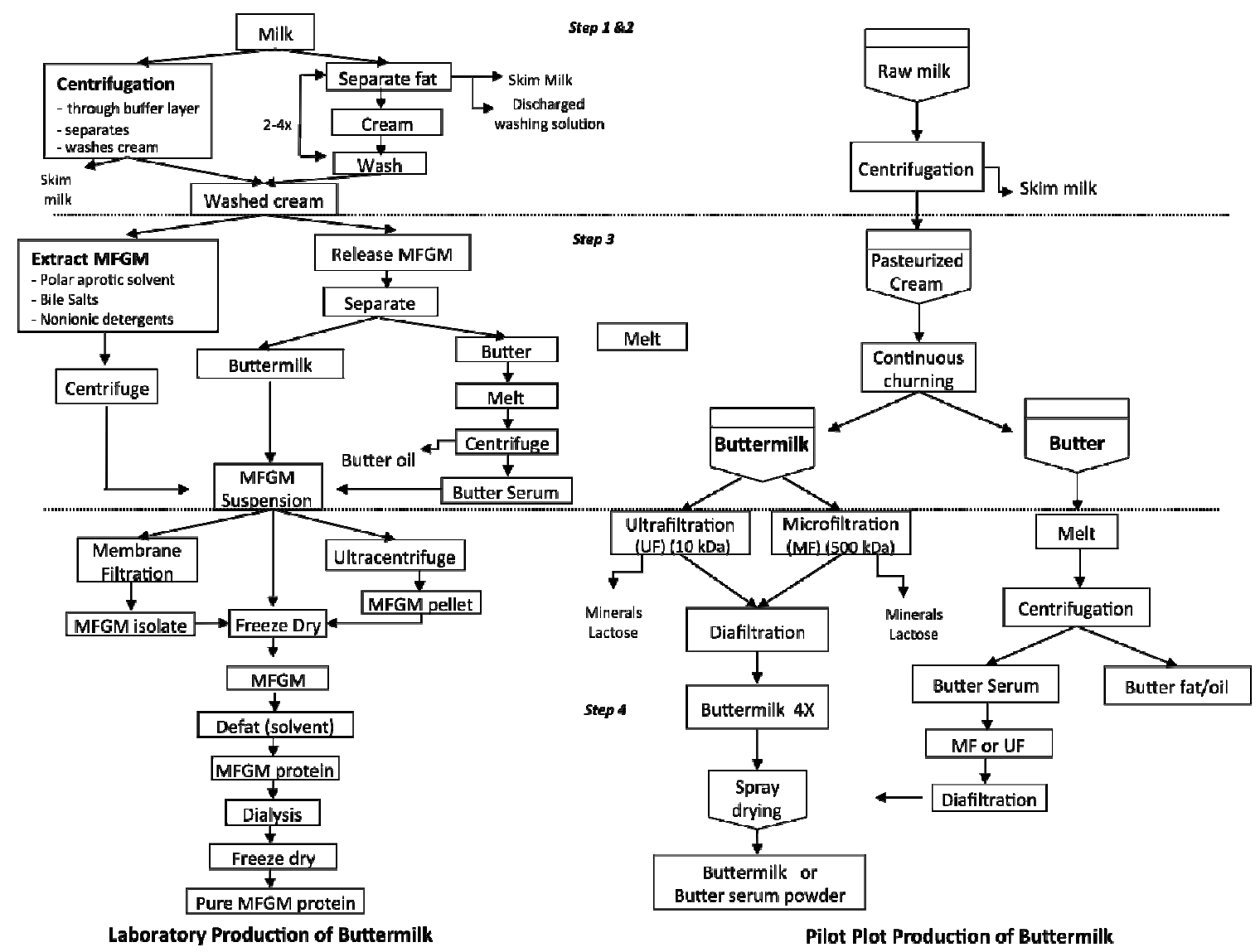

Figure 8. Milk fat globule isolation in a laboratory and pilot plant setting. MFGM proteins can be purified using a four-step procedure: Step 1. cream (fat globule) isolation; Step 2. washing of globules; step 3. Disruption of globules, and step 4. Membrane collection (Dewettinck et al., 2008). 


\section{Commercial Production of MFGM}

On a commercial-scale MFGM isolation is more suitable from buttermilk, whey serum, or acid serum. Acid and whey serums have 0.5 to $1.03 \%$ (in dry-matter) residual fat that interferes with whey protein concentrate production (Glass and Hedrick, 1977); therefore, side purification techniques have been developed to obtain MFGM material and facilitate concentration of whey proteins (Rombaut and Dewettinck, 2007).

Currently, microfiltration and ultrafiltration are the most widely used techniques to purify or concentrate milk fat.

\section{a) Microfiltration}

Microfiltration features a pressure-driven membrane filtration, with pressure less than one bar and membrane pore size between $10^{-1}-10^{1} \mu \mathrm{m}$, which is commonly used for the removal of bacteria and separation of macro molecules (Corredig et al., 2003; Morin et al., 2006). In the dairy industry, this is employed to remove lipids from whey for production of whey protein concentrate (WPC). With regard to MFGM purification, casein makes microfiltration difficult even after the use of casein micelle dissociating agents such as citrate. Corredig and Dalgleish (2003) used sodium citrate to dissociate casein micelles resulting in a MFGM concentrate of approximately $60 \%(\mathrm{w} / \mathrm{w})$ protein and $35 \%(w / w)$ lipid. However, citrate dissociation requires the use of diafiltration to wash out minor constituents, and results in high permeate losses (Rombaut et al., 2006b). Morin et al., (2004) demonstrated that microfiltration alone cannot achieve optimal separation of lipids and protein for the production of novel ingredients. The pore size of the membrane and temperature also influenced the final product as well as the starting material (Morin et al., 2004). 
Despite permeate loss, citrate treatment and microfiltration resulted in a MFGM isolate that showed better creaming stability than whole buttermilk concentrate. Such effects were attributed to the compositional difference between these two ingredients (Roesch et al., 2004). Morin et al. (2006) fractionated buttermilk and whey buttermilk using microfiltration, resulting in two-fold and 50\% increases in phospholipid concentration, respectively. Another study by the same group used washed cream to remove some of the caseins and whey proteins that disturb milk fractionation. A two-fold increase in the permeation flux was observed as well as a $66 \%$ increase in the phospholipid content compared to regular cream buttermilk (Morin et al., 2007a). Rombaut et al. (2006b) suggested coagulation of casein by acid or rennet addition, followed by MFGM purification using ultrafiltration or microfiltration techniques. Michalski et al. (2006) patented a microfiltration method to isolate fat globules with different diameters. This technique results in large globules $(6 \mu \mathrm{m})$ that can be churned easily for butter making (Fauquant et al., 2007). Finding effective ways to utilize the byproducts of microfiltration, such as the citrate-containing permeate and the precipitated caseins, should be an active area of research to find relevant applications in foods (Singh, 2006).

\section{b) Ultrafiltration}

Ultrafiltration is utilized to concentrate large and macromolecules such as the proteins in milk and whey. It uses pressure of 1-10 bar and membrane pore sizes between $10^{-2}-10^{-1}$ $\mu \mathrm{m}$. Despite its functionality, this technique has not been fully used to purify MFGM components. Early attempts in the utilization of ultrafiltration resulted in the production of buttermilk concentrate with a high protein content (12.87\%) and excellent rheological as well as emulsifying properties (Real del Sol and Corrales, 1991). Our group is 
currently exploring ultrafiltration to obtain whey buttermilk powder in conjunction with supercritical fluid extraction (SFE). The use of SFE as a solvent to extract non-polar lipids has revolutionized the solvent-extraction methods because it does not leave solvent residues in the final product. This technique concentrates the phospholipids but does not separate out proteins from them (Singh, 2006). Spence et al. (2009) utilized

microfiltration and SFE to remove triglycerides and concentrate the phospholipid content in buttermilk powder, generating powders with a $70 \%$ decrease in total lipids (Spence $e t$ al., 2009). Rezende-Costa et al. (2010) produced a whey buttermilk powder enriched in phospholipids utilizing ultrafiltration/diafiltration and SFE. The total lipid content was reduced by $57 \%$, and the protein was increased up to $53 \%$ (Rezende-Costa et al., 2010). Such techniques can concentrate the phospholipids and MFGM protein content from cheese or butter-by-products, and the resulting fractions can later be incorporated into food matrixes or pharmaceuticals.

\section{c) Purification through Aggregation}

MFGM fragments can also be purified through precipitation from cheese whey. Attebery (1968) patented the use calcium in conjunction with $\mathrm{pH}$ adjustment and moderate heat treatment to clarify whey (Attebery, 1968); such method was later applied to all types of whey (Fauquant et al., 1985; Maubois et al., 1987). Rombaut et al. (2007) optimized these settings to purify MFGM fragments from acid buttermilk cheese whey. Their findings indicate that MFGM recovery is highly dependent on $\mathrm{pH}$ and less dependent on temperature and calcium addition. An optimal treatment at $55^{\circ} \mathrm{C}, \mathrm{pH} 7.7$, and $0.205 \mathrm{~g}$ of calcium/L of whey resulted in a $91 \%$ recovery of whey polar lipids and minimum whey protein association in the aggregates (Rombaut and Dewettinck, 2007). 
With similar techniques, MFGM material can be isolated from whey protein concentrate production and be used in food products.

\section{H. Physical and Chemical Effects of Processing on Fat Globules and MFGM}

Drinking milk undergoes a series of processing steps that physically and chemically affect the composition and characteristics of the MFGM. Other milk-derived products such as buttermilk and butterserum also endure similar conditions that result in MFGM damage; therefore, a lot of research has been done to characterize such changes (Table 4), but without a general definition of the MFGM, measuring these alterations in a constant manner may be difficult. In his review, Evers (2004) was the first one to clearly define the MFGM in order to provide methodologies to measure the damage to fat globules and the membrane (Evers, 2004b). What follows is a summary of the main milk handling practices that affect this membrane and their effects.

\section{Temperature Effect}

\section{a) Cool Temperatures}

Temperature treatments are aimed at preventing spoilage, preserving foods, and increasing the quality of products by either inhibiting microbial growth, killing microorganisms, or inactivating enzymes (Walstra et al., 2006; Huppertz and Kelly, 2006). The intensity of the treatment depends on the combination of temperature and duration to establish specific product or ingredient properties. In the dairy industry, milk goes through cycles of cooling and heating depending on the final product, and these conditions have an effect on the fat globules, especially the proteins and lipids of the MFGM. 
At low temperatures, milk globules undergo mainly physical changes. A cream layer tends to form, which is minimized by regular stirring and by aeration. The latter, in conjunction with temperature fluctuations, contributes to cycles of fat crystallization and melting, which leads to fat globule disruption and clumping. During cold storage, milk fat globules tend to rise in large clusters at a higher rate than individual globules due to the presence of immunoglobulin IgM (Huppertz and Kelly, 2006). Such phenomenon is known as cold agglutination and requires a heat-labile component, IgM, which functions as a cold-agglutinin, and a homogenization-labile skim milk membrane (SMM), which consists of lipoprotein particles present in the aqueous phase of milk. Fat globules agglutinate by interacting with $\operatorname{IgM}$ alone, but extensive clustering is seen in the presence of SMM, which acts a cross-linking agent and interacts with IgM only (Huppertz and Kelly, 2006).

In regards to globule size, batch pasteurization or indirect ultra-high temperature (UHT) heating of milk at $90-150{ }^{\circ} \mathrm{C}$ does not influence the volume surface-weighted mean diameter $d_{v s}$. In contrast, direct UHT decreases $d_{v s}$ as the temperature increases (Huppertz and Kelly, 2006). Coalescence of fat globules is prevented by the presence of the polar head of phospholipids in the MFGM. Removal of such entities results in oilingoff (Huppertz and Kelly, 2006). Indirect UHT treatment can cause aggregation of fat globules.

Furthermore, when fresh milk is cooled, the association of proteins to the MFGM changes (Hohe et al., 1985; Steffensen et al., 2004). The casein proteins, especially $\beta$ casein, dissolve from the casein micelles and go into the serum phase and may be incorporated onto the fat globules (Walstra, 1969). Cooling milk also induces the release of MFGM phospholipids into the serum phase (Baumrucker and Keenan, 1973) as well as 
the liberation of xanthine oxidase from the MFGM and the migration of copper from the fat globules to the milk plasma (Huppertz and Kelly, 2006). Cool temperatures induces the binding to lipoprotein lipase (LPL) and increases the activity of this one, especially after three to five hours after milking when heparin in present (Sundheim and BengtssonOlivecrona, 1985). No further association of LPL with the MFGM is observed beyond this point (Dickow et al., 2011). The activity of xanthine oxidase also increases in cooled milk (Steffensen et al., 2004).

\section{b) Thermal Temperatures}

Milk pasteurization lowers the rate of deterioration caused by microbial and enzymatic action. During heating, the loss of oxygen decreases the rate of oxidation reactions, and the amount of inorganic phosphate increases by hydrolysis of phospholipid esters, especially those of casein micelles, and phospholipids (Walstra et al., 2006; Huppertz and Kelly, 2006). Acylglycerols are also hydrolyzed and interesterified, and lactones and methyl ketones are formed from fat (Walstra et al., 2006).

With respect to proteins, free sulfhydryl groups are formed as shown in Table 7, reactions 2 and 4. Lactose and proteins also undergo Maillard reactions, as denoted by reaction 8 , and provide a brownish color to milk. Most of the serum proteins are denatured and rendered insoluble, especially $\beta$-lactoglobulin, which becomes covalently bound to kappa casein and to some proteins of the fat globule membrane (Walstra and Jenness, 1984). 
Table 7. Biochemical reactions of side chain groups of amino acid residues linked in the peptide chain (I) of proteins at high temperature (Adapted from Walstra et al. 2006).

\begin{tabular}{|c|c|c|c|}
\hline $\mathbf{R x n}$ & Reactant & Direction & Product \\
\hline & $1-\mathrm{CH}_{2} \mathrm{CONH}_{2}+\mathrm{H}_{2} \mathrm{O}$ & & $\mathrm{I}^{-} \mathrm{CH}_{2}-\mathrm{COO}-+\mathrm{NH}_{4}^{+}$ \\
\hline 1 & Asparagine $^{+}$ & $\rightarrow$ & Aspartic acid \\
\hline & ${ }^{-} \mathrm{CH}_{2}^{-} \mathrm{SH}+\mathrm{OH}_{-}^{-}$ & & ${ }^{-} \mathrm{CH}_{2}-\mathrm{S}-{ }^{-}+\mathrm{H}_{2} \mathrm{O}$ \\
\hline 2 & Cysteine & $\leftarrow$ & Charged sulhydryl group \\
\hline & ${ }^{-} \mathrm{CH}_{2}^{-} \mathrm{S}-{ }^{-}+-\mathrm{S}^{-} \mathrm{CH}_{2}^{-}-\mathrm{I}$ & $\begin{array}{l}\text { Oxidation-> } \\
<- \text { Reduction }\end{array}$ & ${ }^{-}-\mathrm{CH}_{2}-\mathrm{S}-\mathrm{S}-\mathrm{CH}_{2}^{-1}+2 \mathrm{e}$ \\
\hline 3 & $\begin{array}{l}\text { Cysteine } \\
\text { A } I^{-} \mathrm{CH}_{2}^{-} \mathrm{S}^{-} \mathrm{S}^{-}\left(\mathrm{CH}_{2}\right)^{-1}\end{array}$ & $<-$-Reduction & $\begin{array}{l}\text { Cystine } \\
\text { A } 1-\mathrm{CH}_{2}^{-} \mathrm{S}-\end{array}$ \\
\hline 4 & $\begin{array}{l}\mathrm{B} \mathrm{C}^{-} \mathrm{CH}_{2}^{-} \mathrm{S}- \\
\text { Sulfhydryl exchange }\end{array}$ & $\leftarrow$ & $\mathrm{B} \mid-\mathrm{CH}_{2}^{-} \mathrm{S}^{-} \mathrm{S}^{-} \mathrm{CH}_{2}^{-1}$ \\
\hline & ${ }^{-} \mathrm{CH}_{2}^{-} \mathrm{S}-{ }^{-}$ & & $\mathrm{l}=\mathrm{CH}_{2}+\mathrm{HS}-$ \\
\hline 5 & Cysteine & $\rightarrow$ & Dehydroalanine \\
\hline 6 & $\begin{array}{l}\mathrm{I}=\mathrm{CH}_{2}+\mathrm{HS}^{-} \mathrm{CH}_{2}^{-1} \\
\text { Dehydroalanine } \quad \text { Cysteine } \\
\mathrm{I}^{-}\left(\mathrm{CH}_{2}\right)_{4}^{-} \mathrm{NH}_{3}^{+}+\mathrm{H}_{2} \mathrm{C}=\mathrm{I}+\mathrm{OH}-\end{array}$ & $\rightarrow$ & $\begin{array}{l}\mathrm{I}^{-} \mathrm{CH}_{2}^{-} \mathrm{S}^{-} \mathrm{CH}_{2}^{-} \mathrm{I} \\
\text { Lanthionine } \\
{ }^{-}\left(\mathrm{CH}_{2}\right)^{-} \mathrm{NH}^{-} \mathrm{CH}_{2}^{-}-1+\mathrm{H}_{2} \mathrm{O}\end{array}$ \\
\hline 7 & Lysoalanine $^{++}$ & $\rightarrow$ & Lysoalanine \\
\hline 8 & $\begin{array}{l}\mathrm{I}^{-} \mathrm{CH}_{2}^{-} \mathrm{COOH}+\mathrm{H}_{2} \mathrm{~N}^{-}\left(\mathrm{CH}_{2}\right)_{4}{ }^{-}-\mathrm{I} \\
\text { Aspartic Acid Lysine }\end{array}$ & $\rightarrow$ & $\begin{array}{l}\mathrm{I}^{-} \mathrm{CH}_{2}^{-} \mathrm{CO}^{-} \mathrm{NH}^{-}\left(\mathrm{CH}_{2}\right)_{4}^{-}-\mathrm{I}+\mathrm{H}_{2} \mathrm{O} \\
\text { Isopeptide }\end{array}$ \\
\hline 8 & $\underset{\text { Lysine }}{\mathrm{I}\left(\mathrm{CH}_{2}\right)_{4}^{-} \mathrm{NH}_{2}^{-}}+\underset{\text { Glucose }}{\mathrm{C}_{6} \mathrm{H}_{12} \mathrm{O}_{6}}$ & $\rightarrow$ & $\begin{array}{l}\mathrm{I}-\left(\mathrm{CH}_{2}\right)_{4}-\mathrm{NH}-\mathrm{C}_{6} \mathrm{H}_{11} \mathrm{O}_{5}+\mathrm{H}_{2} \mathrm{O} \\
\text { Amadori product }\end{array}$ \\
\hline
\end{tabular}

The composition of the MFGM is further altered by thermal treatment and homogenization due to protein denaturation and interactions with serum proteins (Lee and Sherbon, 2002). Upon heat treatment, a layer of whey protein, especially $\beta$ lactoglobulin and $\alpha$-lactalbumin, deposits on the MFGM, possibly through intermolecular disulfide bonding (Kim and Jiménez-Flores, 1995; Michalski and Januel, 2006a; Singh, 2006). Bermudez-Aguirre et al. studied the surface of fat globules microscopically in raw and thermosonificated milk. According to their findings, heat and ultrasonic waves are responsible for disintegrating MFGM and the release of triacylglycerols. Fat globules with a rougher surface (Figure 9) are observed in heat-treated samples due to MFGM disintegration and interaction with casein micelles. Also, smaller fat globules are seen after thermosonification (Bermúdez-Aguirre et al., 2008). 


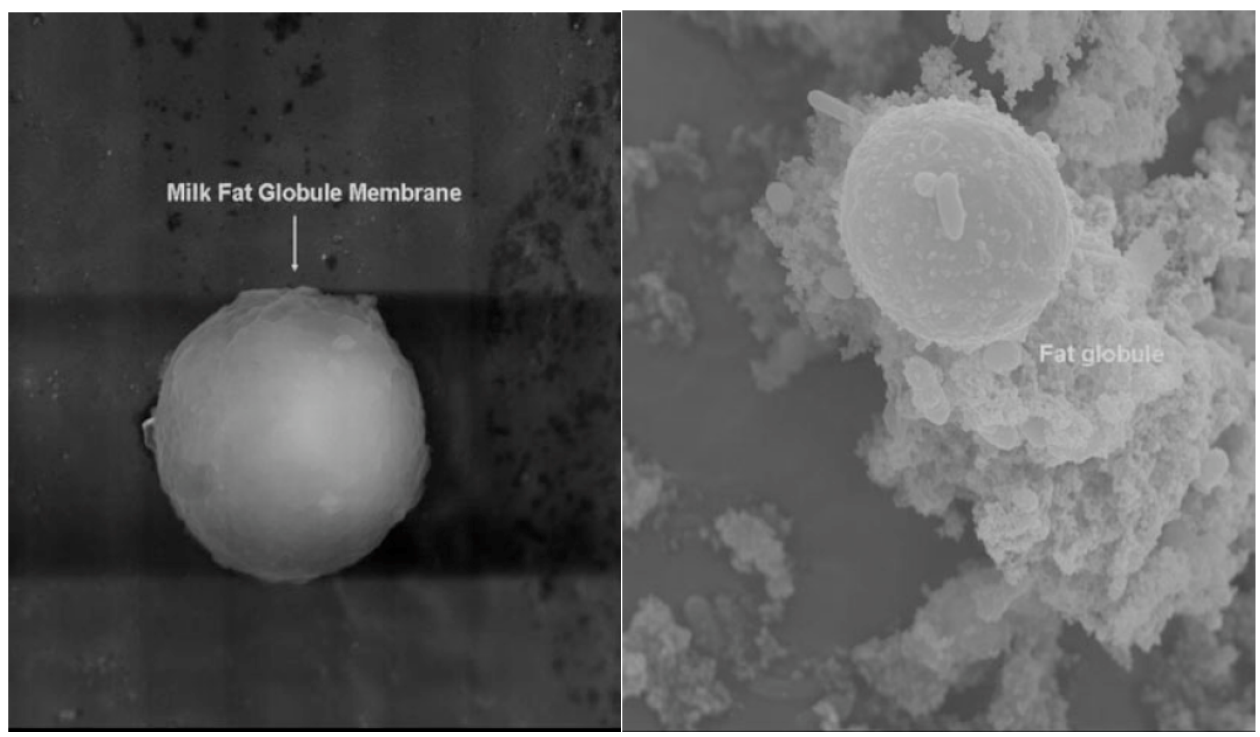

Figure 9. Fat globule in raw milk (left, 7000x) with no change on surface and thermally treated globule (right; $63{ }^{\circ} \mathrm{C}, 30 \mathrm{~min}, 6000 \mathrm{x}$ ) exhibiting deposits of casein proteins. Images captured with scanning electron microscopy (Adapted from BermudezAguirre, D. et al. 2008)

If milk is heated after homogenization, then $\beta$ - and $\alpha$-lactoglobulins absorb to the casein micelles already incorporated onto the membrane (Ye et al., 2004b), making the outside membrane more resistant to coalescence (Bermúdez-Aguirre et al., 2008). The exact mechanism of protein interaction has not been elucidated; however, it has been speculated that it could be via sulfydryl-disulfide interchange (reaction 4 in Table 7) or by displacement of the original MFGM material (Michalski and Januel, 2006a; Singh, 2006). The MFGM's association with $\beta$-lactoglobulin starts at $60-65^{\circ} \mathrm{C}$ and increases with heating time until a plateau level of about $1.0 \mathrm{mg} / \mathrm{g}$ of fat is reached (Corredig and Dalgleish, 1996; Ye et al., 2004b; Ye et al., 2004c); this accounts for $1 \%$ of the $\beta$ lactoglobulin found in milk. There is no evidence on the specific MFGM proteins that associate with $\beta$-lactoglobulin (Singh, 2006).

Association of $\alpha$-lactalbumin displays a similar mechanism but less protein is absorbed onto the membrane. Also, small amounts of $\kappa$-casein seem to interact with the 
MFGM when milk is heated above $80{ }^{\circ} \mathrm{C}$; such interaction may be bridged by the already absorbed $\beta$-lactoglobulin. According to Kim et al. (1995), higher temperature treatments $\left(140{ }^{\circ} \mathrm{C}\right.$ for $\left.16 \mathrm{~s}\right)$ cause less casein adsorption, but studies in direct and indirect UHT determined adsorption of caseins and whey proteins, especially $\kappa$-casein and $\beta$ lactoglobulin in the MFGM (Hillbrick et al., 1999). On the other hand, Dalgleish and Bank believed that presence of casein on the surface of fat globules may originate from partial homogenization, and their data did not support the association of $\kappa$-casein onto the MFGM (Dalgleish and Banks, 1991). Later studies by Ye et al. indicated that $\kappa$-casein facilitates the adsorption of casein micelles to fat globules through disulfide bonding between $\kappa$-casein and MFGM components in heated milk (65-95 $\left.{ }^{\circ} \mathrm{C}, 10 \mathrm{~min}\right)$ (Ye et al., 2004c). Other proteins affected during heating are PAS 6 and 7, which migrate into the serum phase and begin to aggregate at temperature above $80^{\circ} \mathrm{C}$ (Houlihan et al., 1992; Kim and Jiménez-Flores, 1995; Lee and Sherbon, 2002; Ye et al., 2004c); however, in the absence of whey protein, PAS 7 is stable (Ye et al., 2002). Ye et al. (2002) hypothesized that PAS 7 forms a complex with $\beta$-lactoglobulin to later migrate to serum phase.

Heating also decreases the triacylglycerol content of the MFGM and promotes migration of copper from plasma to fat globules. With regard to polar lipids, there is inconclusive evidence for a correlation between the concentration of PLs and heat treatment (Huppertz and Kelly, 2006). Morin et al. (2006) found that production of buttermilk from pasteurized cream results in buttermilk with higher lipid content. In addition, the total MFGM protein that can be isolated from cream depends on the heat treatment (Morin et al., 2007a; Ye et al., 2002). In fact, cream processed at $50{ }^{\circ} \mathrm{C}$ for 10 
min results in approximately 50\% MFGM protein loss and formation of aggregates via intermolecular disulfide bonds in the absence of serum proteins (Ye et al., 2002). Gassi et al. (2008) also observed formation of fat globules aggregates in cream that underwent high heat treatment $\left(70{ }^{\circ} \mathrm{C}, 2 \mathrm{hr}\right.$ followed by $30 \mathrm{~s}$ at $88^{\circ} \mathrm{C}$, and $94{ }^{\circ} \mathrm{C}$ for $\left.80 \mathrm{~s}\right)$. Modifications in the MFGM proteins involve alterations in interfacial properties resulting in fat globule aggregation. Figure 10 represents a schematic representation of these changes in the MFGM and consequently in the fat globules upon heat treatment.
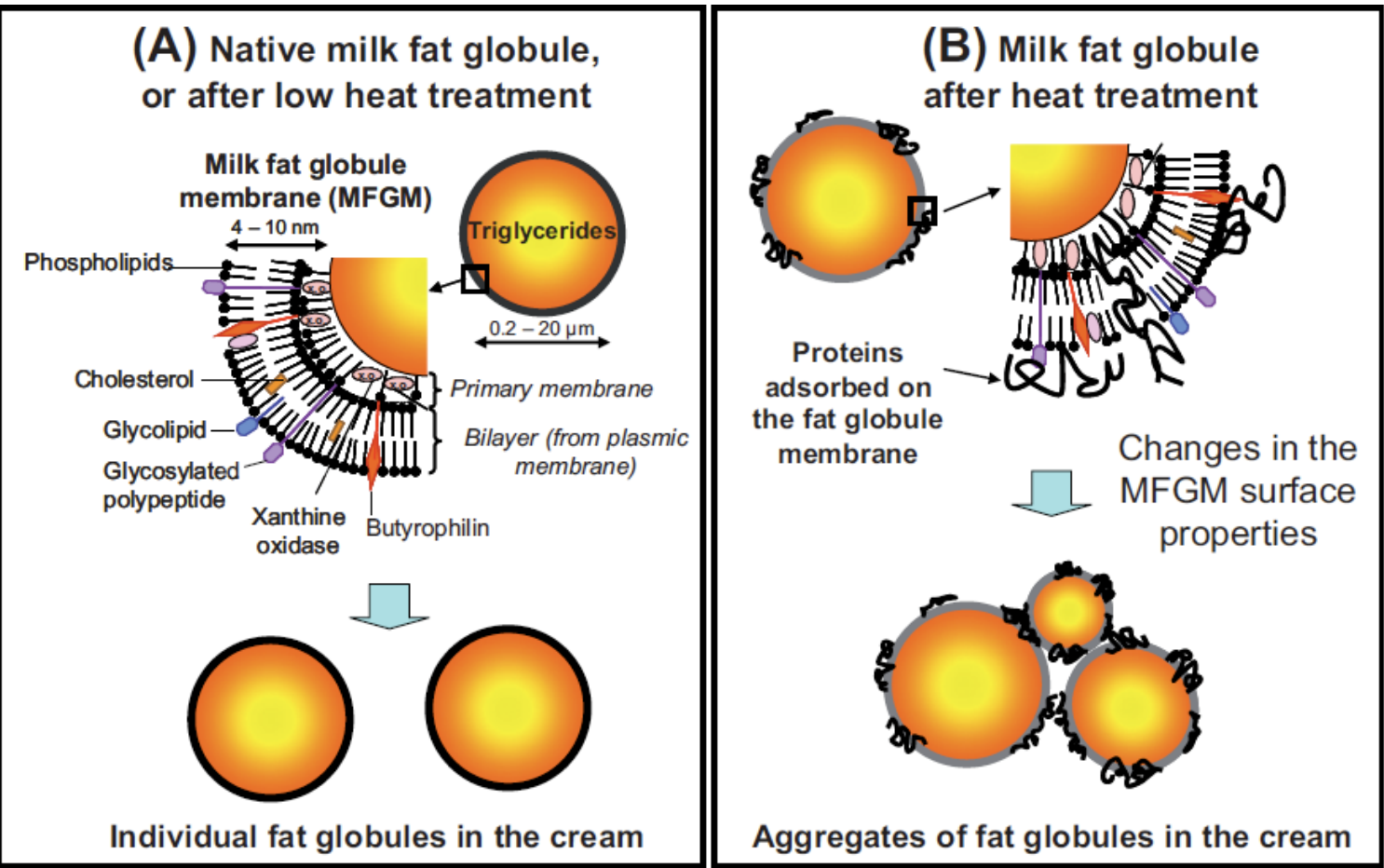

Figure 10. Changes in the MFGM and fat globules as a function of thermal treatment in creams. A) Schematic representation of native fat globules or at low heat, and B) after high heat treatment, which adsops aqueous phase proteins, especially whey proteins (Taken from Gassi et al., 2008).

\section{Homogenization}

In the dairy industry, homogenization is performed to counteract creaming and provide stability toward partial coalescence during the product's shelf life. Coalescence is prevented by reducing the diameter of the fat globules due to the application of high 
pressures (8-20 MPa) through a valve needle (Michalski et al., 2002; Walstra and Jenness, 1984). Droplets of fat globules are deformed and possibly disrupted by shear stress, inertial forces, and cavitation, which cause particles to coalesce and have a bigger surface areas where adsorption of proteins occurs. Temperatures between 42 to $72{ }^{\circ} \mathrm{C}$ are applied during homogenization to increase efficiency; nevertheless, most processes are performed at $60^{\circ} \mathrm{C}$ (Michalski et al., 2002). The type of homogenizer, the homogenizing pressure, and temperature are some of the main factors that affect globule size (Michalski et al., 2002; Walstra et al., 2006).

The main effect of homogenization is the disruption of casein micelles, displacement of MFGM components to the skim milk, and casein adsorption onto the newly formed interface of the fat globules as denoted on Figure 11 (Michalski and Januel, 2006a). The amount of adsorbed proteins increases with homogenization pressure; however, the protein composition of the MFGM is not affected by homogenization alone but also significantly by the heat treatment applied before homogenization (Cano-Ruiz and Richter, 1997). Furthermore, the phospholipid content appears to decrease in the new membrane (McPherson and Kitchen, 1983). Keenan et al. (1983) reported a loss in total lipids, polar lipids, and cholesterols decreased in homogenized milk samples compared to unprocessed samples, but the phospholipid distribution remained the same (Keenan et al., 1983). Homogenization also seems to improve the digestibility of milk; however, premature babies have better digestion of human milk fat globules than the homogenized lipid droplets of infant formula (Favé et al., 2004).

Homogenized milk appears to be responsible for allergic reactions. Michalski et al. (2006) explains that allergenic milk proteins absorb onto the new increased surface area, or perhaps homogenization exposes proteins that may trigger putative allergenic effects. 
Xanthine oxidase (XO) is one of these proteins, and it has also been associated with atherosclerosis. Controversial findings indicate that $\mathrm{XO}$ liberated during homogenization favors the development of coronary diseases, but Spitsberg (2005) and Michalski (2006) argue that populations with high intake of buttermilk or cheese rich in MFGM are not associated with coronary mortality. Other authors claim that MFGM proteins provoke autoimmune and neurological diseases such as diabetes I and multiple sclerosis (Michalski and Januel, 2006a). Despite the controversy, there is a plethora of research highlighting the health effects of MFGM proteins.

\section{$\rightarrow$ Organization of an homogenized lipid droplet}
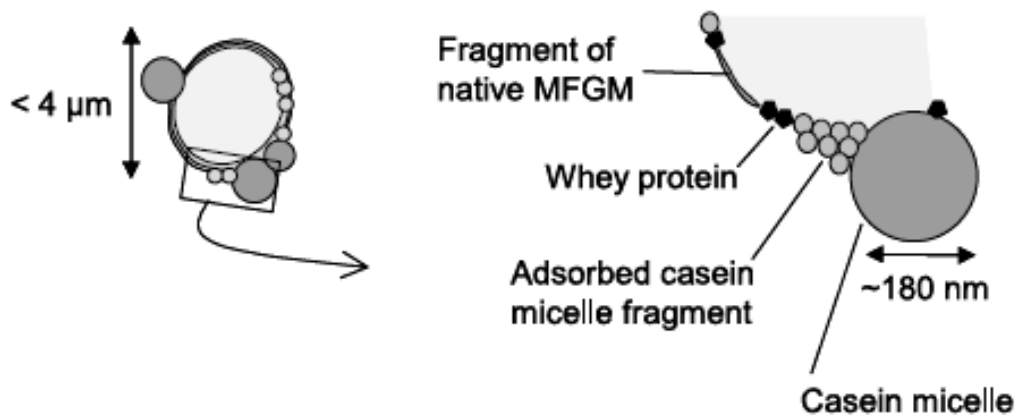

$\rightarrow$ General organization of homogenized milk

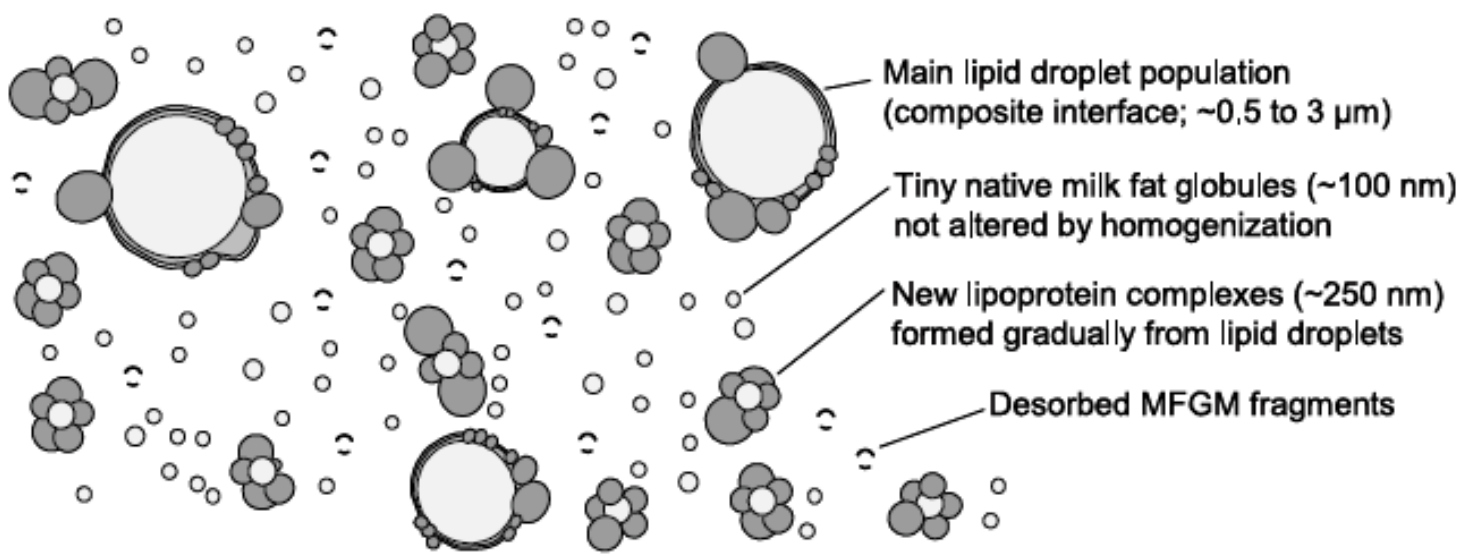

Not to scale \& exaggerated curvatures

Figure 11. Effects of homogenization on milk fat globules. Native fat globules lack adsorption of casein micelles and whey protein. Upon homogenization, serum proteins and casein attached to the interphase of fat droplets (top) and MFGM fragments are desorbed (bottom) (Adapted from Michalski and Januel, 2006). 


\section{Influence of Spray-drying}

Products are usually dried to increase their storage stability, reduce packaging requirements, and reduce shipping weights (Landstrom et al., 2000). In the dairy industry, spray drying is the most common method used to concentrate milk solids, due to milk's seasonal variations, and to produce milk-derived powders, especially whole milk powder (WMP) and skim milk powder (SMP) as fresh milk substitutes (Schuck, 2002; Ye et al., 2007; Singh and Ye, 2010). Milk must undergo heat treatments, homogenization, evaporation, and spray drying to produce powders. First, the liquid product is atomized at the top of the drying chamber and mixed with dry heated air (180$220^{\circ} \mathrm{C}$ ), which evaporates the moisture in the droplets. Atomization provides a large surface area but damages fat globules by shear, causing changes in the fat globule surface protein layer. Since thermal evaporation damages the MFGM, milk to be evaporated is usually homogenized to deposit casein on the fat globules and make the membrane stronger for spray-drying (Morin et al., 2007b).

Rennie et al. (1999) correlated small particle size with stickiness and powder deposition in dairy powders. WMP had twice the powder cohesion than SMP as temperature increased from 30 to $65^{\circ} \mathrm{C}$ due to the presence of fat. Ye et al. (2007) investigated the behavior of milk fat globules during spray drying of whole milk, and concluded that upon spray-drying, the average fat globule size $\left(\mathrm{d}_{32}\right)$ of powders was smaller than the initial products and formation of large globules $(4-80 \mu \mathrm{m})$ occurred. In regard to phospholipids, spray-drying decreases the PL content in buttermilk powders, probably due to complex formations between PL and MFGM proteins from the heat treatment, rapid evaporation, and increased ionic strength created by spray drying (Morin et al., 2007b). In conclusion, milk powder undergoes a lot of processing that causes 
physical and chemical interactions among milk components, and such interactions determine the functional properties for powder reconstitution in water and consumers' acceptability (Schuck, 2002; Ye et al., 2007; Singh and Ye, 2010).

\section{Cold Pasteurization-UV Pulsed Light Treatment}

As an effort to reduce the risk of foodborne illnesses associated with pathogens, especially E. coli O157:H7, Salmonella, and Campylobacter, the U.S. Department of Agriculture (USDA) approved the use of irradiation in food products in 1963. Currently, in the United States irradiation is applied to meat and poultry and includes the use of gamma rays, electron beams, and x-rays in government-approved irradiation facilities (USDA). More than 40 food products are irradiated in 37 countries including wheat and wheat powder, spices, fresh shell eggs, fresh produce, and recently apple juice in countries such as Canada (Health Canada).

For half a century, irradiation has been used to treat food products because no significant changes have been observed. In fact, the American Medical Association and the United Nations' World Health Organization endorsed the use of this technique due to its efficient antimicrobial effects (USDA). Data collected on apple juice concluded that the only degradation products that would occur from UV treatment of juice/cider are byproducts that occur naturally from sunlight (Health Canada). With such findings, irradiation must find its way into the dairy industry to substitute for heat pasteurization of milk, of which in 2010, 193 billion pounds were produced in the United States totaling $\$ 31.4$ billion in cash receipts from marketing (Milk Production, Disposition, and Income 2010 Summary, USDA). It is expected that UV light treatment will minimize the number of spores in USA milk powder and increase its commercialization in other countries that currently reject products that do not meet their standards. 


\section{Bactericidal Effects of UV-light Treatment}

UV-light has a broad range of antimicrobial effects including vegetative cells, especially with spore-formers and pathogenic bacteria, fungi, and yeast (Krishnamurthy et al., 2004; Elmnasser et al., 2007; Smith et al., 2002; Anderson et al., 2000). In addition, microorganisms do not develop resistance to UV treatments (Elmnasser et al., 2007). Chang et al. (1985) investigated the effect of continuous UV-light sterilization on E. coli, S. typhi, S. sonnei, S. faecalis, and S. aureus and concluded that these microorganisms have different resistances to UV-light. All of them were inactivated with $7 \mathrm{~mW}$-sec/ $\mathrm{cm}^{2}$ energy to get a $3-\log _{10}$ reduction with the exception of $S$. faecalis that required more energy (Chang et al., 1985).

Smith et al. (2002) used pulsed UV treatment to inactivate S. aureus and concluded that a minimum dose of $12.6 \mathrm{~J} / \mathrm{cm}^{2}$ is needed to achieve a $2-\log _{10}$ reduction. In addition, they observed a decrease in spore-forming bacteria colonies. Krishnamurthy et al. (2004) also conducted inactivation of $S$. aureus with a pulsed UV-chamber, finding similar results but emphasizing that the volume and the distance between the UV source and the sample as well as energy intensity and time are important in opaque products such as milk. Differences on the microbial lethality between gram-negative and gram-positive bacteria were also investigated and attributed to the composition in bacterial cell wall and their protective and repair mechanisms. Gram (-) microorganisms such as S. enteritidis and E. coli are more susceptible to pulsed-UV light than gram (+) B. cereus (Anderson $e t$ al., 2000). 


\section{Chemical Effects of UV-light Treatment}

Extensive work has been done on the bactericidal effects of UV-light, but there is still little information available on the effects of light treatment on the conformational changes in milk proteins or the production of by-products that could be carcinogenic or affect consumer acceptance. Elmnasser et al. (2008) concluded that pulsed-light treatment does not contribute to conformational changes in milk proteins besides the aggregation of $\beta$-lactoglobulin, which results in the formation of dimmers with molecular weight of $36 \mathrm{kDa}$ due to disulfide bonding. Light treatment may change the polarity of microenvironments, making some amino acids such as tryptophan more exposed to hydrophilic areas and changing protein folding and aggregation as seen in fluorescence spectrophotometry of intrinsic tryptophan. Such alteration can be measured by fluorescence by exciting a sample at $290 \mathrm{~nm}$ and scanning between $305-450 \mathrm{~nm}$. In addition, a decrease in riboflavin concentration, a marker for oxidation that involves radical formation and consequent protein and lipid degradation, resulted in a decrease of the maximum emission wavelength; nevertheless, the authors concluded that there was an absence of oxidation reactions of proteins by lipids (Elmnasser et al., 2008).

On the other hand, goat milk treated with an UV fluid processor resulted in lipid oxidation, as denoted by an increase in thiobarbituric acid (TBA) and acid degrees values (ADV); however, these changes were not enough to detect organoleptic differences in treated samples. Volatiles such as pentanal, hexanal, and heptanal were detectable in treated samples after $1.3 \mathrm{~mJ} / \mathrm{cm}^{2}$ energy (Matak et al., 2007). Furthermore, temperature increments have been observed during prolonged UV treatment, and without the proper cooling system, the quality and nutritional profile of foods may be compromised (Elmnasser et al., 2007). 


\section{J. Methodology to Monitor the Biological Activity of the MFGM}

With the advances in the scientific and technological fields, there are new tools to monitor the biological activity of MFGM in foods, which can increase our knowledge of the membrane structure, especially before processing. Such findings will allow us to select methods to preserve the native structure of the MFGM and set standards for generating a product similar to what the neonate receives. Among the latest technologies, atomic force microscopy, confocal microscopy, and laser tweezers have captivated the attention of scientists due to their ease of use, non-invasive methodology, and plethora of results.

Atomic force microscopy (AFM) has similar resolution to that of electron microscopy (Evers, 2004b). It allows the visualization of monolayer domain formation, binding events, as well as membrane-membrane interactions, among other features (JiménezFlores and Brisson, 2008). It has been used to characterize the structure and properties of the MFGM. In fact, Gallier et al. (2010) monitored the physical behavior of phospholipid monolayers from various dairy products using atomic force microscopy and found that milk processing alters the phospholipid and fatty acid composition in the MFGM and consequently the physical behavior of PL monolayers.

Confocal laser scanning microscopy, lipophilic probes, and fluorescent lectin wheat germ agglutinin (WGA) were first utilized to investigate the organization of the MFGM in milks from animal species (Evers et al., 2008). With the same confocal technique, Lopez et al. (2010b) revealed the heterogeneous organization of the MFGM, especially the lateral structure of polar lipids, glycolipids, and glycoproteins. The MFGM surface, especially the phospholipid monolayer, has been characterized by microscopic techniques at our facility (Gallier et al., 2010a). 
The use of laser tweezers, also known as optical tweezers, has been applied in the MFGM field. This technique arises from the principle that small particles/objects can be imprisoned in the center of a strongly focused laser beam, experiencing a restoring force if they try to leave the high intensity volume. The optical tweezer system has been used for direct manipulation of a variety of micrometer-sized objects and for force measurement in the pico-Newton $(\mathrm{pN})$ region (Jiménez-Flores and Brisson, 2008). In fact, Argov et al. (2008) utilized laser tweezers Raman spectroscopy to characterize submicron-sized particles in human milk. They observed a significant difference in the triacylglycerol composition of human fat globules, depending on their diameter, especially in nanoparticles (less than $1 \mu \mathrm{m}$ ), implying that these components have other functions besides fat delivery. Such findings open the door to nanoscience, which can help us reveal the association between food structure and functionality. Furthermore, our research group has used laser tweezers to objectively measure binding force between lactic acid bacteria and the MFGM (Brisson et al., 2010).

\section{K. Principles of Analysis Methods Utilized}

\section{Cold Pasteurization}

Cold pasteurization is a nonthermal method that utilizes broadspectrum electromagnetic energy to inactivate microorganisms. Its efficiency depends on the intensity $\left(\mathrm{J} * \mathrm{~cm}^{-2}\right)$ and the number of pulses delivered, which inhibits bacterial replication by damaging DNA as pyrimidine dimmers are formed (Krishnamurthy et al., 2004; OmsOliu et al., 2008). Microbial cells can also be disintegrated by the UV photothermal effects, which might cause instantaneous overheating of the cellular constituents and rupture of the cell membrane (Oms-Oliu et al., 2008). 
UV-light sterilization can currently be accomplished using two models: a continuous UV-light or pulsed UV-light treatment. According to research, pulsed UV-light seems to be more efficient in deactivating microorganisms due to the intensity of the energy delivered in short-duration pulses. Continuous UV-light has poor penetration depth and low emission power as compared to pulsed UV-light. The emission power achieved by the continuous system ranges from 100 to $1,000 \mathrm{~W}$ whereas the pulsed system may have a peak of 35 MW (Oms-Oliu et al., 2008). The Food and Drug Administration (FDA) approved the use of the latter technology in 1996, and since then, different systems have come to the market. The SteriPulse-XL system generates UV/Visible light with a xenon flashlamp that delivers up to 505 Joules per pulse $\left(1.27 \mathrm{Joules} / \mathrm{cm}^{2}\right)$ at a rate of 3 pulses/s, providing short pulses (360 $\mu$ s width) that prevent excessive heat buildup.

\section{Milk Analysis}

\section{a) Analysis of Milk Lipids}

The analytical procedure to determine lipid compounds involves lipid extraction from a protein matrix, analytical separation, identification, and quantification (CarrascoPancorbo et al., 2009). In the dairy industry, fat extraction and quantification is mainly performed by the standard Mojonnier method (Association of Official Analytical Chemists, AOAC, 989.05). However, this procedure has its limitations due to the use of ammonium hydroxide to denature proteins in conjunction with heat to evaporate solvents, which can lead to oxidation and hydrolysis of phospholipids (Rombaut et al., 2006c). In addition, the Mojonnier method may not be efficient in extracting all the phospholipids (Morin et al., 2007b). Cold methods such as the Folch method are preferred to purify fat from tissue, utilizing chloroform/methanol to extract lipids in low-fat products and saline 
aqueous solution to wash out non-lipid components (Folch et al., 1957). Its efficiency in extracting lipids is higher, but its reproducibility is lower than the Mojonnier method (Avalli and Contarini, 2005). In addition, the solvents used in the Folch method are highly toxic, and to extract the equivalent of fat in the Mojonnier method, larger volumes of these solvents will be needed using Folch's protocol (Min and Ellefson, 2010).

Phospholipids are further concentrated for analysis through differences in their polarities via solid phase extraction (SPE), which fractionates analytes according to their affinity between a solid and a mobile phase (Descalzo et al., 2003). Bitman et al. (1984) utilized SPE columns to separate neutral lipids from polar lipids using hexane/ether and chloroform/methanol/water, respectively (Bitman et al., 1984). Vaghela and Kilara (1995) presented a protocol to purify phospholipids using methanol preceded by the use of chloroform/isopropanol and acetic acid in ether to eliminate more neutral lipids and free fatty acids, but aminopropyl SPE columns were utilized instead (Vaghela and Kilara, 1995). In 2005, Avalli and Contarini introduced a protocol similar to Bitman, but the ratio of hexane/ether differed to extract more neutral lipids from the final product (Avalli and Contarini, 2005). In a comparison study, the previous three methods were used to extract PLs from buttermilk. Bitman samples were enriched in phosphatidylcholine, sphingomyelin, and saturated lipids while Avalli and Vaghela samples eluted more phosphatidylethanolamine and phosphatidylinositol than Bitman's samples. Such difference in the phospholipid profile played a role in the type of lipid monolayer films observed under fluorescence microscopy (Nelson and Rios, 2007).

Phospholipid analyses have traditionally been performed in thin layer chromatography (TLC) or gas chromatography (GC) (Sprecher et al., 1965; Descalzo et al., 2003); however, the former is tedious and laborious (Fagan and Wijesundera, 2004), 
and the latter requires extensive derivatization. Thus, high performance liquid chromatography (HPLC) has become the method of choice for separation and quantitative determination of the different classes of phospholipids (Rombaut et al., 2005; Rombaut et al., 2006c; Vaghela and Kilara, 1995). This technique has been employed in direct mode or with on-line pre-concentration using a cation-anion exchange or silica guard column to separate the major PL (Fagan and Wijesundera, 2004; CarrascoPancorbo et al., 2009).

HPLC is most commonly coupled with UV or evaporative light scattering detector (ELSD) for PL detection (Rombaut et al., 2005). While UV is limited to compounds that possess a chromophore, ELSD is more efficient for detecting non-volatile compounds such as phospholipids because it is a universal mass detector. With the aid of a nebulizing gas, the solvent evaporates, and the analyte atomize, scattering a laser beam at the end of a heating tube to a sensitive photomultiplier (Carrasco-Pancorbo et al., 2009). A new detector, charged aerosol detector (CAD), offers the same sensitivity as ELSD without the trouble of instrument parameter optimization such as temperature adjustments (Bailey et al.; Moreau, 2006a). It has a high-voltage corona needle to charge molecules, so the response is independent of the analyte's structure (Bailey et al.; Crafts et al.). In addition, CAD has a nearly linear mass-to-peak area relationship for many types of lipids (Moreau, 2006a). A comprehensive review on analytical techniques for lipid is presented by Carrasco-Pancorbo et al. (2009).

\section{b) Fourier Transform Infrared (FTIR) Milk Analysis}

Conventional dairy analyses generate high waste volumes, have expensive labor costs, and require a lot of time to obtain results for laboratories or production environments. In order to increase the efficiency of these facilities, infrared milk 
analyzers (IRMA) emerged to reduce cost (Biggs, 1967; Van de Voort et al., 1987). Later developments introduced fourier transform infra-red (FTIR) as an analytical technique in industrialized countries due to its speed, accuracy, quick sample preparation, and relatively low cost (Rodriguez-Otero et al., 1997). This analytical method is based on infrared spectroscopy, which measures the absorption of different frequencies of infrared radiation by solids, liquids, and gases (Wehling, 2010; Barbano and Clark, 1989). When molecules absorb IR energy at a particular wavelength, chemical bonds vibrate at different frequencies, which can be used to identify characteristic functional groups in a sample (Wehling, 2010).

Mid-IR spectroscopy $\left(4000 \mathrm{~cm}^{-1}\right.$ to $\left.400 \mathrm{~cm}^{-2}\right)$ revolutionized the dairy industry with FTIR spectroscopy because it performs qualitative and quantitative analysis of ingredients and finished foods (Rodriguez-Otero et al., 1997; Barbano and Clark, 1989). It is currently an AOAC and an International Dairy Foundation (IDF) accepted method (Rodriguez-Otero et al., 1997). Currently, the Foss Milkoscan FT2 is widely used in the dairy industry for simultaneous milk composition analysis of lactose, protein, and fat (Rodriguez-Otero et al., 1997).

\section{3. $\quad$ Particle Size Analysis}

Laser diffraction techniques are utilized to determine the particle sizes distribution in wet or dry samples $(\mathrm{Xu}, 2001)$. They are non-destructive and non-intrusive techniques capable of measuring particles in the size range 0.02 to 2000 microns (Kippax). Modern laser diffraction instruments, such as the Coulter LS-230, target a laser beam through a sample, which scatters the incident light onto a Fourier lens (Kippax). The benefits of this technique are the wide dynamic measuring range, flexibility of samples, rapid data acquisition, and high repeatability. 


\section{Sodium Dodecyl Sulfate Polyacrylamide Electrophoresis (SDS-PAGE)}

A protein mixture can be separated and visualized by SDS-PAGE according to the protein's electrophoretic mobility. This technique was first used in the 1950's to separate proteins, and later the use of reducing agents and detergents such as $\beta$-mercaptoethanol and sodium dodecyl sulfate (SDS), respectively, were included to isolate protein subunits. Since then, SDS-PAGE has evolved to separate proteins with simple and quick staining protocols and high protein recovery. In 1975, O'Farrell introduced high-resolution twodimensional gel electrophoresis (2DE). This technique separates proteins first by isoelectric focusing and secondly by molecular weight in SDS-PAGE (O'Farrell, 1975). 2DE has the advantages of high-resolution separation, estimation of molecular weight, quantification of individual proteins, and visualization of the sample's proteome (O'Donnell et al., 2004; Hamdan and Righetti, 2005). Protein expression requires comparison of gels after staining and statistical analysis (Lindmark-Mansson et al., 2005). Some disadvantages include the modest detection limit, detection of only highly abundant proteins, and poor results in extreme $\mathrm{pH}$ as well as high and low molecular weights (Hamdan and Righetti, 2005).

The staining techniques have also been important in protein visualization. According to Candiano et al. (2004), staining procedures can be divided into four categories: organic dyes, silver stains, negative stains, and fluorescent stains. The latter group includes SYPRO Ruby, with a sensitivity of up to $0.5-1.0 \mathrm{ng}$ protein $/ \mathrm{mm}^{2}$ but requires UV excitation to visualize the proteins. Among the organic dyes, there exist Coomassie Blue R-250 and Coomassie Bue G-250, which bind one mg of protein per 1.2 and $1.4 \mathrm{mg}$ of dye, respectively (Candiano et al., 2004). The most sensitive protocol is silver staining that relies on the reduction of ionic to metallic silver onto the protein surface. However, 
irreproducibility and dependence on other parameters makes this stain rather erratic. The most common dye used is Coomassie blue, but it is limited at detecting glycosylated proteins, which require a periodic acid-Schiff $(P A S)$ reagent method to detect oxidizable carbohydrate groups. In proteomics, Coomassie Blue is preffered due to its high sensitivity, simple use, and fewer preparation steps, but protocols have been adapted to have a more sensitive colloidal stain for proteome analyses (Candiano et al., 2004; Westermeier, 2006).

\section{Liquid Chromatography and Proteomics}

In 1995, M. Wilkins introduced the term proteomics from the word "proteome," which indicates "the entire protein complement expressed by a genome, or by a cell or tissue type" (Takahashi and Isobe, 2007). This field of science developed from the need to identify, quantify, and characterize the structure, biochemical activity, and functionality of all the proteins in an organism or specimen and from the necessity to establish how these properties vary in time or physiological state (Gagnaire et al., 2009; Hamdan and Righetti, 2005). This technique became even more popular as protein sequence databases increased, along with arising revolutionary equipments in spectrometry (Gagnaire et al., 2009). Nowadays, proteomics is mostly performed to identify and quantify proteins or modifications such as glycosylation that change in time (Reinhardt and Lippolis, 2008; Beddek et al., 2008). In the dairy field, the first proteomic studies were performed to characterize milk and whey proteins (Lindmark-Mansson et al., 2005; Manso et al., 2005). Current research focuses on low-abundance and/or bioactive proteins such as those in the MFGM (Yamada et al., 2002; Smolenski et al., 2006; Gagnaire et al., 2009; Reinhardt and Lippolis, 2008). 
There are two approaches for protein identification, the top-down and bottom-up approach. In the first approach, complex protein mixtures are digested into peptides from which fragmentation data is obtained and match to a predicted spectra from peptide amino acid sequence (Takahashi and Isobe, 2007). The top down approach is more challenging because the intact mass of a protein is measured, followed by protein fragmentation, and identification from the fragmentation pattern.

Proteins are usually separated in 1D or 2D electrophoresis gels, cation/anion exchange, or isolectric focusing to decrease the complexity of the dynamic range of proteins (Takahashi and Isobe, 2007). Upon separation, isolated protein or spots are digested with trypsin, and peptides are separated and identified with mass spectrometry (MS). In MS, the samples are introduced, ionized, separated, and detected. Nonvolatile, high-molecular-weight compounds such as peptides and proteins can be ionized by matrix-assisted lasser-desorption/ionization (MALDI) or electrospray ionization (ESI) (Hamdan and Righetti, 2005; Takahashi and Isobe, 2007). MALDI is a solid-phase technique utilized on silicon chips that detects singly-charged ions and is usually coupled with a high mass range analyzer such as a time of flight (TOF) mass analyzer. MALDITOF requires fairly pure samples, so it is commonly used in conjunction with protein fractionation with 1DE or 2DE (Hamdan and Righetti, 2005). Identification of proteins is performed by peptide mass fingerprinting (PMF), which compares a list of experimental peptide masses with a theoretical list of peptide masses in protein databases. On the contrary, ESI generates gas-phase ions from liquid samples, and it is usually coupled with on-line chromatographic techniques, such as reversed phase HPLC and anion exchange, to identify ions via quadrupoles and quadrupole ion traps. These instruments are more readily configured as tandem mass spectrometers for mass-selecting and fragmenting 
single components of a mixture (Hamdan and Righetti, 2005). Despite its sensitivity, ESI has limited application in the analysis of complex mixtures unless high-resolution chromatographic equipments are utilized (Hamdan and Righetti, 2005; Takahashi and Isobe, 2007).

Current research attempts to identify minor milk proteins using both direct liquid chromatography-tandem mass spectrometry and 2DE followed by MALDI-TOF (Smolenski et al., 2006). Molecules involved in host defense have been of special interest in the dairy field, and the need to quantify changes during milk lactation has driven many scientists to come up with more sensitive techniques to achieve such goals. O'Donnell et al. (2004) provides a good review of proteomics techniques and the challenges faced in milk proteomics.

\section{Summary of Literature}

Fat lipid formation has been reviewed along with the origins of the crescent milk fat globule membrane, which is constituted of proteins and polar lipids. These components are associated with health and well-being benefits and even nutraceutical properties, which emphasizes the importance of studying the MFGM to its fullest. However, further research to optimize the extraction of MFGM from the richest sources, buttermilk and butter serum, is necessary to maximize the yield. Therefore, the latest procedures in filtration were presented to recover intact MFGM constituents. Also, the technical aspects and methodologies that reveal the MFGM composition with minimal invasion were summarized to provide alternate techniques to study the effects of milk processing, such as cooling, thermal treatment, and homogenization. 


\section{Justification for Present Research}

The milk fat globule membrane is part of the most nutritional product that nature has provided: milk; however, its health-promoting and neutraceutical properties are still unknown to most consumers. A lot of research has been done in characterizing the milk fat globule membrane. Yamada et al. (2002) first attempted to identify low-abundance protein in colostrum and mature milk, identifying specific proteins to each set of milk. Later, developmental changes in the transition from colostrum to milk were published (Reinhardt and Lippolis, 2008) as well as milk glycax using proteomics techniques (Wilson et al., 2008). The latest work profiled the metabolic proteomic of bovine mammary tissue (Beddek et al., 2008), but even with the plethora of studies about the health benefits of MFGM proteins and phospholipids, no work has been performed in studying the damage that MFGM constituents undergo during milk processing in the same line of milk.

With this study, an in depth characterization of the effects of milk processing on the milk's constituents, especially proteins and polar lipids, was performed utilizing established methodologies and sensitive proteomic techniques such as LC/MS and 2-DE gels coupled with MALDI-TOF. Furthermore, protocols for the study of MFGM were established for future research, to determine the best source of MFGM for commercial production, and for incorporation into the food products.

The knowledge obtained from the effect of milk processing on the MFGM will further expand our understanding of the fundamentals that will allow the design of an optimal processes to maintain the function of the MFGM throughout the line of production and absorption of nutrients in the human intestine and receive benefits similar to the ones neonates acquire. 


\section{MATERIALS AND METHODS}

\section{A. Milk Collection \& Processing}

Milk was collected from Cal Poly's milking parlor before it reached the cooling tank and kept at room temperature until analysis were done; this, sample was denoted "Fresh." Then, the milk was left in the cooling unit for $72 \mathrm{hrs,} \mathrm{and} \mathrm{processing} \mathrm{was} \mathrm{performed} \mathrm{as}$ shown in Figure 12. Three independent replicates were performed in different weeks

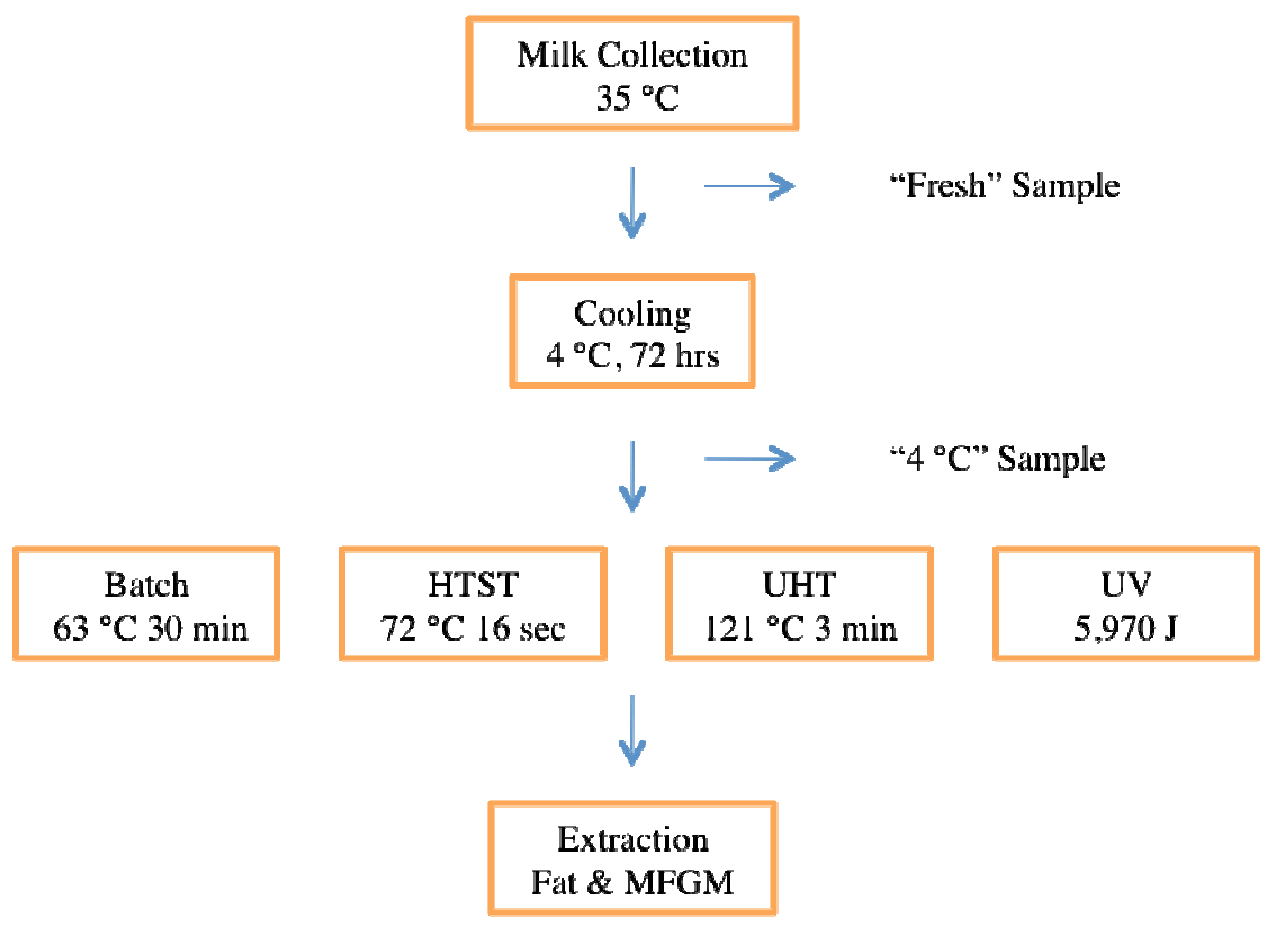

Figure 12. Milk Collection and Processing.

\section{Heat Pasteurization}

Milk processing was conducted at Cal Poly's pilot plant. Batch pasteurization was done in a double walled vessel (Groen DN/RA-60) where steam was applied until the unit reached $63{ }^{\circ} \mathrm{C}$ and maintained for $30 \mathrm{~min}$. Temperature was monitored with a thermometer. The milk was immediately placed at $4{ }^{\circ} \mathrm{C}$ after processing. High temperature short time (HTST) pasteurization was performed with a heat plate exchanger 
(APV, SR II, Cropoco, Inc) controlled with Hardy instrument software (HI2151/20 WC). The conditions were $72{ }^{\circ} \mathrm{C}$ for 16 seconds followed by immediate cooling to $4{ }^{\circ} \mathrm{C}$. Ultra high temperature (UHT) pasteurization was performed in an autoclave (2540E, Tuttnauer Brinkmann). Milk was placed in 500ml pyrex glass bottles and heated to $121^{\circ} \mathrm{C}$ for 3 minutes.

\section{Cold Pasteurization- Pulsed UV Light}

Cold pasteurization was performed according to Elmnasser et al. (2008) and Krishnamurthy et al. (2004)'s descriptions, using a SteriPulse-XL system (RS-3000C, Xenon Corp., USA) equipped with a lamp housing with 16 in quartz flashlamp type C (XL-1957), a sterilization chamber (LH840 LMPHSG), a liteMark-XL 1000 light monitor, and a controller (RC-847). The system was located under a hood to ventilate ozone being produced. The milk sample, five to ten $\mathrm{mL}$, was pipetted into a glass bottom petri dish (9 $\mathrm{cm}$ diameter, Pyrex, USA) and placed at the midpoint of the flashlamp (7.9cm depth $\mathrm{x} 20.3 \mathrm{~cm}$ wide). To receive the maximum energy, the petridish was located $4.5 \mathrm{~cm}$ (1.76 in) from the face of the sterilization chamber's window, which has an intensity of approximately 1.0 Joules $/ \mathrm{cm}^{2} /$ pulse.

\section{a) Microbial Reduction in Milk}

To determine the best settings to reduce the microbial population in a non-transparent liquid such as milk, microbial studies were performed on UV treated milk and compared to raw milk. Two parameters were analyzed, the volume of the fluid placed in the petri dish since this determines the depth penetration of the lamp and the exposure time. Volumes in the range from five to ten mililiters were tested in combination with treatment time of two up to nine seconds. Microbial reduction in aerobic and 
E.coli/coliform counts were enumerated using $3 \mathrm{M}^{\mathrm{TM}}$ Petrifilm ${ }^{\mathrm{TM}}$ Aerobic Count Plates and $3 \mathrm{M}^{\mathrm{TM}}$ Petrifilm ${ }^{\mathrm{TM}}$ E. coli Count Plates (EC), respectively, after 24 and $48 \mathrm{hrs}$ of incubation. Dilutions were made with butterfield phosphate buffer (D599, Hardy Diagnostics, USA), and the samples were plated in duplicates and incubated at $25^{\circ} \mathrm{C}$. One-way ANOVA tests were performed using MiniTab (v.16.1.0, Minitab Inc., State College, PN) to find difference $(\mathrm{p}<0.05)$ among samples. Paired comparisons between means were carried out using the Tukey's test when a significant difference was observed.

\section{b) Milk Processing}

Milk that was kept in the cooling unit for $72 \mathrm{hrs}$ was utilized for this experiment and maintained cold throughout the pulsed UV light treatment. Seven $\mathrm{mL}$ of milk were placed in a petridish and given five pulses of UV light for a total of 5,970 Joules (15 Joules $/ \mathrm{cm}^{2}$ ) of energy. Three petridishes were located on the tray along the midpoint of the flashlamp, and their product consolidated. A final volume of $800 \mathrm{~mL}$ of UV-treated milk was collected and kept at $4{ }^{\circ} \mathrm{C}$ until needed.

\section{B. Physical Properties of the Milk Fat Globule Membrane}

\section{Milk Fractionation}

To separate cream, $35 \mathrm{~g}$ of processed milk was measured in ultracentrifuge tubes (357002, Beckman, CA) and transferred to a pre-chilled Beckman L7-35 Ultracentrifuge at 7,000 rpm for 30 min at $4{ }^{\circ} \mathrm{C}$ (Basch et al., 1985). Upon centrifugation, the cream was scooped out with a spatula and placed on a Whatman \#1 filter paper (No. 100150) for 5 min and later placed into a $15 \mathrm{~mL}$ falcon tube. The skim milk was decanted into clean 
falcon tube containing a net (hair net) to prevent cream chunks from entering the final fluid. Cream and skim milk were kept at room temperature previous to analysis.

\section{Milk Fat Globule Size Distribution}

Particle size diameter distribution of whole milk, skim milk, and $40 \%$ cream were determined according to the method described by Menard et al. (2010) using a laser diffraction particle size analyzer in the Polarization Intensity Differential Scattering (PIDS) optical mode (Beckman Coulter, model LS 230, CA). The analysis chamber was filled manually with one liter of deionized water containing $16 \mathrm{~mL}$ of $35 \mathrm{mM}$ EDTA/NaOH pH 7 buffer ( $>99 \%$ disodium salt dehydrate, Sigma) for a final concentration of $0.1 \mathrm{~mL}$ buffer per liter of water. The instrument was allowed to adjust for electrical offsets and align the laser prior to measuring background, which was measured for $60 \mathrm{sec}$. Sample loading was conducted for 90 seconds. The obscuration rate was held $10 \%$ for milk during the runtime. For whole and skim milks, one $\mathrm{mL}$ of $35 \mathrm{mM}$ EDTA buffer was added to $10 \mathrm{~mL}$ of milk five min before measurements (Mènard et al., 2010). For cream, $35 \mathrm{mM}$ EDTA buffer was use to make the final cream concentration $40 \%(\mathrm{w} / \mathrm{v})$. The pump speed for all the samples was 50\%; laser power, $80 \%$; run length, $60 \mathrm{~s}$, and temperature, 23 to $25^{\circ} \mathrm{C}$.

Standard parameters were calculated by the software (Coulter LS Software v.3.29 August 2003), and measurements were conducted in triplicate. Five parameters were calculated to describe the milk fat globule size distribution in milk, cream, and skim milk. The volume-weighted average diameter $\left(d_{4,3}\right)$, which is defined by Equation 1 as:

$$
d_{4,3}=\frac{\sum n_{i} d_{i}^{4}}{\sum n_{i} d_{i}^{3}}
$$


Where $n_{\mathrm{i}}$ is the number of fat globules of diameter $\left(d_{\mathrm{i}}\right)$. The second parameter is the volume-surface average diameter $\left(d_{3,2}\right)$, described by Equation 2 .

$$
d_{3,2}=\frac{\sum n_{i} d_{i}^{3}}{\sum n_{i} d_{i}^{2}}
$$

The modal diameter (mode) was measured to represent the most important population of fat globules in volume. The fourth parameter is the specific surface area (SSA), which is shown via Equation 3:

$$
S S A=\frac{6 \varphi}{d_{3,2}}
$$

Where is the volume fraction of milk fat, and the size distribution width was calculated using Equation 4 as indicated below. For this equation, $d_{\mathrm{v}, 0.9}, d_{\mathrm{v}, 0.1}$, and $d_{\mathrm{v}, 0.5}$ represent the diameter below which lies $90 \%, 50 \%$, and $10 \%$, respectively, of the globule volume.

$$
\operatorname{Span}=\frac{d_{v 0.9}-d_{v 0.1}}{d_{v 0.5}}
$$

\section{Chemical Composition of Processed Milk}

\section{Evaluation of Milk Composition}

The protein, casein, lactose, fat, and total solids content of processed milks were deterined with a Milkoscan FT2 (Foss, Eden Prairie, MN) utilizing Foss Integrator software package version 1.5.0 (Foss). Prior to the analysis, the instrument was calibrated with DQCI Servies: Dairy Quality Control California Milk Standards (DQCI, Mounds View, MN). The samples were warmed to $40^{\circ} \mathrm{C}$ for five minutes before measurements, and each sample was conducted in triplicates. 


\section{Fat Extraction-Mojonnier}

Milk fat was extracted using the Mojonnier method (AOAC Method 989.05) (Min and Ellefson) with slight modifications to prevent phospholipid degradation. All the reagents were analytical grade and purchased form Fisher Scientific. Prior to extraction, each sample was warmed to $38^{\circ} \mathrm{C}$ for five min to assure a complete homogenization of sample. Five $\mathrm{mL}$ of milk $\left(25^{\circ} \mathrm{C}\right)$ were weighed in a Mojonnier extraction flask (EW34590-65, Cole-Parner, IL) followed by addition of warmed water $\left(38^{\circ} \mathrm{C}\right)$ and mixing for $30 \mathrm{sec}$. The sample was shaken vigorously for $45 \mathrm{sec}$ after each chemical addition with the exception of ammonium hydroxide, which was done for $30 \mathrm{sec}$. To neutralize acids and denature proteins, $1.5 \mathrm{~mL}$ of $\mathrm{NH}_{4} \mathrm{OH}(\mathrm{A} 669-212)$ were added. Gel formation was prevented by adding $10 \mathrm{~mL}$ of $95 \%$ ethanol (A407-4), and the lipids were dissolved by the addition of $25 \mathrm{~mL}$ of ethyl ether (E199-4). A couple drops of a 1\% phenolphthalein solution (SP62) were added to distinguish between the organic and inorganic phases. More lipids were extracted with $25 \mathrm{~mL}$ of petroleum ether (E120-4), which also removed moisture from the organic phase. The sample was spun down in a Garver electrifuge (308M, Garver Manufacturing, IN) for $45 \mathrm{sec}$. The organic phase was decanted in a preweighed Mojonnier fat tin, which was previously dehydrated at $100{ }^{\circ} \mathrm{C}$ for $30 \mathrm{~min}$ and placed in a dessicator. A second extraction was performed without the addition of ammonium but with $5 \mathrm{~mL}$ of ethyl alcohol, $15 \mathrm{~mL}$ of ethyl ether, and $15 \mathrm{~mL}$ of petroleum ether. The solvents were then evaporated on a hot plate at approximately $60{ }^{\circ} \mathrm{C}$ and transferred to a pre-warmed isotemp vacuum oven (281A, Fisher Scientific, CA) for 30 minutes at $60{ }^{\circ} \mathrm{C}$ with at least $20 \mathrm{in} \mathrm{Hg}$ vaccum. The tins were transferred to the dessicator and allowed to cool down before weighing them. The milk fat was transferred to a 4-ml amber vial with the addition of chloroform/methanol $(2: 1, \mathrm{v} / \mathrm{v})$ to a final 
concentration of $100 \mathrm{mg} / \mathrm{mL}$. Nitrogen gas was introduced into the vial for $5 \mathrm{sec}$ to reduce fat oxidation, and the samples were kept at $-15^{\circ} \mathrm{C}$ until needed.

\section{Determination of Phospholipids in the MFGM}

\section{a) Phospholipid Solid Phase Extraction (SPE)}

Milk phospholipids were obtained from the extracted fat according to the method described by Bitman et al. (1984). The reagents were of analytical grade and purchased from Fisher Scientific. The amber vials containing fat were allowed to thaw and placed in a $50 \mathrm{~mL}$ round bottom flask to evaporate the solvents in a rotatory evaporator with a diagonal condenser (Labconco Corp.). The water bath was kept at $45^{\circ} \mathrm{C}$ to prevent lipid degradation, especially with sphingomyelin. Approximately $0.1 \mathrm{~g}$ of fat was utilized to load 2g/12 ml Strata Si-1 Silica (55um, 7A) solid phase extraction tubes (8B-S012-KDG, Phenomenex). The cartridges were placed in a SPE 12-position vacuum manifold (AH06023, Phenomenex), and 9-mL glass tubes were placed under the columns, which were first cleaned by adding $20 \mathrm{ml}$ of chloroform and conditioned by adding $10 \mathrm{ml}$ of hexane. The fat was then transferred onto the columns with two mL of hexane, and an extra two $\mathrm{mL}$ volume of hexane was added to rinse any residue and added to the column. The lipids were allowed to be absorbed onto the columns for approximately five minutes, and the hexane was allowed to drip by gravity. Neutral lipids (fraction 1) were eluted with $40 \mathrm{ml}$ hexane/ethyl ether $(1: 1 \mathrm{v} / \mathrm{v})$ by gravity or by applying vacuum at approximately $5 \mathrm{in} \mathrm{Hg}$. This fraction was discarded, and the glass tubes were replaced with clean ones to elute the phospholipid fraction (fraction 2) with $20 \mathrm{ml}$ methanol, which removes $80 \%$ of the PL. The eluent was transferred into pre-weighed round bottom flasks, and the remaining PL was eluted with $20 \mathrm{ml}$ of chloroform/methanol/water (3:5:2) (fraction 3). The second 
and third fractions were consolidated and evaporated under vacuum with a rotatory evaporator to evaporate organic solvent with the previous settings. The round bottom flasks were then immersed in liquid nitrogen to freeze the water containing PL and placed in a freeze dryer holder (75408, Labconco Corp.) to sublimate the solvent using a freeze dry system (Freezon 4.5, Labconco Corp.) for three hours or until a white residue was observed. The PL powder was dissolved in one $\mathrm{ml}$ of chloroform/methanol $(2: 1, \mathrm{v} / \mathrm{v})$, transferred to amber vials, and stored at $-20^{\circ} \mathrm{C}$.

\section{b) Phospholipid Separation \& Quantification}

For identification purposes, pure polar lipids such as L- $\alpha$ phosphatidylcholine (PC), L- $\alpha$ phosphatidylethanolamine (PE), L- $\alpha$ phosphatidylinositol (PI), L- $\alpha$ phosphatidyl-L serine (PS), and sphingomyelin (SM) from bovine brain were purchased from Sigma Aldrich. Chloroform, methanol, and formic acid were of HPLC grade from Fisher Scientific. Samples were collected and analyzed as indicated in Figure 13.

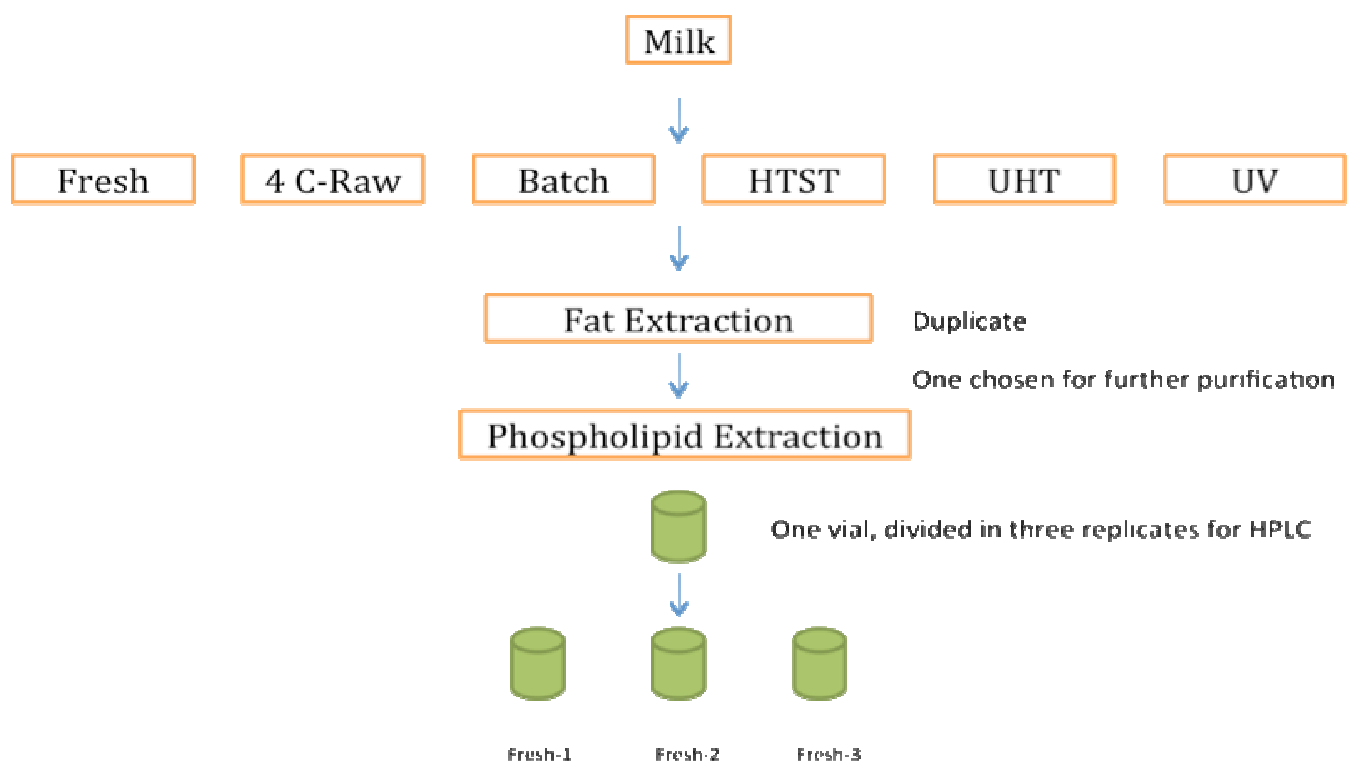

Figure 13. Analysis of milk phospholipids involves fat extraction from milk, isolation of PL from other simple lipids via solid phase extraction (SPE), and separation and quantification of the different phospholipid classes via HPLC. 
Phospholipid separation was performed by high performance liquid chromatography (HPLC) according to the methodology described by Rombaut et al. (2005). A Shimadzu prominence ultra flow liquid chromatography system (LC-20AB, Shimadzu, USA Inc.) consisted of a communication bus module (CBM-20A, Shimadzu), an autosampler (Sil20A HT, Shimadzu), a degasser (DGU-20A ${ }_{3}$, Shimadzu), and a column oven (CTO-20A, Shimadzu) connected to a charge aerosol detection (CAD) detector (Corona Plus, Dionex, USA). Nitrogen was used as a carrier gas at a backpressure of 2.4 bar. A $150 \mathrm{~mm}$ x $3.0 \mathrm{~mm}$ Prevail silica column with a $3 \mu \mathrm{m}$ particle diameter (Part N. 99341, Grace Division, USA) and a $7.5 \mathrm{~mm} \times 3.0 \mathrm{~mm}$ guard silica column with a $5.0 \mu \mathrm{m}$ particle diameter (Prevail ${ }^{\mathrm{TM}}$ All-Guard ${ }^{\mathrm{TM}}$ Part N. 99354, USA) were used. The column and guard column were equilibrated at $40{ }^{\circ} \mathrm{C}$. Samples were kept at room temperature, and $10 \mu \mathrm{l}$ were injected. The injection loop was rinsed with chloroform/methanol $(2: 1, \mathrm{v} / \mathrm{v})$ in between injections. The phospholipid elution was performed with a linear gradient with 87.5: 12: $0.5(\mathrm{v} / \mathrm{v} / \mathrm{v})$ chloroform; methanol; triethylamine (TEA) buffer ( $\mathrm{pH} 3,1 \mathrm{M}$ formic acid) at $\mathrm{t}=0 \mathrm{~min}$ with a flow at $0.5 \mathrm{~mL} / \mathrm{m}$. The TEA buffer was prepared by making a formic acid buffer of $1 \mathrm{M}$, which was neutralized with triethylamine to a final $\mathrm{pH}$ of 3 (see Appendix A.2). At $\mathrm{t}=16 \mathrm{~min}$, the mobile phase was 100\% eluent B (28: 60: $12, \mathrm{v} / \mathrm{v} / \mathrm{v})$. The mobile phase was brought back to $100 \%$ eluent $\mathrm{A}$ at $\mathrm{t}=17 \mathrm{~min}$, and the column was equilibrated until the next injection at $28 \min$ (Rombaut et al., 2005).

The data was collected and analyzed using LCSolution (Shimadzu). Identification of phospholipids was carried out by comparison with the retention time of pure standards. For each PL, calibration curves were created from the area values obtained by injecting $10 \mu \mathrm{L}$ of serially diluted solutions of PE (25-300 $\mu \mathrm{g}), \mathrm{PI}(2.5-30 \mu \mathrm{g}), \mathrm{PS}(1.67-20 \mu \mathrm{g}), \mathrm{PC}$ (21-250 $\mu \mathrm{g})$, and SM (25-300 $\mu \mathrm{g})$. A solution of chloroform/methanol (2:1, v/v) was 
utilized for the solutions. All the samples and standards were run in triplicates, and a linear regression equation $(y=a+b x)$ was applied to each phospholipid standard.

\section{Measurements of $S$-S and SH group levels}

The S-S and SH group levels in the MFGM were determined according to the method of Beveridge et al. (1974) with slight modifications by Lee and Sherbon (2002). To determine free $\mathrm{SH}$ groups, $0.5 \mathrm{ml}$ of MFGM suspension was mixed with $2.5 \mathrm{ml}$ of $5 \mathrm{~g}$ SDS/ per liter of Tris-gly-8M urea (Appendix A.6.h) (Cui et al., 2009) in a polycarbonate ultracentrifuge bottle (357002, Beckman, CA). Then, $20 \mu \mathrm{l}$ of Ellman's reagent at 4mg/ml (5,5'-dithiobis-2, 2'-nitrobenzoic acid (DTNB) in Tris-glycine buffer) were added, and the mixture was allowed to stand for 1 hour at $25^{\circ} \mathrm{C}$. There was no need to clarify solution with the addition of chloroform, but the mixture was centrifuged at $5000 \mathrm{~g}$ for $5 \mathrm{~min}$ at $25^{\circ} \mathrm{C}$ to avoid solids. The absorbance of the supernatant was measured at $412 \mathrm{~nm}$ with a spectrophotometer, and the SH groups were quantified using Equation 5.

$$
\frac{\text { Free } \mathrm{SH} \mu \mathrm{M}}{\mathrm{g} \text { MFGM proteins }}=\frac{73.53 \times \mathrm{Abs}^{412}}{\mathrm{mg} / \mathrm{ml} \text { of }(6.04)}
$$

The term $\mathrm{A}_{412}$ is the absorbance at $412 \mathrm{~nm}, 6.04$ is the dilution factor of the sample, and 73.53 is derived from the conversion from molar to $\mu \mathrm{M} / \mathrm{mL}$ and from $\mathrm{mg}$ solids to $\mathrm{g}$ solids $\left(10^{6}\right)$ over the molar absorptivity of the Ellman's reagent $\left(1.36 \times 10^{4}\right)$ (Beveridge $e t$ $a l ., 1974)$. The total SH was quantified by mixing $0.2 \mathrm{ml}$ of MFGM homogenate with one of $5 \mathrm{~g} \mathrm{SDS} /$ per liter of Tris-gly-8M urea $8 \mathrm{M}$ and $20 \mu \mathrm{l}$ of $\beta$-mercaptoethanol. After incubation for $1 \mathrm{hr}$ at $25^{\circ} \mathrm{C}, 10 \mathrm{ml}$ of a solution of $12 \%(\mathrm{w} / \mathrm{v})$ trichloroacetic acid (TCA) was added and incubated for $1 \mathrm{hr}$ at $25^{\circ} \mathrm{C}$. The solution was then centrifuged at $5000 \mathrm{~g}$ for $15 \mathrm{~min}$, and the precipitation was resuspended in six $\mathrm{ml}$ of TCA, and centrifuged at 
$5000 \mathrm{~g}$ for $15 \mathrm{~min}$ to remove $\beta$-mercaptoethanol. A second wash was repeated with $6 \mathrm{ml}$ of TCA followed by centrifugation. The precipitate was dissolved in $3 \mathrm{ml}$ of $8 \mathrm{M}$ urea and 5g SDS/1 in tris -glycine buffer, and $30 \mu \mathrm{l}$ of Ellman's reagent was added followed by incubation for 1 hour at room temperature. There was no need to add chloroform, but centrifugation was performed for $5 \mathrm{~min}$ at 5000xg. The total $\mathrm{SH}(\mathrm{SH}+$ reduced SS) were quantified using Equation 6.

$$
\frac{\text { Total SH } \mu \text { mol }}{\text { g MFGM proteins }}=\frac{73.53 \times \text { Abs }_{412} \times 15}{\mathrm{mg} / \mathrm{ml} \text { of protein }}
$$

The term 15 is the dilution of the sample in the final volume. The S-S groups were calculated from the difference in free $\mathrm{SH}$ from total $\mathrm{SH}$ as indicated by equation 7.

$$
\frac{\text { SS group } \mu \mathrm{mol}}{\text { g MFGM proteins }}=\frac{\text { Total SH }- \text { Free SH }}{2}
$$

\section{Milk Fat Globule Membrane Extraction}

Milk was brought to room temperature before MFGM extraction, which was performed according to the method of Patton and Huston (1986) with some modifications. The density of serum was increased by adding sucrose to milk at $5 \mathrm{~g}$ per $100 \mathrm{ml}$, and the solution was allowed to dissolve completely for $10 \mathrm{~m}$. Fifteen $\mathrm{mL}$ of phosphate buffer saline (PBS) (1X) (see Appendix A.1) were placed in a $50 \mathrm{~mL}$ conical centrifuge tube, and $35 \mathrm{~mL}$ of the dense milk was carefully deposited underneath the buffer layer using a $25 \mathrm{~mL}$ disposable pipette (Patton and Huston, 1986). The conical tubes were carefully placed in a centrifuge (Eppendorf 5810R) and spun down at 4,000 $\operatorname{rpm}(3200 \mathrm{x} \mathrm{g})$ for $20 \mathrm{~min}$ at $21{ }^{\circ} \mathrm{C}$ to collect the cream (Basch et al., 1985). The cream layer was removed with a spatula and placed in a $50 \mathrm{~mL}$ tube. The cream was 
resuspended with cold $\left(4^{\circ} \mathrm{C}\right) 1 \mathrm{X}$ PBS to a final $40 \%(\mathrm{w} / \mathrm{v})$ solution, and Tween 80 (Fisher, T164) was added to a final 0.2\% (w/v) concentration. The mixture was blended for $45 \mathrm{sec}$ using a commercial blender (Waring Blender 51BL31) in high setting and a pre-chilled $\left(4{ }^{\circ} \mathrm{C}\right)$ steel cup (Eberbach Corporation). The churned cream was placed inside an isotemp bath (Isotemp205, Fisher Scientific, CA) at $42{ }^{\circ} \mathrm{C}$ for $30 \mathrm{~min}$ and spun down in a pre-warmed centrifuge (Eppendorf 5810R) at 4,000 rpm for $20 \mathrm{~min}$ at $40{ }^{\circ} \mathrm{C}$. Centrifugation separated the cream into buttermilk, which contains the MFGM proteins, and oil layers are depicted in Figure 14.

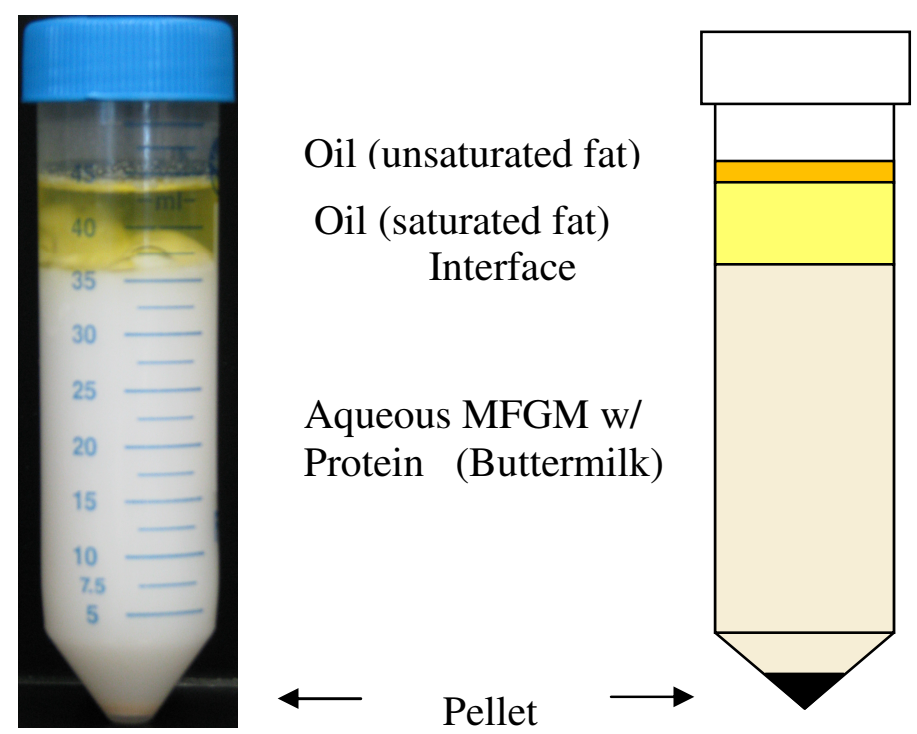

Figure 14. Milk fat separation upon churning and centrifugation. Left. Actual conical tube containing cream layers. Right. Schematic representation. The buttermilk, which contains MFGM proteins, was isolated for the next step in MFGM purification.

The unsaturated and saturated fat layers were discarded with a Pasteur pipette, and the aqueous portion of the churned cream was isolated using a $25 \mathrm{~mL}$ plastic pipette and transferred into a clean $50 \mathrm{~mL}$ conical tube. Then, sodium citrate was added to disintegrate casein micelles at $2 \%(\mathrm{w} / \mathrm{v})$ and gently agitated to dissolve the citrate 
completely. The buttermilk was incubated overnight at $4{ }^{\circ} \mathrm{C}$ to break emulsions. Upon incubation, the buttermilk solution was transferred to a polycarbonate ultracentrifuge bottle (357002, Beckman) and spun down for two hours in a pre-chilled $\left(4{ }^{\circ} \mathrm{C}\right)$ Beckman L7-35 Ultracentrifuge at 25,000 rpm $(50,000 \mathrm{x} \mathrm{g})$. The aqueous phase was decanted without disturbing the pellet, and any remaining saturated fat was removed manually. The pellet was washed with $25 \mathrm{~mL}$ of cold $1 \mathrm{X}$ PBS to remove any remaining detergent, and the tube was placed back in the centrifuge with the same settings for $45 \mathrm{~min}$. Upon centrifugation, the aqueous phase was discarded, and the dry pellet was transferred to a $1.5 \mathrm{~mL}$ microcentrifuge vial and stored at $-4{ }^{\circ} \mathrm{C}$.

\section{E. MFGM Protein Profile from One Dimensional Analysis}

\section{Protein Homogenization}

The MFGM protein pellet was put into solution by adding cold 1X PBS into siliconized microcentrifuge at a final concentration of $0.1 \mathrm{mg} / \mathrm{uL}$. Then, the solution was sonicated using a Sonic Dismembrator (500, Fisher Scientific) with a CE Branson microtip (102C, Fisher Scientific) using three cycles of 12 seconds at 10\% amplitude. The vial containing the homogenized pellet was kept in ice during sonication to avoid local heating, and the tip was washed with acetone and deionized water between samples. The homogenized solution was stored at $-15{ }^{\circ} \mathrm{C}$.

\section{Protein Quantification}

Protein concentration was determined using a $\mathrm{BCA}^{\mathrm{TM}}$ protein assay kit (23227, Pierce, USA), which is based on bicinchoninic acid (BCA) for colorimetric detection and quantitation of total protein. Briefly, a standard curve was constructed from bovine serum albumin (BSA). An aliquot of $25 \mu \mathrm{L}$ of sample or standard was pipetted into a microplate 
well, and $200 \mu \mathrm{L}$ of working reagent was added followed by mixing on a shaker for 30 sec. The plate was transferred to an incubator at $37^{\circ} \mathrm{C}$ for $30 \mathrm{~min}$ and cooled before reading absorbance at $562 \mathrm{~nm}$ using a spectrophotometer. Samples and standards were prepared in duplicates.

\section{Sodium Dodecyl-Sulfate Polyacrylamide Gel Electrophoresis}

The stock MFGM protein solution was diluted to $1.6 \mu \mathrm{g} / \mu \mathrm{L}$ using filtered 1X PBS buffer before SDS-PAGE analysis. Protein samples were prepared for reduced gel electrophoresis using NuPAGE ${ }^{\circledR}$ Novex ${ }^{\circledR}$ reagents (Invitrogen, CA). Five $\mu \mathrm{L}$ of sample was mixed with $2.5 \mu \mathrm{L}$ NuPAGE LDS sample buffer (4X) (NP008), one $\mu \mathrm{L}$ uL NuPAGE reducing agent (10X) (NP0004), and $5 \mu \mathrm{L}$ nanopure water to a final concentration of 0.8 $\mu \mathrm{g} / \mu \mathrm{L}$. The samples were heated at $70{ }^{\circ} \mathrm{C}$ for 10 minutes and immediately cooled down to room temperature with top water. An aliquot of $12 \mu \mathrm{L}$ of the reduced sample was loaded into $1.0 \mathrm{~mm} \times 12$ well NuPAGE 4-12\% Bis-Tris gel (NP0322), which was mounted onto XCell Surelock ${ }^{T M}$ Mini-Cell chamber (EI0001). Novex Sharp pre-stained protein standards (LC5800S), $10 \mu \mathrm{L}$, were included in each gel. The cell was filled with 1X NuPAGE MOPS SDS running buffer (NP0001) containing $500 \mu \mathrm{L}$ of NuPAGE antioxidant (NP0005) at a concentration of $5 \mu \mathrm{L} / \mathrm{mL}$. The cell unit was connected to a BioRad power unit (PAC300, BioRad) and run at $200 \mathrm{~V}$ for approximately 50 minutes. The gel was then transferred to a clean container and washed with nanopure water three times for 5 min. SimplyBlue safe staining solution (LC6060) was added and incubated overnight on a rotatory incubator (Max 2000 E-class, Barnstead, IA) at room temperature. Upon staining, the gels were washed with nanopure water three times for 5 
minutes, and images were captured with an Epson Scanner (Epson Expression 1680) in conjunction with Epson Scan Software in professional mode.

\section{4. $\quad$ Protein Densitometry \& Statistical Analysis}

Quantiy One 1-D Analysis Software (v.4.6.3, BioRad) was used to quantify protein bands. Trace quantity (peak density $\mathrm{x}$ area) was utilized to compare the band intensities in each sample per treatment batch.

\section{LC-MS/MS Analysis}

LC-MS/MS was performed on 1DE gels at UC Davis Genome Center Proteomics Core Facility. First, four sections were excised from a 1DE gel using a razor over a gel sheet (165-7018, BioRad) to avoid contamination: higher than $150 \mathrm{kDa}$, between 150 and $55 \mathrm{kDa}$, between 55 and $35 \mathrm{kDa}$, and less than $35 \mathrm{kDa}$. These samples were sent to UC Davis for protein identification. Briefly, the gel sections were digested overnight with trypsin, and the peptides were purified for further analysis as described by the Proteome Center (Tran). A Thermo Finnigan LTQ ion trap mass spectrometer (Thermo Fisher) coupled with a paradigm HPLC (Michrom Bioresources, Auburn, CA, USA), and a Michrom captive spray ionization source were utilized for peptide identification. The digested peptides were loaded onto a trap column (Zorbax300SB-C18, $5 \mu \mathrm{m}, 5 \times 0.3 \mathrm{~mm}$, Agilent Technologies, Santa Clara, CA, USA) and desalted online followed by elution from the trap column using an increasing gradient of organic solvent $(B)(A=0.1 \%$ Formic Acid, $B=100 \%$ Acetonitrile) onto a reverse-phase Michrom Magic C18AQ (200 $\mu \mathrm{m} \times 150 \mathrm{~mm}$ ) column at a flow rate of $2 \mu \mathrm{L}$ per min. Peptide elution started with $2 \% \mathrm{~B}$ $35 \% \mathrm{~B}$ for $30 \mathrm{~min}, 35 \% \mathrm{~B}$ to $80 \% \mathrm{~B}$ for two min, and held at $80 \% \mathrm{~B}$ for one min. Eluent $\mathrm{B}$ decreased from $80 \% \mathrm{~B}$ to $2 \% \mathrm{~B}$ over $1.5 \mathrm{~min}$, and the column was re-equilibrated at $2 \% \mathrm{~B}$ 
for $26.5 \mathrm{~min}$. The complete run was $60 \mathrm{~min}$, and the following parameters were selected: spray voltage $1.8 \mathrm{kV}$, heated transfer capillary $180^{\circ} \mathrm{C}$, full scan mass range of each sample was 350-1400 mass to charge (m/z) ratio, and the MS/MS data was collected using 35\% normalized collision energy for collision-induced dissociation and an isolation width of 1.0 .

\section{Database Searching and Criteria for Protein Identification}

For database searching, tandem mass spectra were extracted by Bioworks version 3.2. All MS/MS samples were analyzed using X! Tandem (The GPM, thegpm.org; version TORNADO (2010.01.01.4)). The program was set up to search Uniprot Human complete proteome database (December 2010) and the cRAP common laboratory artifacts database along an equal number of reverse decoy sequences assuming the digestion enzyme trypsin. Tandem was searched with a fragment ion mass tolerance of $0.40 \mathrm{D}$ and a parent ion tolerance of $1.8 \mathrm{Da}$. The iodoacetamide derivative of Cys (carbamidomethyl) was specified in X! Tandem as a fixed modification. For variable modifications, deamination of asparagine and glutamine, oxidation of methionine and tryptophan, sulfone of methionine, tryptophan oxidation to formylkynurenin of tryptophan and acetylation of the $\mathrm{N}$-terminus were specified.

For protein identification, Scaffold (version Scaffold_3_00_05, Proteome Software Inc., Portland, OR, USA) was used to validate MS/MS based peptide and protein identifications. This software verifies peptide identifications assigned by SEQUEST and Mascot using the X!Tandem database searching program. Scaffold then probabilistically validates these peptide identifications using Peptide Prophet algorithm (Keller et al., 2002) and derives corresponding protein probabilities using Protein Prophet algorithm (Nesvizhskii et al., 2003). Peptide identifications were accepted if they could be 
established at greater than $70.0 \%$ probability as specified by the Peptide Prophet, and protein identifications were accepted if they could be established at greater than $95.0 \%$ probability and contained at least 2 identified peptides. Proteins that contained similar peptides and could not be differentiated based on MS/MS analysis alone were grouped to satisfy the principles of parsimony. Using the above critereia the false discovery rate (FDR, Decoy; Target) was calculated as $0.1 \%$ on the peptide level and $3.4 \%$ on the protein level using a target-decoy (reverse) search strategy (Tabb, 2007). Protein function was determined using www.uniprot.org and http://www.ncbi.nlm.nih.gov.

\section{F. Statistical Analysis}

Statistical analyses were conducted for milk composition (FTIR), MFGM extraction, particle size distribution, phospholipids, and 1DE SDS-PAGE band intensity, using the General Linear Model (GLM) command in Minitab. Week was a random effect, and treatment was a fixed effect. Differences between the treatment means were compared at the 5\% level of significance using Tukey's method. In addition, a histogram of residuals, normal plot of residuals, residuals versus fits, and residuals versus order were used to test model adequacy and normality.

\section{G. MFGM Protein Profile from Two-Dimensional Analysis}

\section{Protein Homogenization}

The reagents for $2 \mathrm{D}$ analysis were of electrophoresis purity grade from BioRad unless otherwise stated. The working homogenization buffer was prepared fresh by adding $50 \mu \mathrm{L}$ of immobilized $\mathrm{pH}$ gradient (IPG) buffer ( $0.5 \%$ ampholyte) and $62 \mathrm{mg}$ dithiothreitol (DTT) $(40 \mathrm{mM})$ per $10 \mathrm{ml}$ of homogenization buffer (7M urea, 2M thiourea, 1\% ASB-14, 40mM Tris base, $0.001 \%$ bromophenol blue, $0.5 \%$ ampholyte, and 40mM DTT, see 
Appendix A.3.a). An aliquot of $1.2 \mathrm{ml}$ of homogenization buffer was added per 100 to $150 \mathrm{mg}$ of MFGM protein pellet. The membrane was homogenized gently using pellet pestles (749515, Kontes, NJ) into a $1.5 \mathrm{ml}$ centrifuge tube until no fragments of tissue were visible. The samples were kept at room temperature. Homogenized membrane was transferred into $2 \mathrm{~mL}$ siliconized microcentrifuge (02-681-321, Fisher Scientific) tubes and allowed to sit on the bench at room temperature for one hour to solubilize the proteins. Upon incubation, samples were centrifuged at room temperature for $30 \mathrm{~min}$ at $13,500 \mathrm{rpm}$. Solutions were decanted into fresh siliconized tubes, and the solids were left behind and discarded. $400 \mu \mathrm{L}$ aliquots were prepared in $2 \mathrm{ml}$ siliconized microcentrifuge tubes to proceed with a precipitation step.

\section{Protein Precipitation}

To precipitate proteins, $10 \%$ trichloroacetic acid (TCA)/acetone solution (kept at $20{ }^{\circ} \mathrm{C}$ ) was added at $4 \mathrm{x}$ times the volume of protein solution. Thus, $1.6 \mathrm{ml}$ of cold $10 \%$ TCA/acetone (see Appendix A.3.g) was added to each $400 \mu$ l aliquot of protein solution. Microtubes were votexed briefly and stored overnight at $-20^{\circ} \mathrm{C}$. Upon incubation, microcentrifuge tubes were spun down at $4^{\circ} \mathrm{C}$ in a pre-cooled centrifuge (Microfuge 22R, Beckman Coulter) for 15 minutes at 13,5000 rpm. The acetone mixture was decanted into a waste container, and $1.6 \mathrm{~mL}$ of cold $100 \%$ acetone (kept at $-20^{\circ} \mathrm{C}$ ) was added to each tube to wash out TCA and any contaminants out of the protein pellet. The pellets were broken down by vortexing twice for 10 seconds. The centrifuge tubes were immediately transferred to the pre-chilled centrifuge and spun at $4{ }^{\circ} \mathrm{C}$ for 15 minutes at $13,500 \mathrm{rpm}$. The acetone solution was immediately decanted into a waste container, and the tubes were air-dry for a few seconds. To rehydrate the precipitated proteins, $0.4 \mathrm{~mL}$ of fresh 
working IPG rehydration buffer (7M urea, 2M thiourea, 2\% CHAPS, 2\% NP-40, 0.002\% bromophenol blue, $0.5 \%$ ampholyte and 100mM DTE, see Appendix A.3.b) was added to each tube and vortexed for about $10 \mathrm{sec}$. Working IPG rehydration buffer was prepared by adding $6.25 \mu \mathrm{L}$ of IPG buffer and $20 \mathrm{mg}$ DTE per $1.25 \mathrm{~mL}$ of IPG rehydration buffer. Samples were allowed to sit at room temperature for one hour and vortexed every $10 \mathrm{~min}$ for $10 \mathrm{sec}$ to bring the proteins into solution. The tubes were then centrifuged at room temperature for $10 \mathrm{~min}$ at $13,500 \mathrm{rpm}$. The protein solutions were pooled into a clean siliconized microcentrifuge, and any gelatinous pellet was discarded. Solutions were stored at $-80^{\circ} \mathrm{C}$ until needed.

\section{Protein Quantification}

Protein quantification was performed by using a 2D Quant kit (80-6483-56, GE Healthcare, NJ, USA) according to the manufacturer's instructions. Briefly, the precipitated sample first was diluted 1:10 by adding $4.5 \mu \mathrm{l}$ of protein solution into $40.5 \mu \mathrm{l}$ of nanopure water. A standard curve was prepared using bovine serum albumin (BSA). Samples and standards were prepared in duplicates in siliconized microcentrifuge tubes. To precipitate the proteins out of solution, $500 \mu \mathrm{L}$ of precipitant was added to each sample and standard followed by a brief vortex. The microtubes were then incubated for $3 \mathrm{~min}$ at room temperature, and upon incubation, $500 \mu \mathrm{L}$ of coprecipitant was added. The tubes were mixed by inversion and spun down at 10,000xg for 5 min to sediment the protein. Following centrifugation, the supernatant was decanted without disturbing the protein pellet. To dissolve the precipitated protein, $100 \mu \mathrm{L}$ of copper solution and $400 \mu \mathrm{L}$ of nanopure water were added to each microtube followed by a quick vortex. The solutions were then incubated at room temperature for 15-20 min, and their absorbances were read at $480 \mathrm{~nm}$ by transferring $200 \mu \mathrm{L}$ of solution into a 96-well plate in triplicate. 


\section{Isoelectric Focusing (IEF)-First Dimension}

Protein solutions were diluted at a final concentration of $0.5 \mu \mathrm{g} / \mu \mathrm{L}$ using fresh IPG rehydration buffer, and $200 \mu \mathrm{L}$ of this solution were loaded into a lane in a BioRad focusing tray (165-4030) without introducing bubbles. Immobilized pH gradient strips (pH 3-10, $11 \mathrm{~cm} ; 163-2014$, BioRad) were placed with the gel side down in a IEF tray lane making sure the + end of the strip touched the left side of the tray. $1.5 \mathrm{~mL}$ of mineral oil (163-2129) were immediately added to each IEF strip, and the IEF tray was placed in a BioRad Protean IEF cell to separate proteins according to their isoelectric point. Isoelectric focusing started with a passive rehydration step $(5 \mathrm{hr})$, followed by $12 \mathrm{hr}$ of active rehydration $(50 \mathrm{~V})$. The protocol continued with a gradual voltage increase, $500 \mathrm{~V}$ for $1 \mathrm{hr}, 1000 \mathrm{~V}$ for $1 \mathrm{hr}$, and $8000 \mathrm{~V}$ for $2.5 \mathrm{hrs}$ (all voltage changes occurred in rapid mode). Upon separation, the strips were removed from the IEF tray and placed between western blot filter papers to remove excess mineral oil. The strips were then transferred gel side up into a rehydration/equilibration (165-4035) tray and kept at $-80{ }^{\circ} \mathrm{C}$ overnight or until ready to proceed with the second dimension.

\section{SDS-PAGE-Second Dimension}

Frozen strips were thawed and equilibrated first with $1.6 \mathrm{~mL}$ of DTT/equilibration buffer (10mg DTT/mL, $375 \mathrm{mM}$ tris pH 8.8, $6 \mathrm{M}$ urea, 30\% glycerol, 2\% SDS, 0.002\% bromophenol blue, Appendix A.3.c) followed by $1.6 \mathrm{ml}$ of iodoacetamide/equilibration buffer $(25 \mathrm{mg} / \mathrm{mL}$. Equilibration was done at room temperature for $15 \mathrm{~min}$ each on a bidirectional Max/rotator (4361, Barnstead Int., IA, USA), and the equilibration buffer was removed from the strips by decantation. $12.5 \%$ polyacrylamide gels were prepared according to Appendix A.4, using BioRad Criterion cassettes, IPG +1 well 1.0 mm (345- 
9906). The strips were loaded onto the polymerized gels after a quick immersion in $1 \mathrm{X}$ running buffer (see Appendix A.3.d), making sure the (-) side was placed on right side of the gel. An IEF electrode wick (165-4071) containing low range molecular weight standard (161-0304, see Appendix A.3.e) was placed in the far left side of the gel, which was covered with melted $0.8 \%$ agarose containing Laemmeli SDS electrophoresis buffer (25 mmol/L tris-base, $192 \mathrm{mmol} / \mathrm{L}$ glycine, 0.1\% SDS, Appendix A.3.f). Once the agarose was solidified, the cassettes were placed inside a BioRad Criterion Dodeca cell and filled with $1 \mathrm{x}$ buffer. The dodeca box was connected to a cooling system (HAAKE K10, Thermo Scientific, IA, USA) set at $10^{\circ} \mathrm{C}$, and slow stirring was initiated. The unit was connected into a BioRad Power Pac HC and set at 200V constant current for approximately $55 \mathrm{~min}$, or until the blue loading dye reached the bottom of the gel.

\section{Sensitive Stepwise Colloidal Staining}

An adapted protocol described by Westermeier (2006) was utilized for visualization (Westermeier, 2006). The gels were washed three times in nanopure water for five min to remove any remaining detergent followed by overnight fixing in a 50\% ethanol/3\% phosphoric acid solution. Upon incubation, the gels were washed three times for 20 minutes with nanopure water and pre-incubated for hour in staining solution $(34 \%(\mathrm{v} / \mathrm{v})$ $\mathrm{CH}_{3} \mathrm{OH} / 3 \%(\mathrm{v} / \mathrm{v}), \mathrm{H}_{3} \mathrm{PO}_{4} / 17 \%$ (w/v) $\left(\mathrm{NH}_{4}\right)_{2} \mathrm{SO}_{4}$, see Appendix A.5). Then, Coomassie brilliant blue G-250 powder (BP-100, Fisher Biotech) was added at a final concentration of $350 \mathrm{mg}$ per liter of staining solution. The gels were stained for 5 days on a rotator shaker at room temperature. Upon staining, the gels were washed three times with nanopure water for 20 min. Images were captured with an Epson scanner (Epson Expression 1680) in conjunction with Epson Scan Software in professional mode. 


\section{Fluorescent Staining-Sypro-Ruby}

The gels were washed three times in nanopure water for five min to remove any remaining detergent followed by overnight fixing in 10\% methanol/7\% acetic acid, v/v, $(100 \mathrm{~mL}$ per gel) in a clean plastic staining tray. Incubation was performed over a rotational shaker at room temperature, making sure the gels were protected from light during the staining protocol. Upon incubation, the fixing solution was replaced with diluted SYPRO Ruby (170-3127, Biorad, 1:5 with nanopure water) solution. After overnight incubation at room temperature, the gels were transferred into a new clean container to minimize the deposition of stain speckles and washed three times with $10 \%$ methanol/ 7\% acetic acid, $\mathrm{v} / \mathrm{v}$, for $30 \mathrm{~min}$ each at room temperature and rotation at 40 rpm. After washing, the gels were transferred into a large volume of nanopure water to remove methanol and rotated for $10 \mathrm{~min}$.

The gels were scanned with Typhoon Trio $^{+}$variable mode imager (98115, Amersham Biosciences). The Typhoon was allowed to warm up for 20 minutes, and the following scanning parameters were selected: fluorescence acquisition mode; 610 BP30 deeppurple, SYPRO Ruby, EtBr emission filter; 575 PMT; blue $532 \mathrm{~nm}$ laser; normal sensitivity; 200 microns pixels; platen focal plane, and ImageQuant analysis. The glass surface was washed with $70 \%$ ethanol followed with $\mathrm{dH}_{2} \mathrm{O}$, and the gels were placed face down, removing bubbles and blotting puddles around edges with Kimwipe. Once scanning was complete, the file was saved and reopened in ImageQuant 5.2 (Amersham Biosciences) to save them as "tif" files. 


\section{2-DE Gel Image \& Statistical Analysis}

Digitized two-dimensional gel images were analyzed using Delta 2D (version 4.0.8 final 06, Decodon, Greifswald, Germany). The images were imported and connected through match vectors using Group Warping Strategy. Then, all the images were fused to a composite image (proteome map, which represents average volume for each spot) by using Union as fusion type, which adjusts the common regions and eliminates background. After background subtraction, protein spot volumes were normalized against total spot volume of all proteins in a gel image.

Normalized spot volumes were analyzed using an analysis of variance (two-factor ANOVA) for all the treatment. A second statistical analysis was done with all the treatments except UHT because this heat process caused many changes in protein levels, making difficult to overlap gel images. In addition, a two-way ANOVA was performed between Fresh milk and each treatment for a total of seven statistical analyses. For all the analyses, a null distribution was generated using 1000 permutations, and a p-value of $<$ 0.01 was used to limit the number of false positives. To construct a hierarchical clustering, Pearson correlation, and average linking within the statistical tool suite within Delta2D was used.

\section{Protein Excision \& Digestion from SDS-PAGE}

The reagents were of LC/MS grade and kept at room temperature unless otherwise indicated. Eppendorf Safe-Lock microcentrifuge tubes and tips were used to avoid plastic contamination, and glassware was washed with appropriate solvents before use. Proteins with different expression levels were excised from SDS-PAGE gels using a manual tissue arrager puncher (MP15-1.5 mm diameter, Beecher Instruments, Prairie, WI, USA). The 
gels were placed over a gel sheet (165-7018, BioRad) during excision. The gel plugs were stored at $-20^{\circ} \mathrm{C}$.

The gel plugs were thawed, and $200 \mu \mathrm{L}$ of destaining buffer $\left(25 \mathrm{mM} \mathrm{NH}_{4} \mathrm{HCO}_{3} / 50 \%\right.$ acetonitrile, see Appendix A.6.a) were added to each tube. Vials were incubated on shaker at room temperature for $30 \mathrm{~min}$. Upon incubation, the liquid was pipetted out and discarded carefully without discarding the gel plug. If Coomassie stain was still noticeable, an additional destaining step was performed. To dehydrate the plugs, $200 \mu \mathrm{L}$ of $100 \%$ acetonitrile was added to each vial and incubated at room temperature for 10 min. This step was repeated if the gel was not dehydrated, as seen by semi-clear gel plugs. The acetonitrile was discarded, and the samples were allowed to dry completely under the hood for a few minutes with the tube open. To digest the proteins, $15 \mu \mathrm{L}$ of prepared trypsin solution in a $40 \mathrm{mM} \mathrm{NH}_{4} \mathrm{HCO}_{3} / 10 \%$ acetonitrile was added to the bottom of vials at a final concentration of $11 \mu \mathrm{g} / \mu \mathrm{L}$ (see Appendix A.6.c ); vials were incubated at $37^{\circ} \mathrm{C}$ overnight. Upon incubation, the liquid containing the digested protein was transferred into a fresh Eppendorf tube ( $0.6 \mathrm{ml})$, and $25 \mu \mathrm{l}$ of analyte solution (0.1\% TFA/ acetonitrile 2:1 v/v, see Appendix A.6.b) was added to each sample to elute the remaining peptides out of the gel. Samples were incubated for $30 \mathrm{~min}$ at room temperature, and peptide elution was repeated after removing the liquid and consolidating into the collection tube. The consolidated sample $(\sim 65 \mu \mathrm{L})$ was concentrated in a SpeedVac (Eppendorf Vacufuge TM AG 22331, USA) at $45^{\circ} \mathrm{C}$ for 50-60 min. Once the samples were dry, six and $12 \mu \mathrm{L}$ of freshly prepared matrix solution (HCCA, hydroxycyanocinnamic acid, see Appendix A.6.e) were added to each sample and peptide calibration standard (see Appendix A.6.d), respectively. On an AnchorchipTM Target (MTP Anchorchip 600/384 targus, Bruker DaltonicsPlate), one $\mu \mathrm{L}$ of this matrix/analyte 
sample was plated in duplicates onto the $600 \mu \mathrm{m}$ anchors. Samples were allowed to dry under the hood. One replicate of standards and samples was rinsed gently with $10 \mu \mathrm{L}$ of wash buffer (1.15 $\mathrm{NH}_{4} \mathrm{H}_{2} \mathrm{PO}_{4} \mathrm{mg} / \mathrm{mL} 0.1 \% \mathrm{TFA}$, see Appendix A.6.f) by pipetting up and down twice without touching the sample on the target. After drying, the matrix was recrystalized by adding one $\mu \mathrm{L}$ of recrystalization buffer (see Appendix A.6.g) directly to each spot on the target. Spots were allowed to dry before placing in the M/S analysis.

\section{Mass Spectrometry-Protein Identification with MALDI-TOF}

Peptide mass fingerprints (PMGs) were obtained by using a matrix-assisted laser desorption ionization (MALDI) mass spectrometer (Ultraflex II, Bruker Daltonics Inc., Billerica, MA, USA). Twelve peptides were chosen to conduct tandem mass spectrometry (time of flight, TOF) in order to obtain formation about the b- and y-ions of the peptide sequence. Peptide spectra were analyzed with FlexAnalysis (version 3.0, Bruker Daltonics, Inc.) and applied the TopHat algorithm for baseline subtraction, the Savitzky-Golay analysis (with $0.2 \mathrm{~m} / \mathrm{z}$; number of cycles =1) for smoothing and the SNAP algorithm to detect peaks (signal-to-noise ratio: 6 for MS and 1.5 for MS/MS). The charge state of the peptides was assumed to be +1 , and porcine trypsin was used as an internal standard.

Proteins were identified using Mascot (version 3.1, Matrix Science inc., MA, USA) and combined PMFs and tandem mass spectra in a search against NCBI database for Bos taurus. Oxidation of methionine and carbamidomethylation of cysteine were selected as variable modifications, and one missed cleavage during trypsin digestion was allowed. The precursor-ion mass tolerance was set to 0.6 Da for tandem mass spectrometry, and two matched peptides was the lower limit for a significant hit that indicates a positive identification. Most identifications were to bovine sequences although some matches to 
other mammals were accepted if there was not a corresponding bovine sequence in the database. Theoretical pI and molecular weight were predicted using Compute $\mathrm{pI} / \mathrm{Mw}$ in monoisotopic mode at www.expasy.ch. 


\section{RESULTS}

\section{A. Microbial Reduction in Milk}

The efficiency of UV pulsed light to kill aerobic microorganisms was compared to batch, HTST, and UHT pasteurization as seen in Figure 15. In non-transparent fluids, such as milk, the depth of the sample is critical in determining the penetration of irradiation, thus, milk was treated with different pulse times (seconds, s) at different volumes. While conventional methods were able to achieve a log reduction, UV light treatment only reduced $44 \%$ of the initial microbial population present in raw milk. Nevertheless, a decrease in microbial growth is seen as the volume of the sample is reduced.

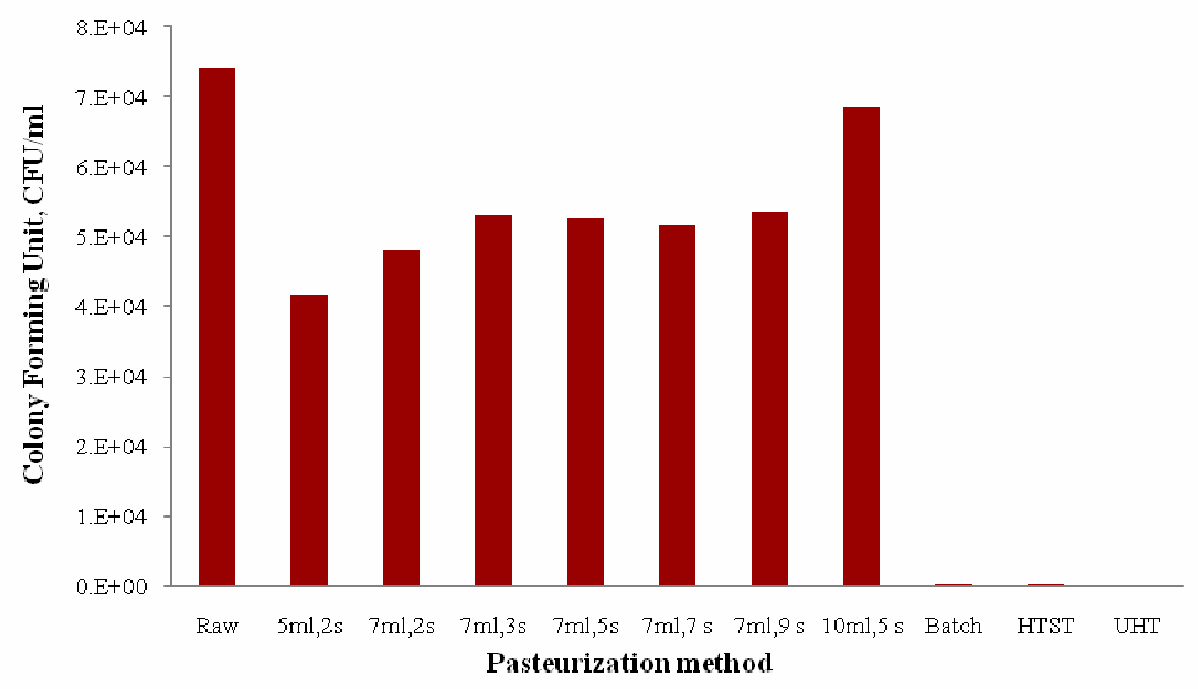

Figure 15. Aerobic bacterial counts in pasteurized and UV pulsed light treated milk. The volume is shown in $\mathrm{ml}$, and the irradiation time is in seconds (s). Each second delivers three Joules $/ \mathrm{cm}^{2}$. Counts after $48 \mathrm{hrs}$ of incubation at $37^{\circ} \mathrm{C}$.

The microbial reduction of coliforms was also determined with UV irradiation (Figure 16). No coliforms were seen in milk after treatment with the conventional methods. On the other hand, a different pattern was observed in the microbial reduction 
with UV pulsed light. The highest reduction was seen in the $7 \mathrm{~mL} / 9 \mathrm{sec}$ milk sample with a $22 \%$ decrease in microbial population.

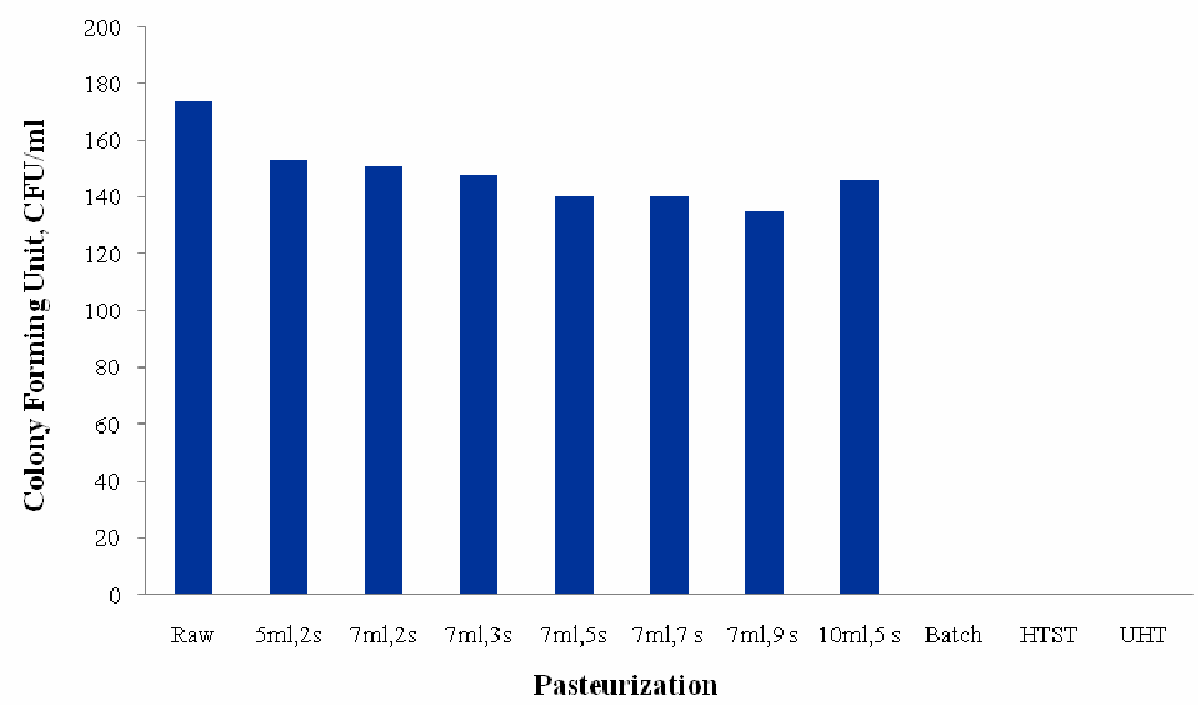

Figure 16. Coliform counts in pasteurized and UV pulsed light treated milk. The volume is shown in $\mathrm{ml}$, and the irradiation time is in seconds (s). Each second delivers three Joules $/ \mathrm{cm}^{2}$. A $22 \%$ reduction is observed in the $7 \mathrm{ml} / 9 \mathrm{sec} \mathrm{UV}$ pulsed treated sample. Counts after $24 \mathrm{hrs}$ of incubation at $37^{\circ} \mathrm{C}$.

To determine the best parameters that allow processing a high volume of samples and decreasing the microbial population, a second study was performed with different sample volumes and irradiation times. As seen in Figure 17, a 7mL-sample with UV energy of 15 Joules $/ \mathrm{cm}^{2}$ resulted in the highest microbial reduction among the treated samples. This treatment was significantly different from the raw material $(\mathrm{p}<0.0001)$, with a $70 \%$ decrease in microbial population. 


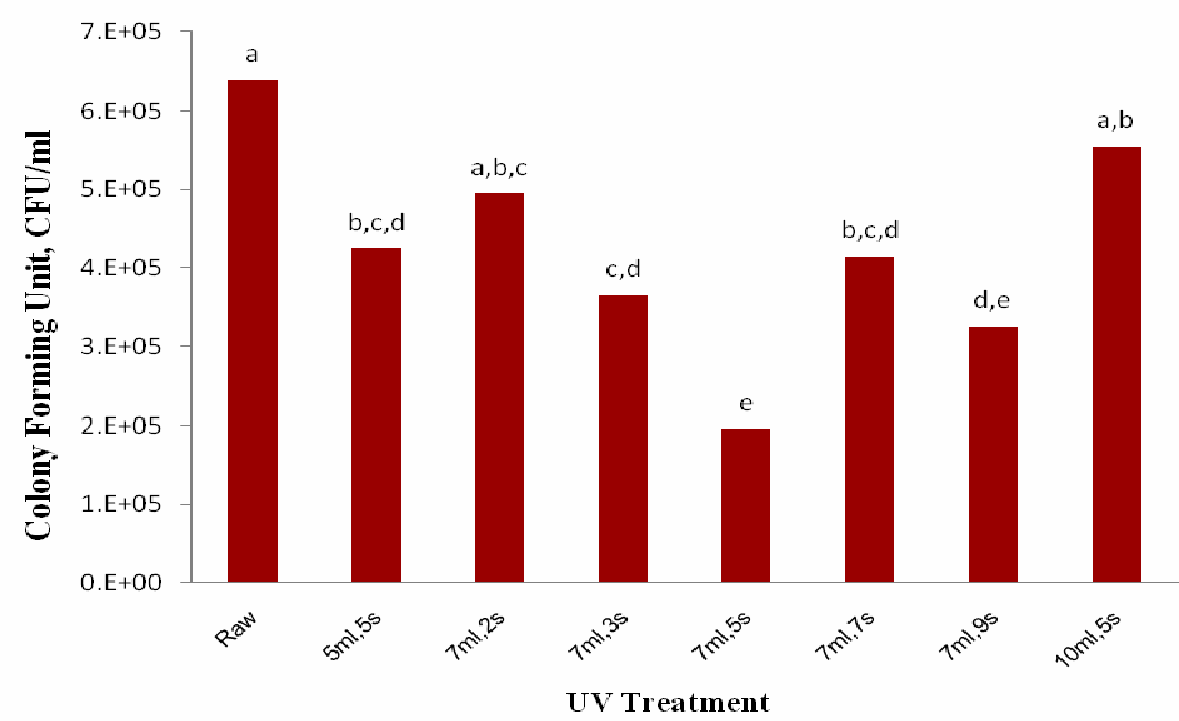

Figure 17. Microbial reduction in aerobic bacteria in UV pulsed treated milk. The volume is shown in $\mathrm{ml}$, and the irradiation time is in seconds (s). Each second delivers three Joules $/ \mathrm{cm}^{2}$. Counts after $48 \mathrm{hrs}$ of incubation at $37^{\circ} \mathrm{C}$. Statistically significant difference in samples is denoted by $(\mathbf{p}<0.0001)$

With regard to coliforms, the highest reduction, $53 \%$, is seen in a $5 \mathrm{~mL}$ sample with 15 Joules $/ \mathrm{cm}^{2}$ of energy followed by the $7 \mathrm{~mL} / 5 \mathrm{sec}$ sample with a $44 \%$ decrease in microbial population as depicted in Figure 18. If the volume is held constant, higher irradiation times are more efficient in killing coliforms and aerobic bacteria; however, higher energy intensities results in more bacterial counts. In fact, in both aerobic and coliforms, 21 Joules $/ \mathrm{cm}^{2}(7 \mathrm{~s})$ of energy is the turning point to observe more CFU. Experiments in our laboratory have demonstrated that higher energy intensities result in spore germination (data not shown). This may explain the higher CFU counts observed in samples that received more energy. There is not a linear relationship that explains this observation, but it can be expected that higher energy intensities at a constant volume may result in similar outcomes. 


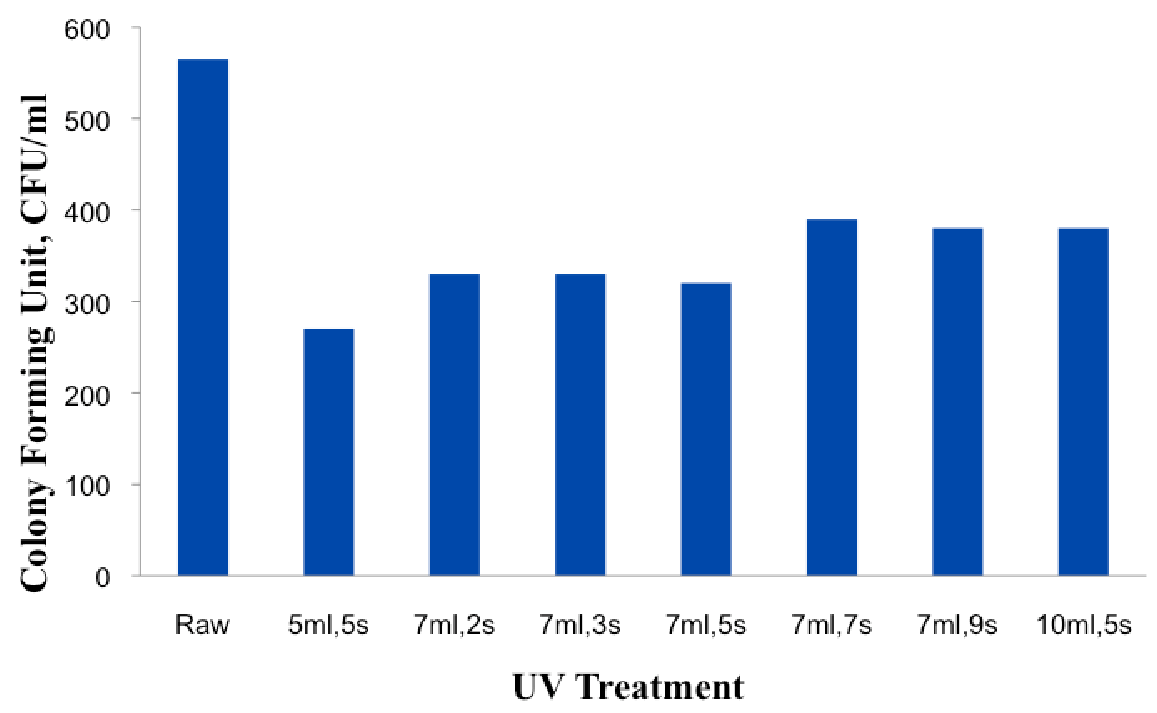

Figure 18. Microbial reduction in coliforms in UV pulsed treated milk. The volume is shown in $\mathrm{ml}$, and the irradiation time is in seconds (s). Each second delivers three Joules/cm ${ }^{2}$. Counts after $24 \mathrm{hrs}$ of incubation at $37^{\circ} \mathrm{C}$.

\section{B. Fat Globule Size Distribution in Milk Processing}

The dispersion of MFG size in processed whole milk, cream, and skim milk was analyzed with five parameters: the volume-weighted average diameter $\left(d_{4,3}\right)$, the volumesurface average diameter $\left(d_{3,2}\right)$, the mode, the specific surface area (SSA), and the size distribution width (Span). To eliminate an apparent increase in the average globule diameter, a chelating agent, EDTA, was used to sequester $\mathrm{Ca}^{+2}$ and dissolve casein micelles, which range between 130 and $206 \mu \mathrm{m}$ (Gassi et al., 2008). Disintegration of casein micelles diminishes fat globule aggregation formation through casein interaction. Figure 19 illustrates the percent volume of whole milk fat globules (MFG) as a function of particle diameter $(\mu \mathrm{m})$ in milk for the six treatments. The plot resembles a Gaussian distribution, which is in accordance with previous studies with milk (Mènard et al., 2010; Garcia-Amezquita et al., 2009). The fat globules range from $0.4 \mu \mathrm{m}$ to $10 \mu \mathrm{m}$, and similar distributions were observed among the trials. 


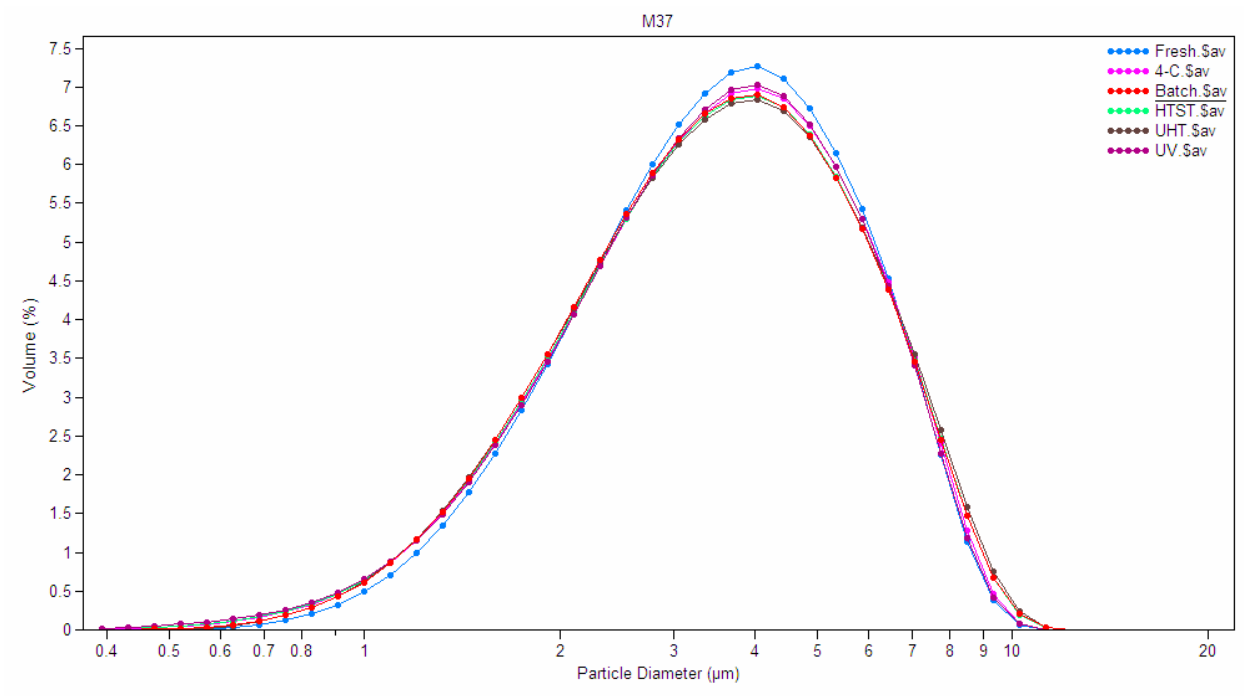

Figure 19. Milk fat globule (MFG) size distribution (volume \%) in milk as a function of particle diameter $(\mu \mathrm{m})$. Data for Trial II. Similar results were observed with the other trials (I, III, and IV). Values are average of tree measurements.

A visual analysis does not indicate a vast change, but statistical analysis of the five parameters determined a significant difference in the volume-surface average diameter, $\mathrm{d}_{3,2}$, which is sensitive to smaller particles $(\mathrm{p}<0.001)$, and consequently in the specific surface area $(\mathrm{SSA})(\mathrm{p}<0.001)$ of milk (Table 8). The Fresh sample has the highest $\mathrm{d}_{3,2}$ and smallest specific surface area indicating a difference in the active surface of the fat globules.

Table 8. Parameters that describe the fat globule size distribution in milk.

\begin{tabular}{lccccc}
\hline Treatment & $\begin{array}{c}\mathbf{D}(\mathbf{3 , 2}) \\
\boldsymbol{\mu m}\end{array}$ & $\begin{array}{c}\text { Mode } \\
\boldsymbol{\mu m}\end{array}$ & $\begin{array}{c}\text { SSA } \\
\mathbf{c m}^{2} / \mathbf{m L}\end{array}$ & $\begin{array}{c}\mathbf{D}(\mathbf{4 , 3}) \\
\boldsymbol{\mu m}\end{array}$ & SPAN \\
\hline Fresh & $3.02^{\mathrm{a}}$ & 4.05 & $19890^{\mathrm{b}}$ & 3.89 & 1.33 \\
4C & $2.90^{\mathrm{b}}$ & 3.93 & $20700^{\mathrm{a}}$ & 3.83 & 1.39 \\
Batch & $2.91^{\mathrm{b}}$ & 3.93 & $20590^{\mathrm{a}}$ & 3.83 & 1.38 \\
HTST & $2.91^{\mathrm{b}}$ & 3.93 & $20600^{\mathrm{a}}$ & 3.89 & 1.40 \\
UHT & $2.92^{\mathrm{b}}$ & 3.93 & $20543^{\mathrm{a}}$ & 3.86 & 1.41 \\
UV & $2.88^{\mathrm{b}}$ & 3.93 & $20838^{\mathrm{a}}$ & 3.85 & 1.41 \\
$\mathrm{~s} /{ }^{\circ} \mathrm{N}$ & 0.01 & 0.05 & 103 & 0.03 & 0.02 \\
\hline
\end{tabular}

$\mathrm{s} / \bullet \mathrm{N}$, standard error of mean among treatments. $\mathrm{N}$, sample size, three trials $\left(d_{4,3}\right)$, volume-weighted average diameter; $\left(d_{3,2}\right)$, volume-surface average;

SSA, specific surface area; SPAN, size distribution width.

Means with different subscripts within a column are statistically different $(\mathrm{p}<0.05)$. 
Despite the variation observed in whole milk, no significant difference $(\mathrm{p}<0.05)$ was described in the particle size distribution of isolated creams, which ranges from $0.4 \mu \mathrm{m}$ to $200 \mu \mathrm{m}$ depending on the treatment (Figure 20). Three peaks are visible in the fat globules distribution that center at $4 \mu \mathrm{m}, 35 \mu \mathrm{m}$, and at about $70 \mu \mathrm{m}$. The first peak belongs to the regular fat globules diameters (Lopez et al., 2010b) while the other two peaks are expected to be medium and large fat globule aggregates. The third peak distribution is very prominent in milk that underwent heat pasteurization, especially in HTST and batch milks with a center at about $90 \mu \mathrm{m}$ and $100 \mu \mathrm{m}$, respectively. UHT milk follows a similar pattern, but the large fat aggregates peak at $60 \mu \mathrm{m}$. The samples that did not undergo heat treatment have a higher percent volume in the normal size fat globule range. In fact, the Fresh and UV samples depict fewer fat aggregates at the $35 \mu \mathrm{m}$ and 70 $\mu \mathrm{m}$ peaks whereas the $4^{\circ} \mathrm{C}$ sample shows a higher percent volume in the $100 \mu \mathrm{m}$ fat globule diameter region. Unfortunately, no trials were performed with $1 \%$ SDS to measure individual fat globule diameter. SDS dissociates fat globule aggregates by providing a net negative charge on the surface of globules that inhibits agglomeration. In addition, the samples that underwent heat treatment present smaller fat globules $(<0.5$ $\mu \mathrm{m})$, which may correspond to vesicles formed by MFGM fragments composed of phospholipids and proteins. 


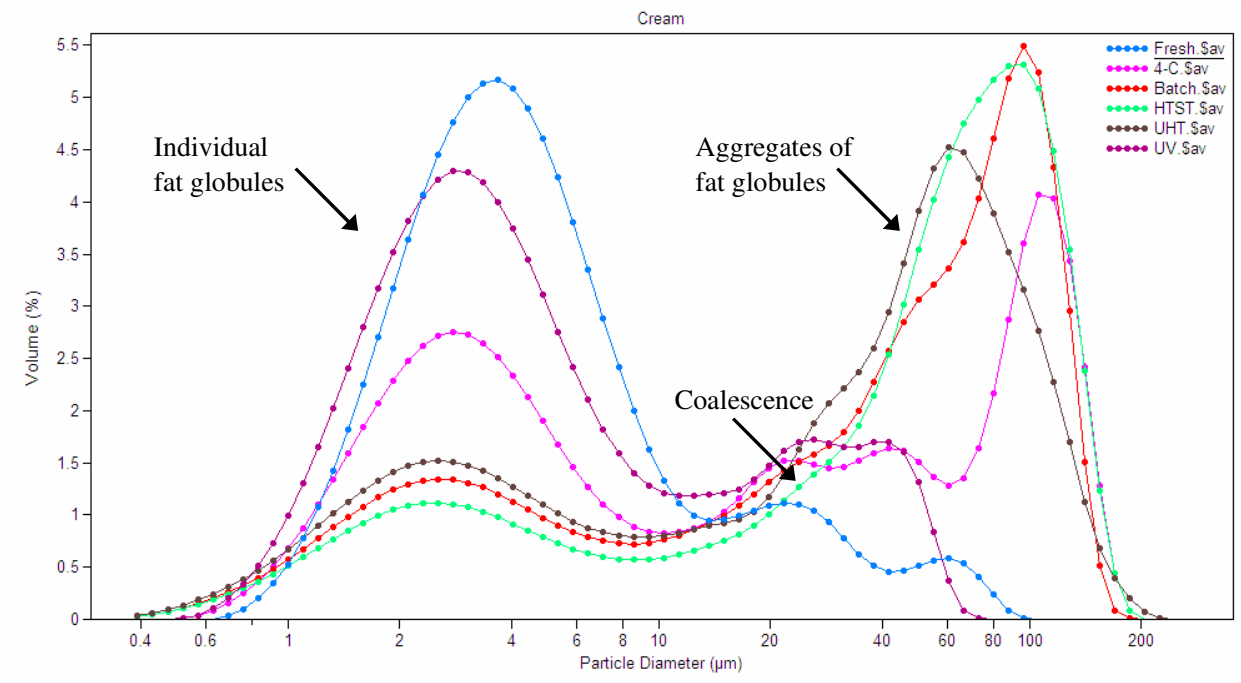

Figure 20. Fat globule (FG) size distribution of $40 \%$ cream as a function of particle diameter $(\mu \mathrm{m})$. Data are shown for Trial IV. Similar results observed for other trials.

As previously observed with whole milk, similar fat globule size distribution patterns were obtained with cream among the trials (Appendix E). The Fresh sample has smallest volume-weighted average diameter $\left(d_{43}\right)$, volume-surface average diameter $\left(d_{3,2}\right)$, mode, and size distribution width (SPAN), but these results are not significantly different from the other treatments (Table 9).

Table 9. Parameters that describe the fat globule size distribution in $40 \%$ cream.

\begin{tabular}{lccccc}
\hline Treatment & $\begin{array}{c}\mathbf{D}(\mathbf{3 , 2}) \\
\boldsymbol{\mu m}\end{array}$ & $\begin{array}{c}\text { Mode } \\
\boldsymbol{\mu m}\end{array}$ & $\begin{array}{c}\text { SSA } \\
\mathbf{c m}^{2} / \mathbf{m L}\end{array}$ & $\begin{array}{c}\mathbf{D}(\mathbf{4 , 3}) \\
\boldsymbol{\mu m}\end{array}$ & SPAN \\
\hline Fresh & 3.23 & 3.63 & 18657 & 6.19 & 3.32 \\
4C & 4.17 & 21.89 & 15429 & 18.80 & 5.52 \\
Batch & 4.16 & 28.88 & 15308 & 19.26 & 3.57 \\
HTST & 4.13 & 50.07 & 15383 & 21.59 & 4.34 \\
UHT & 4.27 & 39.19 & 15150 & 23.44 & 3.35 \\
UV & 4.21 & 27.85 & 15264 & 16.72 & 4.69 \\
s/•N & 0.34 & 13.94 & 1058 & 3.86 & 0.94 \\
\hline
\end{tabular}

$\mathrm{s} / \bullet \mathrm{N}$, standard error of mean among treatments. N, sample size.

$\left(d_{4,3}\right)$, volume-weighted average diameter; $\left(d_{3,2}\right)$, volume-surface average;

SSA, specific surface area; SPAN, size distribution width.

A change in the simulated Gaussian plot distribution of fat globules indicates a change in globule size (Evers, 2004b). Statistically, there is not significant difference, 
probably due to the way the data is analyzed; the measured parameters only indicate a central tendency that does not take into account different regions. Figure 20 clearly shows a defined pattern in cream, so with a novel analysis by Garcia-Amezquita et al. (2009) a difference may be seen. They analyzed MFG size distribution by dividing the plot into four areas: smallest globules $(0.1-1 \mu \mathrm{m})$, medium size globules $(2-4 \mu \mathrm{m})$, large globules $(5-11 \mu \mathrm{m})$, and out of range globules $(20-70 \mu \mathrm{m})$. For this data set, four distinct areas are seen: small globules $(0.4-1.0 \mu \mathrm{m})$, mid-large globules $(1.5-10 \mu \mathrm{m})$, out of range $(20-60$ $\mu \mathrm{m})$, and aggregated globules $(70-200 \mu \mathrm{m})$.

The centrifugation of milk, which was performed at 7,000g to concentrate fat globules, left residual fat globules with normal particle diameter $(0.4$ to $10 \mu \mathrm{m})$ and globules with bigger diameter (40 to $250 \mu \mathrm{m}$, fat globules aggregates) in the skim milk as seen in Figure 21.

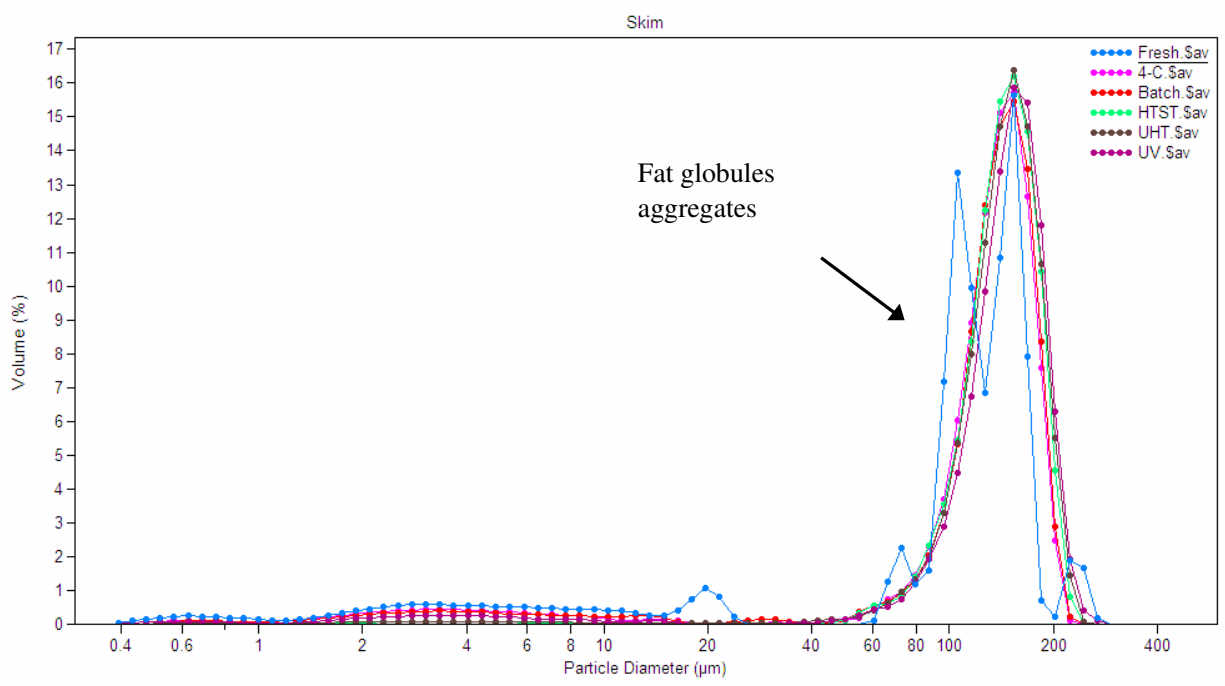

Figure 21. Fat globule (FG) size distribution in skim milk showing residual fat globules aggregates and normal size fat globules.

Table 10 presents the calculated parameters that describe the size distribution in skim milk. Even though the data is not statistically different $(\mathrm{p}>0.05)$, the modal diameter is 
lower in UHT milk compared to other treatments. In regard to surface-volume, smaller values are observed for cooling temperature as well as UHT treatment.

Table 10. Parameters calculated from the size distributions of fat globules in skim milk.

\begin{tabular}{lccccc}
\hline Treatment & $\begin{array}{c}\mathbf{D}(\mathbf{3 , 2}) \\
\boldsymbol{\mu \mathbf { m }}\end{array}$ & $\begin{array}{c}\text { Mode } \\
\boldsymbol{\mu m}\end{array}$ & $\begin{array}{c}\text { SSA } \\
\mathbf{c m}^{2} / \mathbf{m L}\end{array}$ & $\begin{array}{c}\mathbf{D}(\mathbf{4 , 3}) \\
\boldsymbol{\mu m}\end{array}$ & SPAN \\
\hline Fresh & 50.83 & 146.95 & 2297 & 122.47 & 0.86 \\
4C & 18.77 & 140.93 & 3629 & 115.38 & 0.88 \\
Batch & 66.32 & 143.29 & 1412 & 130.33 & 0.70 \\
HTST & 62.12 & 144.81 & 2013 & 127.12 & 0.83 \\
UHT & 24.23 & 95.21 & 2556 & 79.03 & 1.55 \\
UV & 48.61 & 149.53 & 2771 & 124.76 & 0.92 \\
s/•N & 25.48 & 2.77 & 1148 & 18.01 & 0.32 \\
\hline
\end{tabular}

$\mathrm{s} / \bullet \mathrm{N}$, standard error of mean among treatments. N, sample size.

$\left(d_{4,3}\right)$, volume-weighted average diameter; $\left(d_{3,2}\right)$, volume-surface average;

SSA, specific surface area; SPAN, size distribution width.

\section{Chemical Composition of Milk during Milk Processing}

\section{Milk Composition by FTIR Analysis}

The fat, lactose, total solid, and protein content of milk were measured using a FTIR instrument. No significant difference was seen in the above parameters among the samples, as indicated in Table 11. On the other hand, FTIR artifact of $\beta$-lactoglobulin and casein complexes results in a lower casein content for the ultra high temperature (UHT) milk ( $\mathrm{p}=0.05)$. Citric acid content also shows a marginal difference $(\mathrm{p}=0.05)$, especially in UHT milk, but such observations are attributed to detection limits of FTIR, as it has been shown that citric acid does not change with heating (Sommer and Hart, 1918). In addition, the urea content is high in UHT milk $(\mathrm{p}<0.0001)$ probably due to induced protein catabolism at $121{ }^{\circ} \mathrm{C}$ and $15 \mathrm{psi}$, as urea naturally decomposes into ammonia and carbon dioxide (Metwalli et al., 1996; Metwalli and van Boekel, 1998). With regard to free fatty acids (FFA), a significant lower content is observed in Fresh and UHT 
compared to the other treatments $(\mathrm{p}<0.0001)$. Similar findings were described in previous studies (Burton, 1988; Kintner and Day, 1965).

Table 11. Fat, lactose, total solid, and protein content of milk during milk processing.

\begin{tabular}{|c|c|c|c|c|c|c|c|c|c|c|c|c|}
\hline \multirow[b]{2}{*}{ Sample } & \multicolumn{7}{|c|}{ g/100 mL milk } & \multirow{2}{*}{$\begin{array}{c}\text { Acidity } \\
{ }^{\circ} \mathbf{T H}\end{array}$} & \multirow{2}{*}{$\begin{array}{c}\text { Urea } \\
\mathbf{m g} / \mathbf{d L}\end{array}$} & \multirow{2}{*}{$\begin{array}{c}\text { Density } \\
\text { SG }\end{array}$} & \multirow{2}{*}{$\begin{array}{c}\text { FPD } \\
\text { mC }\end{array}$} & \multirow{2}{*}{$\begin{array}{c}\text { FFA } \\
\text { mEkv/l }\end{array}$} \\
\hline & Fat & Prot & Cas & Citric & Lac & TS & SNF & & & & & \\
\hline Fresh & 3.82 & 3.34 & $2.46^{a, b}$ & $0.17^{\mathrm{a}, \mathrm{b}}$ & 4.78 & 12.94 & 8.88 & 16.29 & $365^{\mathrm{b}}$ & 1028.41 & 515.94 & $0.294^{\mathrm{b}}$ \\
\hline $4-\mathrm{C}$ & 3.91 & 3.34 & $2.43^{a, b}$ & $0.17^{\mathrm{a}, \mathrm{b}}$ & 4.76 & 13.04 & 8.99 & 15.86 & $320^{\mathrm{c}}$ & 1028.41 & 513.56 & $0.450^{\mathrm{a}}$ \\
\hline Batch & 3.95 & 3.40 & $2.54^{a, b}$ & $0.18^{\mathrm{a}, \mathrm{b}}$ & 4.86 & 13.22 & 9.13 & 15.63 & $347^{\mathrm{b}, \mathrm{c}}$ & 1029.26 & 522.44 & $0.517^{\mathrm{a}}$ \\
\hline HTST & 3.88 & 3.25 & $2.35^{\mathrm{b}}$ & $0.17^{\mathrm{b}}$ & 4.64 & 12.78 & 8.76 & 15.68 & $327^{\mathrm{b}, \mathrm{c}}$ & 1027.51 & 495.56 & $0.438^{a}$ \\
\hline UHT & 3.94 & 3.39 & $2.65^{\mathrm{a}}$ & $0.19^{\mathrm{a}}$ & 4.75 & 13.10 & 9.00 & 15.83 & $437^{\mathrm{a}}$ & 1028.85 & 521.06 & $0.324^{b}$ \\
\hline UV & 3.90 & 3.36 & $2.48^{a, b}$ & $0.17^{\mathrm{a}, \mathrm{b}}$ & 4.78 & 13.04 & 9.01 & 15.71 & $332^{b, c}$ & 1028.72 & 513.00 & $0.535^{\mathrm{a}}$ \\
\hline $\mathrm{S} / \bullet(\mathrm{N})$ & 0.17 & 0.04 & 0.05 & 0.00 & 0.05 & 0.22 & 0.09 & 0.18 & 7.19 & 0.35 & 6.75 & 0.02 \\
\hline
\end{tabular}

Prot, protein; Cas, casein; Citric, citric acid; Lac, lactose; TS, total solid; SNF, solid nonfat; FPD, freezing point depression; FFA, free fatty acid;

${ }^{\circ} \mathrm{TH}$, Thorner degrees; SG, specific gravity; mEkv/l, milliequivalents/l

$\mathrm{S} / \bullet(\mathrm{N})$, standard deviation of the mean, which was calculated from three independent trials

Subscripts within a column indicate statistically significant values $(\mathrm{p}<0.05)$

\section{Isolation of Milk Fat Globule Membrane}

The isolated MFGM material was not in accordance with previous reports mainly due to the extraction procedure, which did not include washes (Kitchen, 1977; SánchezJuanes et al., 2009); however, the MFGM isolates in this project differed depending on the sample's temperature, as observed by Kim and Jiménez (1995). They described that higher temperatures resulted in less membrane and more insoluble product. In fact, there was a clear reduction in the isolated MFGM pellet as the pasteurization temperature increased. Figure 22 illustrates and compares the extracted MFGM where the UHT isolate is significantly different from the other treatments $(\mathrm{p}<0.0001)$. As pasteurization temperatures increased, the final MFGM material decreased. Samples without heat treatment, such as Fresh, $4{ }^{\circ} \mathrm{C}$, and cold pasteurization UV, had higher membrane material than those where heat was applied. 


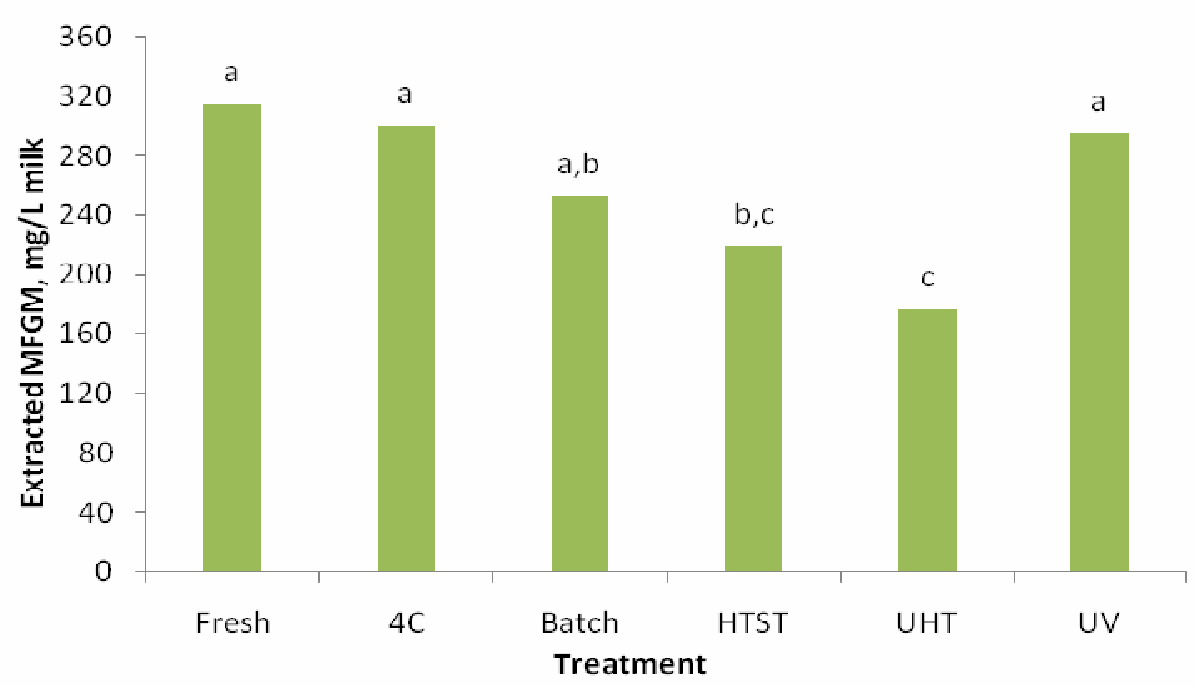

Figure 22. MFGM isolates of samples collected during milk processing. Values represent the mean weight of dry membrane material of four independent experiments, expressed as mg of MFGM (pellet upon ultracentrifugation) per liter of milk. Samples with different subscript are statistically significant different $(p<0.0001)$.

A discoloration was also observed in samples that underwent heat treatment, especially UHT (Figure 23). Corredig and Dalgleish (1998) also reported similar results in heated samples. According to their findings, the color of the MFGM material changed from brown-red in unheated isolates to white-yellow in samples derived from high heat treatments. They attributed the discoloration to the loss of iron content in the MFGM and hypothesized that heat induces the release of iron from xanthine oxidase, a metalloflavo protein, which has four residues holding iron molecules. Structural changes due to XO denaturation liberate iron as a function of heating temperatures since a decrease in iron is seen in temperatures as low as $62^{\circ} \mathrm{C}$. It also exposes the sulfhydryl bonds for chemical interchange and further denaturation. Unfortunately in this project, the iron content was not measured to correlate such observations. Discoloration was more intense in UHT followed by HTST samples. 


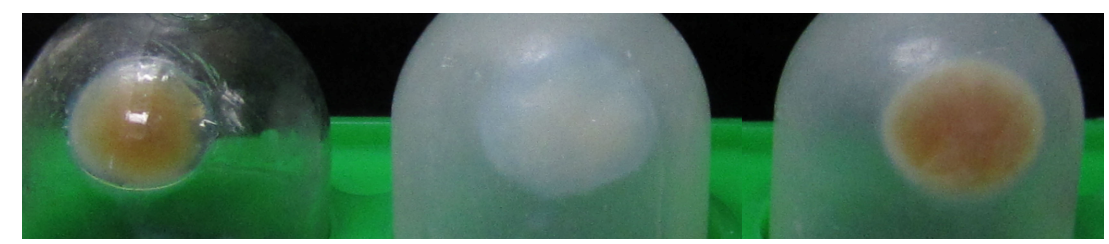

Figure 23. Final MFGM material isolated from milk following a modified protocol by Patton et al. (1986). From left to right: Fresh, UHT, and UV MFGM pellets.

\section{Changes in the Amount of Protein in the Milk Fat Globule Membrane}

The extracted MFGM material was collected as pellet, and the amount of protein was measured using a colorimetric assay. Figure 24 illustrates the amount of protein present in each isolate where HTST had the highest amount of protein per $100 \mathrm{mg}$ of MFGM pellet $(\mathrm{p}<0.0001)$ and Fresh the lowest amount.

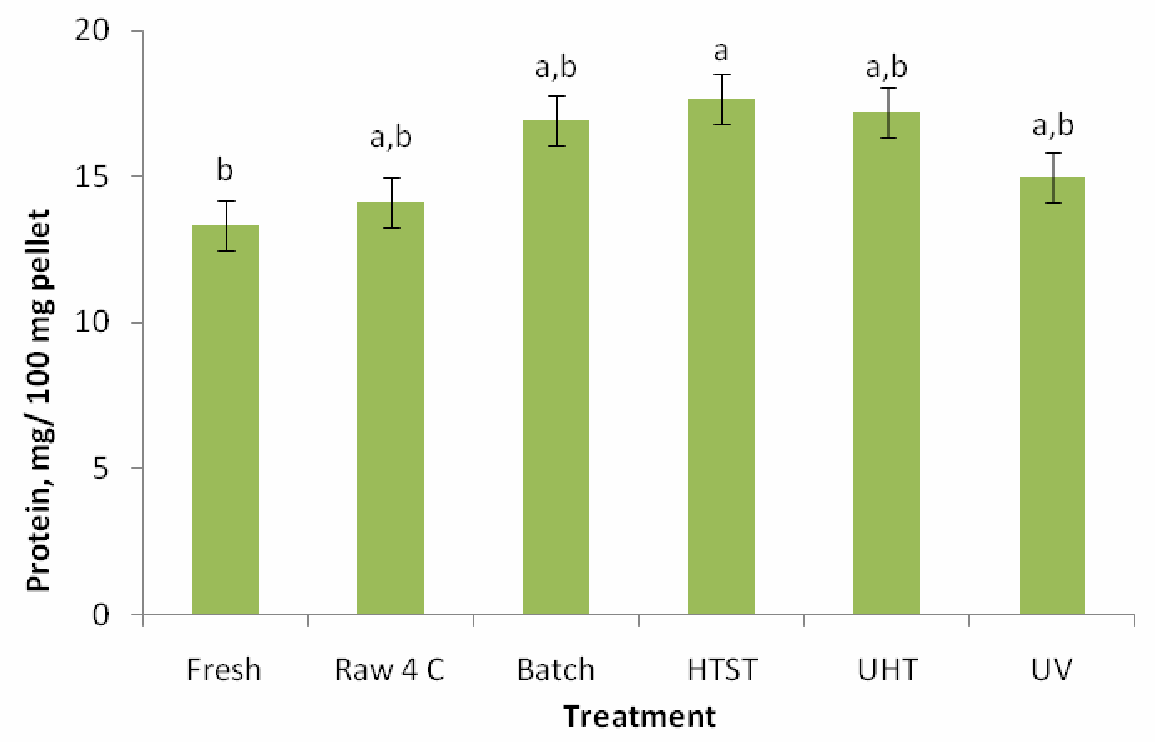

Figure 24. Effect of milk processing on the amount of protein in the milk fat globule membrane. Values represent the mean of three independent experiments, expressed as $\mathrm{mg}$ of protein per $100 \mathrm{mg}$ of MFGM pellet. Samples with different subscript are statistically significant different ( $p<0.0001 ; n=3$ experiments; $n=3$ measurement).

\section{Changes in the Phospholipid of the Milk Fat Globule Membrane}

The major five phospholipids in the MFGM were separated and quantified by HPLC in accordance to a protocol described by Rombaut et al. (2005). Figure 25 depicts a 
typical chromatogram of the phospholipid standards where distinct peaks are seen for each PL. Sphingomyelin from bovine brain had three peaks, which are caused by the absence or presence of an extra hydroxyl group (Rombaut et al., 2006c). These peaks are present in higher intensities compared to the first peak as reported in previous studies (Rombaut et al., 2006c; Fong et al., 2007). Sphingomyelin derived from eggs has only two peaks, peak 2 and 3 (Data not shown).

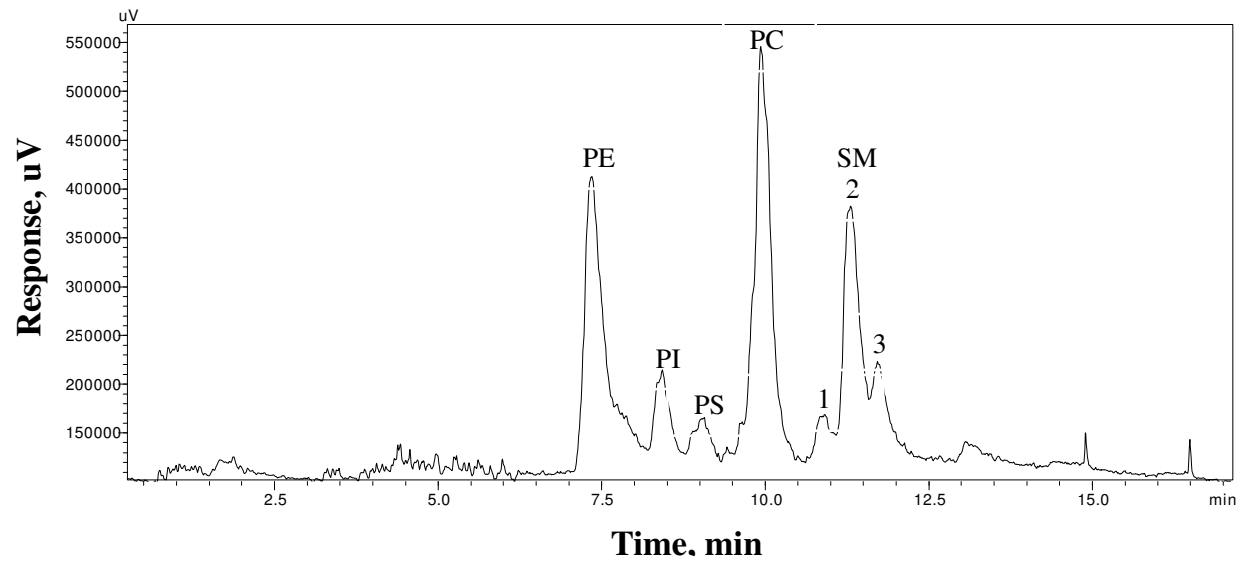

Figure 25. Normal-phase high performance liquid chromatography (HPLC) coupled with charged aerosol detector (CAD) chromatogram of phospholipid standards to quantify the PL from the MFGM, phosphatidylethanolamine (PE), phosphatidylinositol (PI), phosphatidylserine (PS), phosphatidylcholine (PC) and sphingomyelin (SM) with three peaks.

Calibration curves were constructed from the standards to determine PL concentration in each milk sample. The area under each PL peak was calculated with ShimadzuLC software and correlated to individual PL concentration. Since the CAD response is approximately linear over a narrow range, a linear equation was applied to the standard curves, and the resulting formulas are presented in Table 12. All the $\mathrm{R}^{2}$ values are higher or equal to 0.99 , indicating a linear relationship between PL area and PL concentration. 
Table 12. Linear equations of phospholipid standards and respective retention time $\left(T_{R}\right)$.

\begin{tabular}{llll}
\hline PLS & $\mathbf{T}_{\mathbf{R}}(\mathbf{m i n})$ & \multicolumn{1}{c}{ Equation* } & $\mathbf{R}^{2}$ \\
\hline PE & 7.35 & $\mathrm{PE}_{\text {con }}=\left(3.8722 \times 10^{-5}\right) x$ Area -20.3624 & 0.99 \\
PI & 8.42 & $\mathrm{PI}_{\text {con }}=\left(1.9307 \times 10^{-5}\right) x$ Area -1.0866 & 0.99 \\
PS & 8.99 & $\mathrm{PS}_{\text {con }}=\left(2.1852 \times 10^{-5}\right) x$ Area +0.0872 & 1.00 \\
PC & 9.91 & $\mathrm{PC}_{\text {con }}=\left(2.5123 \times 10^{-5}\right) x$ Area -13.6201 & 1.00 \\
SM & 11.28 & $\mathrm{SM}_{\text {con }}=\left(3.3228 \times 10^{-5}\right) x$ Area -5.1631 & 0.99 \\
\hline
\end{tabular}

* Concentration was graphed as a function of PL area,

The actual sample chromatograms were a little different from the standards as seen in Figure 26. Even after SPE concentration and purification, the samples still had some neutral lipids (NL) and other unidentified peaks, which some of them have previously been identified as lactosylceramide, phophatidic acid, or as oxidative products of PL. In addition, each PL class is composed of a complex mixture of fatty acids with different acyl chain length (Lopez et al., 2008; Sánchez-Juanes et al., 2009). In the chromatograms of samples, the PC peak is composed of four individual peaks as reported by Mènard et al. (2010).

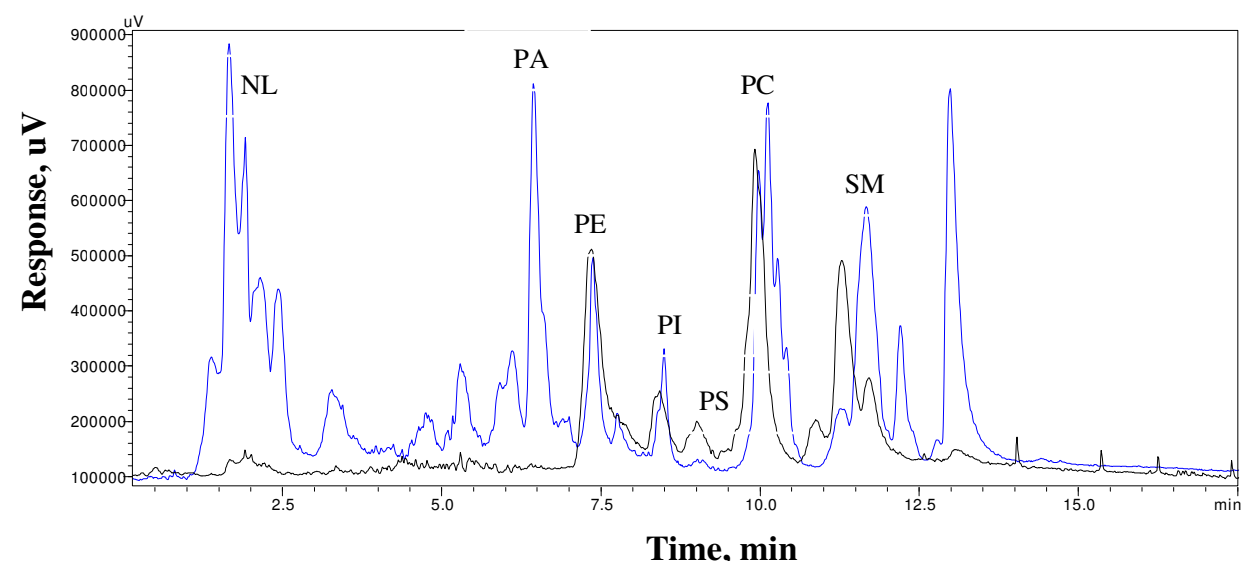

Figure 26. Normal-phase liquid chromatography (LC) coupled with charged aerosol detector (CAD) chromatograms of (Black) PL standards and (Blue) $4{ }^{\circ} \mathrm{C}$ sample. PE, phosphatidylethanolamine; PI, phosphatidylinositol; PS, phosphatidylserine; PC, phosphatidylcholine; SM, sphingomyelin; NL, neutral lipids; PA, phosphatidic acid.

The reported effects of heating on the phospholipids of the milk fat globules are contradictory (Evers, 2004a). It is well established that milk lipids differ with lactation 
(Bitman and Wood, 1990), diet (Lopez et al., 2008) as well as with cow's breed among other factors; therefore, in this study, the same line of milk was used during the processing to discard variations from these factors. Statistical differences $(\mathrm{p}<0.05)$ were observed among each trial (II, III, and IV), which can be attributed to physiological factors such as stage of lactation, time of the year, and sample preparation. The latter encourages lipid oxidation and promotes changes in total phospholipid content. In fact, higher PL concentrations are seen in trial IV compared to trial II (Appendix F).

After accounting for these variations by using blocks and trials as random effects in Minitab, no statistical difference was observed among the six samples (Figure 27). Phospholipids present in lower concentrations such as PI and PS are seen in Figure 28. The concentration of polar lipids that constitute part of the outer bilayer membrane, PC and SM, was very constant throughout milk processing as well as in the innermembrane PI and PS phospholipids. PE, which is located inside the membrane, illustrates a pattern that indicates a change in PE concentration as a function of thermal treatment, but more trials are needed to confirm such observations. These results add to the pool of uncertainty about the fluctuation of phospholipids during processing. 


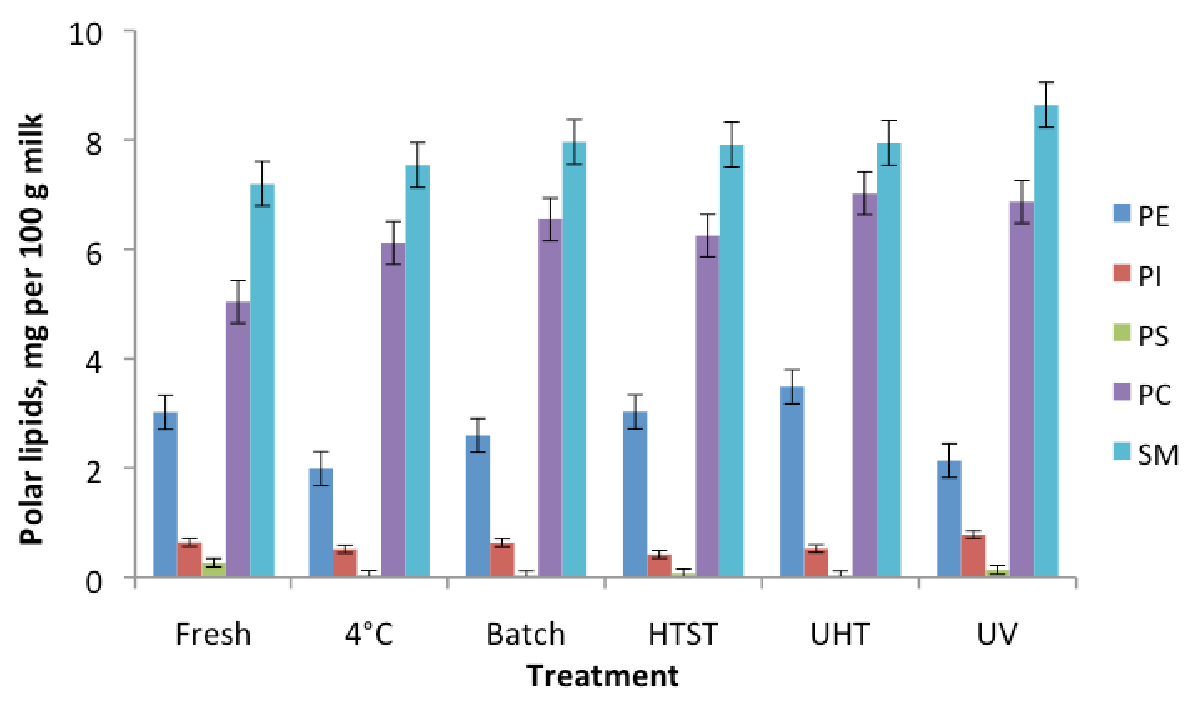

Figure 27. Polar lipid concentration (mg of PL per $\mathrm{g}$ of total lipids) in the milk fat globules. The PL means of two independent experiments are presented with the standard error of mean $(\mathrm{s} / \cdot \mathbf{N})$.

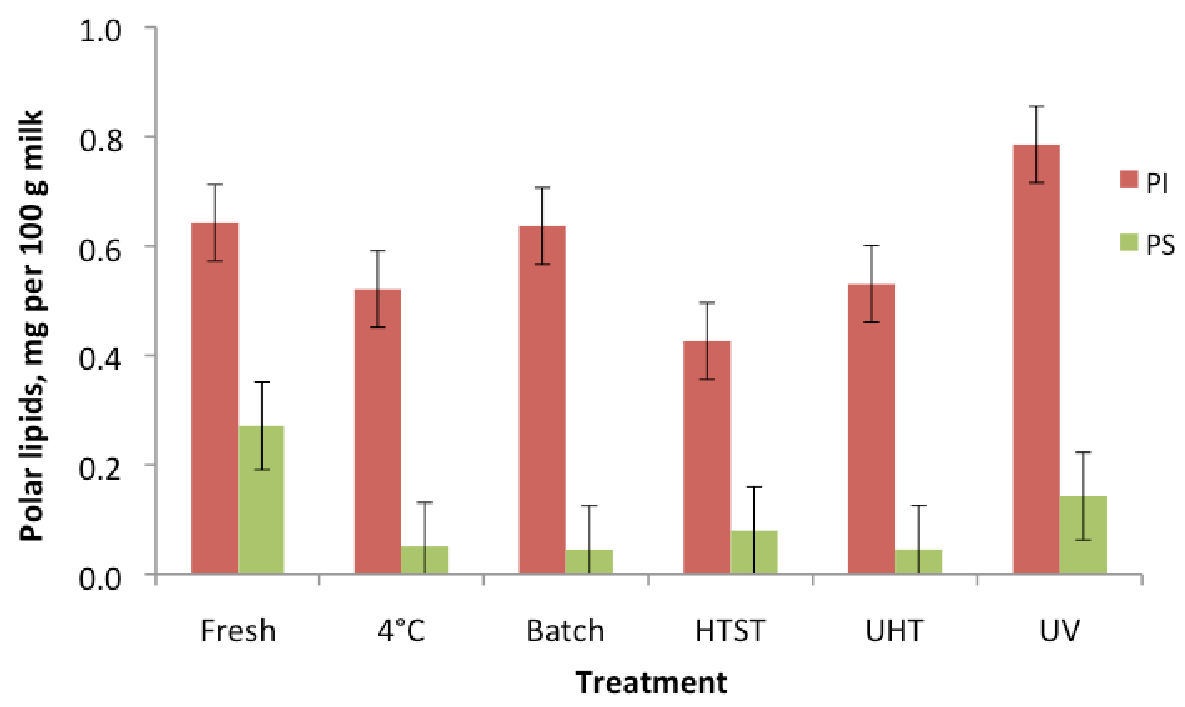

Figure 28. Concentration of PI and PS (mg of PL per $\mathrm{g}$ of total lipid) in the milk fat globules. These PLs are found in lower amounts in the MFGM. The means of two independent experiments are presented with the standard error of mean $(\mathrm{s} / \cdot \mathbf{N})$.

The reported polar lipid content in the MFGM is less than $1 \%$, and in this study, the PL content is in the range of the data in literature (Rombaut et al., 2006c; Sánchez-Juanes et al., 2009; Jensen, 2002). In their review, Rombaut and Dewettinck (2006c) reported 0.35 to $0.53 \mathrm{~g}$ of polar lipids per $100 \mathrm{~g}$ of total lipid in isolated creams whereas Ménard et 
al. (2010) reported $3.64 \mathrm{mg}$ of polar lipid per $\mathrm{g}$ fat in milk. The amount of polar lipids in cream was $0.57 \mathrm{~g}$ of polar lipid per 100 of total lipids while the PLs in milk ranged from 7.7 to $20.5 \mathrm{mg}$ of polar lipid per $100 \mathrm{~g}$ of milk.

The content of each polar lipid was analyzed as a percentage of the total five polar lipids present in the fat globules as mainly reported in most literature (Table 13). The last trial (IV) was included because the percentage of PLs were within the same range as the previous trials.

Table 13. Phospholipid content in fat globules

\begin{tabular}{lccccc}
\hline & \multicolumn{5}{c}{ Phospholipid g per 100 g polar lipid } \\
\cline { 2 - 6 } \multicolumn{1}{c}{ PL } & PE & PI & PS & PC & SM \\
\hline Fresh & 18.70 & 3.96 & 1.66 & 31.20 & 44.49 \\
4C & 12.34 & 3.18 & 0.30 & 37.83 & 46.35 \\
Batch & 14.64 & 3.58 & 0.25 & 36.79 & 44.74 \\
HTST & 17.07 & 2.39 & 0.44 & 35.29 & 44.81 \\
UHT & 18.42 & 2.78 & 0.23 & 36.88 & 41.69 \\
UV & 11.50 & 4.23 & 0.77 & 36.99 & 46.52 \\
\hline
\end{tabular}

Mean percentages of three independent studies

No statistical difference was observed in the analysis of PL percentages; however, the individual PL percentages are in accordance with previous reports (Astaire et al., 2003; Rombaut et al., 2006a). Among the PLs, SM was present in the highest concentration in all the samples (44.5-46.5\%) followed by PC (31.2-37.0\%) and PE (11.5-18.7\%). PI and PS were present in lower concentrations, $(2.4-4.2 \%)$ and $(0.2-1.7 \%)$, respectively. Figure 29 shows a graphical representation of the mean of three trials (II, III, IV). 


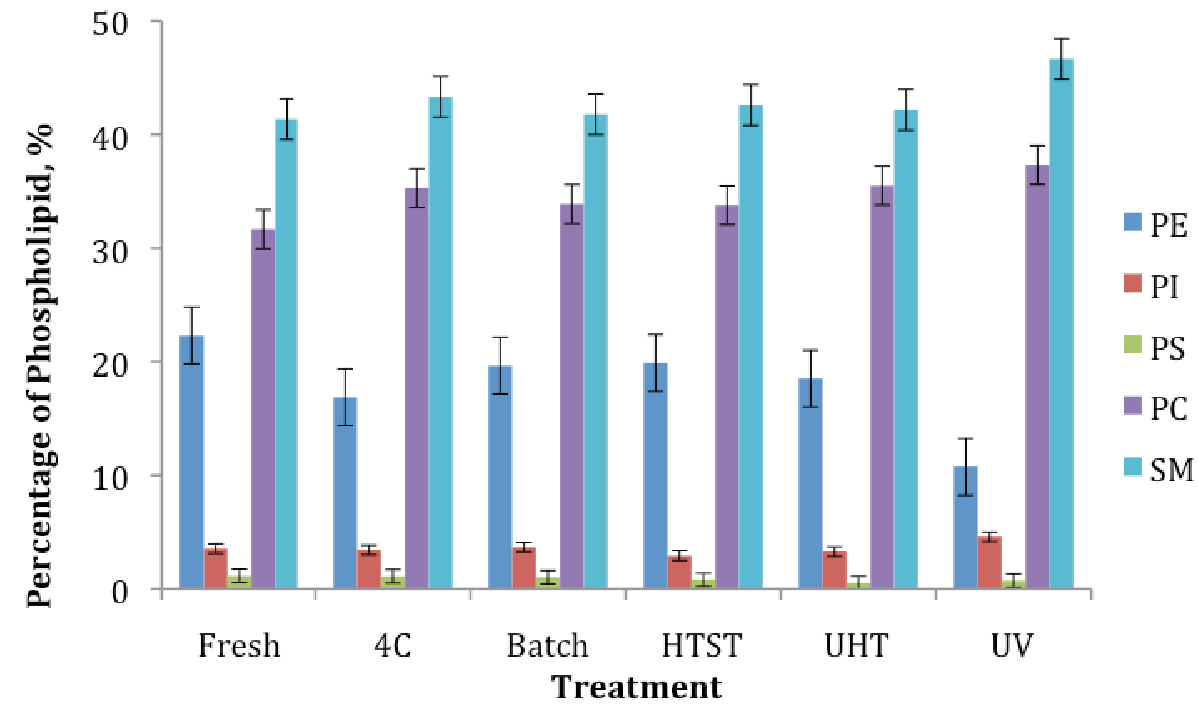

Figure 29. Phospholipid content of milk fat globules presented as percentage of the total phospholipids. The PL means of three independent experimentsis presented with standard error of mean $(\mathrm{s} / \bullet \mathrm{N})$.

The experimental design did not allow for an evaluation of the phospholipid variation during processing, but a pattern may be observed in the $\mathrm{mg} / \mathrm{g}$ fat data set. In fact, Figure 30 shows a global representation of the PL content in fat globules and illustrates that with a larger sample size a difference in polar lipid may be observed. The exact quantification of phospholipid is complicated by the different fatty acid moieties present on the acyl chains, which depend on different factors such as ruminants' diet. 


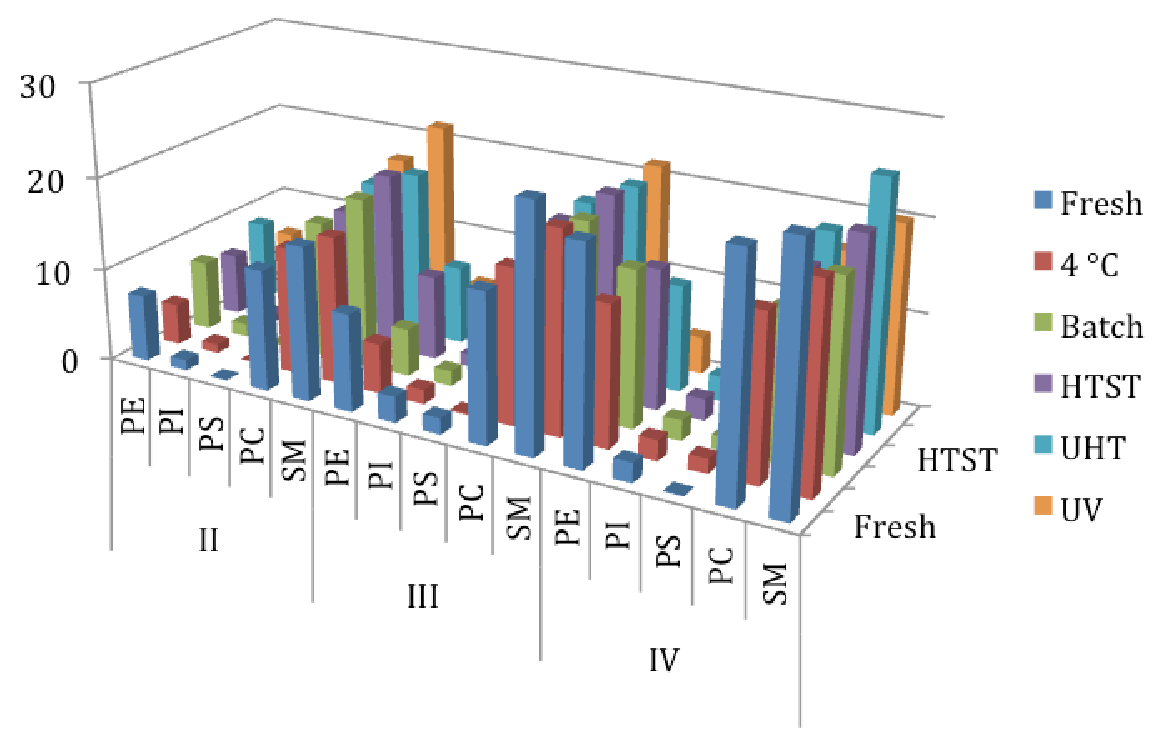

Figure 30. Global representation of phospholipids in treated samples for three independent trials (II, III, and IV). PL content is presented as mean of three HPLC measurements (mg PL per $\mathrm{g}$ of fat).

\section{Changes in the Sulfhydryl (SH) \& Disulfide SS Groups}

Thermal treatment induced SH/S-S exchange reactions and led to an increase in S-S groups. Figure 31 denotes a reduced in SH group level and an increased in SS group level as a function of thermal treatment. Disulfide bonds stabilize the folded conformation of proteins and decreases the conformational entropy leading to more SS group levels as heat treatment was increased. In fact, UHT milk had the lowest free SH groups and the highest SS groups. 


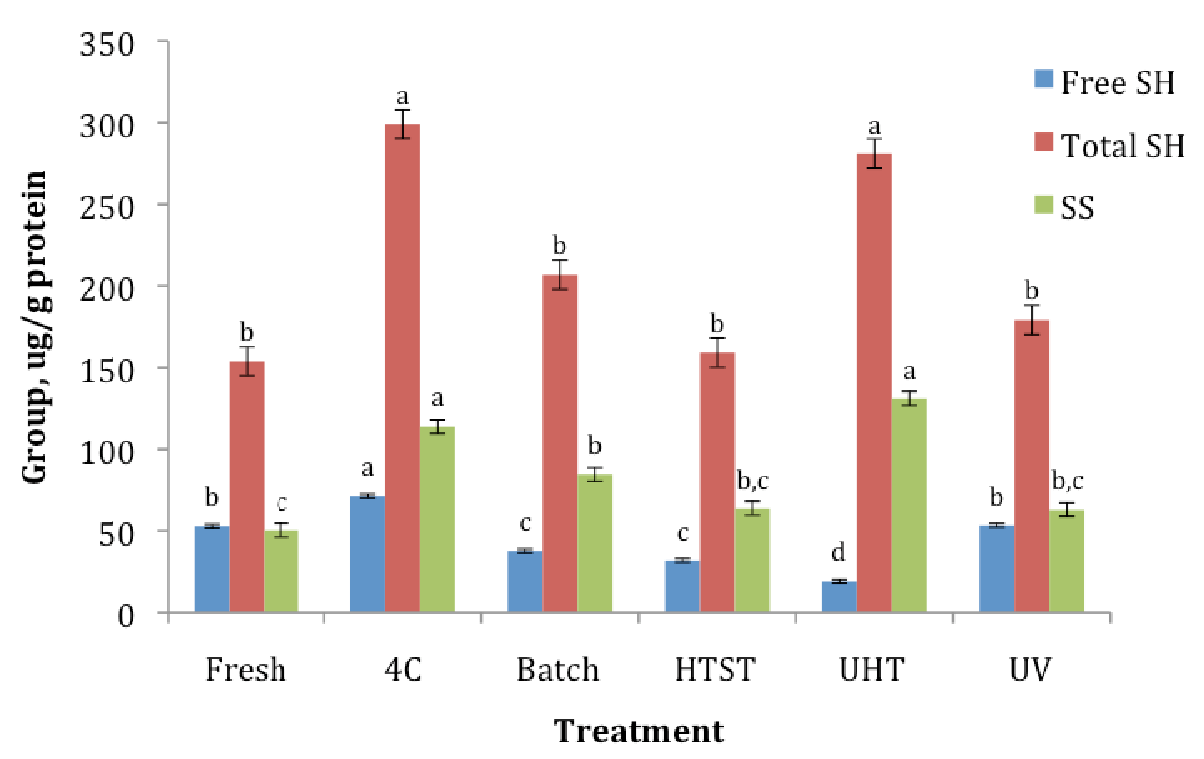

Figure 31. Effect of milk processing on the free and total sulfhydryl (SH) and disulfide (SS) groups of milk fat globule membrane protein

D. Protein Profile from One Dimensional Gels Coupled with LC/MS

\section{Milk Fat Globule Membrane Protein Profile}

When milk is heated above $70{ }^{\circ} \mathrm{C}$, whey protein denatures and deposits on the surface of the milk fat globules interacting with MFGM proteins. These protein interactions are important because they determine the physicochemical and functional properties of MFGM isolates. Figure 32 depicts a representative pattern of MFGM proteins resolved in 4-12\% bis-tris NuPAGE gel after Coomassie staining. The protein profile displays several major bands identified in previous studies by molecular weight (Mather and Keenan, 1975; Evers, 2004a). Butyrophilin ran at apparent molecular weight of $60 \mathrm{kDa}$ when its literature value is $67 \mathrm{kDa}$, probably due to post-translational modifications such as phosphorylation that may affect its electrophoretic mobility. Some glycosylated proteins of the MFGM are not seen because a more sensitive staining technique is needed to identify their location by molecular weight. 


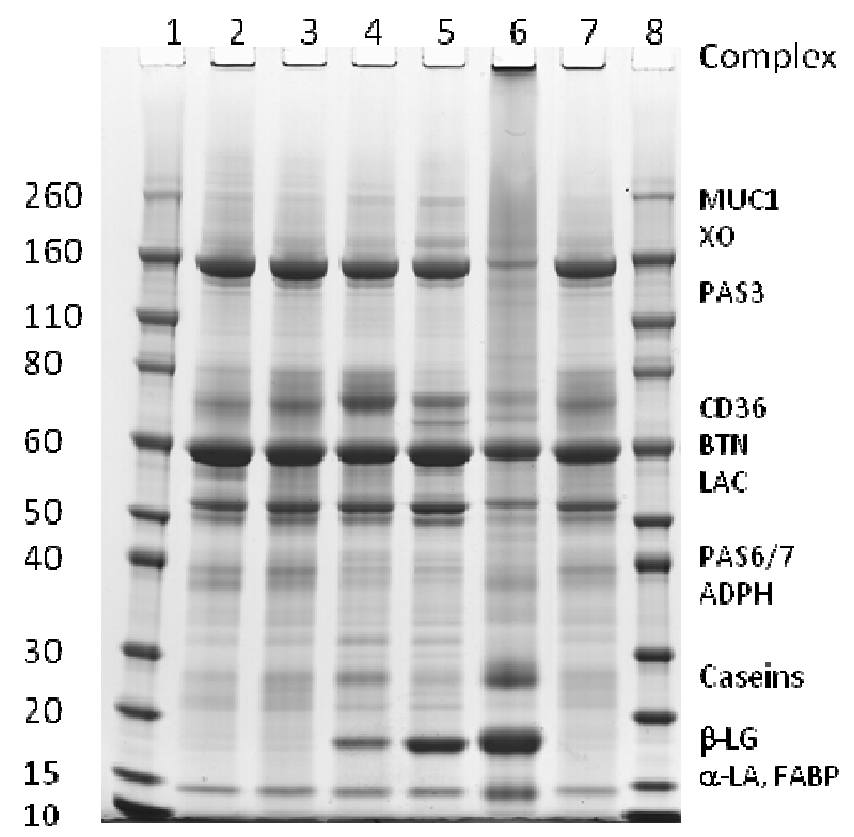

Figure 32. Sodium dodecyl sulfate-PAGE pattern (4-12\% gradient Bis-Tris NuPAGE gel) of milk fat globule membrane material isolated from different fractions of milk processing. 1\&8) Novex Sharp Standards, 2) Fresh, 3) $4{ }^{\circ} \mathrm{C}$, 4) Batch, 5) HTST, 6) UHT, and 7) UV.

Heat treatment resulted in high incorporation of $\beta$-lactoglobulin $(\beta-\mathrm{LG}, 18 \mathrm{kDa})$ in the MFGM isolates (lanes 4, 5,6) as denoted by the staining intensity in the gel. The UHT treatment, in particular was enriched in caseins and $\beta$-LG. Even with a reducing gel, some high-molecular bands are observed in this sample (lane 6), indicating formation of protein complex as a function of time. According to Ye 2004, xanthine oxidase (XO) and butyrophilin (BTN) form complexes above $60{ }^{\circ} \mathrm{C}$, which may be present in these bands. In fact, the bands that identify these two proteins are less intense in the UHT sample compared to the other treatments, confirming XO-BTN complex formation. In addition, fluctuations in other MFGM proteins are observed by changes in band intensity; however, these proteins were identified by comparing molecular weights were performed. 


\section{MFGM Protein Quantification by SDS-PAGE Densitometry}

Table 14. Relative abundance of MFGM proteins during milk processing.

\begin{tabular}{|c|c|c|c|c|c|c|c|c|}
\hline \multirow[b]{2}{*}{ MFGM Proteins } & \multirow{2}{*}{$\begin{array}{l}\text { MW } \\
(\mathbf{k D a})\end{array}$} & \multirow{2}{*}{$\begin{array}{l}\text { Obs. } \\
\text { MW }\end{array}$} & \multicolumn{6}{|c|}{ Relative Protein Abundance } \\
\hline & & & $\mathbf{F}$ & $4^{\circ} \mathrm{C}$ & B & $\mathbf{H}$ & $\mathbf{U}$ & UV \\
\hline Mucin 1 (MUC1)* & $160-500$ & 252 & 1.9 & 1.0 & 1.4 & 1.8 & & \\
\hline \multirow[t]{3}{*}{ BRCA1 and BRCA2 } & 210 & 217 & 1.9 & 1.1 & 1.1 & 1.0 & 6.4 & 3.8 \\
\hline & & 181 & 1.0 & 1.2 & 1.1 & 1.3 & 1.6 & 1.0 \\
\hline & & 174 & 1.0 & 1.2 & & & & 1.9 \\
\hline \multirow[t]{7}{*}{ Xanthine oxidase (XO)+ } & $150-155$ & 151 & $4.6^{\mathrm{a}}$ & $4.7^{\mathrm{a}}$ & $4.2^{\mathrm{a}}$ & $4.3^{\mathrm{a}}$ & $1.0^{\mathrm{b}}$ & $4.3^{\mathrm{a}}$ \\
\hline & & 140 & 1.7 & 1.7 & 1.0 & 1.3 & 1.2 & 1.3 \\
\hline & & 131 & 2.9 & 1.6 & 1.0 & 1.5 & & 1.9 \\
\hline & & 124 & & & & & 1.0 & \\
\hline & & 120 & 1.4 & 1.3 & 1.0 & 1.5 & & 1.2 \\
\hline & & 110 & & & 1.1 & & & 1.0 \\
\hline & & 106 & & & 1.0 & & & \\
\hline Mucin 15 (MUC 15 or PAS III)* & $94-100$ & 101 & 1.2 & 1.0 & 1.3 & 1.0 & & 1.5 \\
\hline \multirow{2}{*}{$\begin{array}{l}\text { Cluster of Differentiation (CD36 } \\
\text { or PAS IV) }\end{array}$} & 88 & $89-87$ & 6.1 & 2.2 & 10.5 & 5.3 & 3.3 & 1.0 \\
\hline & & 80 & 1.1 & 1.0 & & & & 1.3 \\
\hline Lactoferrin & 78 & $76-77$ & & 2.2 & 1.7 & 1.0 & 1.5 & 1.5 \\
\hline \multirow[t]{2}{*}{ Serum Albumin } & 69 & 70 & $8.9^{\mathrm{a}}$ & $11.5^{\mathrm{a}}$ & $11.7^{\mathrm{a}}$ & $9.7^{\mathrm{a}}$ & $1.0^{\mathrm{b}}$ & $10.4^{\mathrm{a}}$ \\
\hline & & 63 & 1.0 & 1.3 & 1.4 & 1.3 & & 1.3 \\
\hline \multirow[t]{3}{*}{ Butyrophilin (BTN) } & 59 & 59 & $2.1^{\mathrm{a}}$ & $2.3^{\mathrm{a}}$ & $2.0^{\mathrm{a}}$ & $2.2^{\mathrm{a}}$ & $1.0^{\mathrm{b}}$ & $2.0^{\mathrm{a}}$ \\
\hline & & $55-56$ & 5.5 & 4.4 & 3.8 & 1.8 & 1.0 & 2.4 \\
\hline & & 53 & 1.3 & 1.0 & 1.8 & 2.8 & 3.5 & 1.0 \\
\hline Adipopholin (ADFP) & 52 & $51-52$ & $5.1^{\mathrm{a}}$ & $6.7^{\mathrm{a}}$ & $5.8^{\mathrm{a}}$ & $6.5^{\mathrm{a}}$ & $1.0^{\mathrm{b}}$ & $5.8^{\mathrm{a}}$ \\
\hline $\begin{array}{l}\text { Lactadherin (PAS 6/7)++ } \\
\text { MFG-E8 }\end{array}$ & $43-59$ & $49-50$ & $6.7^{\mathrm{a}}$ & $9.1^{\mathrm{a}}$ & $7.0^{\mathrm{a}}$ & $8.9^{\mathrm{a}}$ & $1.0^{\mathrm{b}}$ & $8.0^{\mathrm{a}}$ \\
\hline $\begin{array}{l}\text { Monocyte differentiation antigen } \\
\text { (CD14) }\end{array}$ & 40 & $41-43$ & 1.0 & 2.9 & 2.0 & 1.7 & & 4.6 \\
\hline Annexin & 39 & 39 & $3.1^{\mathrm{a}}$ & $3.4^{\mathrm{a}}$ & $1.0^{\mathrm{b}}$ & $1.1^{\mathrm{b}}$ & $3.1^{\mathrm{a}}$ & $1.9^{\mathrm{a}, \mathrm{b}}$ \\
\hline \multirow[t]{4}{*}{ Mucin 15} & 36 & 38 & $3.6^{\mathrm{a}}$ & $2.9^{\mathrm{b}}$ & $1.0^{\mathrm{c}}$ & $1.1^{\mathrm{c}}$ & & $2.3^{\mathrm{b}}$ \\
\hline & & $33-34$ & 1.3 & 1.2 & 1.0 & 1.1 & 1.5 & 1.1 \\
\hline & & 31 & 1.0 & 1.2 & 2.0 & 1.2 & & 1.0 \\
\hline & & 29 & & & 1.3 & 1.0 & & \\
\hline$\alpha-(\mathrm{s} 2)$ - casein & 24 & $25-26$ & $1.0^{\mathrm{c}}$ & $1.6^{\mathrm{b}, \mathrm{c}}$ & $2.8^{\mathrm{b}}$ & $1.4^{\mathrm{c}}$ & $6.3^{\mathrm{a}}$ & $1.3^{\mathrm{c}}$ \\
\hline$\alpha-(s 1)-$ casein & 23 & $21-22$ & $5.6^{\mathrm{a}}$ & $4.8^{\mathrm{a}, \mathrm{b}}$ & $2.1^{\mathrm{b}, \mathrm{c}}$ & $2.5^{\mathrm{a}, \mathrm{b}, \mathrm{c}}$ & $1.0^{\mathrm{c}}$ & $4.7^{\mathrm{a}, \mathrm{b}}$ \\
\hline$\kappa$-casein & 19 & 20 & 1.4 & 1.0 & 1.2 & 1.1 & & 1.1 \\
\hline$\beta$-lactoglobulin & 18 & 18 & $1.8^{\mathrm{c}}$ & $1.2^{\mathrm{c}}$ & $10.3^{\mathrm{b}}$ & $10.2^{\mathrm{b}}$ & $20.5^{\mathrm{a}}$ & $1.0^{\mathrm{c}}$ \\
\hline$\alpha$-lactalbumin & 14.4 & 13 & $1.6^{\mathrm{b}, \mathrm{c}}$ & $1.7^{\mathrm{b}, \mathrm{c}}$ & $2.4^{\mathrm{b}}$ & $2.0^{b, c}$ & $3.8^{\mathrm{a}}$ & $1.0^{\mathrm{c}}$ \\
\hline
\end{tabular}

* Usually identified by PASS staining (Riccio, 2004) ++ Also known as MFG-E8 
In order to assess the change in MFGM proteins upon milk processing, protein bands were identified and quantified by densitometry using the band trace tool (intensity peak $x$ $\mathrm{mm}$ ) in BioRad Quantity One software. The program was automated with the same settings for NuPAGE gels, and the relative abundance of proteins was calculated (Raw data, Appendix G. Table 14 shows the relative abundance of MFGM proteins among samples. Proteins were identified according to their molecular weight in literature, and those bands without a molecular weight match are expected to be unidentified proteins, polypeptides, or complexes of proteins. High-molecular weight proteins were more intense and detectable in Fresh sample (308 $\mathrm{kDa}$ and $284 \mathrm{kDa}$ ) as well as in the $4{ }^{\circ} \mathrm{C}$ sample (284 kDa). They may correspond to fatty acid synthase $(275 \mathrm{kDa})$ and acetyl-CoA carboxylase (265 kDa). A $104 \mathrm{kDa}$ band is also seen in UHT.

\section{MFGM Protein Identification through LC/MS}

SDS-PAGE is an excellent technique to visualize proteins; however, identification of proteins is limited by protein resolution; therefore, to assess the effect of milk processing into more depth, liquid chromatography connected with tandem mass spectrometry (LCMS/MS) was used to detect more proteins from 1DE gel. Results were in accordance to previous studies where more than 120 proteins were identified in bovine MFGM (Reinhardt and Lippolis, 2006). In this study, 117 proteins were identified, which fluctuated depending on the milk processing treatment, especially when heat was applied. Among these proteins, 15 of them are still uncharacterized bovine proteins. Table 15 presents the probabilities of proteins that were identified according to the threshold parameters designated in Scaffold. The false discovery rate (FDR) for peptide identification was determined by Scaffold as $0.1 \%$; thus, yielding high confidence in the identified proteins. 
Table 15. MFGM proteins identified by LC-MS/MS upon milk processing.

\begin{tabular}{|c|c|c|c|c|c|c|c|c|}
\hline \multirow[t]{2}{*}{ Accession Number } & \multirow{2}{*}{$\begin{array}{c}\text { MW } \\
(\mathbf{k D a})\end{array}$} & \multirow[t]{2}{*}{ Identified Proteins $^{+}$} & \multicolumn{6}{|c|}{ Protein Probability (Identification) } \\
\hline & & & Fresh & $4^{\circ} \mathrm{C}$ & Batch & HTST & UHT & UV \\
\hline \multicolumn{9}{|c|}{ Lipid transport/metabolism } \\
\hline BT1A1_BOVIN & 59 & $\begin{array}{l}\text { Butyrophilin subfamily } 1 \text { member } \\
\text { A1 }\end{array}$ & 100 & 100 & 100 & 100 & 100 & 100 \\
\hline PLIN2_BOVIN & 49 & Perilipin-2 (ADFP) & 100 & 100 & 100 & 100 & 100 & 100 \\
\hline XDH_BOVIN & 147 & Xanthine dehydrogenase/oxidase & 100 & 100 & 100 & 100 & 100 & 100 \\
\hline FABPH_BOVIN & 15 & Fatty acid-binding protein, heart & 100 & 100 & 100 & 100 & 100 & 100 \\
\hline CD36_BOVIN & 53 & Platelet glycoprotein 4 & 100 & 100 & 100 & 100 & 100 & 100 \\
\hline Q0VCZ8_BOVIN & 78 & $\begin{array}{l}\text { Acyl-CoA synthetase long-chain } \\
\text { family member } 1\end{array}$ & 100 & 100 & 100 & 100 & 100 & 100 \\
\hline ACACA_BOVIN & 265 & Acetyl-CoA carboxylase 1 & 100 & 100 & 100 & 100 & 100 & 100 \\
\hline FAS_BOVIN & 275 & Fatty acid synthase & 100 & 100 & 100 & 100 & 98 & 98 \\
\hline A4FUX1_BOVIN & 25 & CIDEA protein & 100 & 100 & 100 & 100 & 16 & 100 \\
\hline Q3SX32_BOVIN & 48 & $\begin{array}{l}\text { Mannose } 6 \text { phosphate receptor } \\
\text { binding protein } 1\end{array}$ & 100 & 100 & 83 & 100 & & 100 \\
\hline Q9TSF1_BOVIN & 14 & Butyrophilin (Fragment) & 42 & 98 & 97 & 100 & & \\
\hline Q3ZC65_BOVIN & 46 & Ancient ubiquitous protein 1 & 30 & & & 99 & & \\
\hline ERG7_BOVIN & 83 & Lanosterol synthase & 58 & & 74 & 100 & 100 & \\
\hline A9XTK4_BOVIN & 38 & $\begin{array}{l}\text { 17-beta hydroxysteroid } \\
\text { dehydrogenase }\end{array}$ & 100 & 99 & & 100 & & 41 \\
\hline NSDHL_BOVIN & 40 & $\begin{array}{l}\text { Sterol-4-alpha-carboxylate 3- } \\
\text { dehydrogenase, decarboxylating }\end{array}$ & 73 & & & 100 & 58 & 100 \\
\hline A6H7G0_BOVIN & 34 & CYB5R3 protein & & 83 & 83 & 100 & 100 & 74 \\
\hline A6H7D4_BOVIN & 52 & $\begin{array}{l}\text { Lysophosphatidic acid } \\
\text { acyltransferase, zeta }\end{array}$ & & & 83 & 100 & 40 & 71 \\
\hline A7YWR0_BOVIN & 36 & Apolipoprotein E & & & 83 & 100 & & 53 \\
\hline LIPL_BOVIN & 53 & Lipoprotein lipase & & & & 100 & 21 & \\
\hline FABP7_BOVIN & 15 & Fatty acid-binding protein, brain & & & 100 & & & \\
\hline \multicolumn{9}{|l|}{ Immunity \& defense } \\
\hline Q3T0K7_BOVIN & 48 & MFGE8 protein & 100 & 100 & 100 & 100 & 100 & 100 \\
\hline PIGR_BOVIN & 82 & $\begin{array}{l}\text { Polymeric immunoglobulin } \\
\text { receptor }\end{array}$ & 100 & 100 & 100 & 100 & 100 & 100 \\
\hline Q3T101_BOVIN & 25 & IGL@ protein & 100 & 100 & 100 & 100 & 100 & 100 \\
\hline A7E340_BOVIN & 36 & Mucin 15 , cell surface associated & 58 & 71 & 79 & 99 & 98 & 51 \\
\hline CTHL1_BOVIN & 18 & Cathelicidin-1 & 100 & 100 & 100 & 100 & & 100 \\
\hline MUC1_BOVIN & 58 & Mucin-1 & 100 & 100 & 71 & 50 & & 100 \\
\hline Q3SYR8_BOVIN & 18 & Immunoglobulin $\mathrm{J}$ chain & 100 & 100 & 100 & 71 & & 74 \\
\hline ANXA1_BOVIN & 39 & Annexin A1 & 73 & & & 50 & & 100 \\
\hline B0JYP6_BOVIN & 26 & IGK protein & 100 & 100 & 100 & & & 100 \\
\hline GLCM1_BOVIN & 17 & $\begin{array}{l}\text { Glycosylation-dependent cell } \\
\text { adhesion molecule } 1\end{array}$ & & 100 & 100 & 100 & 80 & \\
\hline A6QNL0_BOVIN & 40 & CD14 & & 63 & 100 & 100 & 98 & \\
\hline Q1RMN8_BOVIN & 25 & $\begin{array}{l}\text { Immunoglobulin light chain, } \lambda \\
\text { gene cluster }\end{array}$ & & 100 & 100 & & 75 & \\
\hline
\end{tabular}




\begin{tabular}{|c|c|c|c|c|c|c|c|c|}
\hline \multirow[t]{2}{*}{ Accession Number } & \multirow{2}{*}{$\begin{array}{c}\text { MW } \\
(\mathbf{k D a})\end{array}$} & \multirow[t]{2}{*}{ Identified Proteins $^{+}$} & \multicolumn{6}{|c|}{ Protein Probability (Identification) } \\
\hline & & & Fresh & $4^{\circ} \mathrm{C}$ & Batch & HTST & UHT & $\mathbf{U V}$ \\
\hline PERL_BOVIN & 81 & Lactoperoxidase & & 63 & & 50 & 99 & \\
\hline B5T263_9CETA & 90 & Toll-like receptor 2 & & & & 97 & & \\
\hline \multicolumn{9}{|c|}{ Membrane/protein trafficking } \\
\hline RAB18_BOVIN & 23 & Ras-related protein Rab-18 & 100 & 100 & 100 & 100 & 100 & 100 \\
\hline RB11A_BOVIN & 24 & Ras-related protein Rab-11A & 100 & 99 & 100 & 100 & 70 & 100 \\
\hline Q2T9M8_BOVIN & 23 & $\begin{array}{l}\text { Synaptosomal-associated protein } \\
23 \text { isoform SNAP23A }\end{array}$ & 100 & 100 & 99 & 100 & & 100 \\
\hline SAR1A_BOVIN & 22 & GTP-binding protein SAR1a & 100 & 100 & 98 & 100 & & 100 \\
\hline RAB7A_BOVIN & 24 & Ras-related protein $\mathrm{Rab}-7 \mathrm{a}$ & 100 & 100 & 100 & 100 & & 74 \\
\hline YKT6_BOVIN & 22 & Synaptobrevin homolog YKT6 & 35 & 100 & & 71 & & 100 \\
\hline ARF1_BOVIN & 21 & ADP-ribosylation factor 1 & 100 & 73 & & & & 74 \\
\hline A6QLH3_BOVIN & 33 & STX3 protein & 100 & 51 & & 50 & & 71 \\
\hline RAB13_BOVIN & 23 & Ras-related protein Rab-13 & 73 & & & 100 & & \\
\hline Q2TBH2_BOVIN & 24 & $\begin{array}{l}\text { Related RAS viral (R-ras) } \\
\text { oncogene homolog }\end{array}$ & 100 & 99 & & & & 100 \\
\hline RAB5C_BOVIN & 23 & Ras-related protein Rab-5C & 73 & 100 & & & & \\
\hline A5D7E0_BOVIN & 23 & RAB35 protein & & 100 & & 71 & 39 & 74 \\
\hline RAB8A_BOVIN & 24 & Ras-related protein Rab-8A & 99 & & & & & \\
\hline \multicolumn{9}{|c|}{ G-protein mediated cell signaling } \\
\hline A1L528_BOVIN & 23 & $\begin{array}{l}\text { RAB1A, member RAS oncogene } \\
\text { family }\end{array}$ & 100 & 100 & 100 & 100 & 100 & 100 \\
\hline GBB2_BOVIN & 37 & $\begin{array}{l}\text { Guanine nucleotide-binding protein } \\
\mathrm{G}(\mathrm{I}) / \mathrm{G}(\mathrm{S}) / \mathrm{G}(\mathrm{T}) \text { subunit beta-2 }\end{array}$ & 100 & 100 & 100 & 100 & 100 & 100 \\
\hline GBB1_BOVIN & 37 & $\begin{array}{l}\text { Guanine nucleotide-binding protein } \\
\mathrm{G}(\mathrm{I}) / \mathrm{G}(\mathrm{S}) / \mathrm{G}(\mathrm{T}) \text { subunit beta-1 }\end{array}$ & 100 & 83 & 83 & 100 & 100 & 99 \\
\hline GNAS2_BOVIN & 46 & $\begin{array}{l}\text { Guanine nucleotide-binding protein } \\
\mathrm{G}(\mathrm{s}) \text { subunit alpha isoforms short }\end{array}$ & 100 & 73 & 83 & 100 & 32 & \\
\hline RAC1_BOVIN & 21 & $\begin{array}{l}\text { Ras-related } \mathrm{C} 3 \text { botulinum toxin } \\
\text { substrate } 1\end{array}$ & 100 & 73 & 73 & 100 & & 99 \\
\hline RAP1A_BOVIN & 21 & Ras-related protein Rap-1A & 100 & 100 & 73 & 99 & & 98 \\
\hline ARL15_BOVIN & 23 & $\begin{array}{l}\text { ADP-ribosylation factor-like } \\
\text { protein } 15\end{array}$ & 98 & 97 & & 100 & & 74 \\
\hline B6VAP7_BOVIN & 21 & CDC42 protein & 100 & 100 & & 99 & & \\
\hline A5D7R9_BOVIN & 21 & NRAS protein & & & 97 & & & 100 \\
\hline RHOC_BOVIN & 22 & $\begin{array}{l}\text { Rho-related GTP-binding protein } \\
\text { RhoC }\end{array}$ & 73 & & & 100 & & \\
\hline GNAI1_BOVIN & 40 & $\begin{array}{l}\text { Guanine nucleotide-binding protein } \\
\text { G(i) subunit alpha-1 }\end{array}$ & 99 & & & & 31 & \\
\hline \multicolumn{9}{|c|}{ Protein synthesis, binding and/or folding } \\
\hline Q861V9_BOVIN & 16 & $\begin{array}{l}\text { Similar to peptidylprolyl isomerase } \\
\text { A (Cyclophilin A) (Fragment) }\end{array}$ & 100 & 100 & 100 & 100 & 43 & 100 \\
\hline SEP15_BOVIN & 18 & $15 \mathrm{kDa}$ selenoprotein & 73 & 73 & 99 & 100 & & 74 \\
\hline B0JYL8_BOVIN & 19 & Cofilin 1 & 73 & 100 & 73 & 71 & & 100 \\
\hline HSP7C_BOVIN & 71 & Heat shock cognate $71 \mathrm{kDa}$ protein & 100 & & & 50 & & \\
\hline
\end{tabular}




\begin{tabular}{|c|c|c|c|c|c|c|c|c|}
\hline \multirow[t]{2}{*}{ Accession Number } & \multirow{2}{*}{$\begin{array}{c}\text { MW } \\
\text { (kDa) }\end{array}$} & \multirow[t]{2}{*}{ Identified Proteins $^{+}$} & \multicolumn{6}{|c|}{ Protein Probability (Identification) } \\
\hline & & & Fresh & $4^{\circ} \mathrm{C}$ & Batch & HTST & UHT & UV \\
\hline Q99BK3_9ALPH & 88 & $\begin{array}{l}\text { Ribonucleotide reductase large } \\
\text { subunit }\end{array}$ & 61 & 100 & 79 & & & \\
\hline A5D7N2_BOVIN & 14 & HIST2H2BE protein & & 99 & & & & 98 \\
\hline A2VDV1_BOVIN & 22 & Ankyrin repeat domain 22 & & 73 & & 99 & & 74 \\
\hline EF1A1_BOVIN & 50 & Elongation factor 1 -alpha 1 & 100 & & & & & 28 \\
\hline A5D792_BOVIN & 18 & DCK protein & & & & & & 100 \\
\hline
\end{tabular}

\section{Homeostatic regulator}

\begin{tabular}{|c|c|c|c|c|c|c|c|}
\hline D5HSX1_BOVIN & 87 & $\begin{array}{l}\text { cGMP-dependant type II protein } \\
\text { kinase }\end{array}$ & 100 & 64 & & 100 & \\
\hline Q6QRN7_BOVIN & 34 & PP1201 protein & 73 & 100 & & 71 & \\
\hline Q2KIS4_BOVIN & 34 & $\begin{array}{l}\text { Dehydrogenase/reductase (SDR } \\
\text { family) member } 1\end{array}$ & 97 & & & 100 & \\
\hline B3VTM3_BOVIN & 78 & Lactoferrin & & & 100 & 100 & 100 \\
\hline ANXA5_BOVIN & 36 & Annexin A5 & & & 38 & 100 & \\
\hline ALBU_BOVIN & 69 & Serum albumin & & & & 100 & 100 \\
\hline ACOC_BOVIN & 98 & Cytoplasmic aconitate hydratase & 100 & & & & \\
\hline
\end{tabular}

\section{General Transporter}

\begin{tabular}{|c|c|c|c|c|c|c|c|}
\hline ABCG2_BOVIN & 73 & $\begin{array}{l}\text { ATP-binding cassette sub-family G } \\
\text { member } 2\end{array}$ & 100 & 100 & 100 & 100 & 100 \\
\hline A8E4P3_BOVIN & 31 & STOM protein & 100 & 100 & 100 & 100 & 50 \\
\hline NPT2B_BOVIN & 76 & $\begin{array}{l}\text { Sodium-dependent phosphate } \\
\text { transport protein } 2 \mathrm{~B}\end{array}$ & 100 & 100 & 100 & 100 & 100 \\
\hline Q8MKB7_BOVIN & 73 & $\mathrm{Na}+$ glucose cotransporter & 73 & 83 & & & 100 \\
\hline 5NTD_BOVIN & 63 & 5'-nucleotidase & 19 & 71 & & 100 & 100 \\
\hline CHP1_BOVIN & 22 & Calcium-binding protein $\mathrm{p} 22$ & 73 & 100 & & & \\
\hline
\end{tabular}

\section{Cell Structure}

$\begin{array}{lllllllll}\text { A6QNZ7_BOVIN } & 55 & \text { Keratin 10 } & 100 & 100 & 71 & 100 & 100 & 98 \\ \text { A4FV94_BOVIN } & 61 & \text { KRT6A protein } & 73 & 100 & 79 & 100 & 100 & 74 \\ \text { A5D7M6_BOVIN } & 63 & \text { KRT5 protein } & 99 & 100 & & 99 & 100 & 20 \\ \text { ACTB_BOVIN } & 42 & \text { Actin, cytoplasmic 1 } & 100 & 100 & 100 & 100 & 58 & 100 \\ \text { Q17QL7_BOVIN } & 49 & \text { KRT15 protein } & 73 & 100 & & & 50 & \\ \text { GIPC2_BOVIN } & 35 & \text { PDZ domain-containing protein } & 100 & & & 100 & \end{array}$

\section{Cell surface receptor mediated signal transduction}

\begin{tabular}{lllllll} 
A5PKG9_BOVIN & 59 & FGR protein & 73 & \multicolumn{2}{c}{100} & \\
ANXA2_BOVIN & 39 & Annexin A2 & 73 & 83 & 99 & 45 \\
D4QGC1_BOVIN & 59 & Tyrosine-protein kinase Lyn & & & 100
\end{tabular}

\section{Milk proteins}

CASA1_BOVIN

25 Alpha-S1-casein

$\begin{array}{llll}100 & 100 & 100 & 100\end{array}$

$100 \quad 100$ 


\begin{tabular}{|c|c|c|c|c|c|c|c|c|}
\hline \multirow[t]{2}{*}{ Accession Number } & \multirow{2}{*}{$\begin{array}{c}\text { MW } \\
(\mathbf{k D a})\end{array}$} & \multirow[t]{2}{*}{ Identified Proteins $^{+}$} & \multicolumn{6}{|c|}{ Protein Probability (Identification) } \\
\hline & & & Fresh & $4^{\circ} \mathrm{C}$ & Batch & HTST & UHT & $\mathbf{U V}$ \\
\hline CASK_BOVIN & 21 & Kappa-casein & 98 & 100 & 100 & 100 & 100 & 100 \\
\hline CASA2_BOVIN & 26 & Alpha-S2-casein & 73 & 100 & 100 & 100 & 100 & 100 \\
\hline \multicolumn{9}{|l|}{ Whey proteins } \\
\hline B5B0D4_BOVIN & 20 & Major allergen beta-lactoglobulin & 73 & 100 & 100 & 100 & 100 & 100 \\
\hline LACB_BOVIN & 20 & $\beta$-lactoglobulin & & & 73 & 100 & 100 & \\
\hline Q28049_BOVIN & 14 & $\alpha$-lactalbumin (Fragment) & & & & 100 & 100 & \\
\hline Q9TRB9_BOVIN & 2 & $\begin{array}{l}\text { Enterotoxin-binding glycoprotein } \\
\text { PP20K (Fragment) }\end{array}$ & & & 28 & 100 & 100 & \\
\hline \multicolumn{9}{|l|}{ Unknown function } \\
\hline ENPP3_BOVIN & 100 & $\begin{array}{l}\text { Ectonucleotide pyrophosphatase/ } \\
\text { phosphodiesterase family member3 }\end{array}$ & 100 & 100 & 100 & 100 & 100 & 100 \\
\hline Q0IIA4_BOVIN & 59 & Glycoprotein 2 & 100 & 100 & 100 & 100 & & 100 \\
\hline PPBT_BOVIN & 57 & Alkaline phosphatase & & & & 99 & & \\
\hline A4FUH8_BOVIN & 21 & $\begin{array}{l}\text { Chromosome } 1 \text { open reading frame } \\
93 \text { ortholog }\end{array}$ & & & & 99 & & \\
\hline
\end{tabular}

HTST, high temperature short time; UHT, ultra high temperature; UV, UV pulsed light treatment

It is well known that heat induces protein interactions and protein displacement as well as protein adsorption on the milk fat globule membrane (Singh, 2006; Evers, 2004a). LCMS identified these proteins and permitted the graphical representation of the number of proteins identified in each treatment (Figure 33). HTST milk had the highest protein identification, $83 \%$, from the 102 total identified proteins. Tyrosine-protein kinase Lyn, alkaline phosphatase, chromosome 1 open reading frame 93 ortholog, and most importantly toll-like receptor 2 were four proteins exclusively found in HTST, indicating that heating may have contributed to fix these proteins to the MFGM. The Fresh and $4{ }^{\circ} \mathrm{C}$ treatments had almost the same number of proteins identified, 76 and 71, respectively, and UHT had the least number of identified proteins. 


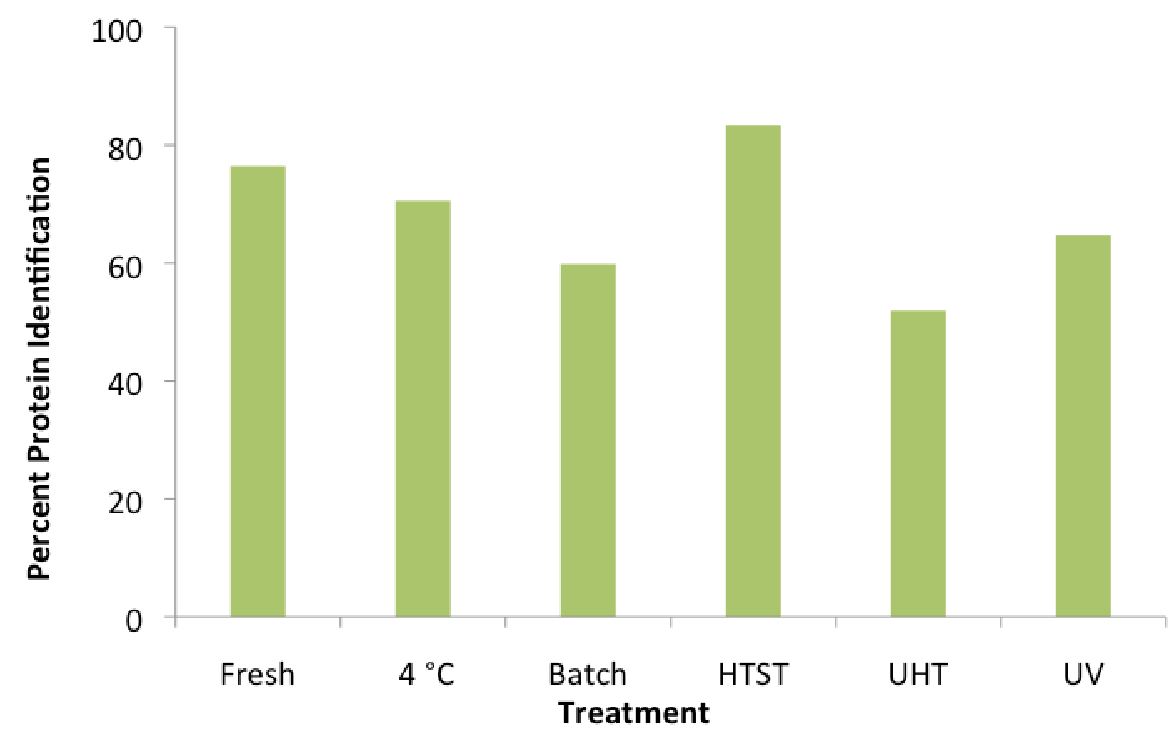

Figure 33. Percentage of identified proteins in each milk treatment from the 102 total characterized proteins identified by LC-MS .

The deoxycytidine kinase (DCK) enzyme was exclusively present in the UV pulsed treatment, and the ras-related protein Rab-8A and the cytoplasmic aconitase hydratase proteins were only present in the Fresh treatment. The elongation factor 1-alpha-1 was also present only in Fresh and with a low probability in the UV treatment. Appendix $\mathbf{J}$ shows the protein probability, identified peptide, and peptide coverage for each protein according to every treatment.

For MFGM, one of the greatest obstacles is identifying low abundance proteins due to the high abundance of some proteins such as butyrophilin, which results in fewer proteins being identified with high confidence; therefore, in order to minimize the high dynamic range in protein abundance that complicates proteomic analysis, $1 \mathrm{DE}$ gels were cut into molecular weight regions (I, II, III, and IV) for protein identification. Tables 16 through 19 depict the proteins present at specific intervals in the 1DE gels and possible interactions among MFGM proteins.

Table 16. Proteins identified in region I ( higher than $150 \mathrm{kDa}$ ) of MFGM isolates through LC/MS. 


\begin{tabular}{|c|c|c|c|c|c|c|c|c|}
\hline \multirow{2}{*}{$\begin{array}{l}\text { Accession } \\
\text { Number }\end{array}$} & \multirow{2}{*}{$\begin{array}{l}\text { MW } \\
(\mathbf{k D a})\end{array}$} & \multirow{2}{*}{$\begin{array}{l}\text { Identified Proteins in } \\
>150 \text { kDa Region }(\mathrm{I}) *\end{array}$} & \multicolumn{6}{|c|}{ Protein Probability } \\
\hline & & & $\mathbf{F}$ & $4^{\circ} \mathrm{C}$ & B & $\mathbf{H}$ & $\mathbf{U}$ & UV \\
\hline BT1A1_BOVIN & 59 & Butyrophilin subfamily 1 member A1 & 100 & 100 & 100 & 100 & 100 & 100 \\
\hline PLIN2_BOVIN & 49 & Isoform 2 of Perilipin-2 & 100 & 100 & 100 & 100 & 100 & 100 \\
\hline XDH_BOVIN & 147 & Xanthine dehydrogenase/oxidase & 100 & 100 & 100 & 100 & 100 & 100 \\
\hline ACACA_BOVIN & 265 & Acetyl-CoA carboxylase 1 & 100 & 100 & 100 & 100 & 100 & 100 \\
\hline ABCG2_BOVIN & 73 & $\begin{array}{l}\text { ATP-binding cassette sub-family G } \\
\text { member } 2\end{array}$ & 100 & 100 & 100 & 100 & 100 & 100 \\
\hline ENPP3_BOVIN & 100 & $\begin{array}{l}\text { Ectonucleotide pyrophosphatase/ } \\
\text { phosphodiesterase family member } 3\end{array}$ & 100 & 100 & 100 & 100 & 100 & 100 \\
\hline FAS_BOVIN & 275 & Fatty acid synthase & 100 & 100 & 100 & 100 & 99 & 99 \\
\hline CD36_BOVIN & 53 & Platelet glycoprotein 4 & 100 & 100 & 100 & 100 & 100 & 100 \\
\hline Q3T0K7_BOVIN & 48 & MFGE8 protein & 100 & 100 & 68 & 100 & 100 & 100 \\
\hline A6QNZ7_BOVIN & 55 & Keratin 10 & 100 & 100 & 68 & 100 & 100 & 98 \\
\hline K2C7_BOVIN & 52 & $\begin{array}{l}\text { Keratin, type II cytoskeletal } 7 \\
\text { Acyl-CoA synthetase long-chain }\end{array}$ & 100 & 100 & 68 & 99 & 50 & 58 \\
\hline Q0VCZ8_BOVIN & 78 & family member 1 & 100 & 100 & & 100 & 100 & 100 \\
\hline A4FV94_BOVIN & 61 & KRT6A protein & 100 & 100 & 68 & & 100 & 99 \\
\hline MUC1_BOVIN & 58 & Mucin-1 & 100 & 100 & 68 & 50 & & 100 \\
\hline NPT2B_BOVIN & 76 & $\begin{array}{l}\text { Sodium-dependent phosphate transport } \\
\text { protein } 2 B \\
\text { Guanine nucleotide-binding protein } \\
G(\mathrm{I}) / \mathrm{G}(\mathrm{S}) / \mathrm{G}(\mathrm{T})\end{array}$ & 100 & 100 & & 100 & 100 & \\
\hline GBB2_BOVIN & 37 & subunit beta- 2 & 53 & 55 & & & 100 & 30 \\
\hline K2C71_BOVIN & 57 & Keratin, type II cytoskeletal 71 & 97 & 55 & & & 29 & 98 \\
\hline A7E340_BOVIN & 36 & Mucin 15 , cell surface associated & 30 & & & & & 17 \\
\hline RAB18_BOVIN & 23 & Ras-related protein Rab-18 & 99 & & & 49 & 50 & 58 \\
\hline Q17QL7_BOVIN & 49 & KRT15 protein & 53 & & & & 50 & \\
\hline B5B0D4_BOVIN & 20 & $\begin{array}{l}\text { Major allergen beta-lactoglobulin } \\
\text { Isoform Short of Polymeric }\end{array}$ & & & 68 & 100 & 100 & 100 \\
\hline PIGR_BOVIN & 59 & immunoglobulin receptor & & & 100 & 100 & 100 & \\
\hline FABPH_BOVIN & 15 & Fatty acid-binding protein, heart & & & & 100 & 50 & \\
\hline ALBU_BOVIN & 69 & $\begin{array}{l}\text { Serum albumin } \\
\text { Enterotoxin-binding glycoprotein }\end{array}$ & & & & 100 & 100 & \\
\hline Q9TRB9_BOVIN & 2 & PP20K (Fragment) & & & & 50 & 22 & \\
\hline PERL_BOVIN & 81 & Lactoperoxidase & & & & 98 & 100 & \\
\hline CASB_BOVIN & 25 & $\begin{array}{l}\text { Beta-casein } \\
\text { Pentatricopeptide repeat-containing }\end{array}$ & & & & & 50 & 58 \\
\hline PTCD2_BOVIN & 44 & protein 2 & & & & & 96 & \\
\hline A4FUX1_BOVIN & 25 & $\begin{array}{l}\text { CIDEA protein } \\
\text { cGMP-dependant type II protein }\end{array}$ & & 98 & & & 22 & 100 \\
\hline D5HSX1_BOVIN & 87 & kinase & & 99 & & & & 58 \\
\hline GLCM1_BOVIN & 17 & $\begin{array}{l}\text { Glycosylation-dependent cell adhesion } \\
\text { molecule } 1\end{array}$ & & 22 & & 50 & 50 & \\
\hline A6QQR3_BOVIN & 36 & APOL3 protein & 98 & & & & & \\
\hline CASA1_BOVIN & 25 & Alpha-S1-casein & 30 & & & & & \\
\hline HSP7C_BOVIN & 71 & Heat shock cognate $71 \mathrm{kDa}$ protein & 53 & & & & & \\
\hline Q2T9M8_BOVIN & 23 & $\begin{array}{l}\text { Synaptosomal-associated protein } \\
\text { RAB1A, member RAS oncogene }\end{array}$ & & 26 & & & & \\
\hline A1L528_BOVIN & 23 & family & & 55 & & & & \\
\hline
\end{tabular}




\begin{tabular}{|c|c|c|c|c|c|c|c|c|}
\hline \multirow{2}{*}{$\begin{array}{l}\text { Accession } \\
\text { Number }\end{array}$} & \multirow{2}{*}{$\begin{array}{c}\text { MW } \\
\text { (kDa) }\end{array}$} & \multirow{2}{*}{$\begin{array}{l}\text { Identified Proteins in } \\
>150 \text { kDa Region }(\mathrm{I}) *\end{array}$} & \multicolumn{6}{|c|}{ Protein Probability } \\
\hline & & & $\mathbf{F}$ & $4^{\circ} \mathrm{C}$ & B & H & $\mathbf{U}$ & UV \\
\hline ANXA2_BOVIN & 39 & Annexin A2 & & & 68 & & & \\
\hline Q8MKB7_BOVIN & 73 & $\mathrm{Na}+$ /glucose cotransporter & & & & & 100 & \\
\hline 5NTD_BOVIN & 63 & 5'-nucleotidase & & & & & 50 & \\
\hline A8E4P3_BOVIN & 31 & $\begin{array}{l}\text { STOM protein } \\
\text { Guanine nucleotide-binding protein }\end{array}$ & & & & & 50 & \\
\hline GBB1_BOVIN & 37 & $\mathrm{G}(\mathrm{I}) / \mathrm{G}(\mathrm{S}) / \mathrm{G}(\mathrm{T})$ subunit beta-1 & & & & & 45 & \\
\hline A6QLW3_BOVIN & 37 & RPRD1B protein & & & & & 99 & \\
\hline B3VTM3_BOVIN & 78 & Lactoferrin & & & & & 100 & \\
\hline LACB_BOVIN & 20 & Beta-lactoglobulin & & & & & 100 & \\
\hline Q28049_BOVIN & 14 & Alpha lactalbumin (Fragment) & & & & & 100 & \\
\hline CASK_BOVIN & 21 & Kappa-casein & & & & & 100 & \\
\hline ANXA1_BOVIN & 39 & Annexin A2 & & & & & & 58 \\
\hline
\end{tabular}

F, Fresh; B, Batch; H, HTST; U, UHT; UV

A total of 48 proteins were identified.

Table 17. Proteins identified in region II (higher than 55 and less than $150 \mathrm{kDa}$ ) of MFGM isolates through LC/MS.

\begin{tabular}{|c|c|c|c|c|c|c|c|c|}
\hline \multirow{2}{*}{$\begin{array}{l}\text { Accession } \\
\text { Number }\end{array}$} & \multirow{2}{*}{$\begin{array}{c}\text { MW } \\
(\mathbf{k D a})\end{array}$} & \multirow{2}{*}{$\begin{array}{c}\text { Identified Proteins in } \\
>55<150 \text { kDa Region (II)* }\end{array}$} & \multicolumn{6}{|c|}{ Protein Probability } \\
\hline & & & $\mathbf{F}$ & $4^{\circ} \mathrm{C}$ & B & $\mathbf{H}$ & $\mathbf{U}$ & UV \\
\hline BT1A1_BOVIN & 59 & Butyrophilin subfamily 1 member A1 & 100 & 100 & 100 & 100 & 100 & 100 \\
\hline PLIN2_BOVIN & 49 & Isoform 2 of Perilipin-2 & 100 & 100 & 100 & 100 & 100 & 100 \\
\hline XDH_BOVIN & 147 & Xanthine dehydrogenase/oxidase & 100 & 100 & 100 & 100 & 100 & 100 \\
\hline Q3T0K7_BOVIN & 48 & MFGE8 protein & 100 & 100 & 100 & 100 & 100 & 100 \\
\hline ABCG2_BOVIN & 73 & $\begin{array}{l}\text { ATP-binding cassette sub-family G } \\
\text { member } 2 \\
\text { Isoform Short of Polymeric }\end{array}$ & 100 & 100 & 100 & 100 & 100 & 100 \\
\hline PIGR_BOVIN & 59 & immunoglobulin receptor & 100 & 100 & 100 & 100 & 100 & 100 \\
\hline CD36_BOVIN & 53 & $\begin{array}{l}\text { Platelet glycoprotein } 4 \\
\text { Acyl-CoA synthetase long-chain }\end{array}$ & 100 & 100 & 100 & 100 & 100 & 100 \\
\hline Q0VCZ8_BOVIN & 78 & family member 1 & 100 & 100 & 100 & 100 & 100 & 100 \\
\hline A7E340_BOVIN & 36 & $\begin{array}{l}\text { Mucin 15, cell surface associated } \\
\text { Glycoprotein } 2 \text { (Zymogen granule }\end{array}$ & 98 & 98 & 73 & 100 & 98 & 64 \\
\hline Q0IIA4_BOVIN & 59 & $\begin{array}{l}\text { membrane) } \\
\text { Sodium-dependent phosphate }\end{array}$ & 100 & 100 & 100 & 100 & & 100 \\
\hline NPT2B_BOVIN & 76 & transport protein $2 \mathrm{~B}$ & 100 & 100 & 100 & 100 & 99 & \\
\hline A4FV94_BOVIN & 61 & KRT6A protein & 100 & 100 & 73 & 100 & 100 & \\
\hline K2C7_BOVIN & 52 & Keratin, type II cytoskeletal 7 & 50 & 100 & 73 & 100 & 100 & \\
\hline K2C71_BOVIN & 57 & Keratin, type II cytoskeletal 71 & & 99 & & 50 & 99 & \\
\hline A6QNZ7_BOVIN & 55 & Keratin 10 & 50 & 100 & & 100 & 100 & \\
\hline GBB2_BOVIN & 37 & $\begin{array}{l}\text { Guanine nucleotide-binding protein } \\
\text { G(I)/G(S)/G(T) subunit beta-2 } \\
\text { cGMP-dependant type II protein }\end{array}$ & 98 & & & & 100 & \\
\hline D5HSX1_BOVIN & 87 & kinase & 100 & & & 100 & & \\
\hline ERG7_BOVIN & 83 & $\begin{array}{l}\text { Lanosterol synthase } \\
\text { Acetylcholine receptor subunit }\end{array}$ & 50 & & 59 & 99 & 100 & \\
\hline ACHE_BOVIN & 55 & epsilon & 19 & & & 50 & 96 & 25 \\
\hline
\end{tabular}




\begin{tabular}{|c|c|c|c|c|c|c|c|c|}
\hline \multirow{2}{*}{$\begin{array}{l}\text { Accession } \\
\text { Number }\end{array}$} & \multirow{2}{*}{$\begin{array}{c}\text { MW } \\
(\mathbf{k D a})\end{array}$} & \multirow{2}{*}{$\begin{array}{c}\text { Identified Proteins in } \\
>55<150 \text { kDa Region }(\text { II }) *\end{array}$} & \multicolumn{6}{|c|}{ Protein Probability } \\
\hline & & & $\mathbf{F}$ & $4^{\circ} \mathrm{C}$ & B & $\mathbf{H}$ & $\mathbf{U}$ & $\mathbf{U V}$ \\
\hline 5NTD_BOVIN & 63 & 5'-nucleotidase & 25 & 99 & & 100 & 100 & \\
\hline Q8MKB7_BOVIN & 73 & $\mathrm{Na}+$ /glucose cotransporter & 50 & 54 & & & & 64 \\
\hline Q9TSF1_BOVIN & 14 & Butyrophilin (Fragment) & & 19 & 98 & 16 & & 62 \\
\hline CASA1_BOVIN & 25 & $\begin{array}{l}\text { Alpha-S1-casein } \\
\text { Glycosylation-dependent cell }\end{array}$ & & 100 & & 50 & 99 & 64 \\
\hline GLCM1_BOVIN & 17 & adhesion molecule 1 & & 100 & & 50 & & \\
\hline B3VTM3_BOVIN & 78 & Lactoferrin & & & 100 & 100 & 100 & \\
\hline B5B0D4_BOVIN & 20 & Major allergen beta-lactoglobulin & & & & 100 & 100 & \\
\hline ALBU_BOVIN & 69 & $\begin{array}{l}\text { Serum albumin } \\
\text { Enterotoxin-binding glycoprotein }\end{array}$ & & & & 100 & 100 & \\
\hline Q9TRB9_BOVIN & 2 & PP20K (Fragment) & & & & 13 & 47 & \\
\hline PERL_BOVIN & 81 & Lactoperoxidase & & & & 12 & 50 & \\
\hline HSP7C_BOVIN & 71 & Heat shock cognate $71 \mathrm{kDa}$ protein & 100 & & & 50 & & \\
\hline GBB1_BOVIN & 37 & $\begin{array}{l}\text { Guanine nucleotide-binding protein } \\
\mathrm{G}(\mathrm{I}) / \mathrm{G}(\mathrm{S}) / \mathrm{G}(\mathrm{T}) \text { subunit beta-1 }\end{array}$ & 12 & & & & & \\
\hline A6QQR3_BOVIN & 36 & APOL3 protein & 100 & & 98 & & & \\
\hline RAB18_BOVIN & 23 & Ras-related protein Rab-18 & 100 & & & & & \\
\hline ACOC_BOVIN & 98 & Cytoplasmic aconitate hydratase & 100 & & & & & \\
\hline A4FUX1_BOVIN & 25 & CIDEA protein & 37 & & & & & \\
\hline FABPH_BOVIN & 15 & Fatty acid-binding protein, heart & 14 & & & & & \\
\hline Q08E14_BOVIN & 138 & Collagen, type III, alpha 1 & & 100 & & & & \\
\hline Q08DZ4_BOVIN & 98 & Smoothelin & & 98 & & & & \\
\hline PPBT_BOVIN & 57 & Alkaline phosphatase & & & & 100 & & \\
\hline LACB_BOVIN & 20 & Beta-lactoglobulin & & & & & 100 & \\
\hline Q28049_BOVIN & 14 & Alpha lactalbumin (Fragment) & & & & & 100 & \\
\hline CASK_BOVIN & 21 & Kappa-casein & & & & & 100 & \\
\hline A6QNL0_BOVIN & 40 & CD14 protein & & & & & 50 & \\
\hline Q17QL7_BOVIN & 49 & $\begin{array}{l}\text { KRT15 protein } \\
\text { RAB1A, member RAS oncogene }\end{array}$ & & & & & 50 & \\
\hline A1L528_BOVIN & 23 & family & & & & & 17 & \\
\hline
\end{tabular}

F, Fresh; B, Batch; H, HTST; U, UHT; UV

A total of 46 proteins were identified

Table 18. Proteins identified in region III (higher than 35 and less than $55 \mathrm{kDa}$ ) of MFGM isolates through LC/MS.

\begin{tabular}{|c|c|c|c|c|c|c|c|c|}
\hline \multirow{2}{*}{$\begin{array}{c}\text { Accession } \\
\text { Number }\end{array}$} & \multirow{2}{*}{$\begin{array}{l}\text { MW } \\
(\mathbf{k D a})\end{array}$} & \multirow{2}{*}{$\begin{array}{c}\text { Identified Proteins in } \\
>35<55 \mathrm{kDa} \text { Region (III)* }\end{array}$} & \multicolumn{6}{|c|}{ Protein Probability } \\
\hline & & & $\mathbf{F}$ & $4^{\circ} \mathrm{C}$ & B & $\mathbf{H}$ & $\mathbf{U}$ & $\mathbf{U V}$ \\
\hline BT1A1_BOVIN & 59 & Butyrophilin subfamily 1 member A1 & 100 & 100 & 100 & 100 & 100 & 100 \\
\hline PLIN2_BOVIN & 49 & Isoform 2 of Perilipin-2 (ADFP) & 100 & 100 & 100 & 100 & 100 & 100 \\
\hline XDH_BOVIN & 147 & Xanthine dehydrogenase/oxidase & 100 & 100 & 100 & 100 & 100 & 100 \\
\hline Q3T0K7_BOVIN & 48 & $\begin{array}{l}\text { MFGE8 protein } \\
\text { ATP-binding cassette sub-family G }\end{array}$ & 100 & 100 & 100 & 100 & 100 & 100 \\
\hline ABCG2_BOVIN & 73 & $\begin{array}{l}\text { Member } 2 \\
\text { Guanine nucleotide-binding protein }\end{array}$ & 100 & 100 & 100 & 99 & 100 & 100 \\
\hline GBB2_BOVIN & 37 & $\mathrm{G}(\mathrm{I}) / \mathrm{G}(\mathrm{S}) / \mathrm{G}(\mathrm{T})$ subunit beta-2 & 100 & 100 & 100 & 100 & 100 & 100 \\
\hline
\end{tabular}




\begin{tabular}{|c|c|c|c|c|c|c|c|c|}
\hline \multirow{2}{*}{$\begin{array}{l}\text { Accession } \\
\text { Number }\end{array}$} & \multirow{2}{*}{$\begin{array}{c}\text { MW } \\
(\mathbf{k D a})\end{array}$} & \multirow{2}{*}{$\begin{array}{c}\text { Identified Proteins in } \\
>35<55 \text { kDa Region (III)* }\end{array}$} & \multicolumn{6}{|c|}{ Protein Probability } \\
\hline & & & $\mathbf{F}$ & $4^{\circ} \mathrm{C}$ & B & $\mathbf{H}$ & $\mathbf{U}$ & UV \\
\hline K2C7_BOVIN & 52 & Keratin, type II cytoskeletal 7 & 100 & 100 & 75 & 51 & 50 & 73 \\
\hline ACTB_BOVIN & 42 & $\begin{array}{l}\text { Actin, cytoplasmic } 1 \\
\text { Guanine nucleotide-binding protein }\end{array}$ & 100 & 100 & 100 & 100 & 50 & 100 \\
\hline GBB1_BOVIN & 37 & $\mathrm{G}(\mathrm{I}) / \mathrm{G}(\mathrm{S}) / \mathrm{G}(\mathrm{T})$ subunit beta-1 & 100 & 80 & 98 & 100 & 100 & 100 \\
\hline CASA1_BOVIN & 25 & Alpha-S1-casein & 99 & 68 & 75 & 100 & 100 & 100 \\
\hline A4FV94_BOVIN & 61 & KRT6A protein & 100 & 100 & & 100 & 100 & 73 \\
\hline A9XTK4_BOVIN & 38 & 17-beta hydroxysteroid dehydrogenase & 100 & 80 & & 100 & & 64 \\
\hline A6QNZ7_BOVIN & 55 & Keratin 10 & 100 & 100 & & 99 & 50 & \\
\hline GNA11_BOVIN & 42 & $\begin{array}{l}\text { Guanine nucleotide-binding protein subunit } \\
\text { alpha-11 }\end{array}$ & 100 & & 36 & 100 & 99 & 73 \\
\hline GNAS2_BOVIN & 44 & $\begin{array}{l}\text { Isoform Alpha-S1 of Guanine nucleotide- } \\
\text { binding protein G(s) subunit alpha isoform } \\
\text { Mannose } 6 \text { phosphate receptor binding }\end{array}$ & 100 & & 98 & 100 & 45 & \\
\hline Q3SX32_BOVIN & 48 & protein 1 & 100 & & 75 & 100 & & 100 \\
\hline NSDHL_BOVIN & 40 & Sterol-4-alpha-carboxylate 3-dehydrogenase & 99 & & & 100 & 98 & 100 \\
\hline CD36_BOVIN & 53 & Platelet glycoprotein 4 & 99 & & 75 & & 100 & 73 \\
\hline A8E4P3_BOVIN & 31 & STOM protein & 99 & & & 100 & & 73 \\
\hline K2C71_BOVIN & 57 & Keratin, type II cytoskeletal 71 & 63 & & & 90 & & \\
\hline Q8MKB7_BOVIN & 73 & $\mathrm{Na}+$ /glucose cotransporter & 98 & 98 & & & & \\
\hline Q17QL7_BOVIN & 49 & KRT15 protein & 63 & 100 & & & & \\
\hline ANXA2_BOVIN & 39 & Annexin A2 & 63 & 80 & & 100 & 22 & \\
\hline GIPC2_BOVIN & 35 & PDZ domain-containing protein GIPC2 & 100 & & & 100 & & \\
\hline ANXA1_BOVIN & 39 & Annexin A1 & 63 & & & 51 & & 100 \\
\hline A6QLH3_BOVIN & 33 & STX3 protein & 100 & 57 & & 51 & & 99 \\
\hline Q2KIS4_BOVIN & 34 & $\begin{array}{l}\text { Dehydrogenase/reductase (SDR family) } \\
\text { member } 1\end{array}$ & 98 & & & 100 & & \\
\hline A5PKG9_BOVIN & 59 & FGR protein & 63 & & & 100 & & \\
\hline A7MBH9_BOVIN & 40 & GNAI2 protein & 100 & 60 & & & & \\
\hline Q0VCZ8_BOVIN & 78 & $\begin{array}{l}\text { Acyl-CoA synthetase long-chain family } \\
\text { member } 1\end{array}$ & & 98 & & & & 99 \\
\hline ACHE_BOVIN & 55 & $\begin{array}{l}\text { Acetylcholine receptor subunit epsilon } \\
\text { Isoform Short of Polymeric immunoglobulin }\end{array}$ & & & & & & 55 \\
\hline PIGR_BOVIN & 59 & receptor & & & 100 & 100 & 100 & 100 \\
\hline A7YWR0_BOVIN & 36 & Apolipoprotein E & & & 98 & 100 & & 73 \\
\hline A6H7D4_BOVIN & 52 & Lysophosphatidic acid acyltransferase, zeta & & & 75 & 100 & 47 & 73 \\
\hline B5B0D4_BOVIN & 20 & Major allergen beta-lactoglobulin & & & 75 & 100 & 100 & 99 \\
\hline CASA2_BOVIN & 26 & Alpha-S2-casein & & & & 100 & 100 & \\
\hline A6H7G0_BOVIN & 34 & CYB5R3 protein & & 80 & 75 & 100 & 100 & \\
\hline A6QNL0_BOVIN & 40 & CD14 protein & & 66 & 100 & 100 & 99 & \\
\hline ANXA5_BOVIN & 36 & Annexin A5 & & & 51 & 100 & & \\
\hline CASK_BOVIN & 21 & Kappa-casein & & & & 100 & 100 & \\
\hline ALBU_BOVIN & 69 & Serum albumin & & & & 99 & 100 & \\
\hline LIPL_BOVIN & 53 & Lipoprotein lipase & & & & 100 & 97 & \\
\hline EF1A1_BOVIN & 50 & Elongation factor 1-alpha 1 & 100 & & & & & 29 \\
\hline NPT2B_BOVIN & 76 & Sodium-dependent phosphate transport-2B & 100 & & & & & \\
\hline HSP7C_BOVIN & 71 & Heat shock cognate $71 \mathrm{kDa}$ protein & 99 & & & & & \\
\hline
\end{tabular}




\begin{tabular}{|c|c|c|c|c|c|c|c|c|}
\hline \multirow{2}{*}{$\begin{array}{c}\text { Accession } \\
\text { Number }\end{array}$} & \multirow{2}{*}{$\begin{array}{c}\text { MW } \\
(\mathbf{k D a})\end{array}$} & \multirow{2}{*}{$\begin{array}{c}\text { Identified Proteins in } \\
>35<55 \text { kDa Region (III)* }\end{array}$} & \multicolumn{6}{|c|}{ Protein Probability } \\
\hline & & & $\mathbf{F}$ & $4^{\circ} \mathrm{C}$ & B & $\mathbf{H}$ & $\mathbf{U}$ & UV \\
\hline K1C17_BOVIN & 49 & Keratin, type I cytoskeletal 17 & & 98 & & & & \\
\hline PIPNA_BOVIN & 32 & 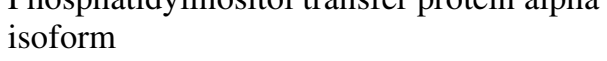 & & 97 & & & & \\
\hline 5NTD_BOVIN & 63 & 5'-nucleotidase & & & & & & \\
\hline A1L528_BOVIN & 23 & RAB1A, member RAS oncogene family & & & 75 & & & \\
\hline D4QGC1_BOVIN & 59 & Tyrosine-protein kinase Lyn & & & & 100 & & \\
\hline RAB18_BOVIN & 23 & Ras-related protein Rab-18 & & & & & 100 & \\
\hline LACB_BOVIN & 20 & Beta-lactoglobulin & & & & & 100 & \\
\hline Q28049_BOVIN & 14 & Alpha lactalbumin (Fragment) & & & & & 100 & \\
\hline CASB_BOVIN & 25 & Beta-casein & & & & & 98 & \\
\hline Q3T101_BOVIN & 25 & IGL@ protein & & & & & 98 & \\
\hline Q0IIA4_BOVIN & 59 & Glycoprotein 2 & & & & & & 100 \\
\hline
\end{tabular}

F, Fresh; B, Batch; H, HTST; U, UHT; UV

A total of 58 proteins were identified

Table 19. Proteins identified in region IV (less than $35 \mathrm{kDa}$ ) of MFGM isolates through LC/MS.

\begin{tabular}{|c|c|c|c|c|c|c|c|c|}
\hline \multirow{2}{*}{$\begin{array}{l}\text { Accession } \\
\text { Number }\end{array}$} & \multirow{2}{*}{$\begin{array}{c}\text { MW } \\
(\mathbf{k D a})\end{array}$} & \multirow{2}{*}{$\begin{array}{l}\text { Identified Proteins in } \\
<35 \text { kDa Region (IV)* }\end{array}$} & \multicolumn{6}{|c|}{ Protein Probability } \\
\hline & & & $\mathbf{F}$ & $4^{\circ} \mathrm{C}$ & $\mathbf{B}$ & $\mathbf{H}$ & $\mathbf{U}$ & UV \\
\hline BT1A1_BOVIN & 59 & Butyrophilin subfamily 1 member A1 & 100 & 100 & 100 & 100 & 100 & 100 \\
\hline PLIN2_BOVIN & 49 & Isoform 2 of Perilipin-2 (ADFP) & 100 & 100 & 100 & 100 & 100 & 100 \\
\hline XDH_BOVIN & 147 & Xanthine dehydrogenase/oxidase & 100 & 100 & 100 & 99 & 100 & 100 \\
\hline Q3T0K7_BOVIN & 48 & MFGE8 protein & 100 & 100 & 100 & 100 & 78 & 100 \\
\hline Q3T101_BOVIN & 25 & IGL@ protein & 100 & 100 & 100 & 100 & 100 & 100 \\
\hline FABPH_BOVIN & 15 & Fatty acid-binding protein, heart & 100 & 100 & 100 & 100 & 100 & 100 \\
\hline RAB18_BOVIN & 23 & Ras-related protein Rab-18 & 100 & 100 & 100 & 100 & 100 & 100 \\
\hline B5B0D4_BOVIN & 20 & Major allergen beta-lactoglobulin & 72 & 100 & 100 & 100 & 100 & 100 \\
\hline CASA1_BOVIN & 25 & Alpha-S1-casein & 100 & 100 & 100 & 100 & 100 & 100 \\
\hline A4FV94_BOVIN & 61 & KRT6A protein & 72 & 100 & 68 & 100 & 100 & 98 \\
\hline A1L528_BOVIN & 23 & RAB1A, member RAS oncogene family & 100 & 100 & 100 & 100 & 100 & 100 \\
\hline CASA2_BOVIN & 26 & Alpha-S2-casein & 72 & 100 & 100 & 100 & 100 & 100 \\
\hline CASK_BOVIN & 21 & Kappa-casein & 98 & 100 & 100 & 100 & 100 & 100 \\
\hline K2C7_BOVIN & 52 & Keratin, type II cytoskeletal 7 & 100 & 100 & 98 & 70 & 78 & 70 \\
\hline RB11A_BOVIN & 24 & Ras-related protein Rab-11A & 100 & 100 & 100 & 100 & 69 & 100 \\
\hline A8E4P3_BOVIN & 31 & STOM protein & 100 & 100 & 100 & 100 & & 100 \\
\hline Q861V9_BOVIN & 16 & Peptidyl-prolyl cis-trans isomerase (Frag) & 100 & 100 & 100 & 100 & 62 & 100 \\
\hline CASB_BOVIN & 25 & Beta-casein & 100 & 100 & & 100 & 78 & 100 \\
\hline A4FUX1_BOVIN & 25 & CIDEA protein & 100 & 100 & 100 & 100 & & 100 \\
\hline Q2T9M8_BOVIN & 23 & Synaptosomal-associated protein & 100 & 100 & 100 & 100 & & 100 \\
\hline CTHL1_BOVIN & 18 & Cathelicidin-1 & 100 & 100 & 100 & 100 & & 100 \\
\hline Q3SYR8_BOVIN & 18 & Immunoglobulin J chain & 100 & 100 & 100 & 70 & & 70 \\
\hline RAC1_BOVIN & 21 & Ras-related $\mathrm{C} 3$ botulinum toxin substrate 1 & 100 & 73 & 68 & 100 & & 97 \\
\hline SAR1A_BOVIN & 22 & GTP-binding protein SAR1a & 100 & 100 & 99 & 100 & & 100 \\
\hline
\end{tabular}




\begin{tabular}{|c|c|c|c|c|c|c|c|c|}
\hline \multirow{2}{*}{$\begin{array}{l}\text { Accession } \\
\text { Number }\end{array}$} & \multirow{2}{*}{$\begin{array}{c}\text { MW } \\
(\mathbf{k D a})\end{array}$} & \multirow{2}{*}{$\begin{array}{l}\text { Identified Proteins in } \\
<35 \text { kDa Region (IV)* }\end{array}$} & \multicolumn{6}{|c|}{ Protein Probability } \\
\hline & & & $\mathbf{F}$ & $4^{\circ} \mathrm{C}$ & B & $\mathbf{H}$ & $\mathbf{U}$ & UV \\
\hline RAB7A_BOVIN & 24 & Ras-related protein Rab-7a & 100 & 100 & 100 & 100 & & 70 \\
\hline RAP1A_BOVIN & 21 & Ras-related protein Rap-1A & 100 & 100 & 68 & 99 & & 98 \\
\hline B6VAP7_BOVIN & 21 & $\mathrm{CDC} 42$ protein & 100 & 100 & & 100 & & \\
\hline SEP15_BOVIN & 18 & $15 \mathrm{kDa}$ selenoprotein & 72 & 73 & 99 & 100 & & 70 \\
\hline B0JYL8_BOVIN & 19 & Cofilin 1 & 72 & 100 & 68 & 70 & & 100 \\
\hline MUC1_BOVIN & 58 & Mucin-1 & 100 & 98 & 57 & & & 27 \\
\hline B0JYP6_BOVIN & 26 & IGK protein & 100 & 100 & 100 & & & 100 \\
\hline ABCG2_BOVIN & 73 & ATP-binding cassette sub-family G-2 & 72 & 100 & 68 & & & 100 \\
\hline Q0IIA4_BOVIN & 59 & $\begin{array}{l}\text { Glycoprotein } 2 \\
\text { Related RAS viral (R-ras) oncogene }\end{array}$ & & 98 & & & & 70 \\
\hline Q2TBH2_BOVIN & 24 & homolog & 100 & 100 & & & & 100 \\
\hline CHP1_BOVIN & 22 & Calcium-binding protein p22 & 72 & 100 & & & & 100 \\
\hline ARF1_BOVIN & 21 & $\begin{array}{l}\text { ADP-ribosylation factor } 1 \\
\text { Guanine nucleotide-binding protein }\end{array}$ & 100 & 73 & & & & 70 \\
\hline GBB2_BOVIN & 37 & $\mathrm{G}(\mathrm{I}) / \mathrm{G}(\mathrm{S}) / \mathrm{G}(\mathrm{T})$ subunit beta-2 & 72 & 73 & 47 & & & \\
\hline YKT6_BOVIN & 22 & Synaptobrevin homolog YKT6 & 72 & 100 & & 70 & & 100 \\
\hline ARL15_BOVIN & 23 & ADP-ribosylation factor-like protein 15 & 99 & 99 & & 100 & & 70 \\
\hline Q6QRN7_BOVIN & 34 & PP1201 protein & 72 & 100 & & 70 & & 100 \\
\hline A5D7E0_BOVIN & 23 & RAB35 protein & & 100 & & 99 & 64 & 70 \\
\hline Q1RMN8_BOVIN & 25 & Immunoglobulin light chain, $\lambda$ gene cluster & & 100 & 100 & & 70 & \\
\hline A5D7R9_BOVIN & 21 & NRAS protein & & & 99 & & & 100 \\
\hline PROF1_BOVIN & 15 & Profilin-1 & & & & 70 & & 99 \\
\hline A4FUH8_BOVIN & 21 & $\begin{array}{l}\text { Chromosome } 1 \text { open reading frame } 93 \\
\text { ortholog }\end{array}$ & & & & 100 & & \\
\hline A6QQR3_BOVIN & 36 & APOL3 protein & & 73 & 28 & & & \\
\hline A7YWR0_BOVIN & 36 & Apolipoprotein E & & & & 28 & & \\
\hline A6QNZ7_BOVIN & 55 & $\begin{array}{l}\text { Keratin } 10 \\
\text { Glycosylation-dependent cell adhesion }\end{array}$ & & 99 & 34 & 100 & 100 & 98 \\
\hline GLCM1_BOVIN & 17 & $\begin{array}{l}\text { molecule } 1 \\
\text { Enterotoxin-binding glycoprotein PP20K }\end{array}$ & & 100 & 100 & 100 & 98 & \\
\hline Q9TRB9_BOVIN & 2 & (Fragment) & & 53 & 31 & 100 & 100 & \\
\hline LACB_BOVIN & 20 & Beta-lactoglobulin & & & 68 & 100 & 100 & \\
\hline Q28049_BOVIN & 14 & $\begin{array}{l}\text { Alpha lactalbumin (Fragment) } \\
\text { Acyl-CoA synthetase long-chain family }\end{array}$ & & & & 100 & 100 & \\
\hline Q0VCZ8_BOVIN & 78 & member 1 & & 44 & & 27 & & 42 \\
\hline K2C71_BOVIN & 57 & Keratin, type II cytoskeletal 71 & & 99 & & 66 & & 47 \\
\hline ACTB_BOVIN & 42 & Actin, cytoplasmic 1 & & 100 & & & & 100 \\
\hline A6H7G0_BOVIN & 34 & CYB5R3 protein & & 73 & & & & 100 \\
\hline GNAS2_BOVIN & 44 & $\begin{array}{l}\text { Alpha-S1 of Guanine nucleotide-binding } \\
\text { protein G(s) subunit alpha isoforms short } \\
\text { CKLF-like MARVEL transmembrane }\end{array}$ & & 73 & & & & 47 \\
\hline Q1JQ95_BOVIN & 18 & domain containing 7 & & & & & & 100 \\
\hline A5D7N2_BOVIN & 14 & Histone $\mathrm{H} 2 \mathrm{~B}$ & & 99 & & & & 99 \\
\hline RAB5C_BOVIN & 23 & Ras-related protein Rab-5C & 72 & 100 & & & & \\
\hline RAB1B_BOVIN & 22 & Ras-related protein Rab-1B & 95 & 58 & & 70 & & \\
\hline RAB13_BOVIN & 23 & Ras-related protein Rab-13 & 72 & & & 100 & & \\
\hline RHOC_BOVIN & 22 & Rho-related GTP-binding protein $\mathrm{RhoC}$ & 72 & & & 100 & & \\
\hline
\end{tabular}




\begin{tabular}{|c|c|c|c|c|c|c|c|c|}
\hline \multirow{2}{*}{$\begin{array}{l}\text { Accession } \\
\text { Number }\end{array}$} & \multirow{2}{*}{$\begin{array}{l}\text { MW } \\
(\mathbf{k D a})\end{array}$} & \multirow{2}{*}{$\begin{array}{l}\text { Identified Proteins in } \\
<35 \text { kDa Region }(\text { IV)* }\end{array}$} & \multicolumn{6}{|c|}{ Protein Probability } \\
\hline & & & $\mathbf{F}$ & $4^{\circ} \mathrm{C}$ & B & $\mathbf{H}$ & $\mathbf{U}$ & UV \\
\hline RAB8A_BOVIN & 24 & Ras-related protein $\mathrm{Rab}-8 \mathrm{~A}$ & 99 & & & & & \\
\hline Q3SX32_BOVIN & 48 & $\begin{array}{l}\text { Mannose } 6 \text { phosphate receptor binding } \\
\text { protein } 1\end{array}$ & & 100 & & & & \\
\hline 1433B_BOVIN & 28 & Isoform Short of 14-3-3 protein beta/alpha & & 95 & & & & \\
\hline PERL_BOVIN & 81 & Lactoperoxidase & & 73 & & & & \\
\hline Q9TSF1_BOVIN & 14 & Butyrophilin (Fragment) & & 96 & & & & \\
\hline FABP7_BOVIN & 15 & Fatty acid-binding protein, brain & & & 100 & & & \\
\hline A7E340_BOVIN & 36 & Mucin 15 , cell surface associated & & & & & 31 & \\
\hline RBM22_BOVIN & 47 & Pre-mRNA-splicing factor RBM22 & & & & & & 98 \\
\hline A5D792_BOVIN & 18 & $\begin{array}{l}\text { DCK protein } \\
\text { Guanine nucleotide-binding protein }\end{array}$ & & & & & & 100 \\
\hline GBB1_BOVIN & 37 & $\mathrm{G}(\mathrm{I}) / \mathrm{G}(\mathrm{S}) / \mathrm{G}(\mathrm{T})$ subunit beta-1 & & & & & & 70 \\
\hline FAS_BOVIN & 275 & Fatty acid synthase & & & & & & 54 \\
\hline
\end{tabular}

\section{E. MFGM Protein Profile from 2-Dimensional Gel Coupled with MALDI-TOF}

\section{Visualization of MFGM Proteins with Fluorescent Dye}

SyproRuby is one of the most sensitive stains in the market, capable of detecting as little as 0.5-1 ng of protein per $\mathrm{mm}^{2}$ (Candiano et al., 2004). In this research, this fluorescent dye was utilized in preliminary studies to determine the MFGM protein pattern. Studies have shown that the sensitivity of SyproRuby is superior to colloidal Coomassie brilliant blue (Berggren et al., 2000). It specifically binds to proteins by noncovalent interactions, avoiding impurities in samples such as lipids. As observed in Figure 34, SyproRuby resulted in similar 2-DE maps as the ones analyzed in the research. 

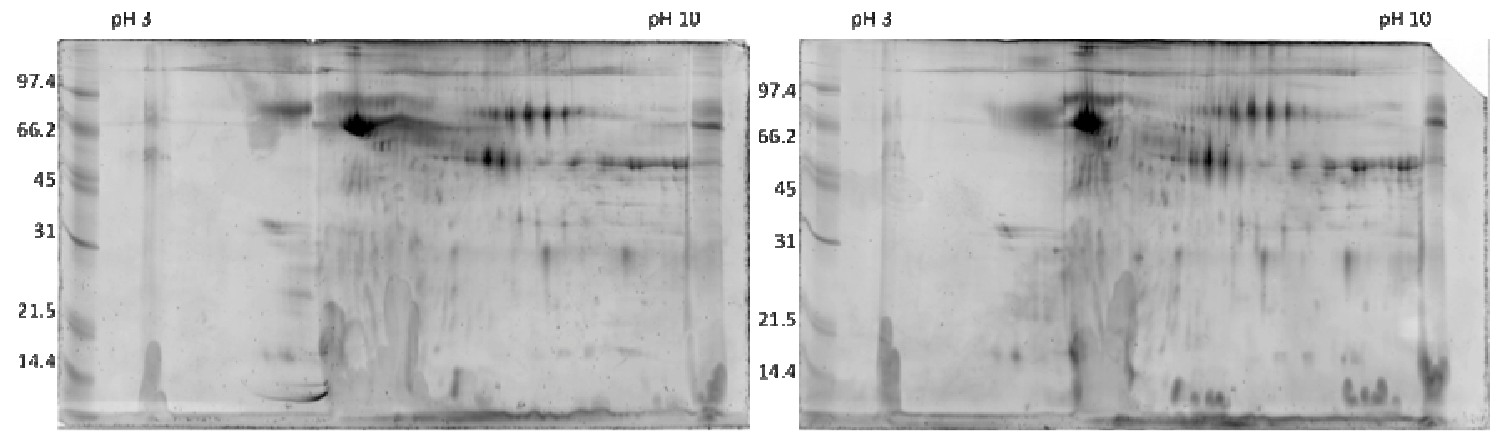

Figure 34. Representative 2-DE map of Batch (left) and high temperature short time (HTST) pasteurization treatments dyed with fluorescent dye, Sypro-Ruby. A total of $100 \mu \mathrm{g}$ of protein was loaded and stained with a 1:5 dilution of the dye.

\section{Visualization of MFGM Protein with Coomassie Blue}

For a better understanding of the changes in the MFGM proteins during milk processing, 2DE gels were performed on the six treatments. Different concentrations were tested to optimize the protocol and obtain good resolution as well as sensitivity. The use of sensitive colloidal stain, which utilizes Coomassie Blue (Westermeier, 2006), permitted loading only $100 \mu \mathrm{g}$ of protein. Figure 35 depicts the $2 \mathrm{DE}$ pattern for each treatment. 

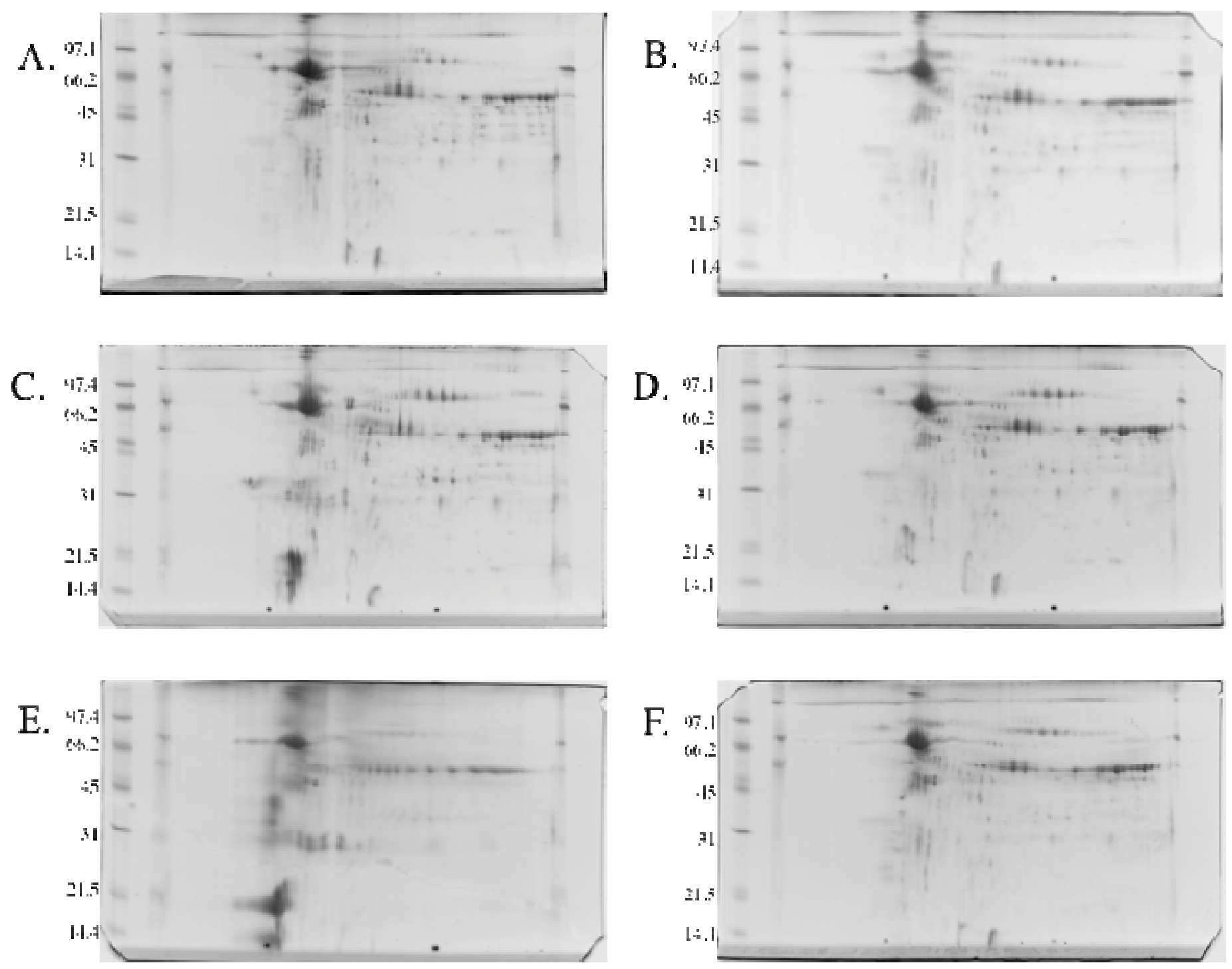

Figure 35. Representative 2-DE map of MFGM proteins during milk processing. A $12.5 \%$ SDS-PAGE stained w sensitive colloidal. A) Fresh, B) $4{ }^{\circ} \mathrm{C}$, C) Batch, D) HTST, E) UHT, and F) UV.

All the treatments had good resolution with the exception of UHT, which resulted in streaks and spotting, probably due to the presence of complexes (Figure 35.E).

\section{3. $\quad$ MFGM Protein Variation during Milk Processing}

With the help of Delta2D, the 2-D gels were compared in a two-way ANOVA using the Fresh sample as a control to determine protein fluctuation $(\mathrm{p}<0.01)$. Figure 36 shows a graphical representation of the percent protein change between each treatment and the 
control, Fresh milk. As expected, UHT had the highest percent change among the comparisons followed by the batch treatment. The complete ANOVA-2 results are shown in Appendix K.

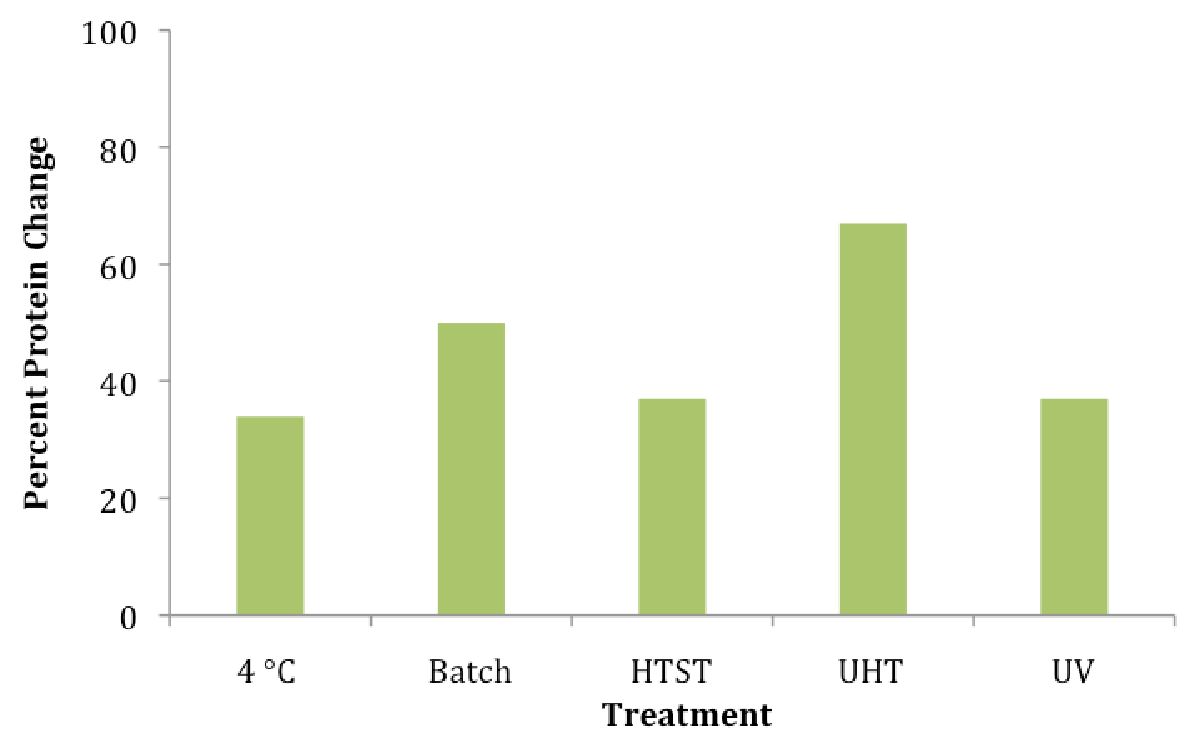

Figure 36. Protein expression change during milk processing. 2DE gels were compared using a statistical program. Each treatment was compared against the Fresh sample, and the change in protein expression is indicated as a percentage (Delta2D, $p<0.01$ ).

The global change during the entire milk processing, including the cold treatment, can be visualized in Figure $37(\mathrm{p}<0.01)$. An increase in temperature induced a $86 \%$ change in MFGM proteins; however, almost $20 \%$ of this fluctuation was due to UHT. Batch pasteurization also produced a high protein change, probably due to the prolonged time during the treatment. Cold pasteurization resulted in a protein fluctuation similar to $4{ }^{\circ} \mathrm{C}$. Analysis of the treatments without heat (Fresh, $4{ }^{\circ} \mathrm{C}$, and UV) resulted in a $52 \%$ change (Figure 37). 


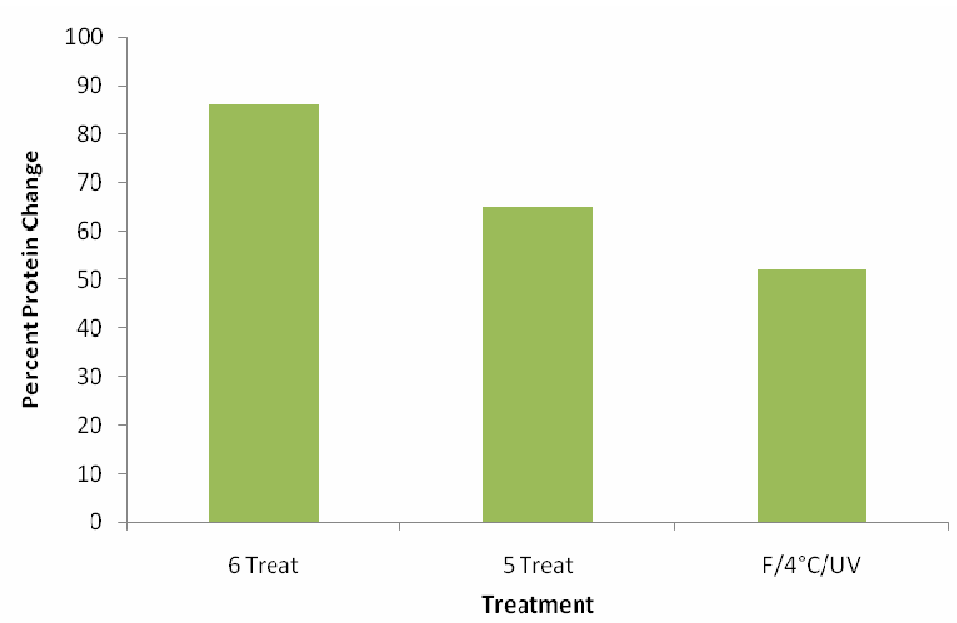

Figure 37. Protein expression change during milk processing. 2DE gels were compared using a statistical program. All the treatments were compared against the Fresh sample (6 Treat), without UHT (5 Treat), and no heat application (Fresh, $\left.4{ }^{\circ} \mathrm{C}, \mathrm{UV}\right)$. The change in protein expression is indicated as a percentage.

This data indicates that protein variation during milk processing can be visualized with 2DE gels and analyzed with Delta2D; but the latter is a tool that can be further used to help us interpret results.

\section{Identification of MFGM Proteins during Milk Processing}

Milk fat globule membrane proteins that are altered during milk processing were detected using Peptide Mass Fingerprinting (PMF). More than 300 spots were detected on the 2-dimensional gels with a $\mathrm{pI}$ range of 3 to 7 that differed significantly $(\mathrm{p}<0.01)$ as a function of temperature. Region with high variation were chosen for further identification; however, only $65 \%$ of the these spots were successfully identified via MALDI-TOF. Limitations such as incompleteness of bovine protein databases and relatively high threshold parameters used to define a positive identification may have reduced the number of hits obtained. In addition, some proteins may have been irreversibly denatured and not rehydrated during the 2D sample preparation step, which avoided their final detection. 
Among the identified proteins that vary during cold storage $\left(4^{\circ} \mathrm{C}\right)$, many isoforms of the major MFGM proteins were observed in accordance to previous studies (Fong et al., 2007). Butyrophilin was detected in different areas of the composite gel image (proteome map) of the Fresh $/ 4{ }^{\circ} \mathrm{C}$ set (Figure 35). These results corroborate previous observations that BTN is present in multiple forms. Indeed, Vanderghem, et al. (2008) identified three groups, $67 \mathrm{kDa}, 62 \mathrm{kDA}$, and a third group at $80 \mathrm{kDa}$. The BTN present in this study has molecular weight of approximately $52 \mathrm{kDa}$.

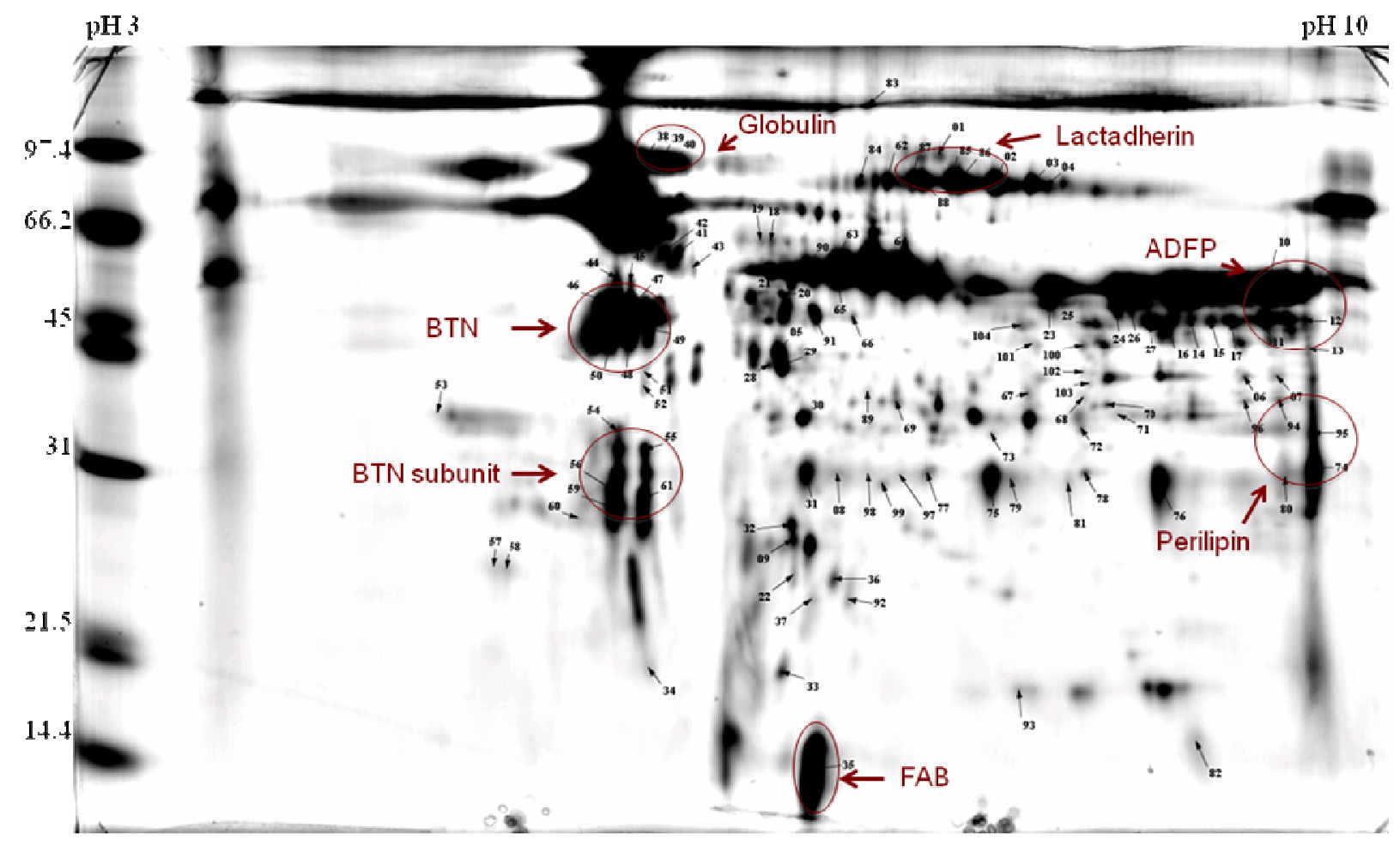

Figure 38. Proteome map (Delta 2D) depicting 104 spots from the $4^{\circ} \mathrm{C}$ milk sample versus the Fresh milk sample (control). The proteome map represents average pixel volumes for each protein spot. Labeled spots showed changes in abundance in response to cold storage temperature (two-way ANOVA, $p<0.01$, total spots 305 ).

Lactadherin also varied in abundance during the storage conditions of milk, and it was observed as a train of spots at a molecular weight of approximately $90 \mathrm{kDa}$. Previous studies described two groups of lactadherin, with $60 \mathrm{kDa}$ and $80 \mathrm{kDa}$ (Vanderghem et al., 
2008). Other molecules that were altered in concentration during cold condition were adipophilin and perilipins. Mather (2000) reported two adipophilin with different isoelectric points (pI), 7.5 and 7.8. In another study, five isoelectric variants were found in $2 \mathrm{DE}$ gels. In this research, adipophilin with a predicted $\mathrm{pI}$ of 5.85 was observed, and the lower pI is probably due to phosphorylation (Table 20). The constant region of immunoglobulin heavy chain was identified indicating that immunoglobulins are altered and even denatured during cold temperatures. Fong et al. (2007) also identified this protein in the MFGM. For a positive identification, a minimum of two peptides was required along with a Mascot score of 50.

Table 20. Identified proteins in the proteome map from $4{ }^{\circ} \mathrm{C}$ milk sample versus the Fresh milk sample that vary during milk processing.

\begin{tabular}{llllllll}
\hline $\begin{array}{c}\text { Spot } \\
\text { ID }\end{array}$ & \multicolumn{1}{c}{ Protein ID } & $\begin{array}{c}\text { MW } \\
\text { (kDa) }\end{array}$ & pI & $\begin{array}{c}\text { GenBank } \\
\text { ID }\end{array}$ & $\begin{array}{c}\text { Mascot } \\
\text { Score }\end{array}$ & $\begin{array}{c}\text { Pep } \\
\text { (\%) }\end{array}$ \\
\hline 5 & Butyrophilin & 59.21 & 5.11 & gil2266432 & 283 & 6 & 25 \\
2 & Polymeric immunoglobulin & 82.47 & 7.68 & gil296479365 & 69 & 2 & 9 \\
& receptor precursor & & & & & & \\
6 & Perilipin-2 & 49.31 & 8.72 & gil296484843 & 276 & 7 & 30 \\
9 & rho-related GTP-binding protein ThoC- & 21.93 & 6.20 & gil327271431 & 246 & 2 & 23 \\
& like & & & & & & \\
10 & Perilipin-2 & 49.31 & 8.72 & gil296484843 & 472 & 8 & 36 \\
11 & Perilipin-2 & 49.31 & 8.72 & gil296484843 & 414 & 9 & 36 \\
12 & ADFP protein & 49.04 & 5.85 & gil74354901 & 82 & 3 & 11 \\
13 & ADFP protein & 49.04 & 5.85 & gil74354901 & 49 & 4 & 17 \\
16 & ADFP protein & 49.04 & 5.85 & gil74354901 & 115 & 4 & 15 \\
17 & ADFP protein & 49.04 & 5.85 & gil74354901 & 114 & 4 & 13 \\
20 & rab GDP dissociation inhibitor beta & 50.46 & 5.94 & gil76253900 & 47 & 2 & 11 \\
$22 B$ & Perilipin-2 & 49.31 & 8.72 & gil296484843 & 204 & 6 & 27 \\
24 & ADFP protein & 49.31 & 5.85 & gil74354901 & 122 & 5 & 13 \\
26 & Perilipin-2 & 49.31 & 8.72 & gil296484843 & 94 & 4 & 19 \\
27 & Perilipin-2 & 49.31 & 8.72 & gil296484843 & 357 & 9 & 36 \\
28 & Butyrophilin-Fragment* & 14.13 & 4.99 & gil40388469 & 44 & 1 & 2 \\
29 & Butyrophilin & 59.21 & 5.11 & gil2266432 & 285 & 5 & 21 \\
30 & Butyrophilin subfamily 1 member & 59.22 & 5.10 & gil27806233] & 194 & 5 & 32 \\
& A1 precursor $\dagger$ & & & & & & \\
32 & Protein phosphatase 1J & 87.05 & 8.94 & gil296208863 & 204 & 3 & 26 \\
35 A & Fatty acid-binding protein, heart & 14.77 & 6.73 & gil27805809 & 280 & 5 & 28 \\
$35 B$ & Fatty acid-binding protein, heart & 14.77 & 6.73 & gil27805809 & 316 & 5 & 28 \\
36 & CDC42 protein & 21.23 & 5.5 & gil210062862 & 173 & 3 & 21 \\
\hline & & & & & & \\
\hline
\end{tabular}




\begin{tabular}{llcclccc}
\hline $\begin{array}{c}\text { Spot } \\
\text { ID }\end{array}$ & \multicolumn{1}{c}{ Protein ID } & $\begin{array}{c}\text { MW } \\
\text { (kDa) }\end{array}$ & pI & $\begin{array}{c}\text { GenBank } \\
\text { ID }\end{array}$ & $\begin{array}{c}\text { Mascot } \\
\text { Score }\end{array}$ & Pep & $\begin{array}{c}\text { Seq. } \\
\text { (\%) }\end{array}$ \\
\hline 38 & immunoglobulin heavy chain & 49.91 & 5.09 & gil34538498 & 86 & 3 & 25 \\
& constant region § & & & & & & \\
39 & immunoglobulin heavy chain § & 49.91 & 5.09 & gil34538498 & 122 & 3 & 25 \\
40 & immunoglobulin heavy chain § & 49.91 & 5.09 & gil34538498 & 74 & 2 & 30 \\
41 & Butyrophilin & 59.21 & 5.11 & gil2266432 & 248 & 4 & 26 \\
42 & Butyrophilin & 59.21 & 5.11 & gil2266432 & 281 & 5 & 21 \\
43 & Butyrophilin & 59.21 & 5.11 & gil2266432 & 176 & 5 & 21 \\
44 & Butyrophilin & 59.21 & 5.11 & gil2266432 & 260 & 4 & 26 \\
45 & Butyrophilin & 59.21 & 5.11 & gil2266432 & 149 & 4 & 27 \\
47 & Butyrophilin & 59.21 & 5.11 & gil2266432 & 159 & 3 & 20 \\
48 & Butyrophilin & 59.21 & 5.11 & gil2266432 & 377 & 6 & 39 \\
49 & Butyrophilin & 59.21 & 5.11 & gil2266432 & 276 & 5 & 34 \\
50 & Butyrophilin & 59.21 & 5.11 & gil2266432 & 322 & 6 & 34 \\
53 & Alpha S1 casein* & & & gil159793193 & 68 & 1 & 8 \\
54 & Butyrophilin subfamily 1 member $\dagger$ & 59.22 & 5.10 & gil27806233 & 71 & 2 & 11 \\
55 & Butyrophilin subfamily 1 member $\dagger$ & 59.22 & 5.10 & gil27806233 & 143 & 4 & 21 \\
56 & Butyrophilin subfamily 1 member $\dagger$ & 59.22 & 5.10 & gil27806233 & 165 & 5 & 27 \\
$59 A$ & Butyrophilin subfamily 1 member $\dagger$ & 59.22 & 5.10 & gil27806233 & 148 & 5 & 27 \\
$59 B$ & Butyrophilin subfamily 1 member $\dagger$ & 59.22 & 5.10 & gil27806233 & 179 & 5 & 27 \\
60 & Butyrophilin subfamily 1 member $\dagger$ & 59.22 & 5.10 & gil27806233 & 108 & 4 & 22 \\
63 & Lactadherin & 47.82 & 6.80 & gil296475529 & 385 & 8 & 28 \\
63 & Lactadherin & 47.82 & 6.80 & gil296475529 & 423 & 8 & 28 \\
65 & Lacadherin & 47.82 & 6.80 & gil296475529 & 536 & 10 & 35 \\
68 & ADFP protein & 49.04 & 5.85 & gil74354901 & 143 & 5 & 13 \\
74 & Perilipin-2 & 49.31 & 8.72 & gil296484843 & 185 & 7 & 34 \\
78 & Perilipin-2* & 49.31 & 8.72 & gil296484843 & 49 & 1 & 13 \\
91 & Butyrophilin & 59.21 & 5.11 & gil2266432 & 173 & 5 & 21 \\
\hline
\end{tabular}

* Marginal identification

$\dagger$ Butyrophilin subfamily 1 member A1 precursor; § Immunoglobulin heavy chain constant region Pep. match, Peptide matches; Seq. (\%), sequence coverage (\%); MW, molecular weight.

After milking, milk goes into cold storage where it remains from hours to days before pasteurization. In this research, three types of pasteurization were performed on the milk after storage. Batch pasteurization $\left(65^{\circ} \mathrm{C}, 30 \mathrm{~m}\right)$ resulted in dramatic protein alterations. In fact, 344 spots were detected, from which 175 were significantly different $(\mathrm{p}<0.01)$ as shown in Figure 39. The main proteins that change in concentration during batch treatment are alpha casein, CSN2, CSN3, $\beta$-lactoglobulin, and $\alpha$-lactalbumin. The results from the 1D-LC/MS analysis highlighted the same findings (Figure 36). 


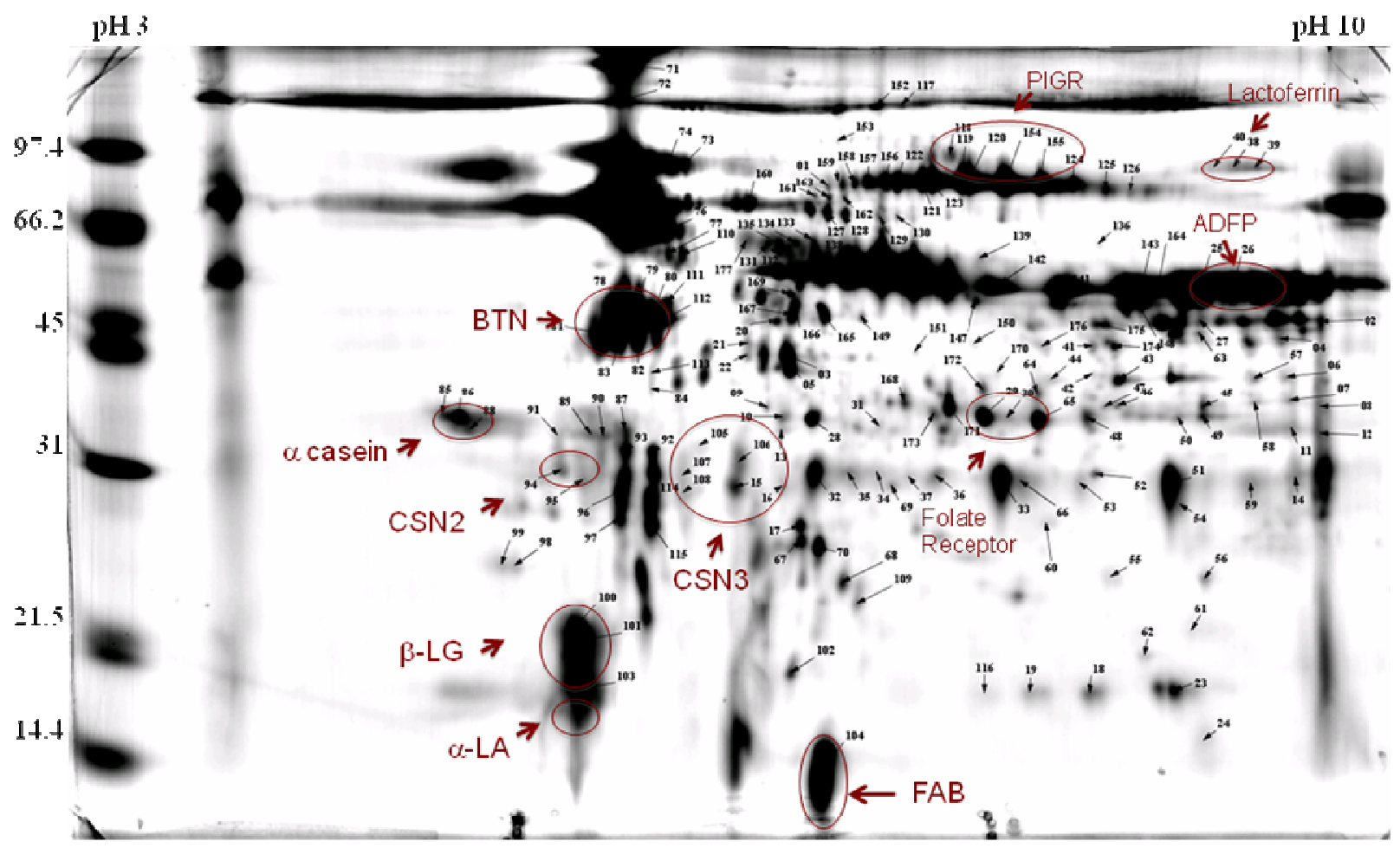

Figure 39. Proteome map (Delta 2D) depicting 175 spots from Batch milk sample versus the Fresh milk sample (control). The proteome map represents average pixel volumes for each protein spot. Labeled spots showed changes in abundance in response to thermal treatment $\left(65^{\circ} \mathrm{C}, 30 \mathrm{~m}\right.$; two-way ANOVA, p < 0.01, total spots 344).

As in the $4{ }^{\circ} \mathrm{C}$ sample, butyrophilin, ADFP, and perilipins were also altered. A change in lactoferrin was specific to this thermal treatment as well as in the folate receptor 1-like protein (Table 21). A train of spots in the $90 \mathrm{kDa}$ region was identified as polymeric immunoglogulin receptor (PIGR), which was in an area close to the lactadherin protein, which also fluctuated during this treatment.

Table 21. Identified proteins in the proteome map from Batch milk sample versus the Fresh milk sample that vary during milk processing.

\begin{tabular}{cllcllll}
\hline $\begin{array}{c}\text { Spot } \\
\text { ID }\end{array}$ & \multicolumn{1}{c}{ Protein ID } & $\begin{array}{c}\text { MW } \\
\text { (kDA) }\end{array}$ & pI & $\begin{array}{c}\text { GenBank } \\
\text { ID }\end{array}$ & $\begin{array}{c}\text { Mascot } \\
\text { Score }\end{array}$ & Pep & $\begin{array}{c}\text { Seq. } \\
(\%)\end{array}$ \\
\hline 15 & CSN3 protein- Kappa casein & 21.22 & 6.83 & gil36988716 & 128 & 4 & 24 \\
16 & CSN3 protein- Kappa casein & 21.22 & 6.83 & gil36988716 & 81 & 2 & 16 \\
18 & Peptidyl-prolyl cis-trans isomerase A $\dagger$ & 17.86 & 8.34 & gil47523764 & 139 & 3 & 23 \\
23 & Peptidyl-prolyl cis-trans isomerase A $\dagger$ & 17.86 & 8.34 & gil47523764 & 55 & 2 & 17 \\
25 & Perilipin-2 & 49.31 & 8.72 & gil296484843 & 522 & 9 & 38 \\
26 & Perilipin-2 & 49.31 & 8.72 & gil296484843 & 443 & 9 & 38 \\
\hline
\end{tabular}




\begin{tabular}{|c|c|c|c|c|c|c|c|}
\hline $\begin{array}{l}\text { Spot } \\
\text { ID }\end{array}$ & Protein ID & $\begin{array}{c}\text { MW } \\
\text { (kDA) }\end{array}$ & pI & $\begin{array}{c}\text { GenBank } \\
\text { ID }\end{array}$ & $\begin{array}{c}\text { Mascot } \\
\text { Score }\end{array}$ & Pep & $\begin{array}{l}\text { Seq. } \\
(\%)\end{array}$ \\
\hline 29 & Folate receptor 1-like & 52.81 & 8.09 & gil297460991 & 311 & 7 & 32 \\
\hline 38 & Lactoferrin & 78.03 & 8.73 & gil9650974 & 179 & 6 & 27 \\
\hline 40 & Lactoferrin & 78.03 & 8.73 & gil9650974 & 139 & 5 & 27 \\
\hline 65 & Folate receptor 1-like & 52.81 & 8.09 & gil297460991 & 253 & 5 & 26 \\
\hline 78 & Butyrophilin & 59.21 & 5.11 & gil2266432 & 151 & 5 & 27 \\
\hline 86 & Alpha $\mathrm{S} 1$ casein & 18.67 & 5.23 & gil159793193 & 375 & 6 & 28 \\
\hline 87A & CSN1S2 protein-alpha-S2-casein & 26.07 & 8.55 & gil92097520 & 125 & 3 & 17 \\
\hline 87B & CSN1S2 protein-alpha-S2-casein & 26.07 & 8.55 & gil92097520 & 150 & 4 & 22 \\
\hline 88 & Alpha S1 casein & 18.67 & 5.23 & gil159793193 & 343 & 6 & 28 \\
\hline $90 \mathrm{~A}$ & CSN1S2 protein-alpha-S2-casein & 26.07 & 8.55 & gil92097520 & 125 & 4 & 22 \\
\hline 91 & CSN2 protein-beta casein & 25.20 & 5.53 & gil83406093 & 49 & 2 & 16 \\
\hline 94 & CSN2 protein-beta casein & 25.20 & 5.53 & gil83406093 & 127 & 3 & 16 \\
\hline 95 & CSN2 protein-beta casein & 25.20 & 5.53 & gil83406093 & 96 & 3 & 16 \\
\hline 100 & Beta lactoglobulin & 17.16 & 4.75 & gil162748 & 283 & 6 & 31 \\
\hline 101 & Beta lactoglobulin & 17.16 & 4.75 & gil162748 & 309 & 6 & 35 \\
\hline $103 \mathrm{~A}$ & Beta lactoglobulin & 17.16 & 4.75 & gil162748 & 283 & 6 & 31 \\
\hline 103B & Alpha lactalbumin & 16.21 & 4.92 & gil7542833 & 76 & 2 & 10 \\
\hline $104 \mathrm{~A}$ & Keratin, Type 1 cytoskeletal- Bovine & 54.50 & 4.97 & gil296476308 & 126 & 3 & 12 \\
\hline 104B & Fatty acid-binding protein, heart & 14.77 & 6.73 & gil27805809 & 324 & 6 & 28 \\
\hline 105 & CSN3- kappa casein & 21.22 & 6.83 & gi|36988716 & 115 & 4 & 24 \\
\hline 106 & CSN3- kappa casein & 21.22 & 6.83 & gil36988716 & 140 & 4 & 24 \\
\hline 107 & CSN3- kappa casein & 21.22 & 6.83 & gil36988716 & 96 & 3 & 24 \\
\hline 108 & CSN3- kappa casein & 21.22 & 6.83 & gil36988716 & 117 & 3 & 24 \\
\hline 111 & Actin, beta cytoplasmic & 41.68 & 5.29 & gil148744172 & 90 & 2 & 16 \\
\hline 115 & Butyrophilin & 59.21 & 5.11 & gil2266432 & 98 & 3 & 16 \\
\hline 118 & PIGR & 82.46 & 7.08 & gil151555693 & 98 & 3 & 18 \\
\hline 119 & PIGR & 82.46 & 7.08 & gil151555693 & 142 & 7 & 11 \\
\hline 120 & PIGR & 82.46 & 7.08 & gil151555693 & 144 & 4 & 25 \\
\hline 121 & PIGR & 82.46 & 7.08 & gil151555693 & 143 & 2 & 9 \\
\hline 122 & PIGR & 82.46 & 7.08 & gil151555693 & 129 & 3 & 18 \\
\hline 124 & PIGR & 82.46 & 7.08 & gil151555693 & 68 & 2 & 9 \\
\hline 127 & 5'-nucleotidase $\dagger$ & 62.84 & 6.22 & gil194035289 & 90 & 3 & 13 \\
\hline 128 & 5'-nucleotidase $\dagger$ & 62.84 & 6.22 & gil194035289 & 99 & 2 & 10 \\
\hline 129 & Lactadherin & 47.82 & 6.80 & gil296475529 & 133 & 4 & 12 \\
\hline 133 & IgG1 Heavy Chain constant region & 35.83 & 6.09 & gil7547266 & 120 & 2 & 22 \\
\hline 143 & ADFP protein & 49.04 & 5.85 & gil74354901 & 43 & 2 & 17 \\
\hline 147 & Lactadherin & 47.82 & 6.80 & gil296475529 & 42 & 2 & 14 \\
\hline 154 & PIGR & 82.46 & 7.08 & gil151555693 & 140 & 7 & 7 \\
\hline 155 & PIGR & 82.46 & 7.08 & gil151555693 & 115 & 4 & 6 \\
\hline 161 & ALB-serum albumin & 69.19 & 5.88 & gil74267962 & 56 & 3 & 18 \\
\hline 163 & Serotransferrin precursor & 77.69 & 6.75 & gil114326282 & 104 & 3 & 14 \\
\hline 164 & Perilipin-2 & 49.31 & 8.72 & gil296484843 & 384 & 8 & 31 \\
\hline 167 & Butyrophilin & 59.21 & 5.11 & gil2266432 & 42 & 1 & 6 \\
\hline
\end{tabular}

Pep. match, Peptide matches; Seq. (\%), sequence coverage (\%); MW, molecular weight. $\dagger$ Sus scrofa

In the high temperature short time (HTST) pasteurization treatment, 350 spots were identified, and 128 spots were temperature significant $(\mathrm{p}<0.01)$ (Figure 40$)$. The 
proteome map is similar to the $4{ }^{\circ} \mathrm{C}$ sample, but with other alterations as in the batch milk. Lactoferrin also fluctuated during this treatment.

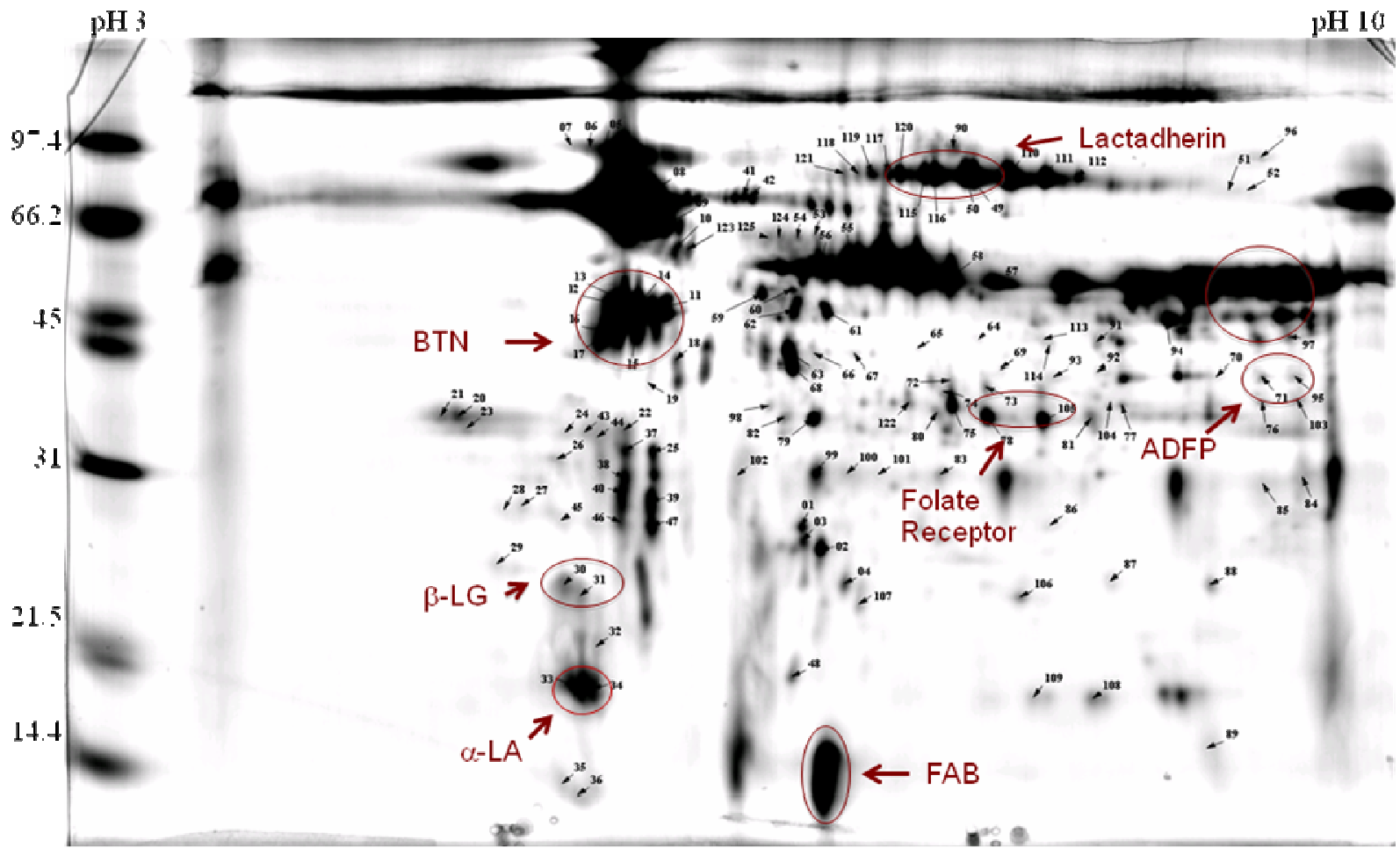

Figure 40. Proteome map (Delta 2D) depicting 128 spots from high temperature short time (HTST) milk sample versus the Fresh milk sample (control). The proteome map represents average pixel volumes for each protein spot. Labeled spots showed changes in abundance in response to thermal treatment $\left(72{ }^{\circ} \mathrm{C}, 16 \mathrm{~s}\right.$; two-way ANOVA, $\mathrm{p}<0.01$, total spots 350 ).

The main proteins that change in concentration during HTST are $\beta$-lactoglobulin and $\alpha$-lactalbumin but in a smaller degree compared to batch treatment. A GTP-binding protein SAR1a varied during this treatment (Table 22). GTP-binding proteins play a role in regulating exocytosis.

Table 22. Identified proteins in the proteome map from HTST milk sample versus the Fresh milk sample that vary during milk processing.

\begin{tabular}{cllccccc}
\hline $\begin{array}{c}\text { Spot } \\
\text { ID }\end{array}$ & \multicolumn{1}{c}{ Protein ID } & $\begin{array}{c}\text { MW } \\
\text { (kDA) }\end{array}$ & pI & $\begin{array}{c}\text { GenBank } \\
\text { ID }\end{array}$ & $\begin{array}{c}\text { Mascot } \\
\text { Score }\end{array}$ & $\begin{array}{c}\text { Seq. } \\
\text { Pep }\end{array}$ \\
\hline 2 & GTP-binding protein SAR1a & 22.39 & 6.22 & gil72535188 & 124 & 2 & 12 \\
9 & Butyrophilin & 59.21 & 5.11 & gil2266432 & 182 & 3 & 20 \\
\hline
\end{tabular}

Pep. match, Peptide matches; Seq. (\%), sequence coverage (\%); MW, molecular weight. 
Ultra high temperature (UHT) pasteurization resulted in 186 spots that were temperature significant $(\mathrm{p}<0.01)$. The casein profile underwent a new pattern in the proteome map compared to batch and HTST pasteurization (Figure 41).

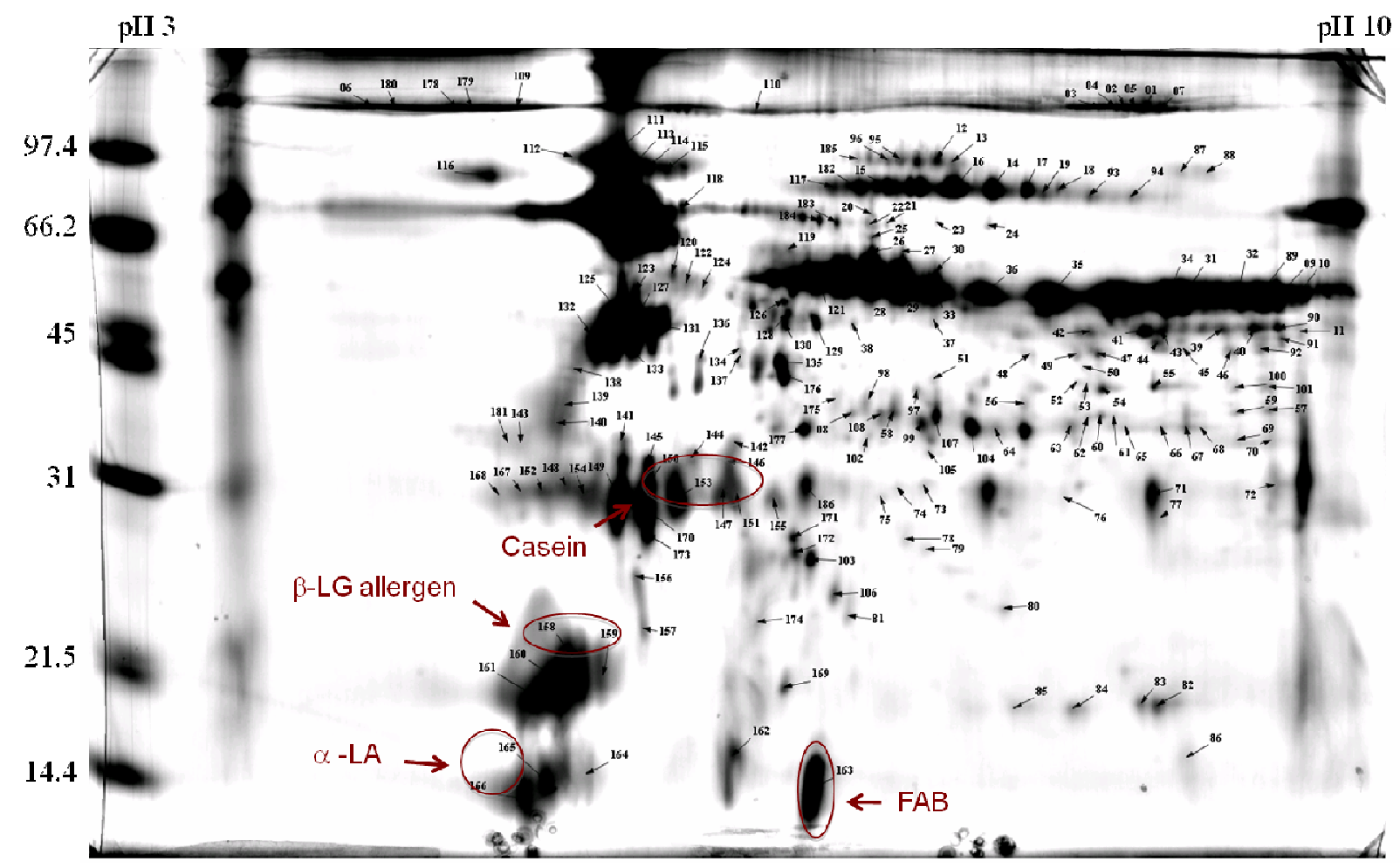

Figure 41. Proteome map (Delta 2D) depicting 186 spots from ultra high temperature (UHT) milk sample versus the Fresh milk sample (control). The proteome map represents average pixel volumes for each protein spot. Labeled spots showed changes in abundance in response to high thermal treatment $\left(121^{\circ} \mathrm{C}, 3 \mathrm{~m}\right.$; two-way ANOVA, p $<0.01$, total spots 277).

Streaking diminished the number of identified proteins due to the complexity in matching spots between the UHT samples and Fresh milk. Nevertheless, the proteome map depicts clear changes in the casein, $\beta$-lactoglobulin, and $\alpha$-lactalbumin proteins. The major milk allergen, $\beta$-lactoglobulin fragment, was identified in this thermal treatment (Table 23). 
Table 23. Identified proteins in the proteome map from UHT milk sample versus the Fresh milk sample that vary during milk processing.

\begin{tabular}{llllllll}
\hline $\begin{array}{c}\text { Spot } \\
\text { ID }\end{array}$ & \multicolumn{1}{c}{ Protein ID } & $\begin{array}{c}\text { MW } \\
\mathbf{( k D a )}\end{array}$ & pI & $\begin{array}{c}\text { GenBank } \\
\text { ID }\end{array}$ & $\begin{array}{c}\text { Mascot } \\
\text { Score }\end{array}$ & $\begin{array}{c}\text { Pep } \\
\text { Seq. }\end{array}$ \\
\hline 1A & CSN3 protein- Kappa casein & 21.22 & 6.83 & gil36988716 & 62 & 2 & 15 \\
1B & CSN3 protein- Kappa casein & 21.22 & 6.83 & gil36988716 & 150 & 3 & 24 \\
2A & CSN3 protein- Kappa casein & 21.22 & 6.83 & gil36988716 & 88 & 4 & 24 \\
2B & CSN3 protein- Kappa casein & 21.22 & 6.83 & gil36988716 & 115 & 3 & 23 \\
3A & CSN3 protein- Kappa casein & 21.22 & 6.83 & gil36988716 & 156 & 4 & 24 \\
3B & CSN3 protein- Kappa casein & 21.22 & 6.83 & gil36988716 & 87 & 4 & 22 \\
4A & CSN3 protein- Kappa casein & 21.22 & 6.83 & gil36988716 & 118 & 4 & 24 \\
4B & CSN3 protein- Kappa casein & 21.22 & 6.83 & gil36988716 & 56 & 2 & 16 \\
10 & Major Allergen Beta-lactoglobulin & 19.96 & 4.85 & gil195957138 & 71 & 3 & 21 \\
11 & CSN3 protein- Kappa casein & 21.22 & 6.83 & gil36988716 & 104 & 4 & 24 \\
158A & Major Allergen Beta-lactoglobulin & 19.96 & 4.85 & gil195957138 & 211 & 4 & 23 \\
158B & Major Allergen Beta-lactoglobulin & 19.96 & 4.85 & gil195957138 & 157 & 4 & 17 \\
160B & Beta lactoglobulin & 17.16 & 4.75 & gil162748 & 186 & 5 & 22 \\
165 & Alpha lactalbumin & 16.21 & 4.92 & gil7542833 & 146 & 3 & 20 \\
166 & Alpha lactalbumin & 16.21 & 4.92 & gil7542833 & 74 & 1 & 8 \\
\hline
\end{tabular}

Pep. match, Peptide matches; Seq. (\%), sequence coverage (\%); MW, molecular weight.

The last variant in this study was cold pasteurization via pulse ultraviolet treatment (UV). The proteome map permitted the detection of 344 spots from which 116 were temperature significant ( $p<0.01$, Figure 42 ). The percent protein change (37\%) in the UV treatment versus Fresh milk is in the same range as cold storage and HTST thermal treatment; however, visually the proteome map looks more like the $4{ }^{\circ} \mathrm{C}$ sample. 


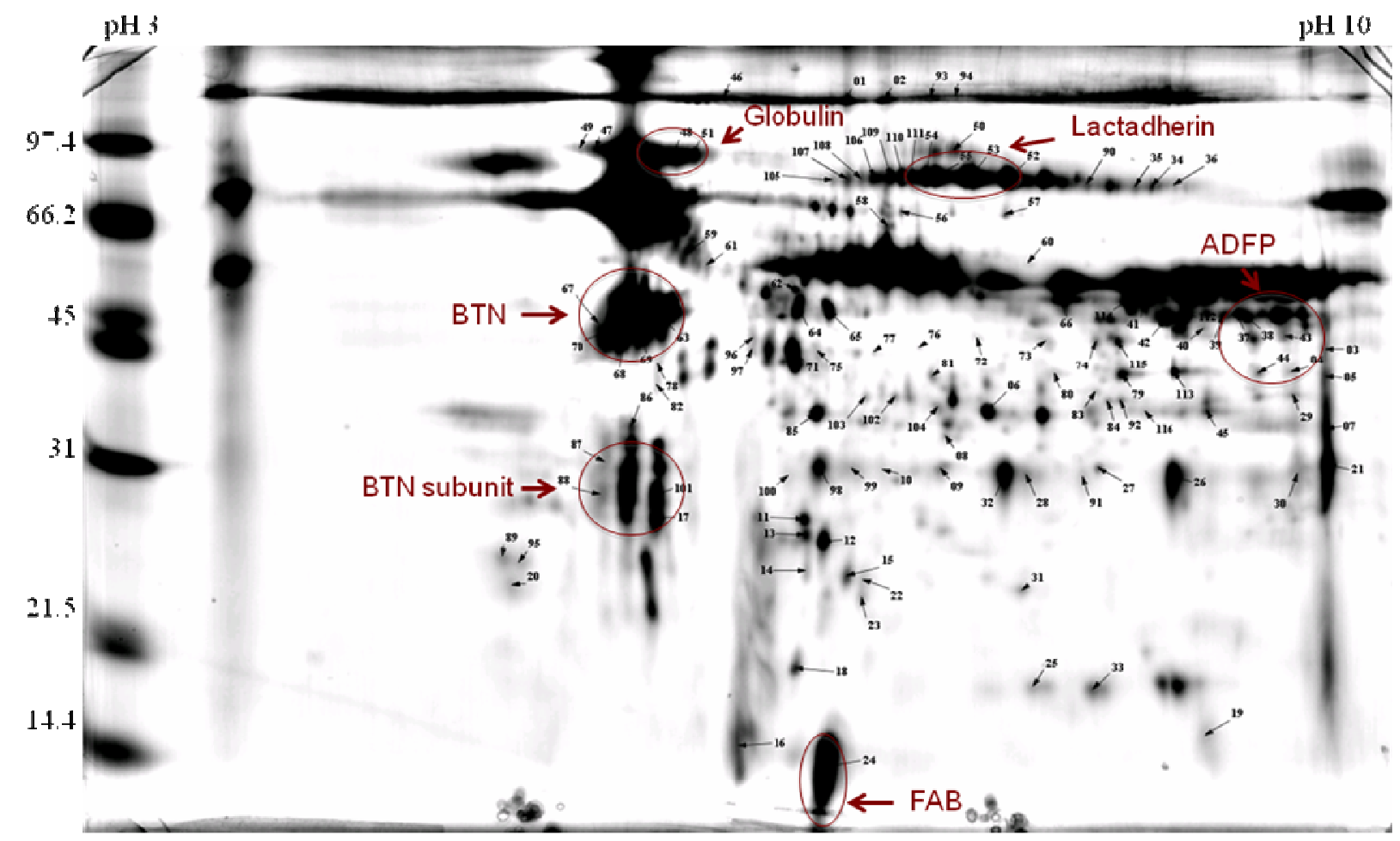

Figure 42. Proteome map (Delta 2D) depicting 116 spots from cold pasteurization (pulsed ultraviolet, UV) milk sample versus the Fresh milk sample (control). The proteome map represents average pixel volumes for each protein spot. Labeled spots showed changes in abundance in response to thermal treatment $\left(1.0 \mathrm{Joules} / \mathrm{cm}^{2} / \mathrm{pulse}\right.$; twoway ANOVA, p $<0.01$, total spots 344).

Proteins with high carbohydrate content were not identified as altered proteins during milk processing, probably due to inhibitory action from the carbohydrate moieties, which may inhibit trypsin digestion and/or impair ionization of glycopeptides during mass spectrometry analyses.

\section{DISCUSSION}

\section{A. Effects of Milk Processing on the Physical Properties of the MFGM}

The particle size distribution in milk was between 0.4 to $10 \mu \mathrm{m}$ in diameter in accordance to literature (Gassi et al., 2008; Fong et al., 2007; Mènard et al., 2010). The Fresh milk has the highest volume-surface diameter $\left(\mathrm{d}_{3,2}\right)$, indicating the presence of small fat globules with larger surface area in unprocessed milk (Table ). Cooling, thermal 
treatment, and cold pasteurization did not have a pronounced influence on the particle size of milk; however, the fat globule size distribution width (Span) in these samples is wider, implying the presence of smaller vesicles and larger fat globules. Milk processing might induce the formation of smaller vesicles, which were first described by Waninge et al. (2004) utilizing cryogenic transmission electron microscopy (Cryo-TEM). They proposed that milk procedures such as cooling and homogenization lead to phospholipid release from the membrane and gives birth to phospholipid vesicles. These vesicles could also originate from milk fat globule coalescence and consist of lost membrane material (Waninge et al., 2004). Walstra (1969) highlighted the presence of small fat globules (< $200 \mathrm{~nm}$ ) even in milk after milking (Walstra, 1969); however, Michalski et al. (2002) later concluded that small fat droplets $(<500 \mathrm{~nm})$ start to appear in early processing stages but not right after milking. Using confocal microscopy, Gallier et al. confirmed variation in fat globule size in milk upon milk processing (Gallier et al., 2010a).

With respect to the fat globules in cream, there is more variation in the size distribution, which ranges from $0.4 \mu \mathrm{m}$ to $200 \mu \mathrm{m}$. Four peak areas are visible, which correspond to small globules $(0.4-1.0 \mu \mathrm{m})$, mid-large globules $(1.5-10 \mu \mathrm{m})$, out of range

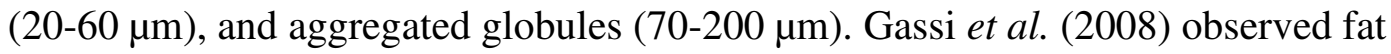
globules from $0.02 \mu \mathrm{m}$ to $200 \mu \mathrm{m}$ with three peaks centering at $0.5 \mu \mathrm{m}, 4 \mu \mathrm{m}$, and $45 \mu \mathrm{m}$. The large fat globules $(>20 \mu \mathrm{m})$ were more pronounced in cream with medium and high heat treatments, and the results were ascribed to the fusion of smaller globules to form larger ones due to coalescence. Addition of SDS decreased the third peak (45 $\mu \mathrm{m})$ indicating that it corresponds to aggregates of fat globules. In this study, it is expected that the third and four distributions represent fat globule aggregates of large globules since large fat globules are more predisposed to coalescence and lipolysis during milking 
operations such as pumping and agitation (Wiking et al., 2004). In fact, these areas are very prominent in milk that underwent heat pasteurization, especially in HTST, Batch, and UHT, whereas the samples that did not undergo heat treatment exhibit a higher percent volume in the normal size fat globule range. Prolonged and higher temperature treatments, such as in Batch and UHT, may have deactivated lipases and contributed to the stability of fat globules and therefore to less coalescence as compared to the HTST milk. Lipases are not always completely inactivated during regular pasteurization temperatures, so lipid breakdown continues during the milk's lifespan after heat treatment as well as of free fatty acid production. Furthermore, thermal treatment resulted in smaller fat globules $(<0.5 \mu \mathrm{m})$, which may correspond to vesicles formed by MFGM fragments composed of phospholipids and proteins as previously discussed.

\section{B. Effects of Milk Processing on the Chemical Composition of the MFGM}

\section{Changes in Milk Composition}

No significant difference was seen in the fat, lactose, total solid, and protein content of milk ( $\mathrm{p}>0.05)$. However, the casein content was marginally higher for UHT milk ( $\mathrm{p}$ $=0.05)$. Complexes between $\beta$-lactoglobulin and casein may explain this observation. In buttermilk, higher casein content has been attributed to thermal treatment since whey proteins are titrated with the casein fraction, making casein value higher (Gassi et al.). The citric acid content also is higher in UHT milk compared to the other milk treatments $(\mathrm{p}=0.05)$. Such findings were ascribed to the detection limits of FTIR as research indicates that citric acid does not vary with heating (Sommer and Hart, 1918). The urea content in UHT milk was higher $(\mathrm{p}<0.0001)$ probably due to induced protein catabolism at $121{ }^{\circ} \mathrm{C}$ at $15 \mathrm{psi}$ as urea naturally decomposes into ammonia and carbon dioxide 
(Metwalli et al., 1996; Metwalli and van Boekel, 1998). This may also explain the higher urea content in the Fresh sample that gradually decreases in concentration in milk. The Fresh and UHT milk also exhibit a lower free fatty acid (FFA) content $(\mathrm{p}<0.0001)$ in accordance to literature (Burton, 1988; Kintner and Day, 1965). Kintner and Day (1965) found that as the intensity of thermal treatment increases, the amount of FFA decreased. Higher FFA content in milk has been accredited to the survival of heat-resistant lipases of natural milk origins or produced by psychrotrophic bacteria during cold storage (Burton, 1988). The higher FFA content in $4{ }^{\circ} \mathrm{C}$, Batch, HTST, and UV indicate instability of fat globules probably due to lipase activity from microbiological or natural origins or from fat globule damage during milk processing. In fact, lipoprotein lipase reaches optimal binding to MFGM after four hours of milking, and thereby, contributed to the high FFA in these samples (Dickow et al., 2011; Wiking et al., 2005).

\section{Effects on MFGM Isolates \& Protein}

The MFGM isolates obtained, ranging from 171 to $315 \mathrm{mg}$ of dry weight (pellet) per liter of milk, were higher than that previously described in literature, which correspond to approximately $95 \mathrm{mg}$ dry weight per liter of fresh milk (Sánchez-Juanes et al., 2009). These high values may have resulted from omission of cream washes that contribute to more material in the final product. Furthermore, the amount of MFGM isolate decreased as a function of thermal treatment as observed in previous research (Kim and JiménezFlores, 1995). According to their findings, higher temperatures resulted in less membrane and more insoluble product. The insolubility of the MFGM was not measured, but it was noticed that MFGM material from UHT sample had a difficult time going into solution. In addition, the isolated MFGM pellet in pasteurized samples was lower in protein content than those samples without thermal treatment $(\mathrm{p}<0.0001)$. The amount of 
protein in these isolates was lower than those previously reported, $48.7 \mathrm{mg}$ of protein per 100 mg of MFGM (Sánchez-Juanes et al., 2009). In this research, the protein in the isolates varies from 13.3 to $17.7 \mathrm{mg}$ of protein per $100 \mathrm{mg}$ of MFGM isolates, explaining the high amount of MFGM in the final pellets, which may contain other milk components. Thermal treatment resulted in higher protein content in the isolates compared to Fresh milk, indicating interactions between MFGM proteins and milk components, especially proteins, as temperature increased.

Discoloration was also observed in MFGM isolates as thermal treatment increased in accordance to other authors (Morin et al., 2007b; Corredig and Dalgleish, 1998). Milk without thermal treatment such as Fresh and UV were reddish-brown compared to yellow-white from HTST milk. This result is believed to be caused by a decrease in the amount of iron in the MFGM. Corredig and Dalgleish actually measured the iron content by atomic absorption in samples that underwent heat treatment, concluding that the amount of iron in the MFGM decreased as a function of heating temperature even in temperatures as low as $62{ }^{\circ} \mathrm{C}$. They hypothesized that heat induces the release of iron from xanthine oxidase, which has four residues holding an iron molecule. Iron release coupled with structural changes in $\mathrm{XO}$ make the protein available for disulfide exchange with other cyteine-containing proteins causing permanent denaturation and iron loss. Morin et al. (2007b) supported this hypothesis with a pronounced lower ash content in pasteurized cream compared to raw cream. We hypothesized that other iron-containing proteins such as lactoferrin denaturation may contribute to the discoloration, which becomes more prominent in ultra high temperature milk. 


\section{Effects on the Phospholipid Profile of the MFG}

Separation and quantification of milk polar lipids were in accordance to literature (Rombaut et al., 2005). The five major entities were isolated as single peaks with the exception of sphingomyelin (SM), which depicted three peaks. Peak 2 and 3 have been interpreted as derivatives of SM with extra hydroxyl groups (Rombaut et al., 2006a). In other studies, three peaks were reported corresponding to different sphingoloid bases and fatty acids (Lopez et al., 2008; Fong et al., 2007). Phosphatidylethanolamine (PE) and phosphatidylcholine (PC) containing different acyl groups were separated resulting in elution of phospholipids with longest to shortest acyl chain (18:0, 12:0, and 6:0) (Fagan and Wijesundera, 2004). With this evidence, it is suspected that the three peaks of SM correspond to derivatives with varying acyl chain length. PC also depicted different peaks, but the effect was not as pronounced as SM. These peaks have previously been correlated to changes in the fatty acid composition of polar lipids due to cow diet (Lopez et al., 2008).

The amount of total polar lipids isolated in this study is in accordance with previous studies where PLs in milk range from 9.4 to $35.5 \mathrm{mg}$ per $100 \mathrm{~g}$ of product (Christie et al., 1987; Fong et al., 2007). In this research, 7.7 to $20.5 \mathrm{mg}$ of polar lipid were detected per $100 \mathrm{~g}$ of milk, which equals to 0.21 to $0.57 \mathrm{~g}$ of polar lipid per 100 of total lipids. The individual concentrations of polar lipids was not significantly differently $(p>0.05)$, implying that milk processing such as cooling and thermal treatment does not influence the concentration of PLs. In literature, conflicting results on the effect of temperature on polar lipids from whole milk fat globules have been reported. According to Rombaut $e t$ al. (2006), variations in polar lipids can be ascribed to differences in the methodology used in the analysis. The Mojonnier procedure may not extract all the individual polar 
lipids, including lecithins, and cephalins (Morin et al., 2007b), which contribute to the polar lipid variation. In fact, the lower concentrations of PI and PS observed in the samples are probably due to the use of ammonium to dissociate the MFGM matrix, as indicated in previous studies (Avalli and Contarini, 2005). Their acidic characteristics might have solubilized them in the aqueous phase.

With the experimental design utilized in this research, it was difficult to discern how milk processing affects the concentration of individual polar lipids in the milk fat globule membrane. The literature reported for this topic is also inconsistent. According to Houlihan et al. (1992), heating alone had little or no effect on polar lipids whereas Christie et al. (1987) did not detect PLs in UHT powders, attributing such observations to the effect of heat during processing, especially oxidation of polyunsaturated fatty acids (PUFA). Buttermilk produced from pasteurized cream resulted in lower phospholipid concentration, especially PE, PS, and PI (Morin et al., 2007b). The authors hypothesized that during cream churning the inner membrane of the fat globules is exposed to milk serum, inducing possible interactions as well as dislocation of the MFGM. Gassi et al. (2008) found no variation in total PL content of creams that underwent different heat treatments while the PL content increased in their respective buttermilk by a factor of seven. During cream churning, more PE and less SM are observed in skim milk predicting that loosely bound polar lipids appear in skim milk due to high shear forces that destroy the surface of fat globules (Morin et al., 2008).

Migration of lipids from MFGM to serum only occurs in the presence of serum components (Houlihan et al., 1992). Residual MFGM material is found in skim milk, and since SM and PC are located in the outer leaflet, they are more likely to migrate into the milk serum upon centrifugation (Anderson and Brooker, 1974). Gallier et al. (2010a) 
confirmed these observations in her PL quantification where SM and PC were less abundant in cream than in raw milk (Christie et al., 1987). PE was three times less abundant in buttermilk and more concentrated in cream. Since PE is more hydrophobic than PC and SM, it might partition into the butter phase during butter manufacture and MFGM preparation.

Larger fat globules are more prone to coalescence due to changes in the MFGM (Mulder and Walstra, 1974) while small fat globules are more stable at high temperatures, enriching high-heat buttermilk in PL content (Gassi et al., 2008). Studies indicate that proteins and glycoproteins play a role in stabilization of fat globules by interrupting clustering (Shimizu et al., 1980). Removal of phopholipids' polar heads diminished the stability of cream by coalescence of fat globules and promoting oiling-off. Shimizu et al. (1980) concluded that PLs interrupt coalesce by repulsive forces derived from the ionogenic groups of the phospholipids. According to Lopez et al. (2010a), glycolipids and glycoproteins are heterogeneously present in the MFGM among glycerophospholipids, contributing to the stabilization of globules. The liquid-ordered domains, lipid rafts, are devoid of carbohydrate-containing molecules and enriched in SM and cholesterol. Only the outer layer of the bilayer allows lateral plane movement (Lopez et al., 2010b) where SM may disengage from the MFGM throughout milk processing. On the other hand, similar phospholipid organization was seen in processed cream and native globules, indicating membrane component reorganization after drastic processing (Gallier et al., 2010a).

The lower amounts of polar lipids in the first trials denote autooxidation of the polyunsaturated fatty acids during sample preparation or storage. The appearance of a polar peak, expected to be phosphatidyl acid (after the elution of SM) suggests 
phospholipid degradation. LysoPC was not quantified in this research but in the literature more lysoPC is indicative of PC degradation during milk processing (Gallier et al., 2010a). Moreover, Fong et al. (2007) reported levels of lyso-PE and lyso-PC even when lipids were stored at $-80^{\circ} \mathrm{C}$. Gallier et al. (2010) concluded that milk processing leads to difference in phospholipid composition (Gallier et al., 2010a); however, her samples did not originate from the same milk line. Since polar lipids change as a function of the fat content, season, stage of lactation, feeding, and breed (Jensen, 2002; Bitman and Wood, 1990), the absence of statistical differences in phospholipid concentration during milk processing might be a result of the effects discussed previously as well as the contribution of PL oxidation in our samples.

\section{Changes in the Sulfhydryl (SH) and Disulfide (SS) Groups}

Thermal treatment is indirectly proportional to the amount of free sulfhydryl ( $\mathrm{SH})$ groups and directly proportional to the amount of disulfide (SS) groups. This study indicates that heat treatments such in UHT result in lower free sulfhydryl groups and therefore more disulfide-bonding indicative of protein interactions and denaturation. Cold pasteurization on the contrary has similar values to the ones observed in Fresh milk. An interesting finding is the higher amount of free SH and SS in $4{ }^{\circ} \mathrm{C}$ compared to Fresh milk. Cooling may promote the association between milk and whey proteins via other interactions besides covalent bonding, which may explain the higher free sulfhydryl groups present in storage milk. These interactions were strong enough to maintain protein association during MFGM extraction, especially in centrifugation for cream collection. During storage, milk is contantly agitated to prevent creaming, so this process introduced air bubbles in the milk, and thereby, promoted the formation of disulfide bonds from the oxidation of free sulfhydryl groups or from thiol-disulfide exchange reactions. It must be 
emphasized that these observations are only preliminary studies with regard to SH and SS quantification.

\section{Effects of Milk Processing on the MFGM Proteins from 1DE Perspectives}

\section{Quantification of Protein Variation during Milk Processing}

The proteins of the milk fat globule fluctuate during milk processing; however, the introduction of milk and whey proteins is more pronounced. Thermal treatment resulted in the absorption of $\beta$-lactoglobulin as a function of heat intensity, as previously seen in literature (Fong et al., 2007). The amount of $\beta$-casein and $\alpha$-lactalbumin in MFGM isolates also increased in heat-treated samples, especially in UHT milk. In the contrary, the amount of $\alpha$-casein decreased in thermally treated milks, probably due to interactions with other proteins. Figure 43 illustrates the relative abundance of these proteins in the MFGM from SDS-PAGE densitometry $(\mathrm{p}<0.0001)$.

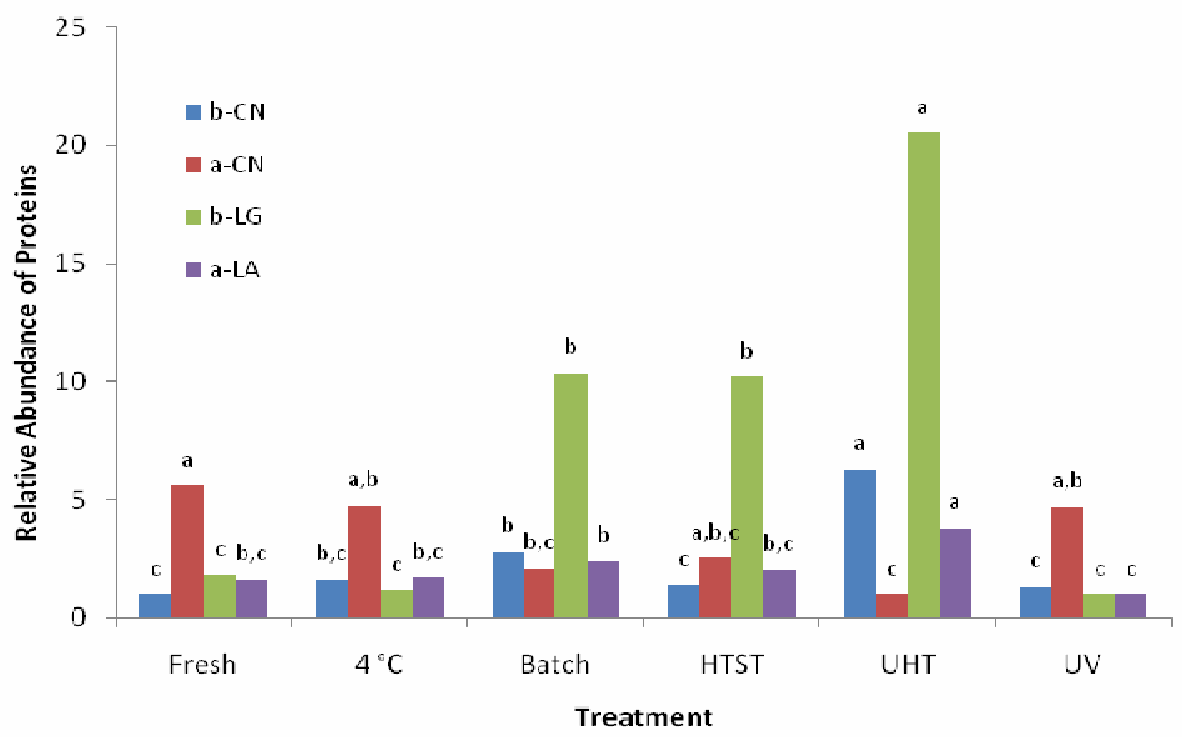

Figure 43. Fluctuation of milk and whey proteins in the MFGM during milk processing. Results obtained from SDS-PAGE densitometry $(p<0.0001$, three independent trials, and three replicates). 
Thermal treatment of milk can induce desorption of protein and lipids from the MFGM. The complex formed by $\beta$-lactoglobulin and $\kappa$-casein during heat treatment may displace the proteins from the MFGM (Houlihan et al., 1992). In fact, xanthine oxidase, butyrophilin, and ADFP are less abundant in UHT milk compared to the other treatments (Figure 44). These three proteins are the main MFGM proteins involved in fat globule excretion and are located within the trilayer, indicating complete disruption of the membrane during UHT pasteurization.

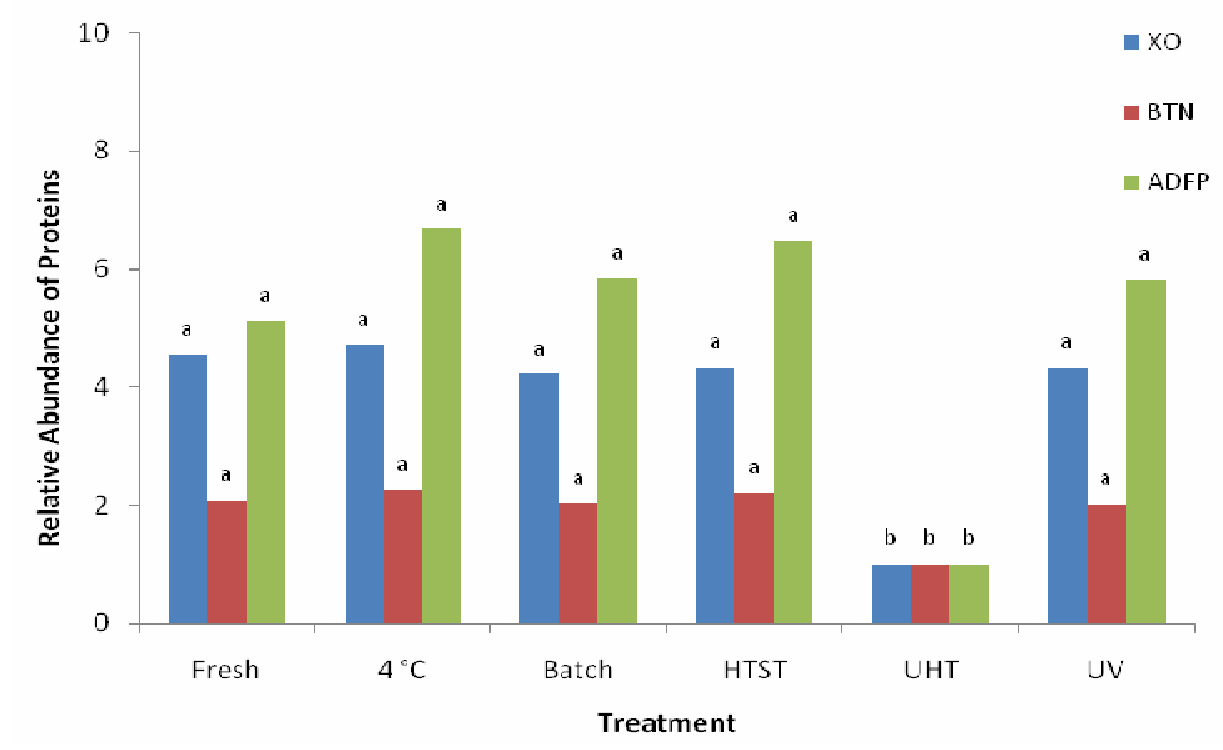

Figure 44. Fluctuation of the main MFGM proteins during milk processing. Results obtained from SDS-PAGE densitometry $(p<0.0001$, three independent trials, and three replicates).

Other MFGM proteins such as MFG-E8, Mucin 15, annexin, and another protein with an apparent molecular weight of $69 \mathrm{kDa}$ (denoted as $X$, Figure 45) fluctuate highly under intensive heat treatments. At this molecular weight, proteins such as serum albumin and heat shock cognate $71 \mathrm{kDa}$ may be present; nevertheless, this band could encompass other proteins with similar weight. UHT causes the disappearance of Mucin 15, monocyte differentiaton antigen (CD14), and $\kappa$-casein in their apparent MW region while high 
molecular weight bands are observed even in reducing conditions (Figure 32). Also, UHT milk depicted more streaking, which originates from polypeptides resulting from protein denaturation.

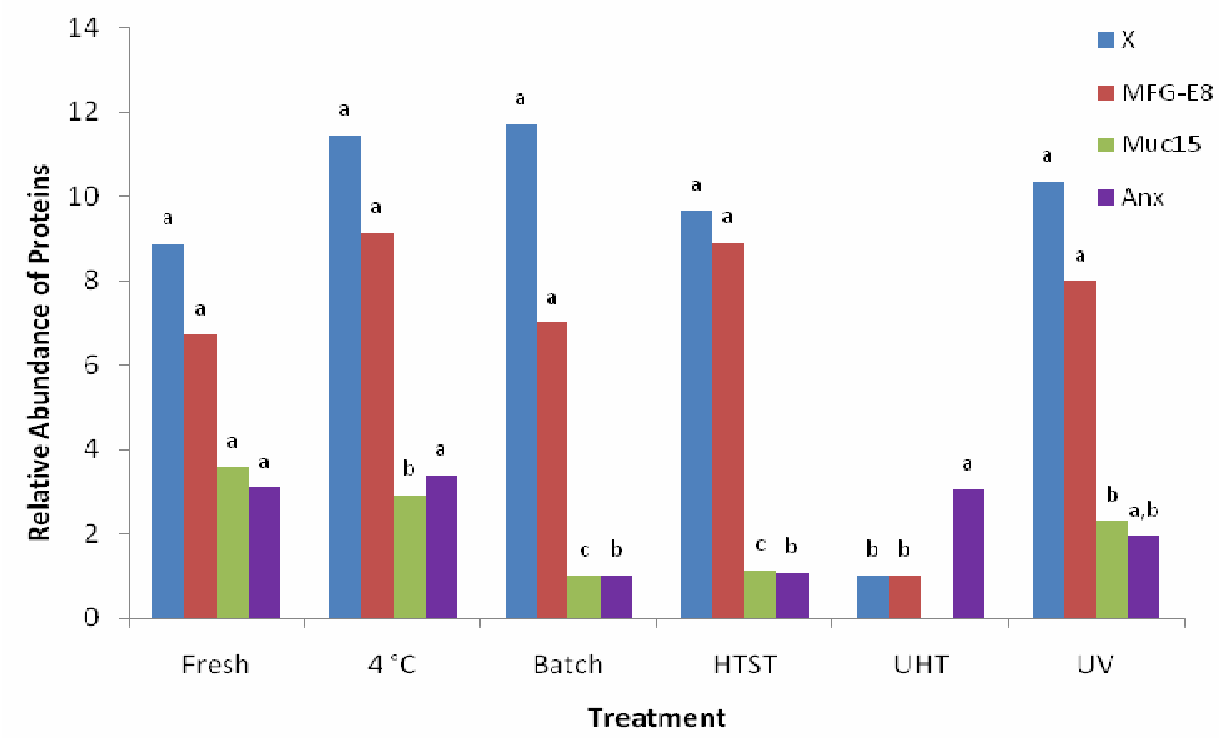

Figure 45. Fluctuation of MFGM proteins during milk processing. Results obtained from SDS-PAGE densitometry. $X$ unidentified protein band $(p<0.0001$, three independent trials, and three replicates).

2. Identification of Proteins that Change in Milk Processing

a) Proteins in Globlal Composition

Heat induces protein interactions and displacement as well as adsorption on the milk fat globule membrane (Singh, 2006; Evers, 2004a). LC/MS identified changes in the MFGM protein profile in each treatment and permitted the functional classification of these. From this work, the 100 identified proteins were categorized into 13 groups, with the lipid transport/metabolism as the highest section followed by the immunity \& defense section (Figure 46). 


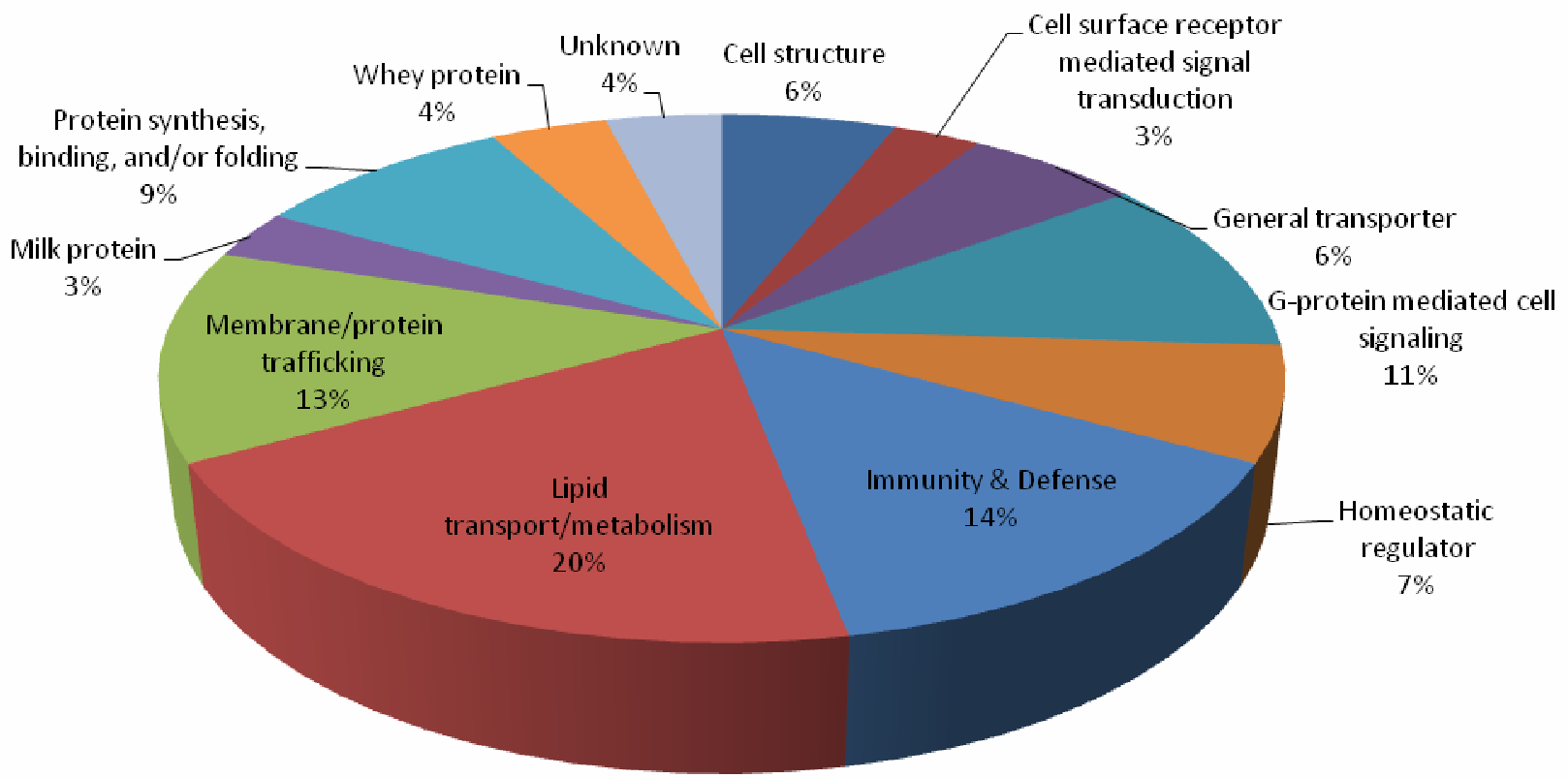

Figure 46. Functional category assignments for identified proteins. A total of 13 categories were assigned based on information in Uniprot and NCBI.

To better understand the changes that milk undergoes during regular milk processing, the frequency of proteins in eacth treatment was compared in each category. The following spider graphs represent a treatment for each angle, and only the proteins that showed variation are graphed. The protein probability is given as a percentage; this is a straightforward means to evaluate the relative abundance change of each protein for each processing treatment. The following graphs depict each group of proteins by function, and its variation given the processing steps. The categories for function are:

- Lipid transport / metabolism (Figure 47)

- Immunity / Defense (Figure 48)

- Membrane / Protein trafficking (Figure 49)

- G-protein mediated signaling (Figure 50)

- Protein synthesis, binding and/or folding (Figure 51) 
- Homeostatic regulators (Figure 52)

General transporters, Cell Structure, Cell surface receptor mediated signal transduction, Milk proteins, Whey proteins, and Unknown function proteins are better understood in a table (Table 15).
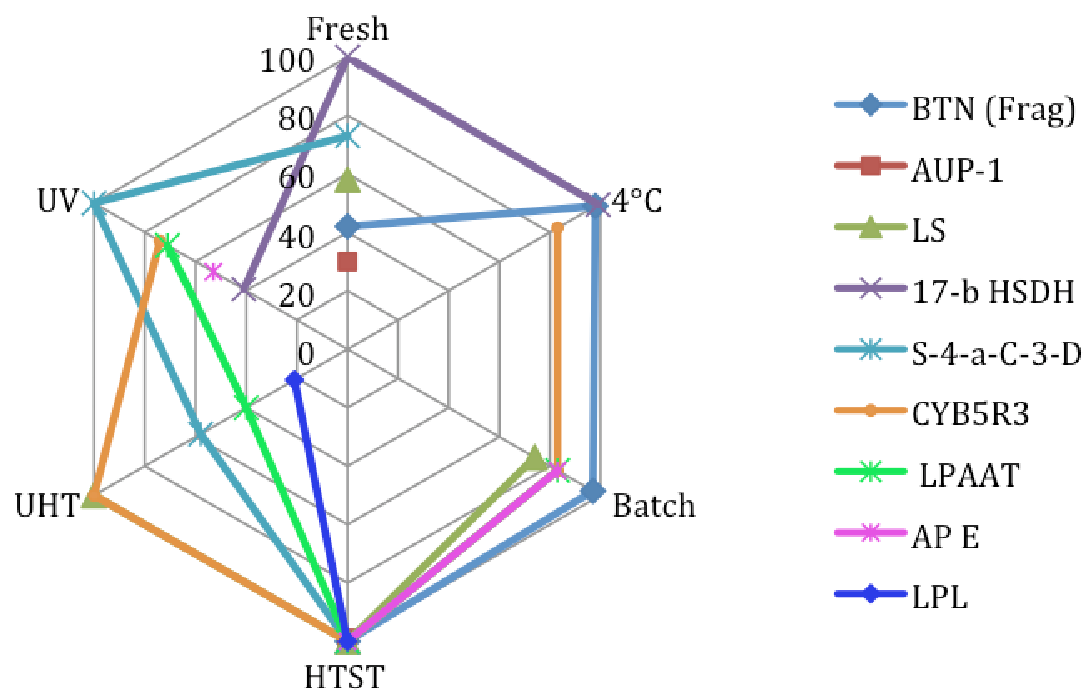

Figure 47. Variation of proteins involved in lipid tranport/metabolism during milk processing. BTN (Frag), Butyrophilin (Fragment); AUP-1, Ancient ubiquitous protein 1; LS, Lanosterol synthase; 17-b HSDH, 17-beta hydroxysteroid dehydrogenase; S-4-a-C-3-D, Sterol-4-alpha-carboxylate 3-dehydrogenase, decarboxylating; CYB5R3, CYB5R3 protein; LPAAT, Lysophosphatidic acid acyltransferase, zeta; AP E, Apolipoprotein E; LPL, Lipoprotein lipase; FABP (brain), Fatty acid-binding protein, brain

A total of 20 proteins involving lipid transport/metabolism were identified, but nine of them are present in all the samples with high probabilities including the two main MFGM proteins, XO and BTN. Mannose-6- phosphate receptor binding protein 1 was absent from UHT milk while CDEA protein, which plays a role in fat accumulation, had a low probability (16\%) in the same sample. CIDEA also inhibits triglyceride hydrolysis and promotes lipid storage (Christianson et al., 2010). The remaining nine proteins fluctuated as indicated in Figure 47. More proteins are observed as thermal treatment 
increases, indicating association of lipid transport/metabolism proteins during heating and explaining the higher levels of SH and SS groups observed in $4{ }^{\circ} \mathrm{C}$ milk, which gradually decreases as heat intensity augments.

Fourteen proteins associated with immunity and defense were identified, of which four are constantly present throughout milk processing such as MFG-E8 (lacthaderin), immunoglobulin receptor, and mucin 15. Cathelicidin-1, mucin-1, and immunoglobulin $\mathbf{J}$ chain disappeared in UHT milk. Six proteins varied among the treatments (Figure 48), including Annexin A1, a calcium-dependent membrane aggregatin protein that mediates inflammation (Perretti and D'Acquisto, 2009). The toll-like receptor 2, implicated in pathogen recognition, was uniquely present in HTST.

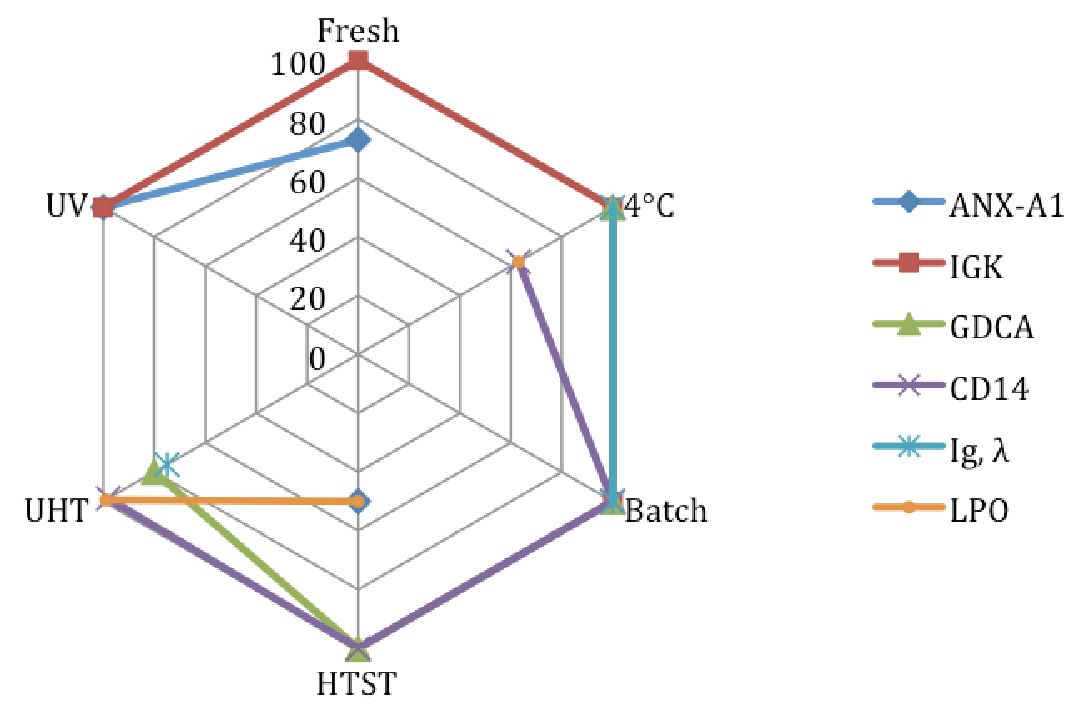

Figure 48. Variation of proteins involved in immunity $\&$ defense during milk processing. ANX-A1, Annexin A1; IGK , IGK protein; GDCA, Glycosylation-dependent cell adhesion molecule 1; CD14, Monocyte differentiation antigen CD14; Ig ( ), Immunoglobulin light chain, lambda gene cluster; LPO, Lactoperoxidase.

Proteins involved in membrane/protein trafficking were also a major group in the MFGM isolates. A total of 13 proteins were identified, including two Ras-related proteins (Rab-18 and Rab 11A) persistently observed in all the samples whereas three proteins 
implicated in vesicular transport (SNAP23A and SAR1a) and late endocytic tranport (Rab-7a) were missing exclusively in the UHT milk. Seven proteins seem to fade in the thermal treatment, Batch and UHT (Figure 49). Ras-related protein Rab-8A was observed solely in Fresh milk.
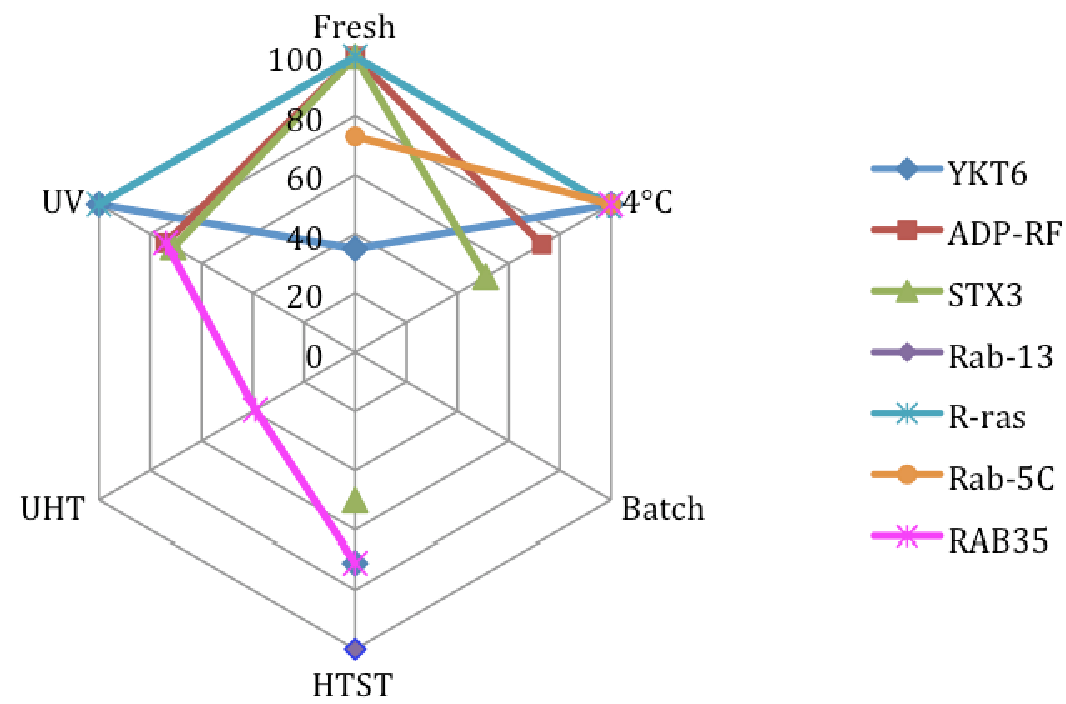

Figure 49. Variation of proteins involved in membrane protein trafficking during milk processing. YKT6, Synaptobrevin homolog YKT6; ADP-RF, ADP-ribosylation factor 1; STX3, STX3 protein; Rab-13, Ras-related protein Rab-13; R-ras, Related RAS viral (R-ras) oncogene homolog; Rab-5C, Ras-related protein Rab-5C; RAB35, RAB35 protein; Rab-8A, Ras-related protein Rab-8A.

In the G-protein mediated cell signaling group, 11 proteins were identified including two subunits of the guanine nucleotide-binding protein $\mathrm{G}(\mathrm{I}) / \mathrm{G}(\mathrm{S}) / \mathrm{G}(\mathrm{T})$ constantly identified throughout milk processing and seven proteins that varied highly in all the samples with the exception of UHT milk where they were completely absent (Figure 50). 


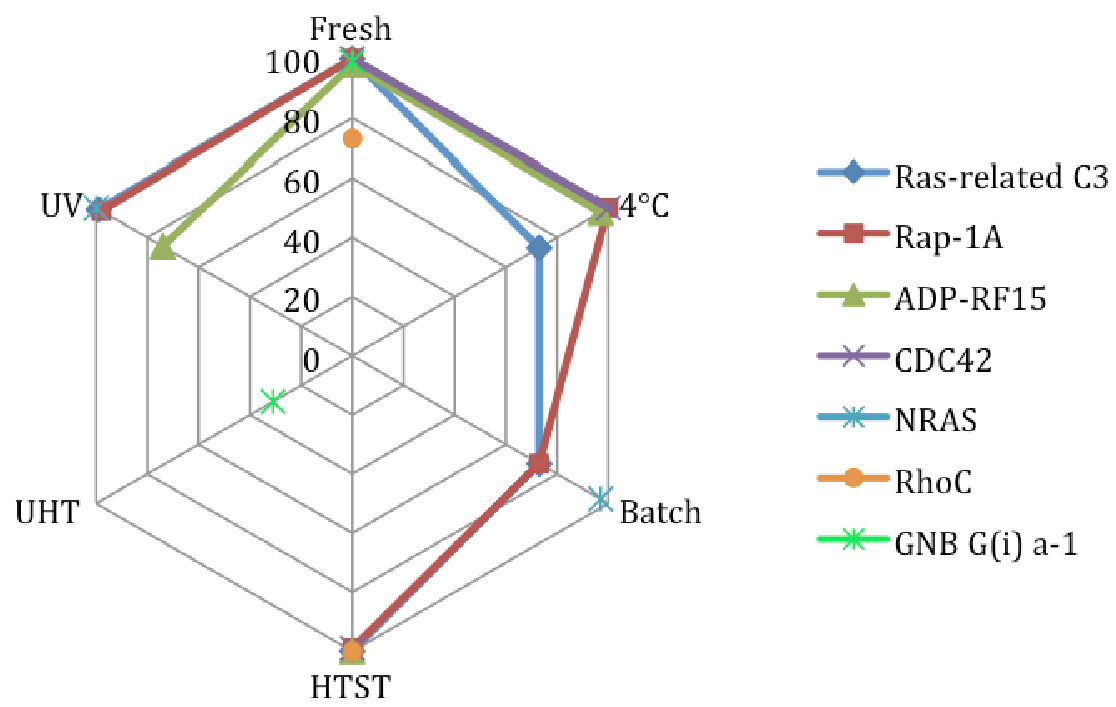

Figure 50. Variation in proteins involved in G-mediated cell signaling during milk processing. Ras-related C3, Ras-related C3 botulinum toxin substrate 1; Rap-1A, Ras-related protein Rap-1A; ADP-RF15, ADP-ribosylation factor-like protein 15; CDC42, CDC42 protein; NRAS, NRAS protein; RhoC, Rho-related GTP-binding protein RhoC; GNB G(i) a-1, Guanine nucleotide-binding protein G(i) subunit alpha-1.

Nine proteins implicated in protein synthesis, binding, and/or folding were recognized, from which a fragment of a protein similar to peptidylprolyl isomerase A (cyclophilin A) was picked in all the samples. As in previous groups, UHT was depleted of many proteins observed in the other milk treatments (Figure 51). This data in conjuction with other analysis are indicative of protein denaturation and exclusion in the UHT MFGM isolate. The elongation factor 1-alpha1 was present almost exclusively in Fresh, but a low-probability is also seen in UV milk. The latter was also the host of DCK protein, which is a core component of nucleosome. 


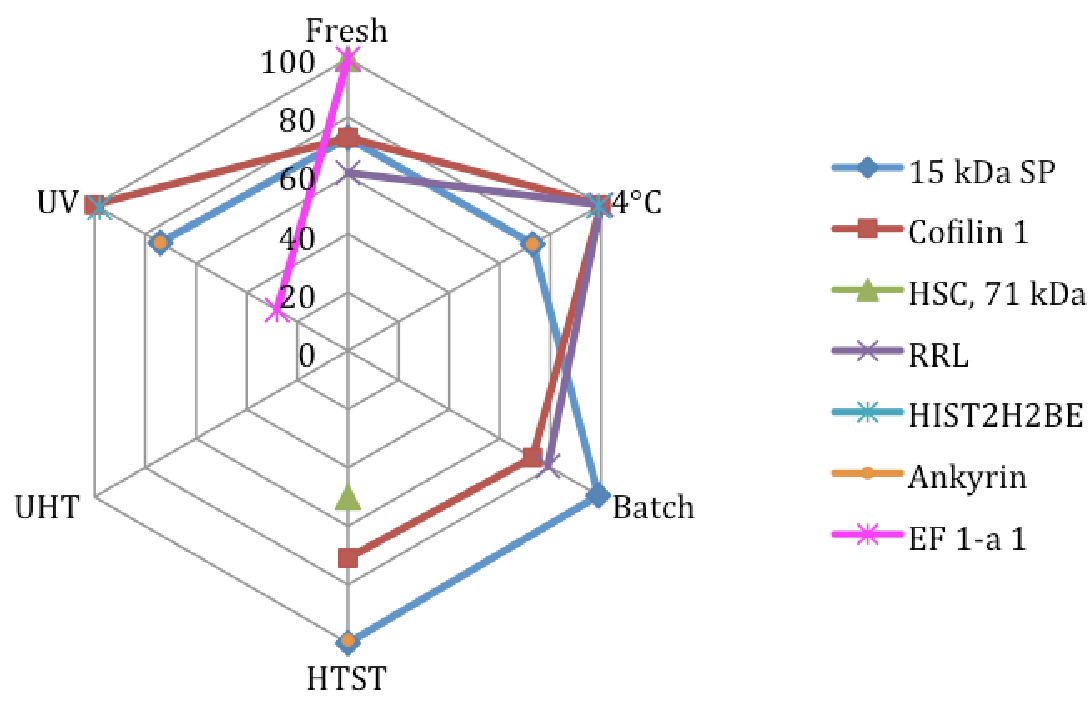

Figure 51. Variation of proteins involved in protein synthesis, binding, and/ or folding during milk processing. $15 \mathrm{kDa}$ SP, 15 kDa selenoprotein; Cofilin 1, Cofilin 1 (Nonmuscle); HSC, 71 kDa, Heat shock cognate 71 kDa protein; RRL, Ribonucleotide reductase large subunit; HIST2H2BE, HIST2H2BE protein; Ankyrin, Ankyrin repeat domain 22; EF 1-a 1, Elongation factor 1-alpha 1; DCK , DCK protein.

Homeostatic regulators were also identified in the MFGM isolates with high variation throughout milk processing (Figure 52). A total of seven proteins were detected. One of them, cytoplasmic aconitate hydratase, an iron sensor, was solely identified in Fresh milk. This group of proteins was more abundant in thermal treated samples. 


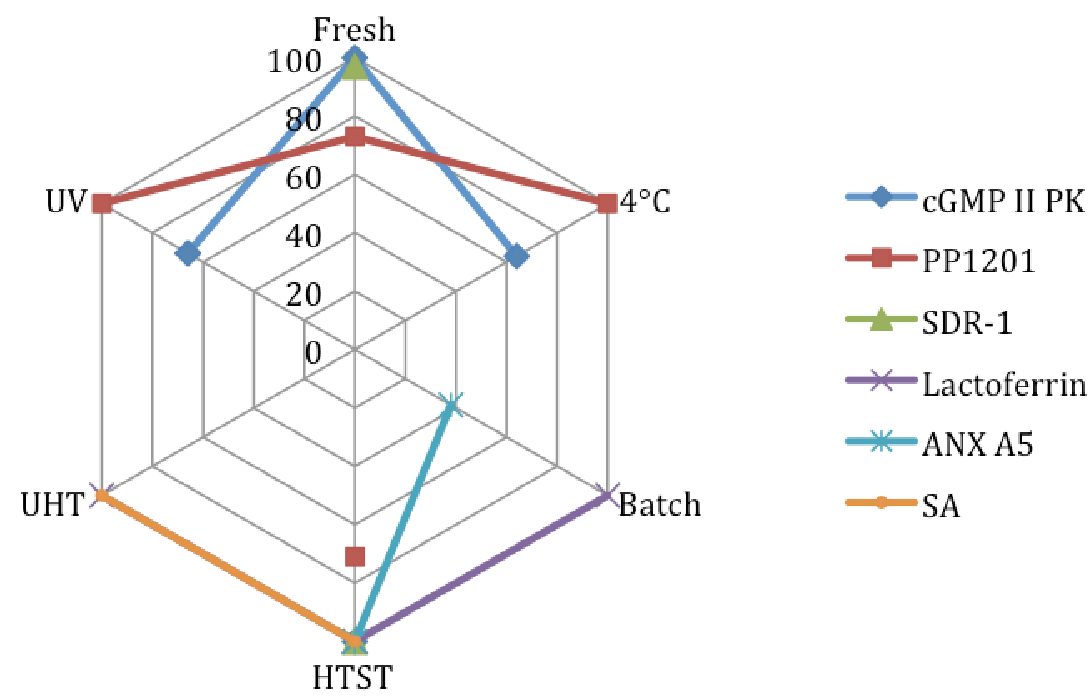

Figure 52. Variation in proteins involved in homeostatic regulation during milk processing. cGMP II PK, cGMP-dependant type II protein kinase; PP1201, PP1201 protein; SDR-1, Dehydrogenase/reductase (SDR family) member 1; ANX A5, Annexin A5; SA, Serum albumin.

The general transporter and cell structure groups are not illustrated in spider graphs, but less variation was observed in these proteins (Table 15). Only three proteins were associated with cell surface receptor mediated signal transduction, which are mainly present in Fresh and HTST milk. The milk proteins $\alpha$-S1-casein, $\alpha$-S2-casein, and $\kappa-$ casein were adsorbed onto the MFGM throughout milk processing. On the other hand, whey proteins, $\alpha$-lactalbumin and $\beta$-lactoglobulin, were more abundant in intense thermal treatments such as HTST and UHT. Four proteins with unknown or unspecified roles were detected whereas Reinhard and Lipolis (2010) identified more than 20 proteins in this category, including MUC proteins, which in this research have been classified in the Immunity \& Defense group. The fragment of $\beta$-lactoglobulin, enterotoxin-binding glycoprotein PP20K, was seen in thermally treated samples, and it has been shown that this protein binds to MFGM during heating (Shida et al., 1994). 


\section{b) Proteins Identification in Molecular Weight Regions}

Four regions were analyzed in 1-DE gels that encompass a higher than $150 \mathrm{kDa}$ (Region I), higher than 55 and less than $150 \mathrm{kDa}$ (Region II), higher than 35 and less than $55 \mathrm{kDa}$ (Region III), and less than $35 \mathrm{kDa}$ (Region IV). In region I (Table 16), only three proteins with high molecular weight were observed, including XO (155 kDa), acetyl-CoA carboxylase $1(265 \mathrm{kDa})$, and fatty acid synthase $(275 \mathrm{kDa})$.
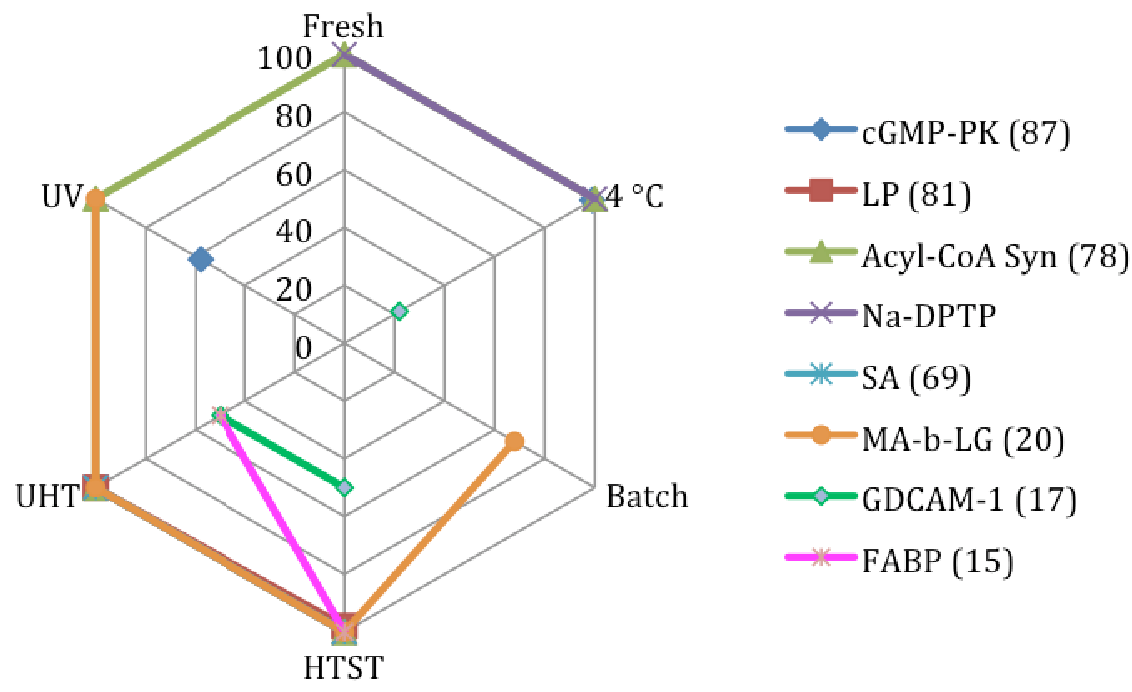

Figure 53. Protein identified in region $I(>150 \mathrm{kDa})$. Molecular weight is shown in parenthesis. cGMP-PK (87), cGMP-dependant type II protein kinase; LP (81), Lactoperoxidase; Acyl-CoA Syn (78), Acyl-CoA synthetase long-chain family member 1; Na-DPTP, Sodium-dependent phosphate transport protein 2B; SA (69), Serum albumin; MA-b-LG (20), Major allergen beta-lactoglobulin; GDCAM-1 (17), Glycosylation-dependent cell adhesion molecule 1; FABP (15), Fatty acid-binding protein.

The other 45 proteins have lower molecular weights than the expected region, indicating complex formations among them. Therefore, HTST and especially UHT produce more low-molecular weight proteins such as FABP, SA, PP20K extrinsic protein, and $\beta$-casein. UHT was exclusively enriched in lactoferrin, $\beta$-lactoglobulin, $\alpha$ lactalbumin in this region. Figure 53 illustrates some of proteins with high variation in 
this region, embracing the homeostatic regular serum albumin and lactoperoxidase, an antimicrobial agent believed to protect cow's udder from infection.

In region II (Table 17), a total of 46 proteins were identified of which 22 proteins had a lower-molecular weight outside the range for this region. Figure 54 denotes some of the region two proteins that fluctuated during milk processing. The toll-like receptor 2 (TLR2) and alkaline phosphatase, an enzyme utilized to verify pasteurization, were identified specifically in this region in the HTST sample whereas cytoplasmic aconitate hydratase, an iron sensor, was exclusive to Fresh milk. As observed before, whey proteins were adsorbed onto UHT MFGM isolates.
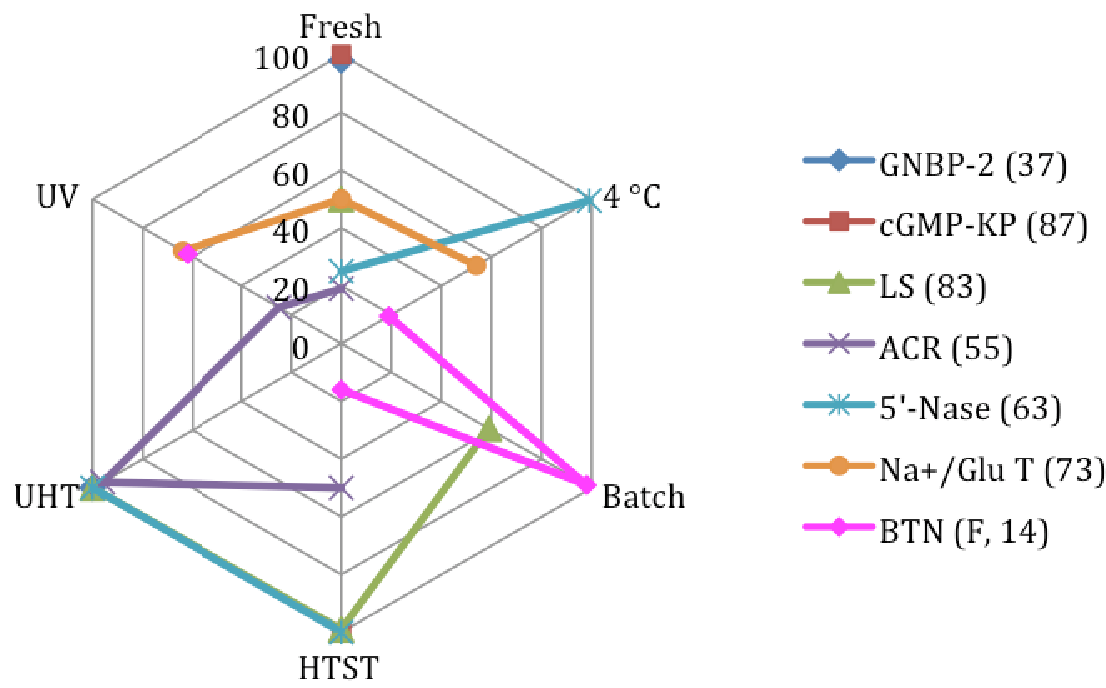

Figure 54. Protein identified in region II ( $>55$ and $<150 \mathrm{kDa})$. Molecular weight is shown in parenthesis. GNBP-2 (37), Guanine nucleotide-binding protein $\mathbf{G ( I ) / G ( S ) / G ( T ) ~}$ subunit beta-2; cGMP-KP (87), cGMP-dependant type II protein kinase; LS (83), Lanosterol synthase; ACR (55), Acetylcholine receptor subunit epsilon; 5'-Nase (63), 5'-nucleotidase; Na+/Glu T (73), Na+/glucose cotransporter; BTN (F, 14), Butyrophilin (Fragment).

Region III (Table 18) resulted in the recognition of 60 proteins, including nine and twelve outside the upper limit and lower limits, respectively. Seven proteins varied highly among the treatments and are shown in Figure 55. Phosphatidylinositol transfer protein 
alpha form $(32 \mathrm{kDa})$ was identified in this region in the $4{ }^{\circ} \mathrm{C}$ milk but was not picked in the global identification. CD14 was observed in thermally treated samples including $4{ }^{\circ} \mathrm{C}$ but not in Fresh and UV milks.
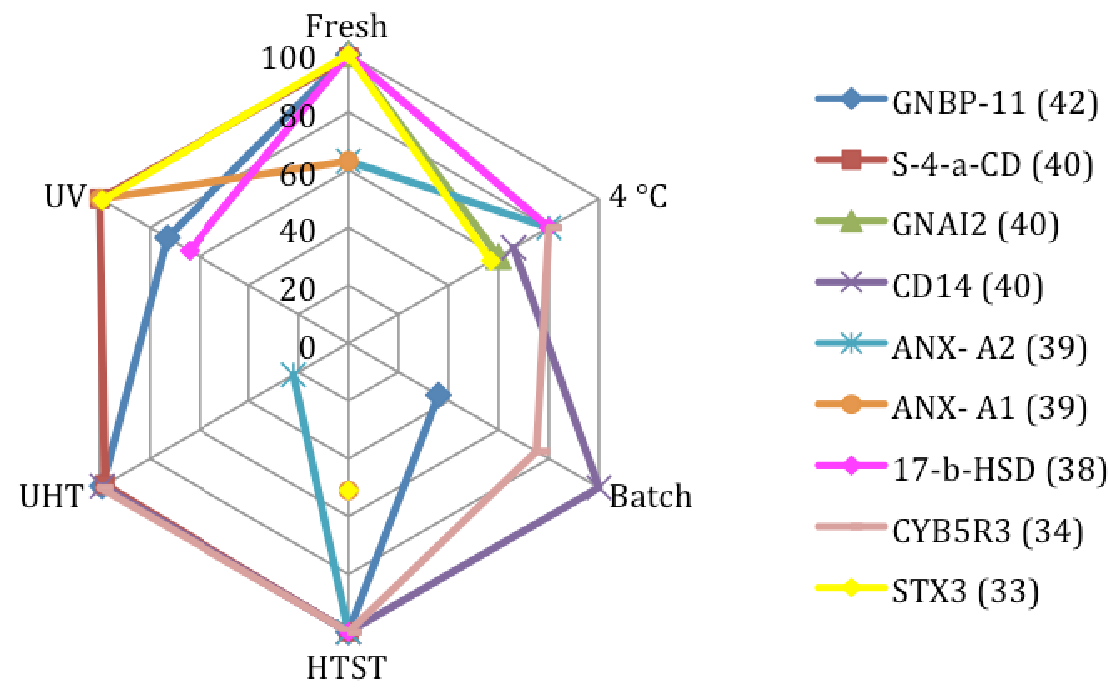

Figure 55. Proteins identified in region III ( $>35$ and $<55 \mathrm{kDa}$ ). Molecular weight is shown in parenthesis. GNBP-11 (42), Guanine nucleotide-binding protein subunit alpha-11; S-4-a-CD (40), Sterol-4-alpha-carboxylate 3-dehydrogenase; GNAI2 (40), GNAI2 protein; CD14 (40), CD14 protein; ANX- A2 (39), Annexin A2; ANX- A1 (39), Annexin A1; 17-b-HSD (38), 17-beta hydroxysteroid dehydrogenase; CYB5R3 , CYB5R3 protein; STX3, STX3 protein.

Region IV (Table 19) resulted in 74 proteins mainly from protein denaturation and the recognition of polypeptides in this section. A total of 58 proteins were identified in the proper molecular weight.

\section{Effects of Milk Processing on the MFGM Proteins from 2DE Perspectives}

From the time milk leaves the cow udder, it undergoes changes in temperature as well as mechanical processing such as agitation and thermal treatment, causing interactions among MFGM, milk, and whey proteins. Using 2-DE gels coupled with MALDI-TOF, protein variation was observed along milk processing. 
As the majority of the milk proteins have $\mathrm{pI}$ in the range of 4 to 7 , a linear $\mathrm{pH} 3$ to 10 was expected to resolve more protein from the MFGM. Cooling is the least invasive process that influences the association of $\alpha$ - and $\beta$-casein to MFGM proteins as well as changes in butyrophilin and adipophilin. Cryatallization of the fat causes volume changes in the fat globules and thus renders the MFGM to the adsorption of other proteins as shown in Figure 56 (Dickow et al., 2011). BTN seems to be damaged more readily than other MFGM because it is exposed on the surface of fat globules due to its glycosylated nature (Dewettinck et al., 2008). Adipophilin on the other hand locates specifically within inner phospholipid layer of the MFGM, and variation can be ascribed to exposed monolayer regions as well as damaged bilayer (Robenek et al., 2006a). XO is embedded between the inner and bilayers, which may preclude denaturation due to milk processing. It cannot be ruled out that the protocol used in this analysis prevented the identification of XO.

\section{CONCLUSIONS \& LIMITATIONS}

In milk processing, the most abrupt thermal treatment can be considered UHT pasteurization since the intensity of the heat disturbs the native structure of fat globules and MFGM constituents. In fact, Christie et al. (1987) did not detect PLs in UHT powders, attributing such findings to autoxidation and the harsh treatment. Also, thermal treatment promotes fat globule aggregates as observed in previous studies (Gassi et al., 2008). In this research, fewer aggregates were observed in non-thermal processes such as Fresh, $4{ }^{\circ} \mathrm{C}$, and UV. Among these, Fresh resulted in the smallest globules, and thereby, was expected to be enriched in more polar lipids. The latter molecules remained 
unaffected during milk processing, but these findings add to the plethora of conflicting PL research that attempted to characterize the effect of thermal treatment on polar lipids.

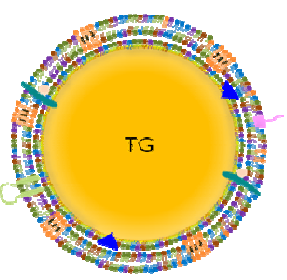

Native Globule

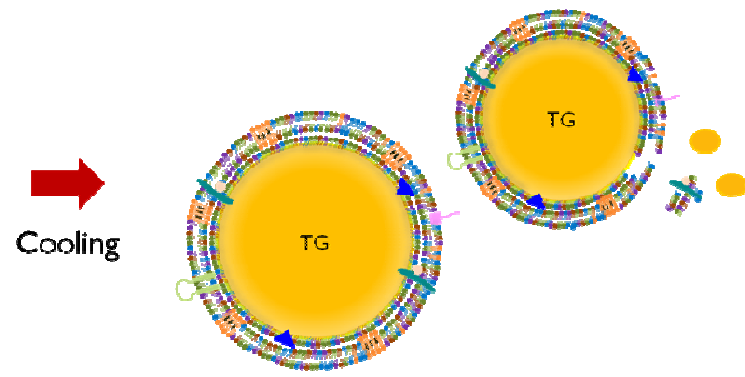

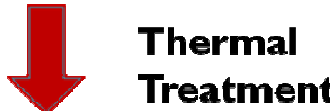
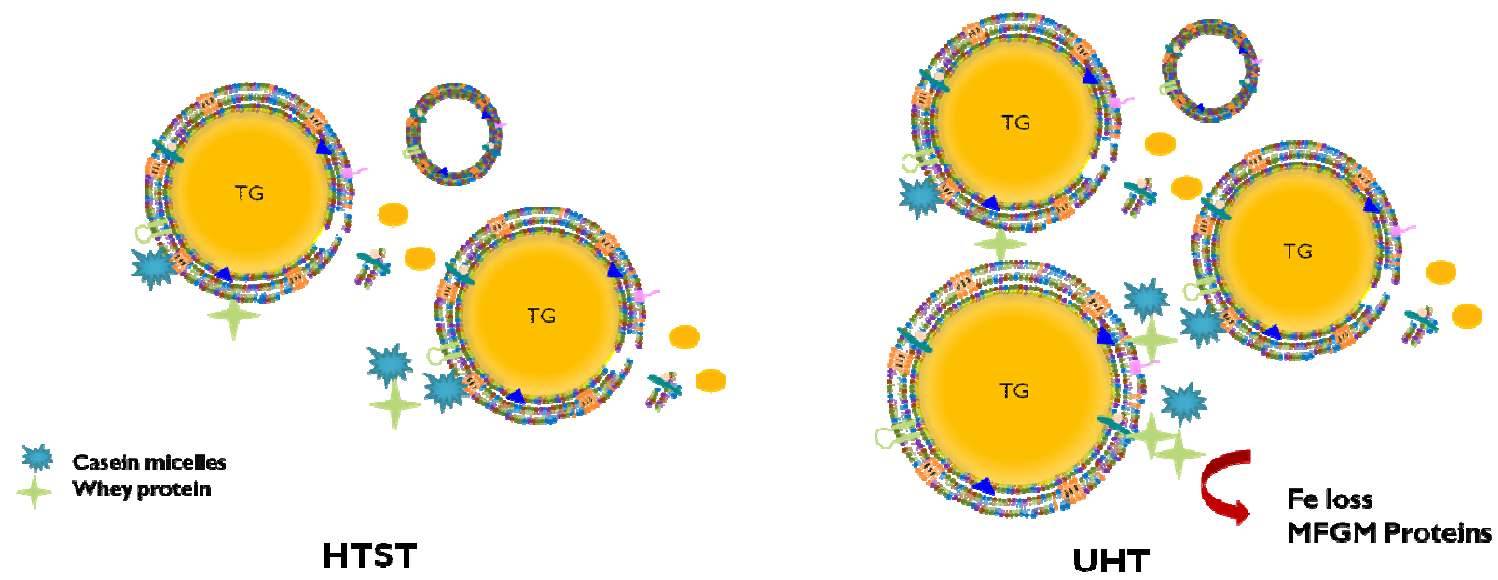

Figure 56. Milk processing effects on milk fat globules and milk fat globule membrane proteins. Globules are smaller in Fresh milk, and as processing proceeds, some triacylglycerides are released in cooling as well MFGM membrane. Thermal treatment enhances rearrangements between proteins and lipids of the membrane and promotes aggregation of globules and vesicle formation. Casein micelles and whey proteins are the main proteins that are adsorbed to the globule surface.

Even though the procedure utilized in this research was not the exact UHT protocol, the environment was simulated enough to observe reactions. In real UHT milk, mechanical stress also plays a role in milk processing and probably adds to the effect of heat treatment. In general, it can be stated that as the intensity of heat increases, more milk and whey proteins absorbed onto the milk fat globule membrane and augmented MFGM proteins displacement. In addition, a decrease in the amount of free sulfhydryl 
(SH) and an increase in disulfide bonds (SS) in the line production of milk correlates with protein interactions. Even cooling promoted the association of proteins, probably through hydrophobic bonding, contributing to the amount of SH and SS levels. Figure 56 represents the main effects of milk processing on the milk fat globule membrane as milk proceeds in the dairy industry from the dairy unit, cooling, and thermal treatment.

In summary, pulsed UV light is clearly effective in inactivating microorganisms in vitro, but its potential in real foods and efficacy still need research despite the minimal effects observed in this study. Further research to separate MFGM from milk sources is also necessary (Singh, 2006); however, this task will not be easy as MFGM is sensitive to processing and handling. Nevertheless, with our findings it can be concluded that HTST milk is an optimal source of MFGM to supplement formulated foods that attempt to satisfy consumer's expectation of health-oriented and nutritious food products.

\section{DIRECTIONS FOR FUTURE RESEARCH}

The interaction between polar lipids and proteins are important aspects of the MFGM that deserve more research in order to help us understand their functions (Gubbens et al., 2009). Characterizing the alterations of these molecules during the regular path that milk takes from the dairy unit to our table is even more important to help us establish parameters that will preserve the integrity of polar lipids and proteins that have been ascribed with health-promoting effects. Another process to consider in milk production is spray-drying, as milk powder is the most common source of milk in developing countries, and so, the need to preserve the MFGM is also required. As Fong et al. (2007) suggested, some MFGM proteins may be used as alternates to synthetic anti-bacterial and anti-viral agents on top of their use as supplements; however, further work is required on 
the optimization of food-grade downstream production processes for MFGM isolates that results in products similar to native state (El-Loly, 2011) and thereby allowing us to benefit from the effects that neonates received in milk.

\section{REFERENCES}

Affolter, M, Grass, L, Vanrobaeys, F, Casado, B and Kussmann, M (2010) Qualitative and quantitative profiling of the bovine milk fat globule membrane proteome. Journal of Proteomics 73 1079-1088.

Ahn, E H and Schroeder, J J (2002) Bioactive Sphingolipids are Constituents of Soy and Dairy Products. Journal of Food Science 67 522-524.

Ait-Oufella, H, Kinugawa, K, Zoll, J, et al. (2007) Lactadherin Deficiency Leads to Apoptotic Cell Accumulation and Accelerated Atherosclerosis in Mice. Circulation $1152168-2177$.

Andersen, M H, Berglund, L, Rasmussen, J T and Petersen, T E (1997) Bovine PAS-6/7 Binds V 5 Integrin and Anionic Phospholipids through Two Domains. Biochemistry 36 5441-5446.

Anderson, J G, Rowan, N J, Macgregor, S J, Fouracre, R A and Farish, O (2000) Inactivation of food-borne enteropathogenic bacteria and spoilage fungi using pulsedlight. Plasma Science, IEEE Transactions on 28 83-88.

Anderson, M and Brooker, B E (1974) Loss of material during the isolation of milk fat globule membrane. Journal of dairy science 58 1442-1448.

Anderson, M, Cheeseman, G C, Knight, D J and Shipe, W F (1972) The effect of ageing cooled milk on the composition of the fat globule membrane. Journal of Dairy Research 39 95-105. 
Argov, N, Lemay, D G and German, J B (2008a) Milk fat globule structure and function: nanoscience comes to milk production. Trends in Food Science \& Technology 19 617-623.

Argov, N, Wachsmann-Hogiu, S, Freeman, S L, Huser, T, Lebrilla, C B and German, J B (2008b) Size-Dependent Lipid Content in Human Milk Fat Globules. Journal of Agricultural and Food Chemistry 56 7446-7450.

Arla (2011) Milk fat globular membrane URL http://www.arlafoodsingredients.com/products/milk-protein--minerals/alphalactalbumin/. Accessed 18-May 2011.

Astaire, J C, Ward, R, German, J B and Jimenez-Flores, R (2003) Concentration of Polar MFGM Lipids from Buttermilk by Microfiltration and Supercritical Fluid Extraction. J. Dairy Sci. 86 2297-2307.

Attebery, J M (1968) Removing lipid material from whey.

Avalli, A and Contarini, G (2005) Determination of phospholipids in dairy products by SPE/HPLC/ELSD. Journal of Chromatography A 1071 185-190.

Bailey, B, Plante, M, Crafts, C and Acworth, I Advances in Universal Detection. DIONEX ed. Chelmsford.

Barbano, D M and Clark, J L (1989) Infrared Milk Analysis -- Challenges for the Future. Journal of dairy science 72 1627-1636.

Basch, J J, Greenberg, R and Farrell Jr, H M (1985) Identification of the milk fat globule membrane proteins.: II. Isolation of major proteins from electrophoretic gels and comparison of their amino acid compositions. Biochimica et Biophysica Acta (BBA) Protein Structure and Molecular Enzymology 830 127-135. 
Baumrucker, C R and Keenan, T W (1973) Membranes of Mammary Gland. VII. Stability of Milk Fat Globule Membrane in Secreted Milk. Journal of dairy science 56 1092-1094.

Baumrucker, C R, Schanbacher, F, Shang, Y and Green, M H (2006) Lactoferrin interaction with retinoid signaling: Cell growth and apoptosis in mammary cells. Domestic Animal Endocrinology 30 289-303.

Beddek, a J, Rawson, P, Peng, L F, et al. (2008) Profiling the metabolic proteome of bovine mammary tissue. PROTEOMICS 8 1502-1515.

Berggren, K, Chernokalskaya, E, Steinberg, T H, et al. (2000) Background-free, high sensitivity staining of proteins in one- and two-dimensional sodium dodecyl sulfatepolyacrylamide gels using a luminescent ruthenium complex. Electrophoresis 21 2509-2521.

Bermúdez-Aguirre, D, Mawson, R and Barbosa-Cánovas, G V (2008) Microstructure of Fat Globules in Whole Milk after Thermosonication Treatment. Journal of Food Science 73 E325-E332.

Beveridge, T, Toma, S J and Nakai, S (1974) Determination of SH- and SS-groups in some food proteins using Ellman's reagent. Journal of Food Science 39 49-51.

Bezelgues, J-B, Morgan, F, Palomo, G, Crosset-Perrotin, L and Ducret, P (2009) Short communication: Milk fat globule membrane as a potential delivery system for liposoluble nutrients. J. Dairy Sci. 92 2524-2528.

Biggs, D A (1967) Milk Analysis with the Infrared Milk Analyzer. Journal of dairy science $\mathbf{5 0} 799-803$.

Bionaz, M and Loor, J J (2008) Gene networks driving bovine milk fat synthesis during the lactation cycle. BMC Genomics 9 366-387. 
Bitman, J, Wood, D, Mehta, N, Hamosh, P and Hamosh, M (1984) Comparison of the phospholipid composition of breast milk from mothers of term and preterm infants during lactation. The American Journal of Clinical Nutrition 40 1103-1119.

Bitman, J and Wood, D L (1990) Changes in Milk Fat Phospholipids During Lactation. Journal of dairy science 73 1208-1216.

Boddaert, J, Kinugawa, K, Lambert, J-C, et al. (2007) Evidence of a Role for Lactadherin in Alzheimer's Disease. Am J Pathol 170 921-929.

Bouter, A, Gounou, C, Berat, R, et al. (2011) Annexin-A5 assembled into twodimensional arrays promotes cell membrane repair. Nat Commun 2270.

Brasaemle, D L (2007) Thematic review series: Adipocyte Biology. The perilipin family of structural lipid droplet proteins: stabilization of lipid droplets and control of lipolysis. Journal of Lipid Research 48 2547-2559.

Brisson, G, Payken, H F, Sharpe, J P and Jimeãånez-Flores, R (2010) Characterization of Lactobacillus reuteri Interaction with Milk Fat Globule Membrane Components in Dairy Products. Journal of Agricultural and Food Chemistry 58 5612-5619.

Burton, H (1988) Ultra-high-temperature processing of milk and milk products. London: Elsevier Applied Science.

Candiano, G, Bruschi, M, Musante, L, et al. (2004) Blue silver: A very sensitive colloidal Coomassie G-250 staining for proteome analysis. Electrophoresis 25 1327-1333.

Cano-Ruiz, M E and Richter, R L (1997) Effect of Homogenization Pressure on the Milk Fat Globule Membrane Proteins. Journal of dairy science 80 2732-2739.

Carrasco-Pancorbo, A, Navas-Iglesias, N and Cuadros-Rodríguez, L (2009) From lipid analysis towards lipidomics, a new challenge for the analytical chemistry of the $21 \mathrm{st}$ 
century. Part I: Modern lipid analysis. TrAC Trends in Analytical Chemistry $28263-$ 278.

Chang, B H-J and Chan, L (2007) Regulation of Triglyceride Metabolism. III. Emerging role of lipid droplet protein ADFP in health and disease. Am J Physiol Gastrointest Liver Physiol 292 G1465-1468.

Chang, J C, Ossoff, S F, Lobe, D C, et al. (1985) UV inactivation of pathogenic and indicator microorganisms. Appl. Environ. Microbiol. 49 1361-1365.

Christianson, J L, Boutet, E, Puri, V, Chawla, A and Czech, M P (2010) Identification of the lipid droplet targeting domain of the cidea protein. Journal of Lipid Research.

Christie, W W, Noble, R C and Davies, G (1987) Phospholipids in milk and dairy products. International Journal of Dairy Technology 40 10-12.

Corredig, M and Dalgleish, D G (1996) Effect of different heat treatments on the strong binding interactions between whey proteins and milk fat globules in whole milk. Journal of Dairy Research 63 441-449.

Corredig, M and Dalgleish, D G (1997a) Isolates from Industrial Buttermilk: Emulsifying Properties of Materials Derived from the Milk Fat Globule Membrane. Journal of Agricultural and Food Chemistry 45 4595-4600.

Corredig, M and Dalgleish, D G (1998) Effect of heating of cream on the properties of milk fat globule membrane isolates. Journal of Agricultural and Food Chemistry 46 2533-2540.

Corredig, M, Roesch, R R and Dalgleish, D G (2003) Production of a Novel Ingredient from Buttermilk. J. Dairy Sci. 86 2744-2750. 
Crafts, C, Bailey, B, Acworth, I, Plante, M, Gamache, P and Waraska, J Sensitive Analysis of Commonly Used artificial and Natural Sweeteners Including Stevia and Their Impurities and Degradation Products. DIONEX ed. Chelmsford.

Cui, C, Zhou, X, Zhao, M and Yang, B (2009) Effect of thermal treatment on the enzymatic hydrolysis of chicken proteins. Innovative Food Science \& Emerging Technologies 10 37-41.

Dalgleish, D G and Banks, J M (1991) The formation of complexes between serum proteins and fat globules during heating of whole milk. Kempten, ALLEMAGNE: Agrar-Verlag Allga.

Deeth, H C (1997) The role of phospholipids in the stability of milk fat globules Aust. J. Dairy Technol. 52 44-46.

Descalzo, A, Insani, E and Pensel, N (2003) Light-scattering detection of phospholipids resolved by HPLC. Lipids 38 999-1003.

Dewettinck, K, Rombaut, R, Thienpont, N, Le, T T, Messens, K and Van Camp, J (2008) Nutritional and technological aspects of milk fat globule membrane material. International Dairy Journal 18 436-457.

Dickow, J A, Larsen, L B, Hammersh J, M and Wiking, L (2011) Cooling causes changes in the distribution of lipoprotein lipase and milk fat globule membrane proteins between the skim milk and cream phase. Journal of dairy science 94 646656.

Dittie, A and Kern, H-F (1992) The major zymogen granule membrane protein GP-2 in the rat pancreas is not involved in granule formation. Eur J Cell Biol 58243 - 258.

Dowbenko, D, Kikuta, A, Fennie, C, Gillett, N and Lasky, L A (1993) Glycosylationdependent cell adhesion molecule 1 (GlyCAM 1) mucin is expressed by lactating 
mammary gland epithelial cells and is present in milk. The Journal of Clinical Investigation 92 952-960.

Duan, R-D (2011) Physiological functions and clinical implications of sphingolipids in the gut. Journal of Digestive Diseases 12 60-70.

Duan, R-D and Nilsson, A (2009) Metabolism of sphingolipids in the gut and its relation to inflammation and cancer development. Progress in Lipid Research 48 62-72.

El-Loly, M M (2011) Composition, Properties and Nutritional Aspects of Milk Fat Globule Membrane - a Review. Polish Journal of Food and Nutrition Sciences $617-$ 32.

Elliott, M R and Ravichandran, K S (2010) Clearance of apoptotic cells: implications in health and disease. The Journal of Cell Biology 189 1059-1070.

Elmnasser, N, Dalgalarrondo, M L, Orange, N, et al. (2008) Effect of Pulsed-Light Treatment on Milk Proteins and Lipids. Journal of Agricultural and Food Chemistry 56 1984-1991.

Elmnasser, N, Guillou, S, Leroi, F, Orange, N, Bakhrouf, A and Federighi, M (2007) Pulsed-light system as a novel food decontamination technology: a review. Canadian Journal of Microbiology 53 813-821.

Erwin, R E and Randolph, H E (1975) Influence of Mastitis on Properties of Milk XI. Fat Globule Membrane. Journal of dairy science 58 9-12.

Evers, J M (2004a) The milkfat globule membrane--compositional and structural changes post secretion by the mammary secretory cell. International Dairy Journal 14661 674.

Evers, J M (2004b) The milkfat globule membrane--methodologies for measuring milkfat globule (membrane) damage. International Dairy Journal 14 747-760. 
Evers, J M, Haverkamp, R G, Holroyd, S E, Jameson, G B, Mackenzie, D D S and Mccarthy, O J (2008) Heterogeneity of milk fat globule membrane structure and composition as observed using fluorescence microscopy techniques. International Dairy Journal 18 1081-1089.

Fagan, P and Wijesundera, C (2004) Liquid chromatographic analysis of milk phospholipids with on-line pre-concentration. Journal of Chromatography A 1054 241-249.

Farrell Jr, H M, Jimenez-Flores, R, Bleck, G T, et al. (2004) Nomenclature of the Proteins of Cows' Milk--Sixth Revision. Journal of dairy science 87 1641-1674.

Fauquant, C, Briard, V, Leconte, N and Michalski, M-C (2005) Differently sized native milk fat globules separated by microfiltration: fatty acid composition of the milk fat globule membrane and triglyceride core. EUROPEAN JOURNAL OF LIPID SCIENCE AND TECHNOLOGY 107 80-86.

Fauquant, C, Briard-Bion, V, Leconte, N, Guichardant, M and Michalski, M-C (2007) Membrane phospholipids and sterols in microfiltered milk fat globules. EUROPEAN JOURNAL OF LIPID SCIENCE AND TECHNOLOGY 109 1167-1173.

Fauquant, J, Pierre, A and Brulé, G (1985) Clarification du lactosérum acide de caséinerie. La Technique Laitiere 1003 37-41.

Favé, G, Coste, T C and Armand, M (2004) Physicochemical properties of lipids: New strategies to manage fatty acid bioavailability, pp. 17. Noisy-le-Grand, ROYAUMEUNI: Cellular and Molecular Biology.

Fedotova, Y and Lencki, R (2008) The Effect of Phospholipids on Milkfat Crystallization Behavior. Journal of the American Oil Chemists' Society 85 205-212. 
Fedotova, Y and Lencki, R (2010) The Effect of Phospholipids on Butter Physical and Sensory Properties. Journal of the American Oil Chemists' Society 87 75-82.

Folch, J, Lees, M and Stanley, G H S (1957) A simple method for the isolation and purificatin of total lipids from animal tissues. Journal of Biological Chemistry 226 497-509.

Fong, B Y and Norris, C S (2009) Quantification of Milk Fat Globule Membrane Proteins Using Selected Reaction Monitoring Mass Spectrometry. Journal of Agricultural and Food Chemistry 57 6021-6028.

Fong, B Y, Norris, C S and Macgibbon, a K H (2007) Protein and lipid composition of bovine milk-fat-globule membrane. International Dairy Journal 17 275-288.

Franke, W W, Heid, H, Grund, C, et al. (1981) Antibodies to the major insoluble milk fat globule membrane-associated protein: specific location in apical regions of lactating epithelial cells. J. Cell Biol. 89 485-494.

Fuller, A and Van Eldik, L (2008) MFG-E8 Regulates Microglial Phagocytosis of Apoptotic Neurons. Journal of Neuroimmune Pharmacology 3 246-256.

Gagnaire, V, Jardin, J, Jan, G and Lortal, S (2009) Invited review: Proteomics of milk and bacteria used in fermented dairy products: From qualitative to quantitative advances. Journal of dairy science 92 811-825.

Gallier, S, Gragson, D, Jimenez-Flores, R and Everett, D (2010a) Using Confocal Laser Scanning Microscopy To Probe the Milk Fat Globule Membrane and Associated Proteins. Journal of Agricultural and Food Chemistry 58 4250-4257.

Garcia-Amezquita, L E, Primo-Mora, a R, Barbosa-C·Novas, G V and Sepulveda, D R (2009) Effect of nonthermal technologies on the native size distribution of fat 
globules in bovine cheese-making milk. Innovative Food Science \& Emerging Technologies 10 491-494.

Gassi, J-Y, Famelart, M-H and Lopez, C (2008) Heat treatment of cream affects the physicochemical properties of sweet buttermilk. Dairy Science \& Technology 88369 385.

Glass, L and Hedrick, T I (1977) Nutritional Composition of Sweet- and Acid-Type Dry Wheys. I. Major Factors Including Amino Acids. Journal of dairy science 60 185189.

Govindasamy-Lucey, S, Lin, T, Jaeggi, J J, Johnson, M E and Lucey, J A (2006) Influence of Condensed Sweet Cream Buttermilk on the Manufacture, Yield, and Functionality of Pizza Cheese. Journal of dairy science 89 454-467.

Greenbank, G R and Pallansch, M J (1961) Migration of Phosphatides in Processing Dairy Products. Journal of dairy science 44 1597-1602.

Gubbens, J, Ruijter, E, De Fays, L E V, et al. (2009) Photocrosslinking and Click Chemistry Enable the Specific Detection of Proteins Interacting with Phospholipids at the Membrane Interface. Chemistry \& biology 16 3-14.

Hamdan, M and Righetti, P G (2005) Proteomics today: protein assessment and biomarkers using mass spectrometry, 2D electrophoresis, and microarray technology. John Wiley \& Sons.

Hillbrick, G C, Mcmahon, D J and Mcmanus, W R (1999) Microstructure of Indirectly and Directly Heated Ultra-high-temperature (UHT) Processed Milk Examined using Transmission Electron Microscopy and Immunogold Labelling. LebensmittelWissenschaft und-Technologie 32 486-494. 
Hohe, K A, Dimick, P S and Kilara, A (1985) Milk Lipoprotein Lipase Distribution in the Major Fractions of Bovine Milk. Journal of dairy science 68 1067-1073.

Houlihan, a V, Goddard, P A, Kitchen, B J and Masters, C J (1992) Changes in structure of the bovine milk fat globule membrane on heating whole milk. Journal of Dairy Research 59 321-329.

Huppertz, T and Kelly, a L (2006) Physical Chemistry of Milk Fat Globules. In: Advanced Dairy Chemistry Volume 2 Lipids, pp. 173-212. FOX, P F P L H M ed.: Springer US.

Hvarregaard, J, Andersen, M H, Berglund, L, Rasmussen, J T and Petersen, T E (1996) Characterization of Glycoprotein PAS-6/7 from Membranes of Bovine Milk Fat Globules. European Journal of Biochemistry 240 628-636.

Isaacs, C E, Litov, R E and Thormar, H (1995) Antimicrobial activity of lipids added to human milk, infant formula, and bovine milk. Journal of Nutritional Biochemistry 6 $362-366$.

Jarasch, E-D, Bruder, G, Keenan, T W and Franke, W W (1977) Redox Constituents in Milk Fat Globule Membranes and Rough Endoplasmic Reticulum from Lactating Mammary Gland. The Journal of Cell Biology 73 223-241.

Jensen, R G (2002) The Composition of Bovine Milk Lipids: January 1995 to December 2000. J. Dairy Sci. 85 295-350.

Jiménez-Flores, R and Brisson, G (2008) The milk fat globule membrane as an ingredient: why, how, when? Dairy Science \& Technology 88 5-18.

Jiménez-Flores, R and Higuera-Ciapara, I (2009) Beverages based on milk fat globule memebrane (MFGM) and other novel concepts for dairy-based functional beverages. 
In: Functional and speciality beverage technology, pp. 281-296. PHD, P P ed. Boca Raton, New York, Washington DC.: CRC Press, Woodhead Publishing Limited.

Jinjarak, S, Olabi, A, Jiménez-Flores, R, Sodini, I and Walker, J H (2006) Sensory evaluation of whey and sweet cream buttermilk. Journal of dairy science $\mathbf{8 9} 2441$ 2450.

Kanno, C, Shimomura, Y and Takano, E (1991) Physicochemical properties of milk-fat emulsions stabilized with bovine-milk fat globule-membrane. Journal of Food Science 56 1219-1223.

Keenan, T W and Mather, I H (2006) Intracellular Origin of Milk Fat Globules and the Nature of the Milk Fat Globule Membrane. In: Advanced Dairy Chemistry: Lipids, pp. 137-171. FOX, P F and MCSWEENEY, P L H eds. New York: Springer US. Keenan, T W, Moon, T-W and Dylewski, D P (1983) Lipid Globules Retain Globule Membrane Material After Homogenization. Journal of dairy science 66 196-203.

Keenan, T W, Olson, D E and Mollenhauer, H H (1971) Origin of the Milk Fat Globule Membrane. J. Dairy Sci. 54 295-299.

Keller, A, Nesvizhskii, a I, Kolker, E and Aebersold, R (2002) Empirical Statistical Model To Estimate the Accuracy of Peptide Identifications Made by MS/MS and Database Search. Analytical Chemistry 74 5383-5392.

Kemsley, J (2008) Unraveling breast milk. In: C\&EN: Chemical \& Engineering News, pp. 13-17. C\&EN West coast news bureau: American Chemical Society.

Kim, D H, Kanno, C and Mizokami, Y (1992) Purification and characterization of major glycoproteins, PAS-6 and PAS-7, from bovine milk fat globule membrane. Biochimica et Biophysica Acta (BBA) - Protein Structure and Molecular Enzymology 1122 203-211. 
Kim, H-H Y and Jiménez-Flores, R (1995) Heat-Induced Interactions Between the Proteins of Milk Fat Globule Membrane and Skim Milk. J. Dairy Sci. 78 24-35.

Kintner, J A and Day, E A (1965) Major Free Fatty Acids in Milk and. Journal of dairy science 48 1575-1581.

Kippax, P Measuring Particle Size Using Modern Laser Diffraction Techniques. Worcestershire: Malvern Instruments GmbH.

Kitchen, B J (1977) Fractionation and characterization of the membranes from bovine milk fat globules. Journal of Dairy Research 44 469-482.

Kobylka, D and Carraway, K L (1973) Proteolytic digestion of proteins of the milk fat globule membrane. Biochimica et Biophysica Acta (BBA) - Biomembranes 307133 140.

Koops, J and Tarassuk, N P (1959) The effect of various processing treatments on the partitioning of phosphatides between the fat phase and the milk plasma. Netherlands Milk and Dairy Journal 13 180-189.

Krishnamurthy, K, Demirci, A and Irudayaraj, J (2004) Milk Pasteurization by Pulsed UV-light Treatment. In: ASAE/CSAE Anual Inernational Meeting Ontario, Canada.

Landstrom, K, Alsins, J and Bergenstâhl, B (2000) Competitive protein adsorption between bovine serum albumin and [beta]-lactoglobulin during spray-drying. Food Hydrocolloids 14 75-82.

Lee, S J and Sherbon, J W (2002) Chemical changes in bovine milk fat globule membrane caused by heat treatment and homogenization of whole milk. Journal of Dairy Research $69555-567$. 
Lemonnier, L A, Dillehay, D L, Vespremi, M J, Abrams, J, Brody, E and Schmelz, E M (2003) Sphingomyelin in the suppression of colon tumors: prevention versus intervention. Archives of Biochemistry and Biophysics 419 129-138.

Lennon, N J, Kho, A, Bacskai, B J, Perlmutter, S L, Hyman, B T and Brown, R H (2003) Dysferlin Interacts with Annexins A1 and A2 and Mediates Sarcolemmal Woundhealing. Journal of Biological Chemistry 278 50466-50473.

Lindmark-Mansson, H, Timgren, A, Aldèn, G and Paulsson, M (2005) Two-dimensional gel electrophoresis of proteins and peptides in bovine milk. International Dairy Journal 15 111-121.

Lonnerdal, B, Valencia, N, Graverholt, G and Zavaleta, N (2006) Effect of Fortifying Complementary Food With A Bioactive Milk Protein Fraction With Micronutrients on Growth and Micronutrient Status of Peruvian Infants. Journal of Pediatric Gastroenterology and Nutrition 42 E88.

Lopez, C, Briard-Bion, V, Mènard, O, et al. (2010a) Fat globules selected from whole milk according to their size: Different compositions and structure of the biomembrane, revealing sphingomyelin-rich domains. Food Chemistry 125 355-368.

Lopez, C, Briard-Bion, V, Menard, O, Rousseau, F, Pradel, P and Besle, J-M (2008) Phospholipid, Sphingolipid, and Fatty Acid Compositions of the Milk Fat Globule Membrane are Modified by Diet. Journal of Agricultural and Food Chemistry 56 5226-5236.

Lopez, C, Madec, M-N and Jimenez-Flores, R (2010b) Lipid rafts in the bovine milk fat globule membrane revealed by the lateral segregation of phospholipids and heterogeneous distribution of glycoproteins. Food Chemistry 120 22-33. 
Manso, M A, Lèonil, J, Jan, G and Gagnaire, V (2005) Application of proteomics to the characterisation of milk and dairy products. International Dairy Journal 15 845-855.

Mao, F C, Chen, W, Chiang, Y and Chiang, L C (2007) Composition for preventing and treating cardiovascular disorders. USPO ed.

Martin, H M, Hancock, J T, Salisbury, V and Harrison, R (2004) Role of Xanthine Oxidoreductase as an Antimicrobial Agent. Infect. Immun. 72 4933-4939.

Matak, K E, Sumner, S S, Duncan, S E, et al. (2007) Effects of Ultraviolet Irradiation on Chemical and Sensory Properties of Goat Milk. Journal of dairy science 90 31783186.

Mather, I H (2000) A Review and Proposed Nomenclature for Major Proteins of the Milk-Fat Globule Membrane. J. Dairy Sci. 83 203-247.

Mather, I H and Jacks, L J W (1993) A Review of the Molecular and Cellular Biology of Butyrophilin, the Major Protein of Bovine Milk Fat Globule Membrane. J. Dairy Sci. $763832-3850$.

Mather, I H and Keenan, T W (1975) Studies on the structure of milk fat globule membrane. Journal of Membrane Biology 21 65-85.

Mather, I H and Keenan, T W (1998) Origin and Secretion of Milk Lipids. Journal of Mammary Gland Biology and Neoplasia 3 259-273.

Mather, I H L, C (1999) Methods of modifying the BTN protein to eliminate an autoimmune response and products associated therewith.

Maubois, J L, A. Pierre, J. Fauquant and Piot, M (1987) Industrial fractionation of main whey proteins. Bull. Int. Dairy Fed. 212 154-159. 
Mcmanaman, J L, Russell, T D, Schaack, J, Orlicky, D J and Robenek, H (2007)

Molecular determinants of milk lipid secretion. Journal of Mammary Gland Biology and Neoplasia 12 259-268.

Mcpherson, a V and Kitchen, B J (1983) Reviews of the progress of Dairy Science: The bovine milk fat globule membrane?its formation, composition, structure and behaviour in milk and dairy products. Journal of Dairy Research 50 107-133.

Mènard, O, Ahmad, S, Rousseau, F, Briard-Bion, V, Gaucheron, F and Lopez, C (2010) Buffalo vs. cow milk fat globules: Size distribution, zeta-potential, compositions in total fatty acids and in polar lipids from the milk fat globule membrane. Food Chemistry 120 544-551.

Metwalli, a a M, Metwalli, N H and Boekel, M a J S V (1996) Effect of urea on heatinduced changes in milk. Amsterdam, PAYS-BAS: Centen.

Metwalli, a a M and Van Boekel, M a J S (1998) On the kinetics of heat-induced deamidation and breakdown of caseinate. Food Chemistry 61 53-61.

Michalski, M-C and Januel, C (2006a) Does homogenization affect the human health properties of cow's milk? Trends in Food Science \& Technology 17 423-437.

Michalski, M-C, Michel, F O and Geneste, C (2002) Appearance of submicronic particles in the milk fat globule size distribution upon mechanical treatments. Lait 82 193-208. Min, D B and Ellefson, W C (2010) Fat Analysis, pp. 602. New York: Springer.

Modrak, D E, Rodriguez, M D, Goldenberg, D M, Lew, W and Blumenthal, R D (2002) Sphingomyelin enhances chemotherapy efficacy and increases apoptosis in human colonic tumor xenografts. International Journal of Oncology 20 379-384. 
Mondy, B L and Keenan, T W (1993) Butyrophilin and xanthine oxidase occur in constant molar proportions in milk lipid globule membrane but vary in amount with breed and stage of lactation. Protoplasma 177 32-36.

Moreau, K, Dizin, E, Ray, H, et al. (2006b) BRCA1 affects lipid synthesis through its interaction with acetyl-CoA carboxylase. Journal of Biological Chemistry 2813172 3181.

Moreau, R A (2006a) The analysis of lipids via HPLC with a charged aerosol detector. Lipids 41 727-734.

Morin, P, Britten, M, Jiménez-Flores, R and Pouliot, Y (2007a) Microfiltration of Buttermilk and Washed Cream Buttermilk for Concentration of Milk Fat Globule Membrane Components. J. Dairy Sci. 90 2132-2140.

Morin, P, Jiménez-Flores, R and Pouliot, Y (2007b) Effect of processing on the composition and microstructure of buttermilk and its milk fat globule membranes. International Dairy Journal 17 1179-1187.

Morin, P, Jimènez-Flores, R and Pouliot, Y (2004) Effect of Temperature and Pore Size on the Fractionation of Fresh and Reconstituted Buttermilk by Microfiltration. Journal of dairy science $\mathbf{8 7}$ 267-273.

Morin, P, Pouliot, Y and Britten, M (2008) Effect of Buttermilk Made from Creams with Different Heat Treatment Histories on Properties of Rennet Gels and Model Cheeses. J. Dairy Sci. 91 871-882.

Morin, P, Pouliot, Y and Jimènez-Flores, R (2006) A comparative study of the fractionation of regular buttermilk and whey buttermilk by microfiltration. Journal of Food Engineering 77 521-528. 
Mulder, $\mathrm{H}$ and Walstra, $\mathrm{P}(1974)$ The milk fat globule : emulsion science as applied to milk products and comparable foods. Slough :: Commonwealth Agricultural Bureaux.

Murgiano, L, Timperio, a M, Zolla, L, Bongiorni, S, Valentini, A and Pariset, L (2009) Comparison of Milk Fat Globule Membrane (MFGM) Proteins of Chianina and Holstein Cattle Breed Milk Samples Through Proteomics Methods. Nutrients $1302-$ 315.

Nelson, D L and Cox, M M (2000) Lehninger Principles of biochemistry.

Nelson, T and Rios, D (2007) Fluorescence Microscopy Comparison of Phase Sepration in Milk Fat Globule Membrane Lipid Monolayers. San Luis obispo: California Polytechnic State University.

Nesvizhskii, a I, Keller, A, Kolker, E and Aebersold, R (2003) A Statistical Model for Identifying Proteins by Tandem Mass Spectrometry. Analytical Chemistry 75 46464658.

Nielsen, R L, Andersen, M H, Mabhout, P, Berglund, L, Petersen, T E and Rasmussen, J T (1999) Isolation of Adipophilin and Butyrophilin from Bovine Milk and Characterization of a cDNA Encoding Adipophilin. J. Dairy Sci. 82 2543-2549.

Noh, S K and Koo, S I (2004) Milk Sphingomyelin Is More Effective than Egg Sphingomyelin in Inhibiting Intestinal Absorption of Cholesterol and Fat in Rats. The Journal of Nutrition 134 2611-2616.

Nyberg, L, Duan, R-D and Nilsson, K (2000) A mutual inhibitory effect on absorption of sphingomyelin and cholesterol. The Journal of Nutritional Biochemistry 11 244-249.

O'donnell, R, Holland, J W, Deeth, H C and Alewood, P (2004) Milk proteomics. International Dairy Journal 14 1013-1023. 
O'farrell, P H (1975) High resolution two-dimensional electrophoresis of proteins.

Journal of Biological Chemistry 250 4007-4021.

Oms-Oliu, G, Martín-Belloso, O and Soliva-Fortuny, R (2008) Pulsed Light Treatments for Food Preservation. A Review. Food and Bioprocess Technology 3 13-23.

Pallesen, L T, Pedersen, L R L, Petersen, T E and Rasmussen, J T (2007)

Characterization of carbohydrate structures of bovine MUC15 and distribution of the mucin in bovine milk. Journal of dairy science 90 3143-3152.

Pan, Y, Lee, A, Wan, J, et al. (2006) Antiviral properties of milk proteins and peptides. International Dairy Journal 16 1252-1261.

Parker, P, Sando, L, Pearson, R, Kongsuwan, K, Tellam, R and Smith, S (2010) Bovine Muc1 inhibits binding of enteric bacteria to Caco-2 cells. Glycoconjugate Journal 27 89-97.

Patton, S (2004) Milk: Its remarkable contribution to human health and well-being, pp. 263. New Brunswick and London: Transaction Publishers.

Patton, S and Huston, G (1986) A method for isolation of milk fat globules. Lipids 21 $170-174$.

Patton, S, Long, C and Sooka, T (1980) Effect of Storing Milk on Cholesterol and Phospholipid of Skim Milk. Journal of dairy science 63 697-700.

Perretti, M and D'acquisto, F (2009) Annexin A1 and glucocorticoids as effectors of the resolution of inflammation. Nat Rev Immunol 9 62-70.

Peterson, J A, S. Patton and Hamosh, M (1998) Glycoproteins of the human milk fat globule in the protection of the breast-fed infant against infections. Biol. Neonate 74 143-162. 
Real Del Sol, E and Corrales, J C (1991) Obtención de concentrados del suero de mantequilla por ultrafiltración. Madrid, España: Eypasa.

Reinhardt, T A and Lippolis, J D (2006) Bovine Milk Fat Globule Membrane Proteome. Journal of Dairy Research 73 406-416.

Reinhardt, T A and Lippolis, J D (2008) Developmental Changes in the Milk Fat Globule Membrane Proteome During the Transition from Colostrum to Milk. J. Dairy Sci. 91 $2307-2318$.

Rezende-Costa, M, Elías-Argote, X E, Jimènez-Flores, R and Gigante, M L C (2010) Use of ultrafiltration and supercritical fluid extraction to obtain a whey buttermilk powder enriched in milk fat globule membrane phospholipids. International Dairy Journal 20 598-602.

Riccio, P (2004) The proteins of the milk fat globule membrane in the balance. Trends in Food Science \& Technology 15 458-461.

Robenek, H, Hofnagel, O, Buers, I, et al. (2006a) Butyrophilin controls milk fat globule secretion. Proc. Natl. Acad. Sci. USA 103 10385-10390.

Robenek, H, Hofnagel, O, Buers, I, Robenek, M J, Troyer, D and Severs, N J (2006b) Adipophilin-enriched domains in the ER membrane are sites of lipid droplet biogenesis. J Cell Sci 119 4215-4224.

Rodriguez-Otero, J L, Hermida, M and Centeno, J (1997) Analysis of Dairy Products by Near-Infrared Spectroscopy: A Review. Journal of Agricultural and Food Chemistry 45 2815-2819.

Roesch, R R, Rincon, A and Corredig, M (2004) Emulsifying Properties of Fractions Prepared from Commercial Buttermilk by Microfiltration. Journal of dairy science $\mathbf{8 7}$ 4080-4087. 
Rombaut, Roeland and Dewettinck, K (2006c) Properties, analysis and purification of milk polar lipids. International Dairy Journal 16 1362-1373.

Rombaut, R, Camp, J V and Dewettinck, K (2005) Analysis of Phospho- and Sphingolipids in Dairy Products by a New HPLC Method. Journal of dairy science $88482-488$.

Rombaut, R, Camp, J V and Dewettinck, K (2006a) Phospho- and sphingolipid distribution during processing of milk, butter and whey. International Journal of Food Science \& Technology 41 435-443.

Rombaut, R, Dejonckheere, V and Dewettinck, K (2006b) Microfiltration of Butter Serum Upon Casein Micelle Destabilization. J. Dairy Sci. 89 1915-1925.

Rombaut, R and Dewettinck, K (2007) Thermocalcic Aggregation of Milk Fat Globule Membrane Fragments from Acid Buttermilk Cheese Whey. Journal of dairy science $902665-2674$.

Russell, T D, Palmer, C A, Orlicky, D J, et al. (2007) Cytoplasmic lipid droplet accumulation in developing mammary epithelial cells: roles of adipophilin and lipid metabolism. Journal of Lipid Research 48 1463-1475.

Rutter, E R F (2006) Multiple sclerosis and milk: to drink or not to drink? International Journal of Dairy Technology 59 223-228.

Sánchez, L, Peiró, J M, Castillo, H, Pérez, M D, Ena, J M and Calvo, M (1992) Kinetic Parameters for Denaturation of Bovine Milk Lactoferrin. Journal of Food Science 57 873-879.

Sánchez-Juanes, F, Alonso, J M, Zancada, L and Hueso, P (2009) Distribution and fatty acid content of phospholipids from bovine milk and bovine milk fat globule membranes. International Dairy Journal 19 273-278. 
Scammell, a W (2001) Liquid colostrum for dairy products. USPO ed.

Schmelz, E M, Dillehay, D L, Webb, S K, Reiter, A, Adams, J and Merrill, a H (1996) Sphingomyelin Consumption Suppresses Aberrant Colonic Crypt Foci and Increases the Proportion of Adenomas versus Adenocarcinomas in CF1 Mice Treated with 1,2Dimethylhydrazine: Implications for Dietary Sphingolipids and Colon Carcinogenesis. Cancer Research 56 4936-4941.

Schuck, P (2002) Spray drying of dairy products: state of the art. Lait 82 375-382.

Sharma, S K and Dalgleish, D G (1993) Interactions between milk serum proteins and synthetic fat globule membrane during heating of homogenized whole milk. Journal of Agricultural and Food Chemistry 41 1407-1412.

Sharma, S K and Dalgleish, D G (1994) Effect of heat treatments on the incorporation of milk serum proteins into the fat globule membrane of homogenized milk. Journal of Dairy Research 61 375-384.

Shida, K, Takamizawa, K, Nagaoka, M, Kushiro, A, Osawa, T and Tsujl, T (1994) Enterotoxin-Binding Glycoproteins in a Proteose-Peptone Fraction of Heated Bovine Milk. Journal of dairy science 77 930-939.

Shimizu, M, Yamauchi, K and Kanno, C (1980) Effect of proteolytic digestion of milk fat globule membrane proteins on stability of the globules. Milchwissenschaft: 35 (1) 9$12359-12$.

Shukla, S, Fujita, K-I, Xiao, Q, Liao, Z, Garfield, S and Srinivasula, S (2011) A shear stress responsive gene product PP1201 protects against Fas-mediated apoptosis by reducing Fas expression on the cell surface. Apoptosis 16 162-173. 
Silanikove, N, Merin, U and Leitner, G (2006) Physiological role of indigenous milk enzymes: An overview of an evolving picture. International Dairy Journal 16533 545.

Silanikove, N and Shapiro, F (2007) Distribution of xanthine oxidase and xanthine dehydrogenase activity in bovine milk: Physiological and technological implications. International Dairy Journal 17 1188-1194.

Silvestre, J-S, Thery, C, Hamard, G, et al. (2005) Lactadherin promotes VEGF-dependent neovascularization. Nat Med 11 499-506.

Singh, H (2006) The milk fat globule membrane--A biophysical system for food applications. Current Opinion in Colloid \& Interface Science 11 154-163.

Singh, $\mathrm{H}$ and Ye, A (2010) Controlling milk protein interactions to enhance the reconstitution properties of whole milk powders-a minireview. Dairy Sci. Technol 90 123-136.

Smith, L M and Jack, E L (1959) Isolation of Milk Phospholipids and Determination of Their Polyunsaturated Fatty Acids. Journal of dairy science 42 767-779.

Smith, W L, Lagunas-Solar, M C and Cullor, J S (2002) Use of Pulsed Ultraviolet Laser Light for the Cold Pasteurization of Bovine Milk. Journal of Food Protection 65 1480-1482.

Smolenski, G, Haines, S, Kwan, F Y S, et al. (2006) Characterisation of Host Defence Proteins in Milk Using a Proteomic Approach. Journal of Proteome Research 6 207215.

Snow, D R, Jiménez-Flores, R, Ward, R E, et al. (2010) Dietary Milk Fat Globule Membrane Reduces the Incidence of Aberrant Crypt Foci in Fischer-344 Rats. Journal of Agricultural and Food Chemistry 58 2157-2163. 
Sodini, I, Morin, P, Olabi, A and Jimenez-Flores, R (2006) Compositional and Functional Properties of Buttermilk: A Comparison Between Sweet, Sour, and Whey Buttermilk. J. Dairy Sci. 89 525-536.

Sommer, H H and Hart, E B (1918) Effect of heat on the citric acid content of milk. J. Biol. Chem 35 313-318.

Spence, a J, Jimenez-Flores, R, Qian, M and Goddik, L (2009) The influence of temperature and pressure factors in supercritical fluid extraction for optimizing nonpolar lipid extraction from buttermilk powder. J. Dairy Sci. 92 458-468.

Spitsberg, V L (2005) Invited Review: Bovine Milk Fat Globule Membrane as a Potential Nutraceutical. J. Dairy Sci. 88 2289-2294.

Spitsberg, V L and Gorewit, R C (1997) In vitro phosphorylated bovine milk fat globule membrane proteins. The Journal of Nutritional Biochemistry 8 181-189.

Spitsberg, V L and Gorewit, R C (1998) Solubilization and Purification of Xanthine Oxidase from Bovine Milk Fat Globule Membrane. Protein Expression and Purification 13 229-234.

Spitsberg, V L and Gorewit, R C (1999) Method of detecting expression of and isolating the protein encoded by the BRCA1 gene. USPO ed.

Spitsberg, V L and Gorewit, R C (2002) Isolation, purification and characterization of fatty-acid-binding protein from milk fat globule membrane: effect of bovine growth hormone treatment. Pakistan Journal of Nutrition 1 43-48.

Spitsberg, V L, Matitashvili, E and Gorewit, R C (1995) Association and Coexpression of Fatty-Acid-Binding Protein and Glycoprotein CD36 in the Bovine Mammary Gland. European Journal of Biochemistry 230 872-878. 
Sprecher, H W, Strong, F M and Swanson, a M (1965) Phospholipids of Fresh Milk and of Sterile Whole Milk. J. Agric. Food Chem. 13 17-21.

Stannard, D J (1975) The use of marker enzymes to assay the churning of milk. Journal of Dairy Research 42 241-246.

Steffensen, C L, Hermansen, J E and Nielsen, J H (2004) The effect of milk fat composition on release of xanthine oxidase during cooling. Milchwissenschaft 59 176-179.

Sundheim, G and Bengtsson-Olivecrona, G (1985) Lipolysis in Milk Induced by Cooling or by Heparin: Comparisons of Amount of Lipoprotein Lipase in the Cream Fraction and Degree of Lipolysis. Journal of dairy science 68 589-593.

Suzuki, Y, Lopez, V and Lönnerdal, B (2005) Lactoferrin. Cellular and Molecular Life Sciences $622560-2575$.

Tabb, D L (2007) What's driving false discovery rates? J. Proteome Res. 7 45-46.

Takahashi, N and Isobe, T (2007) Proteomic biology using LC-MS: large scale analysis of cellular dynamics and function. Wiley-Interscience.

Tao, N, Depeters, E J, Freeman, S, German, J B, Grimm, R and Lebrilla, C B (2008) Bovine Milk Glycome. J. Dairy Sci. 91 3768-3778.

Thompson, a K and Singh, H (2006) Preparation of Liposomes from Milk Fat Globule Membrane Phospholipids Using a Microfluidizer. J. Dairy Sci. 89 410-419.

Timby, K (2011) Effects of Milk Fat Globule Membrane (MFGM)-Enriched Formula with Reduced Energy and Protein Content on Growth and Development [Medical Research Study] URL http://clinicaltrials.gov/ct2/show/NCT00624689.

Tran, D (2011) University of California Davis Genome Center. Personal Comunication. 
Umemoto, Y and Sato, Y (1973) Isolation and fractionation of phospholipids and glycolipids from cheddar cheese. Milchwissenschaft 28 550-554.

Vaghela, M and Kilara, A (1995) Quantitative analysis of phospholipids from whey protein concentrates by high-performance liquid chromatography with a narrow-bore column and an evaporative light-scattering detector. Journal of the American Oil Chemists' Society 72 729-733.

Van De Voort, F R, Kermasha, S, Smith, J P, Mills, B L and Ng-Kwai-Hang, K F (1987) A Study of the Stability of Record of Performance Milk Samples for Infrared Milk Analysis. Journal of dairy science 70 1515-1523.

Vanderghem, C, Blecker, C, Danthine, S, et al. (2008) Proteome analysis of the bovine milk fat globule: Enhancement of membrane purification. International Dairy Journal 18 885-893.

Vanderghem, C, Bodson, P, Danthine, S, Paquot, M, Deroanne, C and Blecker, C (2010) Milk fat globule membrane and buttermilks: from composition to valorization. Biotechnologie Agronomie Societe Et Environnement 14 485-500.

Vanderghem, C, Francis, F, Danthine, S, et al. (2011) Study on the susceptibility of the bovine milk fat globule membrane proteins to enzymatic hydrolysis and organization of some of the proteins. International Dairy Journal 21 312-318.

Vesper, H, Schmelz, E-M, Nikolova-Karakashian, M N, Dillehay, D L, Lynch, D V and Merrill, a H (1999) Sphingolipids in Food and the Emerging Importance of Sphingolipids to Nutrition. The Journal of Nutrition 129 1239-1250.

Vissac, C, Lemery, D, Le Corre, L, et al. (2002) Presence of BRCA1 and BRCA2 proteins in human milk fat globules after delivery. Biochimica et Biophysica Acta $158650-56$. 
Walstra, P (1969) Studies on Milk Fat Dispersion 0.2 Globule-Size Distribution of Cows. Netherlands Milk Dairy J. 23 99-110.

Walstra, P and Jenness, R (1984) Dairy Chemistry and Physics. New York: Wiley.

Walstra, P, Wouters, J T M and Geurts, T J (2006) Dairy science and technology. CRC/Taylor \& Francis.

Waninge, R, Kalda, E, Paulsson, M, Nylander, T and Bergenstahl, B (2004) Cryo-TEM of isolated milk fat globule membrane structures in cream. Physical Chemistry Chemical Physics 6 1518-1523.

Wat, E, Tandy, S, Kapera, E, et al. (2009) Dietary phospholipid-rich dairy milk extract reduces hepatomegaly, hepatic steatosis and hyperlipidemia in mice fed a high-fat diet. Atherosclerosis 205 144-150.

Watanabe, S, Takahashi, T, Tanaka, L, et al. (2010) Effect of Milk Sphingloipids on Rodent Plasma and Liver Lipids. In: 101st AOCS Annual Meeting \& Expo. Phoenix, Arizona.

Webb, B H, Johnson, a H and Alford, J A (1974) Fundamentals of Dairy Chemistry, pp. 930. Westport, Connecticut: The Avi Publishing Company, Inc.

Wehling, R L (2010) Infrared Spectroscopy, pp. 602. New York: Springer.

Welsch, U, U. Schumacher, Buchheim, W, I. Schinko, P. Jenness and Patton, S (1990) Histochemical and biochemical observations of milk-fat-globule membranes from several mammalian species. Acta Histochemica, 59-64.

Westermeier, R (2006) Sensitive, Quantitative, and Fast Modifications for Coomassie Blue Staining of Polyacrylamide Gels. PROTEOMICS 6 61-64. 
Wiking, L, Bertram, H C, Bjorck, L and Nielsen, J H (2005) Evaluation of cooling strategies for pumping of milk - Impact of fatty acid composition on free fatty acid levels. Journal of Dairy Research 72 476-481.

Wiking, L, Stagsted, J, Bj^rck, L and Nielsen, J H (2004) Milk fat globule size is affected by fat production in dairy cows. International Dairy Journal 14 909-913.

Wilson, N L, Robinson, L J, Donnet, A, Bovetto, L, Packer, N H and Karlsson, N G (2008) Glycoproteomics of Milk: Differences in Sugar Epitopes on Human and Bovine Milk Fat Globule Membranes. Journal of Proteome Research 7 3687-3696.

Wong, P Y Y and Kitts, D D (2003) Chemistry of buttermilk solid antioxidant activity. Journal of dairy science 86 1541-1547.

Wooding, F B P and Kemp, P (1975) Ultrastructure of the milk fat globule membrane with and without triglyceride. Cell and Tissue Research 165 113-127.

Wooding, F B P, Peaker, M and Linzell, J L (1970) Theories of Milk Secretion : Evidence from the Electron Microscopic Examination of Milk. Nature 226 762-764. Xu, R (2001) Particle Characterization: Light Scattering Methods. Kluwer Academic. Yamada, M, Murakami, K, Wallingford, J C and Yuki, Y (2002) Identification of lowabundance proteins of bovine colostral and mature milk using two-dimensional electrophoresis followed by microsequencing and mass spectrometry. Electrophoresis 23 1153-1160.

Ye, A, Anema, S G and Singh, H (2004a) High-Pressure-Induced Interactions Between Milk Fat Globule Membrane Proteins and Skim Milk Proteins in Whole Milk. $J$. Dairy Sci. 87 4013-4022.

Ye, A, Anema, S G and Singh, H (2007) Behaviour of homogenized fat globules during the spray drying of whole milk. International Dairy Journal 17 374-382. 
Ye, A, Singh, H, James Oldfield, D and Anema, S (2004b) Kinetics of heat-induced association of [beta]-lactoglobulin and [alpha]-lactalbumin with milk fat globule membrane in whole milk. International Dairy Journal 14 389-398.

Ye, A, Singh, H, Taylor, M W and Anema, S (2002) Characterization of protein components of natural and heat-treated milk fat globule membranes. International Dairy Journal 12 393-402.

Ye, A, Singh, H, Taylor, M W and Anema, S (2004c) Interactions of whey proteins with milk fat globule membrane proteins during heat treatment of whole milk. Lait 84 269283.

Yeh, Y Y (1984) Biosynthesis of phospholipids and sphingolipids from acetoacetate and glucose in different regions of developing brain in vivo. Journal of Neuroscience Research 11 383-394.

Yoder, M C (2005) NO role in EPC function. Blood 105 1846-1847.

Zavaleta, N, Valencia, N, Graverholt, G, Staudt-Kvistgaard, A and Lonnerdal, B (2006) Incidence and Duration of Diarrhea in Peruvian Infants Consuming Complementary Food With Bioactive Milk Fat Globule Membrane Proteins. Journal of Pediatric Gastroenterology and Nutrition 42 E39.

Zeisel, S H (2006) The fetal origins of memory: The role of dietary choline in optimal brain development. The Journal of pediatrics 149 S131-S136.

Zhang, J and Mccrae, K R (2005) Annexin A2 mediates endothelial cell activation by antiphospholipid/anti- 2 glycoprotein I antibodies. Blood 105 1964-1969. 


\section{APPENDIX}

\section{A. Protocols for Buffers}

All the reagents were of analytical grade and kept at room temperature unless otherwise stated. With regard to 2D protein analysis, reagents were of electrophoresis purity grade. Nanopure water of $18 \mathrm{M} \Omega / \mathrm{cm}^{2}$ was utilized to make solutions.

\section{10X Phosphate Buffer Saline (PBS)}

To make a 10X stock solution, $87 \mathrm{~g}$ of $\mathrm{NaCl}, 18.2 \mathrm{~g}$ of $\mathrm{K}_{2} \mathrm{HPO}_{4}$, and $2.3 \mathrm{~g}$ of $\mathrm{KH}_{2} \mathrm{PO}_{4}$ were placed into a one-liter bottle and filled with deionized water up to $900 \mathrm{~mL}$. The solutes were dissolved completely, and the $\mathrm{pH}$ was adjusted with $1 \mathrm{~N} \mathrm{NaOH}$ to 7.2. Then, the final volume was adjusted to one liter using a graduated cylinder.

\section{Formic Acid Buffer}

A $1 \mathrm{M}$ formic acid (06440, Fluka) buffer was made and neutralized with triethylamine (TEA) (HPLC grade, 04884, Fisher Scientific) to a final pH of 3. In a small beaker, 80\% of the final buffer volume was placed with nanopure water. The $1 \mathrm{M}$ formic acid was made by adding the equivalent concentrated formic acid $\left(\mathrm{V}_{\mathrm{i}}=\left(\mathrm{C}_{\mathrm{f}} \mathrm{x} \mathrm{V}_{\mathrm{f}}\right) / \mathrm{C}_{\mathrm{i}}\right.$ i=initial. fefinal $\left.{ }_{\text {fina }}\right)$ followed by dropwise addition of TEA. Neutralization point was checked with litmus paper, and for the final $\mathrm{pH}$, a small volume was measured with a $\mathrm{pH}$ meter to avoid introducing contamination. The buffer could be used for one week. 


\section{2-DE-gel Buffers}

\section{a) Homogenization Buffer}

This was a 7M urea, $2 \mathrm{M}$ thiourea, $1 \%$ ASB-14, 40mM Tris base, $0.001 \%$ bromophenol blue, $0.5 \%$ ampholyte and $40 \mathrm{mM}$ DTT. Reagents were purchased from BioRad unless indicated. In a $250 \mathrm{~mL}$ beaker, $42 \mathrm{~g}$ of urea (161-0731), 15.2g of thiourea (T8656, Sigma-Aldrich, MO), 0.484g of Tris base (161-0719), $1 \mathrm{~g}$ of amidosulfobetaine14 (ASB-14) (182750, Calbichem), and $1 \mathrm{~mL}$ of $0.1 \%$ bromophenol blue were combined. The solution's volume was brought up to $100 \mathrm{~mL}$ with nanopure water and stored at $4^{\circ} \mathrm{C}$. Immediately before use, 6mg dithiothreitol (DTT, 161-0611) and 5 $\mu \mathrm{limmobilized} \mathrm{pH}$ gradient (IPG) buffer pH 3-10 (17-6000-87, GE Healthcare, NJ) were added per mL of working homogenization buffer. ASB-14, bromophenol blue, DTT, and IPG buffer were kept at $4^{\circ} \mathrm{C}$.

\section{b) Immobilized pH Gradient (IPG) Rehydration Buffer}

This was a 7M urea, 2M thiourea, 2\% CHAPS, $2 \%$ NP-40, 0.002\% bromophenol blue, $0.5 \%$ ampholyte and $100 \mathrm{mM}$ DTE. In a $200 \mathrm{~mL}$ beaker, $42.4 \mathrm{~g}$ of urea, $15.2 \mathrm{~g}$ thiourea, 2 mL 100\% nonidet P-40 (Fluka), 2.0g CHAPS (C3023, Sigma-Aldrich, MO), $0.5 \mathrm{~mL} 0.1 \%$ Bromophenol Blue. The volume was brought up to $100 \mathrm{~mL}$ with nanopure water, and the solution was filtered with a 0.2 micron filter. The final solution was stored at $4^{\circ} \mathrm{C}$, and before use, 20mg dithioerythritol (DTE, D8255, Sigma-Aldrich, MO) and 6.25ul IPG buffer pH 3-10 were added per $1.25 \mathrm{~mL}$ of rehydration buffer. DTE was kept at $-20^{\circ} \mathrm{C}$. 


\section{c) Equilibration Buffer}

This was a 375mM Tris $\mathrm{pH} 8.8,6 \mathrm{M}$ urea, $30 \%$ glycerol, $2 \%$ SDS, $0.002 \%$ bromophenol blue. In a $400 \mathrm{~mL}$ beaker, $50 \mathrm{~mL}$ of 1.5M Tris-HCl, pH8.8 (161-0798), 72 g urea, 60 mL 99\% glycerol (BP229, Fisher Scientific), 20 mL 20\% SDS (161-0418), and $400 \mu \mathrm{L} 0.1 \%$ bromophenol blue were combined. The volume was brought up to $200 \mathrm{~mL}$ with nanopure water, and the solution was stored at $4{ }^{\circ} \mathrm{C}$. To make working equilibration buffer, the solution was brought to room temperature, and $250 \mathrm{mg}$ of DTT and $625 \mathrm{mg}$ of iodoacetamide (163-2109) were added to $25 \mathrm{~mL}$ of equilibration buffer in separate tubes.

\section{d) 10X SDS-PAGE Running Buffer}

In $1 \mathrm{~L}$ bottle, $50 \mathrm{~mL}$ of $20 \% \mathrm{SDS}, 30 \mathrm{~g}$ of Tris-base, and 144g of glycine were mixed and dissolved with nanopure water to fill one liter. The solution was stored at $4^{\circ} \mathrm{C}$.

\section{e) Molecular Weight Standards for 2-D gels}

All the reagents were molecular grade from BioRad and kept at $4{ }^{\circ} \mathrm{C}$ unless otherwise stated. An aliquot of $950 \mu \mathrm{L}$ of Laemmli sample buffer (161-0737), $50 \mu \mathrm{L}$ of betamercaptoethanol, and $27 \mu \mathrm{L}$ of SDS-PAGE molecular weight standards low range (1610304 , stored at $-20^{\circ} \mathrm{C}$ ) were combined. Aliquots of $40 \mu \mathrm{L}$ were kept in microcentrifuge tube and stored at $-20^{\circ} \mathrm{C}$. To load gels, an aliquot was heated at $100^{\circ} \mathrm{C}$ for 3 min, and $5 \mu \mathrm{L}$ of standard solution was pipetted onto a Biorad IEF electrode wick square (165-4071) placed over parafilm. The wicks were dried completely before placing in cassettes.

$$
\text { f) Agarose (0.8\%) }
$$

This was a $25 \mathrm{mmol} / \mathrm{L}$ Tris-base, $192 \mathrm{mmol} / \mathrm{L}$ glycine, $0.1 \%$ SDS. In a $250 \mathrm{~mL}$ Erlenmeyer flask, $0.8 \mathrm{~g}$ of low melt agarose (161-3111), $100 \mathrm{~mL}$ of $1 \mathrm{x}$ running buffer, and 
$300 \mu \mathrm{L}$ of $0.1 \%$ bromophenol blue were mixed and heated in a microwave. Once the agarose melted, it was stored at $-20^{\circ} \mathrm{C}$. The agarose was reheated for gel electrophoresis and allowed to cool to $40-50^{\circ} \mathrm{C}$ before loading over the IPG strips.

\section{g) $10 \%$ TCA/Acetone}

In a beaker, $20 \mathrm{~g}$ of trichloroacetic acid (TCA, BP555, Fisher Scientific) was placed into $100 \mathrm{ml}$ of $100 \%$ acetone and dissolved completely. The volume was then adjusted with a graduated cylinder up to $200 \mathrm{ml}$ with more $100 \%$ acetone and stored at $-20{ }^{\circ} \mathrm{C}$.

\section{h) Bromophenol Blue (0.1\%)}

In a $250 \mathrm{~mL}$ Erlenmeyer flask, $0.61 \mathrm{~g}$ of Tris base was added to $100 \mathrm{ml}$ nanopure water and mixed with a stir bar until dissolved. Then $0.1 \mathrm{~g}$ of bromophenol blue was added and stirred until completely solubilized. Solution was kept at $4{ }^{\circ} \mathrm{C}$.

\section{SDS-PAGE Gel Preparation}

All the reagents were of electrophoresis purity grade from BioRad and stored at room temperature unless indicated. To make 12 gels at $12.5 \%$ acrylamide, $120 \mathrm{~mL}$ of milliQ $\mathrm{H}_{2} \mathrm{O}, 58.5 \mathrm{~mL}$ of $1.5 \mathrm{M}$ Tris- $\mathrm{HCl} \mathrm{pH} 8.8,75 \mathrm{~mL}$ of $40 \%$ acrylamide/bisacrylimide solution (161-0148, stored at $4{ }^{\circ} \mathrm{C}$ ), and $1.463 \mathrm{~mL}$ of $20 \%$ SDS were combined in a $500 \mathrm{~mL}$ Erlenmeyer vacuum flask. This solution was de-gassed for about 15 min with a vacuum pump. A solution of 10\% ammonium persulfate (APS) (161-0700) was prepared by dissolving $0.10 \mathrm{~g}$ of APS into $1.00 \mathrm{~mL}$ of MilliQ water. Once degassed, $675 \mu \mathrm{l}$ of the $10 \%$ APS solution, the catalyst, and $292.5 \mu \mathrm{L}$ of tetramethylethylenediamine (TEMED, 1610801, kept at $4{ }^{\circ} \mathrm{C}$ ) were added to polymerize the gels. To remove bubbles and smooth the surface, $95 \%$ isopropanol was added to the top of the gels with a glass Pasteur pipette. Gels were set on a leveled surface for $30 \mathrm{~min}$, and the ethanol was decanted off top. The 
gels were then rinsed with nanopure water and dried before placing the equilibrated IPG strips.

\section{Sensitive Colloidal Staining Solution}

This was a 34\% (v/v) methanol, 3\% (v/v) phosphoric acid, 17\% (w/v) ammonium sulfate. In a $1 \mathrm{~L}$ bottle, $400 \mathrm{~mL}$ of water and $30 \mathrm{~mL}$ of $85 \% \mathrm{H}_{3} \mathrm{PO}_{4}$ were mixed. Then, 170 $\mathrm{g}$ of $\left(\mathrm{NH}_{4}\right)_{2} \mathrm{SO}_{4}$ were added to the solution slowly. If $\left(\mathrm{NH}_{4}\right)_{2} \mathrm{SO}_{4}$ is added too quickly, it becomes granulated and hard to dissolve. Once all the $\left(\mathrm{NH}_{4}\right)_{2} \mathrm{SO}_{4}$ was dissolved, $340 \mathrm{~mL}$ of methanol were added slowly to prevent localized precipitation of $\left(\mathrm{NH}_{4}\right)_{2} \mathrm{SO}_{4}$. Once the solution was homogenous, the volume was adjusted to one liter.

\section{Protein Extraction Buffers for MALDI-TOF}

Reagents were of LC/MS grade and kept at room temperature. Glassware was used Small beakers cleaned well and rinsed with the appropriate solvent.

\section{a) Destaining Buffer (25mM $\mathrm{NH}_{4} \mathrm{HCO}_{3} / 50 \%$ acetonitrile)}

In a $50 \mathrm{ml}$ beaker, $0.059 \mathrm{~g}$ of $\mathrm{NH}_{4} \mathrm{HCO}_{3}$ was added to $15 \mathrm{~mL}$ of $100 \%$ acetonitrile. The volume was adjusted to $30 \mathrm{~mL}$ by adding $15 \mathrm{~mL}$ HPLC grade water.

\section{b) Analyte Solution (0.1\% TFA/ Acetonitrile 2:1)}

First a $0.1 \%$ TFA solution was prepared by adding $20 \mu \mathrm{L}$ of TFA (kept at $-20 \mathrm{C}$ ) to 20 mL of HPLC Grade Water (W5-4, Fisher Scientific). Then, the analyte solution was prepared by adding $10 \mathrm{~mL}$ of $0.1 \% \mathrm{TFA}$ and $5 \mathrm{~mL}$ of acetonitrile. The solution was mixed in a glass beaker rinsed with acetonitrile. 


\section{c) Promega Mass Spectrometry Grade Porcine Trypsin Gold}

Aliquots of Promega V5280 trypsin (100ug/vial) were prepared and stored at $-70^{\circ} \mathrm{C}$. First, $50 \mathrm{mM}$ acetic acid was made by diluting $29 \mu \mathrm{L}$ of concentrated acetic acid to 10 $\mathrm{mL}$ with HPLC grade water in a graduated cylinder. Then, $100 \mu \mathrm{L}$ of this solution was added to the vial containing the powdered trypsin. Then, the trypsin solution was mixed and put in $5 \mu \mathrm{L}$ aliquots. To prepare working trypsin solution, a $40 \mathrm{mM} \mathrm{NH}{ }_{4} \mathrm{HCO}_{3} / 10 \%$ acetonitrile solution was prepared by dissolving $31.6 \mathrm{mg}$ of $\mathrm{NH}_{4} \mathrm{HCO}_{3}$ into $9 \mathrm{~mL}$ of HPLC Grade water in a graduated cylinder followed by the addition of one $\mathrm{mL}$ of acetonitrile. Before digestion, an aliquot was thawed, and $450 \mu \mathrm{L}$ of $40 \mathrm{mM}$ $\mathrm{NH}_{4} \mathrm{HCO}_{3} / 10 \%$ acetonitrile were added for a final $165 \mu \mathrm{g} / 15 \mu \mathrm{L}$ trypsin concentration per well.

\section{d) Mass Spectrometry Peptide Standard}

Aliquots of Peptide Calibration Standard (206195, Bruker Corp.) were prepared by adding $0.1 \% \mathrm{TFA} /$ water. First, $2 \mathrm{~mL}$ of HPLC grade water was measured in a graduated cylinder, and $2 \mu \mathrm{L}$ of TFA were added. The peptide mixture was dissolved completely in $125 \mu \mathrm{L}$ of $0.1 \% \mathrm{TFA} /$ water, and $5 \mu \mathrm{L}$ aliquots were stored at $-70^{\circ} \mathrm{C}$.

\section{e) Matrix Solution (0.2mg HCCA/mL 0.1\%TFA/Acetonitrile)}

In a 1.5mL Eppendorf tube, 0.2mg of -hydroxycyanocinnamic acid (HCCA, 201344 mass-spectrometry grade, Bruker Corp., stored at $-20^{\circ} \mathrm{C}$ ) was measured, or enough powder was put in the tube to fill up to the bottom line. To acidify HCCA, $50 \mu \mathrm{L}$ of $0.1 \%$ TFA was added and mixed. Then, $950 \mu \mathrm{L}$ of LC/MS grade acetonitrile was added and vortexed until HCCA was in solution. 


\section{f) Wash Buffer (10mM Ammonium Phosphate in 0.1\%TFA)}

In a $50 \mathrm{~mL}$ beaker, $20 \mu \mathrm{L}$ of TFA (kept at $-20^{\circ} \mathrm{C}$ was added to $20 \mathrm{~mL}$ of HPLC water. Then, $5.75 \mathrm{mg}$ of $\mathrm{NH}_{4} \mathrm{H}_{2} \mathrm{PO}_{4}$ was added to $5 \mathrm{~mL}$ of $0.1 \%$ TFA. The beaker was rinsed with HPLC water.

\section{g) Recrystalization Buffer (Ethanol/acetone/0.1\% TFA, 6:3:1 v/v/v)}

This buffer must be prepared right before use (at the most five min). In a 50ml glass beaker rinsed with ethanol, $6 \mathrm{~mL}$ of ethanol, $3 \mathrm{~mL}$ of acetone, and $1 \mathrm{~mL}$ of $0.1 \%$ TFA were combined.

\section{h) Tris-glycine buffer}

This was a $91.9 \mathrm{mM}$ glycine, $4 \mathrm{mM}$ EDTA. In a 1L bottle, the Tris-glycine buffer was prepared by adding $10.4 \mathrm{~g}$ of Tris (hydroxymethyl) aminomethane and $1.2 \mathrm{~g}$ of EDTA in nanopure water. The $\mathrm{pH}$ was adjusted to 8 , and the final volume to one liter.

\section{i) Tris-glycine/8M urea/ $17 \mathrm{mM}$ SDS buffer}

This was a $91.9 \mathrm{mM}$ glycine, $4 \mathrm{mM}$ EDTA, $8 \mathrm{M}$ urea, $17 \mathrm{mM}$. To a liter of Trisglycine buffer, $480.5 \mathrm{~g}$ of urea was added and allowed to dissolve completely before adding $5 \mathrm{~g}$ of SDS. 


\section{B. Microbial Reduction}

Table 24. Microbial reduction in heat and cold pasteurization. Aerobic and coliforms petrifilms were incubated for 48 and 24 hrs respectively.

\begin{tabular}{lrlll}
\hline & \multicolumn{2}{c}{ CFU/mL } & \multicolumn{2}{c}{ \% Reduction } \\
\hline \multicolumn{1}{c}{ Process } & Aerobic & Coliform & \multicolumn{1}{c}{ Aerobic } & Coliform \\
\hline Raw & $7.43 \mathrm{E}+04$ & 174 & 0 & 0 \\
$5 \mathrm{ml}, 2 \mathrm{~s}$ & $4.15 \mathrm{E}+04$ & 153 & 44 & 12 \\
$7 \mathrm{ml}, 2 \mathrm{~s}$ & $4.80 \mathrm{E}+04$ & 151 & 35 & 13 \\
$7 \mathrm{ml}, 3 \mathrm{~s}$ & $5.30 \mathrm{E}+04$ & 148 & 29 & 15 \\
$7 \mathrm{ml}, 5 \mathrm{~s}$ & $5.25 \mathrm{E}+04$ & 140 & 29 & 20 \\
$7 \mathrm{ml}, 7 \mathrm{~s}$ & $5.15 \mathrm{E}+04$ & 140 & 31 & 20 \\
$7 \mathrm{ml}, 9 \mathrm{~s}$ & $5.35 \mathrm{E}+04$ & 135 & 28 & 22 \\
$10 \mathrm{ml}, 5 \mathrm{~s}$ & $6.85 \mathrm{E}+04$ & 146 & 8 & 16 \\
Batch & $2.65 \mathrm{E}+02$ & 0 & 100 & 100 \\
HTST & $1.05 \mathrm{E}+02$ & 0 & 100 & 100 \\
UHT & 0 & 0 & 100 & 100 \\
\hline
\end{tabular}

Table 25. Microbial reduction in UV pulsed light treatment. Aerobic and coliform petrifilms were incubated for 48 and 24 hrs respectively.

\begin{tabular}{lllll}
\hline & \multicolumn{2}{c}{ CFU/mL } & \multicolumn{2}{c}{ \% Reduction } \\
\hline \multicolumn{1}{c}{ Process } & Aerobic & Coliform & Aerobic & Coliform \\
\hline Raw & $6.40 \mathrm{E}+05$ & 565 & 0 & 0 \\
$5 \mathrm{ml}, 5 \mathrm{~s}$ & $4.25 \mathrm{E}+05$ & 270 & 34 & 52 \\
$7 \mathrm{ml}, 2 \mathrm{~s}$ & $4.95 \mathrm{E}+05$ & 330 & 23 & 42 \\
$7 \mathrm{ml}, 3 \mathrm{~s}$ & $3.65 \mathrm{E}+05$ & 330 & 43 & 42 \\
$7 \mathrm{ml}, 5 \mathrm{~s}$ & $1.95 \mathrm{E}+05$ & 320 & 70 & 43 \\
$7 \mathrm{ml}, 7 \mathrm{~s}$ & $4.15 \mathrm{E}+05$ & 390 & 35 & 31 \\
$7 \mathrm{ml}, 9 \mathrm{~s}$ & $3.25 \mathrm{E}+05$ & 380 & 49 & 33 \\
$10 \mathrm{ml}, 5 \mathrm{~s}$ & $5.55 \mathrm{E}+05$ & 380 & 13 & 33 \\
\hline
\end{tabular}

\section{MFGM Extraction}

Table 26. MFGM material (pellet) from samples.

\begin{tabular}{lccccc}
\hline \multirow{2}{*}{ Treat } & \multicolumn{5}{c}{ MFGM Trials, pellet mg per liter of milk } \\
\cline { 2 - 6 } I & II & III & IV & Mean \\
\hline Fresh & 350 & 325 & 322 & 261 & $315^{\mathrm{a}}$ \\
4C & 328 & 343 & 273 & 257 & $300^{\mathrm{a}}$ \\
Batch & 262 & 311 & 208 & 229 & $252^{\mathrm{a}, \mathrm{b}}$ \\
HTST & 194 & 223 & 184 & 275 & $219^{\mathrm{b}, \mathrm{c}}$ \\
UHT & 160 & 208 & 167 & 150 & $171^{\mathrm{c}}$ \\
UV & 338 & 329 & 274 & 239 & $295^{\mathrm{a}}$ \\
\hline
\end{tabular}




\section{MFGM Protein Quantification}

Table 27. Effect of milk processing on MFGM proteins.

\begin{tabular}{lrrrc}
\hline \multirow{2}{*}{ Treat } & \multicolumn{4}{c}{ Protein Trials, mg per 100 mg of MFGM pellet } \\
\cline { 2 - 5 } & II & III & IV & Mean \pm STD \\
\hline Fresh & 13.28 & 11.56 & 15.18 & $13.34 \pm 1.81$ \\
$4{ }^{\circ} \mathrm{C}$ & 13.04 & 14.64 & 14.68 & $14.12 \pm 0.93$ \\
Batch & 17.90 & 17.08 & 15.86 & $16.95 \pm 1.03$ \\
HTST & 17.89 & 17.83 & 17.27 & $17.66 \pm 0.34$ \\
UHT & 16.35 & 19.83 & 15.45 & $17.21 \pm 2.31$ \\
UV & 14.55 & 14.51 & 15.93 & $15.00 \pm 0.81$ \\
\hline
\end{tabular}

\section{E. Milk Composition}

Table 28. Milk composition for each independent trial.

\begin{tabular}{|c|c|c|c|c|c|c|c|c|c|c|c|c|c|}
\hline \multirow{2}{*}{ MP } & \multirow[b]{2}{*}{ Treat } & \multicolumn{7}{|c|}{ g/100 mL milk } & \multirow{2}{*}{$\begin{array}{c}\text { Acidity } \\
{ }^{\circ} \mathbf{T H}\end{array}$} & \multirow{2}{*}{$\begin{array}{c}\text { Urea } \\
\mathrm{mg} / \mathrm{dL}\end{array}$} & \multirow{2}{*}{$\begin{array}{c}\text { Density } \\
\text { SG }\end{array}$} & \multirow{2}{*}{$\begin{array}{c}\text { FPD } \\
\text { mC }\end{array}$} & \multirow{2}{*}{$\begin{array}{c}\text { FFA } \\
\text { mEkv/l }\end{array}$} \\
\hline & & Fat & Prot & Cas & Citric & Lac & TS & SNF & & & & & \\
\hline \multirow[t]{6}{*}{ II } & Fresh & 4.29 & 3.49 & 2.60 & 0.18 & 4.74 & 13.55 & 9.11 & 16.63 & 385.00 & 1028.47 & 516 & 0.313 \\
\hline & $4-C$ & 4.01 & 3.33 & 2.42 & 0.18 & 4.79 & 13.15 & 9.01 & 15.83 & 328.00 & 1028.33 & 520 & 0.403 \\
\hline & Batch & 4.11 & 3.43 & 2.59 & 0.18 & 4.94 & 13.49 & 9.25 & 15.29 & 360.67 & 1029.67 & 533 & 0.514 \\
\hline & HTST & 4.00 & 3.33 & 2.47 & 0.18 & 4.79 & 13.13 & 9.01 & 15.87 & 346.67 & 1028.33 & 518 & 0.405 \\
\hline & UHT & 4.03 & 3.39 & 2.71 & 0.19 & 4.81 & 13.25 & 9.09 & 16.14 & 479.33 & 1028.80 & 532 & 0.261 \\
\hline & UV & 3.98 & 3.34 & 2.46 & 0.18 & 4.81 & 13.12 & 9.03 & 15.46 & 354.00 & 1028.73 & 517 & 0.519 \\
\hline \multirow[t]{6}{*}{ III } & Fresh & 2.99 & 3.14 & 2.29 & 0.19 & 4.84 & 11.92 & 8.49 & 15.86 & 338.00 & 1028.10 & 512 & 0.240 \\
\hline & $4-\mathrm{C}$ & 4.03 & 3.30 & 2.39 & 0.18 & 4.71 & 13.07 & 8.90 & 15.72 & 305.00 & 1027.90 & 507 & 0.386 \\
\hline & HTST & 3.69 & 3.03 & 2.06 & 0.17 & 4.35 & 12.05 & 8.23 & 14.80 & 283.50 & 1025.30 & 455 & 0.353 \\
\hline & Batch & 4.05 & 3.35 & 2.48 & 0.19 & 4.79 & 13.22 & 9.03 & 15.67 & 328.00 & 1028.65 & 515 & 0.432 \\
\hline & UHT & 4.13 & 3.39 & 2.60 & 0.20 & 4.74 & 13.29 & 9.00 & 15.51 & 399.50 & 1028.90 & 521 & 0.292 \\
\hline & UV & 3.99 & 3.33 & 2.45 & 0.18 & 4.73 & 13.06 & 8.93 & 15.57 & 317.00 & 1028.25 & 507 & 0.488 \\
\hline \multirow[t]{6}{*}{ IV } & Fresh & 4.19 & 3.41 & 2.50 & 0.15 & 4.76 & 13.35 & 9.03 & 16.39 & 372.50 & 1028.65 & 520 & 0.328 \\
\hline & $4-\mathrm{C}$ & 3.70 & 3.41 & 2.49 & 0.16 & 4.79 & 12.90 & 9.05 & 16.04 & 329.50 & 1029.00 & 514 & 0.562 \\
\hline & Batch & 3.69 & 3.43 & 2.55 & 0.16 & 4.85 & 12.95 & 9.13 & 15.93 & 352.00 & 1029.45 & 519 & 0.606 \\
\hline & HTST & 3.95 & 3.40 & 2.53 & 0.16 & 4.77 & 13.15 & 9.04 & 16.39 & 352.00 & 1028.90 & 514 & 0.558 \\
\hline & UHT & 3.67 & 3.40 & 2.65 & 0.17 & 4.69 & 12.75 & 8.92 & 15.85 & 432.50 & 1028.85 & 511 & 0.420 \\
\hline & UV & 3.73 & 3.42 & 2.55 & 0.16 & 4.79 & 12.94 & 9.06 & 16.10 & 325.00 & 1029.18 & 515 & 0.597 \\
\hline
\end{tabular}

MP, milk processing (trial); Prot, protein; Cas, casein; Citric, citric acid; Lac, lactose;

TS, total solid; SNF, solid nonfat; FPD, freezing point depression; FFA, free fatty acid;

${ }^{\circ} \mathrm{TH}$, Thorner degrees; SG, specific gravity; mEkv/l, milliequivalents/l

$\mathrm{S} / \bullet(\mathrm{N})$, standard deviation of the mean, which was calculated from three independent trials

Subscripts within a column indicate statistically significant values $(\mathrm{p}<0.05)$ 


\section{F. Phospholipids in the MFGM}

Table 29. Phospholipid content ${ }^{+}$indicated as mg of phospholipid per gram of milk

\begin{tabular}{lccccccc}
\hline \multirow{2}{*}{ Trial } & PL & \multicolumn{6}{c}{ Treatment, mg PL per gram of milk } \\
\cline { 3 - 7 } & & Fresh & 4C & Batch & HTST & UHT & UV \\
\hline II & PE & $3.04 \pm 0.06$ & $1.83 \pm 0.04$ & $3.14 \pm 0.04$ & $2.68 \pm 0.06$ & $3.55 \pm 0.07$ & $2.38 \pm 0.04$ \\
& PI & $0.47 \pm 0.02$ & $0.41 \pm 0.02$ & $0.62 \pm 0.01$ & $0.34 \pm 0.02$ & $0.48 \pm 0.01$ & $0.80 \pm 0.09$ \\
& PS & $0.04 \pm 0.01$ & $0.02 \pm 0.01$ & $0.03 \pm 0.02$ & $0.04 \pm 0.01$ & $0.02 \pm 0.01$ & $0.11 \pm 0.09$ \\
& PC & $5.49 \pm 0.04$ & $5.59 \pm 0.18$ & $6.18 \pm 0.06$ & $5.80 \pm 0.05$ & $6.52 \pm 0.17$ & $6.91 \pm 0.41$ \\
& SM & $6.96 \pm 0.16$ & $6.47 \pm 0.12$ & $7.65 \pm 0.36$ & $7.75 \pm 0.15$ & $7.30 \pm 0.21$ & $8.71 \pm 0.36$ \\
& & & & & & & \\
III & PE & $3.01 \pm 0.07$ & $2.15 \pm 0.11$ & $2.06 \pm 0.06$ & $3.39 \pm 0.14$ & $3.43 \pm 0.04$ & $1.90 \pm 0.13$ \\
& PI & $0.82 \pm 0.05$ & $0.63 \pm 0.01$ & $0.65 \pm 0.05$ & $0.51 \pm 0.10$ & $0.58 \pm 0.10$ & $0.77 \pm 0.10$ \\
& PS & $0.50 \pm 0.03$ & $0.08 \pm 0.00$ & $0.06 \pm 0.0$ & $0.12 \pm 0.05$ & $0.07 \pm 0.0$ & $0.17 \pm 0.01$ \\
& PC & $4.59 \pm 0.15$ & $6.64 \pm 0.09$ & $6.92 \pm 0.28$ & $6.70 \pm 0.21$ & $7.52 \pm 0.07$ & $6.82 \pm 0.25$ \\
& SM & $7.44 \pm 0.17$ & $8.61 \pm 0.22$ & $8.27 \pm 0.25$ & $8.07 \pm 0.14$ & $8.59 \pm 0.09$ & $8.57 \pm 0.22$ \\
& & & & & & \\
IV & & & & & \\
& PE & $4.61 \pm 0.31$ & $2.69 \pm 0.04$ & $2.99 \pm 0.02$ & $2.89 \pm 0.03$ & $2.05 \pm 0.03$ & $0.72 \pm 0.02$ \\
& PI & $0.42 \pm 0.0$ & $0.41 \pm 0.01$ & $0.39 \pm 0.01$ & $0.46 \pm 0.01$ & $0.47 \pm 0.00$ & $0.41 \pm 0.01$ \\
& PS & $0.02 \pm 0.01$ & $0.28 \pm 0.02$ & $0.26 \pm 0.01$ & $0.18 \pm 0.01$ & $0.12 \pm 0.01$ & $0.05 \pm 0.0$ \\
& PC & $5.09 \pm 0.52$ & $3.13 \pm 0.04$ & $2.83 \pm 0.10$ & $3.49 \pm 0.00$ & $3.60 \pm 0.03$ & $2.94 \pm 0.01$ \\
& SM & $5.48 \pm 0.38$ & $3.86 \pm 0.06$ & $3.62 \pm 0.04$ & $4.33 \pm 0.07$ & $4.74 \pm 0.02$ & $3.63 \pm 0.03$ \\
\hline
\end{tabular}

+ Mean and standard deviation of three HPLC measurements

Table 30. Polar lipids quantification in milk during processing (trials II \& III).

\begin{tabular}{lcccccc}
\hline \multirow{2}{*}{ Treat } & \multicolumn{6}{c}{ Polar lipids, mg per 100 g of milk } \\
\cline { 2 - 7 } & PE & PI & PS & PC & SM & Total \\
\hline Fresh & 3.02 & 0.64 & 0.27 & 5.04 & 7.20 & 16.18 \\
$4^{\circ} \mathrm{C}$ & 1.99 & 0.52 & 0.05 & 6.12 & 7.54 & 16.22 \\
Batch & 2.60 & 0.64 & 0.05 & 6.55 & 7.96 & 17.79 \\
HTST & 3.03 & 0.43 & 0.08 & 6.25 & 7.91 & 17.70 \\
UHT & 3.49 & 0.53 & 0.05 & 7.02 & 7.95 & 19.04 \\
UV & 2.14 & 0.79 & 0.14 & 6.87 & 8.64 & 18.58 \\
S/SR(N) & 0.31 & 0.07 & 0.08 & 0.39 & 0.41 & 0.83 \\
\hline
\end{tabular}

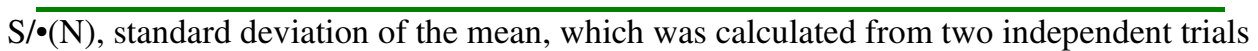


Table 31. Polar lipid quantification in milk during processing (trials II, III, and IV).

\begin{tabular}{lcccccc}
\hline \multirow{2}{*}{ Treat } & \multicolumn{6}{c}{ Polar lipids, mg per 100 g of milk } \\
\cline { 2 - 7 } & PE & PI & PS & PC & SM & Total \\
\hline Fresh & 3.55 & 0.57 & 0.19 & 5.06 & 6.62 & 15.99 \\
$4^{\circ} \mathrm{C}$ & 2.22 & 0.48 & 0.13 & 5.12 & 6.32 & 14.27 \\
Batch & 2.73 & 0.55 & 0.12 & 5.31 & 6.51 & 15.22 \\
HTST & 2.99 & 0.44 & 0.11 & 5.33 & 6.72 & 15.58 \\
UHT & 3.01 & 0.51 & 0.07 & 5.88 & 6.88 & 16.35 \\
UV & 1.67 & 0.66 & 0.11 & 5.56 & 6.97 & 14.97 \\
S/SR(N) & 0.44 & 0.06 & 0.08 & 0.54 & 0.44 & 1.23
\end{tabular}

$\mathrm{S} / \bullet(\mathrm{N})$, standard deviation of the mean, which was calculated from three independent trials

Table 32. Phospholipids in total lipids (mg/100 g total lipids).

\begin{tabular}{|c|c|c|c|c|c|c|c|}
\hline \multirow[b]{2}{*}{ Trial } & \multirow[b]{2}{*}{ PL } & \multicolumn{6}{|c|}{ Treatments mg PL per 100 gram total lipids } \\
\hline & & Fresh & $4 \mathrm{C}$ & Batch & HTST & UHT & UV \\
\hline \multirow[t]{6}{*}{ II } & $\mathrm{PE}$ & 71.97 & 44.72 & 74.87 & 66.46 & 87.01 & 59.45 \\
\hline & PI & 11.08 & 10.11 & 14.76 & 8.48 & 11.89 & 20.04 \\
\hline & PS & 0.92 & 0.58 & 0.82 & 1.08 & 0.41 & 2.78 \\
\hline & $\mathrm{PC}$ & 129.88 & 136.33 & 147.31 & 144.00 & 160.06 & 172.53 \\
\hline & SM & 164.64 & 158.01 & 182.55 & 192.34 & 179.00 & 217.40 \\
\hline & Total & 378.49 & 349.75 & 420.31 & 412.35 & 438.38 & 472.20 \\
\hline \multirow[t]{6}{*}{ III } & PE & 104.28 & 53.66 & 51.16 & 90.82 & 83.69 & 47.85 \\
\hline & PI & 28.34 & 15.65 & 16.24 & 13.69 & 14.07 & 19.37 \\
\hline & PS & 17.48 & 1.95 & 1.40 & 3.11 & 1.81 & 4.39 \\
\hline & PC & 159.35 & 165.57 & 171.83 & 179.60 & 183.45 & 172.11 \\
\hline & SM & 258.08 & 214.47 & 205.36 & 216.44 & 209.54 & 216.05 \\
\hline & Total & 567.52 & 451.30 & 445.99 & 503.65 & 492.56 & 459.76 \\
\hline \multirow[t]{6}{*}{ IV } & PE & 113.71 & 74.73 & 83.08 & 74.63 & 57.01 & 19.89 \\
\hline & PI & 10.38 & 11.31 & 10.80 & 11.75 & 13.02 & 11.29 \\
\hline & PS & 0.57 & 7.89 & 7.26 & 4.53 & 3.42 & 1.41 \\
\hline & $\mathrm{PC}$ & 125.52 & 87.06 & 78.60 & 89.98 & 99.86 & 81.59 \\
\hline & SM & 135.04 & 107.48 & 100.36 & 111.76 & 131.43 & 100.79 \\
\hline & Total & 385.23 & 288.47 & 280.09 & 292.66 & 304.74 & 214.96 \\
\hline
\end{tabular}


Table 33. Polar lipids quantification in cream during processing (trials II \& III).

\begin{tabular}{lrrrrrr}
\hline \multirow{2}{*}{ Treat } & \multicolumn{5}{c}{ Polar lipids, mg per 100 g of total lipids } \\
\cline { 2 - 7 } & PE & PI & PS & PC & SM & Total \\
\hline Fresh & 88.13 & 19.71 & 9.20 & 144.61 & 211.36 & 224.91 \\
4C & 49.19 & 12.88 & 1.26 & 150.95 & 186.24 & 128.41 \\
Batch & 63.02 & 15.50 & 1.11 & 159.57 & 193.95 & 96.16 \\
HTST & 78.64 & 11.08 & 2.09 & 161.80 & 204.39 & 93.36 \\
UHT & 85.35 & 12.98 & 1.11 & 171.76 & 194.27 & 97.55 \\
UV & 53.65 & 19.70 & 3.58 & 172.32 & 216.73 & 101.58 \\
\hline
\end{tabular}

$\mathrm{S} / \cdot(\mathrm{N})$, standard deviation of the mean, which was calculated from two independent trials

\section{G. SH \& SS Quantification}

Table 34. Effect of heat treatment on the amounts of free and total sulfhdryl (SH) and disulfide (SS) groups in the milk fat globule membrane.

\begin{tabular}{llll}
\hline \multirow{2}{*}{ Sample } & \multicolumn{3}{c}{$\boldsymbol{\mu m o l}$ per gram of protein } \\
\cline { 2 - 4 } & FreeSH & TotalSH & \multicolumn{1}{c}{ SS } \\
\hline Fresh & $52.94^{\mathrm{b}}$ & $153.78^{\mathrm{b}}$ & $50.42^{\mathrm{c}}$ \\
$4^{\circ} \mathrm{C}$ & $71.40^{\mathrm{a}}$ & $298.98^{\mathrm{a}}$ & $113.79^{\mathrm{a}}$ \\
Batch & $37.73^{\mathrm{c}}$ & $206.92^{\mathrm{b}}$ & $84.60^{\mathrm{b}}$ \\
HTST & $31.86^{\mathrm{c}}$ & $159.14^{\mathrm{b}}$ & $63.64^{\mathrm{b}}$ \\
UHT & $19.04^{\mathrm{d}}$ & $280.98^{\mathrm{a}}$ & $130.97^{\mathrm{a}}$ \\
UV & $53.39^{\mathrm{b}}$ & $179.16^{\mathrm{b}}$ & $62.88^{\mathrm{b}, \mathrm{c}}$ \\
\hline
\end{tabular}




\section{H. Particle Size Analysis}

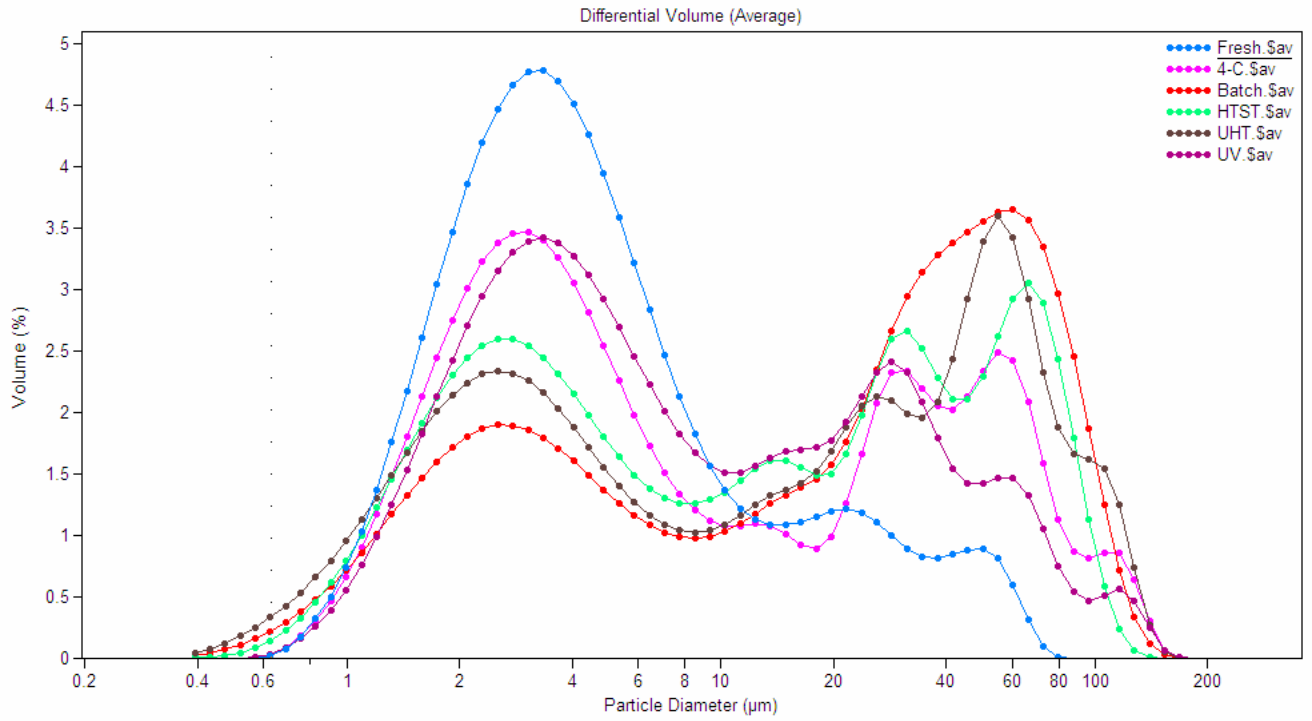

Figure 57. Fat globule (FG) size distribution of $40 \%$ cream as a function of particle diameter $(\mu \mathrm{m})$. Data for Trial III.

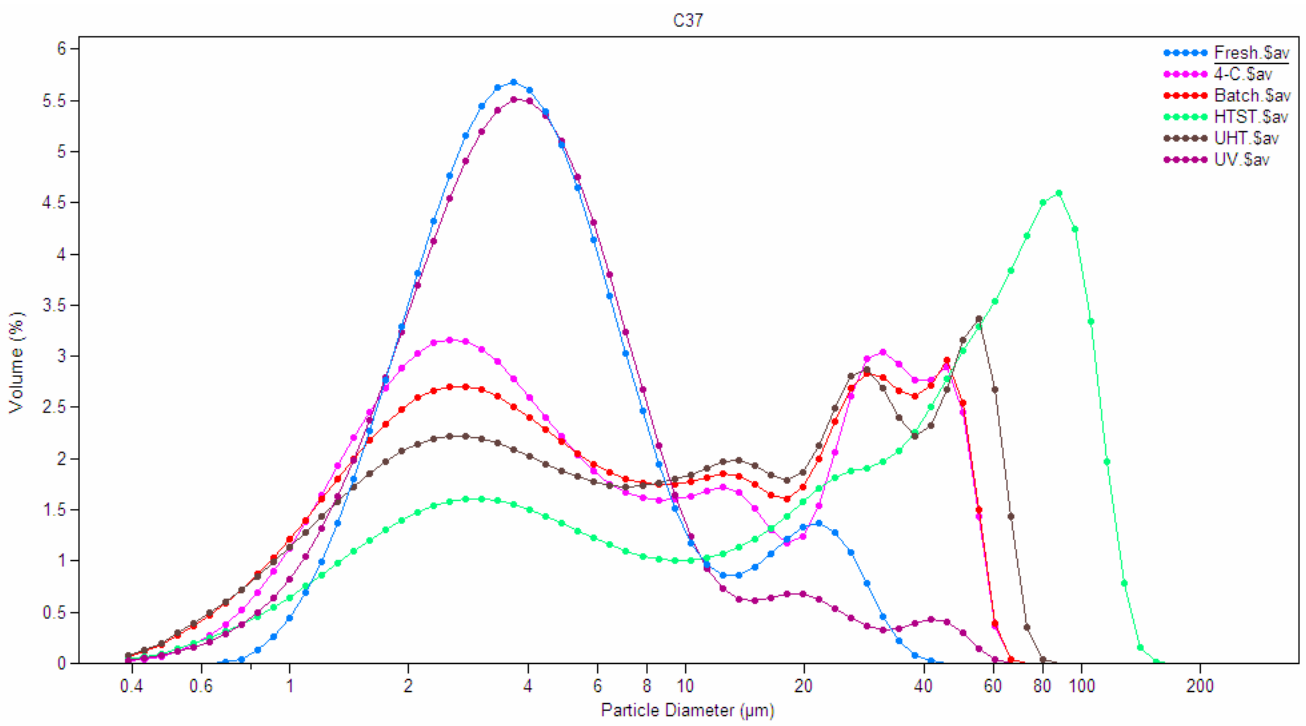

Figure 58. Fat globule (FG) size distribution of $40 \%$ cream as a function of particle diameter $(\mu \mathrm{m})$. Data for Trial II. 


\section{SDS-PAGE Quantification}

Table 35. Quantification of MFGM proteins by SDS-PAGE densitometry.

\begin{tabular}{|c|c|c|c|c|c|c|c|}
\hline \multirow[b]{2}{*}{ Band \# } & \multicolumn{7}{|c|}{ Relative Concentration (Intensity x mm )+ } \\
\hline & Fresh & $4^{\circ} \mathrm{C}$ & Batch & HTST & UHT & UV & STD \\
\hline 308 & 2707 & & & & & & \\
\hline 284 & 4743 & 4834 & & & & & \\
\hline 252 & 10796 & 5580 & 7794 & 9813 & & & 1690 \\
\hline 217 & 10506 & 6181 & 5999 & 5540 & 35239 & 21148 & \\
\hline $\begin{array}{l}181 \\
174\end{array}$ & $\begin{array}{l}10370 \\
9340\end{array}$ & $\begin{array}{l}12283 \\
10978\end{array}$ & 11782 & 13813 & 16848 & $\begin{array}{l}10837 \\
18197\end{array}$ & 1228 \\
\hline 151 & $89227^{a}$ & $92421^{a}$ & $82725^{\mathrm{a}}$ & $84773^{a}$ & $19588^{b}$ & $84899^{a}$ & 3413 \\
\hline 140 & 14169 & 13844 & 8301 & 10534 & 10270 & 11204 & 1471 \\
\hline 131 & 9620 & 5167 & 3313 & 4826 & & 6327 & 1199 \\
\hline 124 & & & & & 6532 & & \\
\hline 120 & 6508 & 6327 & 4703 & 6827 & ND & 5590 & 859 \\
\hline 110 & & & 3025 & & & 2817 & \\
\hline 106 & & & 2162 & & & & \\
\hline 101 & 1636 & 1392 & 1802 & 1335 & & 1975 & 200 \\
\hline $89-87$ & 7530 & 2729 & 12864 & 6481 & 4066 & 1226 & 1360 \\
\hline 80 & 13363 & 12493 & & & & 15980 & 2947 \\
\hline 76-77 & & 19139 & 14721 & 8896 & 12925 & 12913 & 4095 \\
\hline 70 & $45472^{a}$ & $58776^{\mathrm{a}}$ & $60092^{a}$ & $49616^{\mathrm{a}}$ & $5132^{\mathrm{b}}$ & $53127^{\mathrm{a}}$ & 4085 \\
\hline 63 & 12984 & 17455 & 18158 & 17058 & ND & 16307 & 5114 \\
\hline 59 & $107741^{\mathrm{a}}$ & $116856^{\mathrm{a}}$ & $104980^{\mathrm{a}}$ & $113828^{a}$ & $51726^{\mathrm{b}}$ & $104538^{a}$ & 4420 \\
\hline $55-56$ & 21114 & 16874 & 14302 & 6929 & 3810 & 9062 & 3455 \\
\hline 53 & 6296 & 4979 & 8867 & 13673 & 16791 & 4846 & 2968 \\
\hline $51-52$ & $38187^{\mathrm{a}}$ & $49789^{a}$ & $43582^{a}$ & $48326^{\mathrm{a}}$ & $7457^{\mathrm{b}}$ & $43408^{a}$ & 3220 \\
\hline $49-50$ & $19506^{\mathrm{a}}$ & $26504^{a}$ & $20307^{\mathrm{a}}$ & $25785^{\mathrm{a}}$ & $2900^{b}$ & $23182^{\mathrm{a}}$ & 1734 \\
\hline $41-43$ & 2905 & 8350 & 5819 & 4957 & & 13441 & 2256 \\
\hline $39+$ & $20923^{\mathrm{a}}$ & $22870^{\mathrm{a}}$ & $6745^{\mathrm{b}}$ & $7225^{\mathrm{b}}$ & $20640^{\mathrm{a}}$ & $13094^{\mathrm{ab}}$ & 2149 \\
\hline 38 & $21746^{\mathrm{a}}$ & $17659^{\mathrm{b}}$ & $6059^{c}$ & $6834^{\mathrm{c}}$ & & $14004^{\mathrm{b}}$ & 605 \\
\hline $33-34$ & 6650 & 6445 & 5267 & 6044 & 7977 & 5623 & 579 \\
\hline 31 & 3057 & 3539 & 5951 & 3791 & & 3046 & 1595 \\
\hline 29 & & & 8347 & 6193 & & & \\
\hline $25-26$ & $9695^{c}$ & $15745^{\mathrm{bc}}$ & $26934^{b}$ & $13215^{\mathrm{c}}$ & $60784^{a}$ & $12751^{\mathrm{c}}$ & 3466 \\
\hline $21-22++$ & $13307^{\mathrm{a}}$ & $11312^{a, b}$ & $4982^{\mathrm{bc}}$ & $6010^{\mathrm{abc}}$ & $2378^{c}$ & $11182^{\mathrm{ab}}$ & 1577 \\
\hline 20 & 9737 & 6872 & 8017 & 7335 & & 7682 & 751 \\
\hline 18 & $7978^{\mathrm{c}}$ & $5168^{\mathrm{c}}$ & $45421^{\mathrm{b}}$ & $44815^{\mathrm{b}}$ & $90121^{\mathrm{a}}$ & $4391^{\mathrm{c}}$ & 6805 \\
\hline 13 & $17031^{\mathrm{bc}}$ & $17935^{\mathrm{b}, \mathrm{c}}$ & $25333^{\mathrm{b}}$ & $21306^{\mathrm{bc}}$ & $40186^{\mathrm{a}}$ & $10577^{\mathrm{c}}$ & 2833 \\
\hline 10 & 6424 & 8859 & 9542 & 4586 & 6860 & 17465 & 3577 \\
\hline
\end{tabular}

Relative concentration is the band trace, which is determined by peak intensity and band length Band number indicates the MW

Groups within a row are statistically different, $\mathrm{p}<0.000 .+\mathrm{p}<0.001,++\mathrm{p}<0.004$. 


\section{J. $1 D E \&$ Mass Tandem Spectrometry}

LC/MS data from 1DE was analyzed using Scaffold (TM). The Scaffold's settings were 95\% probability, min 2 peptide, and $70 \%$ peptide coverage. The analysis resulted in 123 identified proteins from which 100 have been identified, and the rest are uncharacterized proteins. Tables 38 and 39 show the results as the percent protein probability, peptides recognized, and peptide coverage. Table 40 presents the functional classification of MFGM proteins.

Table 36. LCMS results for Fresh, 4 C, and Batch treatments.

\begin{tabular}{|c|c|c|c|c|c|c|c|c|c|c|c|}
\hline \multirow[t]{2}{*}{ Accession Number } & \multirow[t]{2}{*}{ MW } & \multirow[t]{2}{*}{ Identified Proteins* } & \multicolumn{3}{|c|}{ Fresh } & \multicolumn{3}{|c|}{$4^{\circ} \mathrm{C}$} & \multicolumn{3}{|c|}{ Batch } \\
\hline & & & Pro & Pep & $\% \mathrm{C}$ & Pro & Pep & $\% \mathrm{C}$ & Pro & Pep & $\% \mathrm{C}$ \\
\hline BT1A1_BOVIN & 59 & Butyrophilin subfamily 1 member A1 & 100 & 73 & 72 & 100 & 54 & 65 & 100 & 42 & 53 \\
\hline PLIN2_BOVIN & 49 & Perilipin-2 & 100 & 66 & 83 & 100 & 55 & 71 & 100 & 50 & 77 \\
\hline XDH_BOVIN & 147 & Xanthine dehydrogenase/oxidase & 100 & 84 & 59 & 100 & 80 & 55 & 100 & 67 & 50 \\
\hline Q3T0K7_BOVIN & 48 & MFGE8 protein & 100 & 23 & 51 & 100 & 19 & 48 & 100 & 20 & 46 \\
\hline ABCG2_BOVIN & 73 & ATP-binding cassette sub-family G member 2 & 100 & 19 & 29 & 100 & 15 & 21 & 100 & 9 & 9 \\
\hline PIGR_BOVIN & 82 & Polymeric immunoglobulin receptor & 100 & 10 & 19 & 100 & 14 & 19 & 100 & 20 & 25 \\
\hline FABPH_BOVIN & 15 & Fatty acid-binding protein, heart & 100 & 16 & 86 & 100 & 15 & 75 & 100 & 14 & 68 \\
\hline CD36_BOVIN & 53 & Platelet glycoprotein 4 & 100 & 9 & 15 & 100 & 7 & 12 & 100 & 6 & 12 \\
\hline RAB18_BOVIN & 23 & Ras-related protein Rab-18 & 100 & 12 & 60 & 100 & 11 & 57 & 100 & 11 & 60 \\
\hline CASK_BOVIN & 21 & Kappa-casein & 98 & 1 & 5 & 100 & 4 & 24 & 100 & 5 & 23 \\
\hline Q0VCZ8_BOVIN & 78 & Acyl-CoA synthetase long-chain family member 1 & 100 & 10 & 17 & 100 & 11 & 19 & 100 & 3 & 9 \\
\hline CASA1_BOVIN & 25 & Alpha-S1-casein & 100 & 6 & 31 & 100 & 8 & 37 & 100 & 5 & 29 \\
\hline A1L528_BOVIN & 23 & RAB1A, member RAS oncogene family & 100 & 5 & 31 & 100 & 10 & 63 & 100 & 9 & 55 \\
\hline Q3T101_BOVIN & 25 & IGL@ protein & 100 & 5 & 26 & 100 & 8 & 38 & 100 & 7 & 39 \\
\hline ACACA_BOVIN $(+1)$ & 265 & Acetyl-CoA carboxylase 1 & 100 & 8 & 5 & 100 & 3 & 2 & 100 & 5 & 3 \\
\hline
\end{tabular}




\begin{tabular}{|c|c|c|c|c|c|c|c|c|c|c|c|}
\hline \multirow[t]{2}{*}{ Accession Number } & \multirow[t]{2}{*}{ MW } & \multirow[t]{2}{*}{ Identified Proteins* } & \multicolumn{3}{|c|}{ Fresh } & \multicolumn{3}{|c|}{$4^{\circ} \mathrm{C}$} & \multicolumn{3}{|c|}{ Batch } \\
\hline & & & Pro & Pep & $\% \mathrm{C}$ & Pro & Pep & $\% \mathrm{C}$ & Pro & Pep & $\% \mathrm{C}$ \\
\hline Q861V9_BOVIN & 16 & Similar to peptidylprolyl isomerase A (Cyclophilin A) (Fragment) & 100 & 6 & 33 & 100 & 7 & 67 & 100 & 2 & 15 \\
\hline GBB2_BOVIN & 37 & Guanine nucleotide-binding protein $\mathrm{G}(\mathrm{I}) / \mathrm{G}(\mathrm{S}) / \mathrm{G}(\mathrm{T})$ subunit beta-2 & 100 & 7 & 24 & 100 & 3 & 10 & 100 & 3 & 12 \\
\hline ENPP3_BOVIN & 100 & Ectonucleotide pyrophosphatase/phosphodiesterase family member 3 & 100 & 6 & 9 & 100 & 6 & 9 & 100 & 3 & 5 \\
\hline FAS_BOVIN & 275 & Fatty acid synthase & 100 & 4 & 3 & 100 & 4 & 2 & 100 & 2 & 1 \\
\hline B5B0D4_BOVIN & 20 & Major allergen beta-lactoglobulin & 73 & 1 & 8 & 100 & 2 & 19 & 100 & 10 & 68 \\
\hline NPT2B_BOVIN & 76 & Sodium-dependent phosphate transport protein $2 \mathrm{~B}$ & 100 & 14 & 17 & 100 & 8 & 13 & 100 & 6 & 10 \\
\hline A6QNZ7_BOVIN (+1) & 55 & Keratin 10 (Epidermolytic hyperkeratosis; keratosis palmaris et plantaris) & 100 & 5 & 9 & 100 & 6 & 8 & 71 & 1 & 2 \\
\hline A4FV94_BOVIN & 61 & KRT6A protein & 73 & 1 & 4 & 100 & 2 & 5.4 & 79 & 1 & 2 \\
\hline CASA2_BOVIN & 26 & Alpha-S2-casein & 73 & 1 & 4 & 100 & 2 & 9 & 100 & 2 & 9 \\
\hline GBB1_BOVIN (+1) & 37 & Guanine nucleotide-binding protein $\mathrm{G}(\mathrm{I}) / \mathrm{G}(\mathrm{S}) / \mathrm{G}(\mathrm{T})$ subunit beta-1 & 100 & 4 & 23 & 83 & 1 & 10 & 83 & 1 & 7 \\
\hline A5D7M6_BOVIN (+2) & 63 & KRT5 protein & 99 & 2 & 4 & 100 & 3 & 6 & & & \\
\hline A7E340_BOVIN (+2) & 36 & Mucin 15 , cell surface associated & 58 & 1 & 3 & 71 & 1 & 3 & 79 & 1 & 3 \\
\hline RB11A_BOVIN (+1) & 24 & Ras-related protein Rab-11A & 100 & 3 & 16 & 99 & 2 & 11 & 100 & 3 & 16 \\
\hline A6H7J7_BOVIN & 25 & Putative uncharacterized protein & 73 & 1 & 30 & 73 & 1 & 41 & 100 & 2 & 30 \\
\hline ACTB_BOVIN (+3) & 42 & Actin, cytoplasmic 1 & 100 & 4 & 15 & 100 & 2 & 7 & 100 & 3 & 10 \\
\hline A8E4P3_BOVIN & 31 & STOM protein & 100 & 9 & 32 & 100 & 7 & 31 & 100 & 4 & 18 \\
\hline A4FUX1_BOVIN & 25 & CIDEA protein & 100 & 3 & 22 & 100 & 5 & 27 & 100 & 3 & 22 \\
\hline Q9TSF1_BOVIN & 14 & Butyrophilin (Fragment) & 42 & 1 & 62 & 98 & 1 & 31 & 97 & 1 & 45 \\
\hline GNAS2_BOVIN & 46 & Guanine nucleotide-binding protein $\mathrm{G}(\mathrm{s})$ subunit alpha isoforms short & 100 & 2 & 5 & 73 & 1 & 3 & 83 & 1 & 3 \\
\hline Q2T9M8_BOVIN & 23 & Synaptosomal-associated protein 23 isoform SNAP23A & 100 & 5 & 34 & 100 & 5 & 34 & 99 & 2 & 18 \\
\hline Q0IIA4_BOVIN & 59 & Glycoprotein 2 (Zymogen granule membrane) & 100 & 9 & 20 & 100 & 11 & 22 & 100 & 8 & 16 \\
\hline CTHL1_BOVIN & 18 & Cathelicidin-1 & 100 & 3 & 27 & 100 & 7 & 44 & 100 & 2 & 23 \\
\hline A5D7Q2_BOVIN & 52 & Putative uncharacterized protein & 100 & 3 & 7 & 98 & 1 & 2 & 100 & 5 & 14 \\
\hline SAR1A_BOVIN & 22 & GTP-binding protein SAR1a & 100 & 5 & 36 & 100 & 3 & 30 & 98 & 1 & 13 \\
\hline RAB7A_BOVIN & 24 & Ras-related protein Rab-7a & 100 & 3 & 19 & 100 & 3 & 14 & 100 & 3 & 22 \\
\hline MUC1_BOVIN & 58 & Mucin-1 & 100 & 3 & 3 & 100 & 4 & 5 & 71 & 2 & 2 \\
\hline
\end{tabular}




\begin{tabular}{|c|c|c|c|c|c|c|c|c|c|c|c|}
\hline \multirow{2}{*}{ Accession Number } & \multirow[t]{2}{*}{ MW } & \multirow{2}{*}{ Identified Proteins* } & \multicolumn{3}{|c|}{ Fresh } & \multicolumn{3}{|c|}{$4^{\circ} \mathrm{C}$} & \multicolumn{3}{|c|}{ Batch } \\
\hline & & & Pro & Pep & $\% \mathrm{C}$ & Pro & Pep & $\% \mathrm{C}$ & Pro & Pep & $\% \mathbf{C}$ \\
\hline Q3SYR8_BOVIN & 18 & Immunoglobulin J chain & 100 & 2 & 17 & 100 & 2 & 17 & 100 & 2 & 17 \\
\hline RAC1_BOVIN & 21 & Ras-related C3 botulinum toxin substrate 1 & 100 & 2 & 13 & 73 & 1 & 5 & 73 & 1 & 5 \\
\hline Q3SX32_BOVIN & 48 & Mannose 6 phosphate receptor binding protein 1 & 100 & 5 & 18 & 100 & 2 & 6 & 83 & 1 & 6 \\
\hline RAP1A_BOVIN (+1) & 21 & Ras-related protein Rap-1A & 100 & 2 & 14 & 100 & 2 & 14 & 73 & 1 & 8 \\
\hline SEP15_BOVIN & 18 & $15 \mathrm{kDa}$ selenoprotein & 73 & 1 & 10 & 73 & 1 & 10 & 99 & 2 & 15 \\
\hline B0JYL8_BOVIN (+2) & 19 & Cofilin 1 (Non-muscle) & 73 & 1 & 17 & 100 & 2 & 24 & 73 & 1 & 17 \\
\hline B0JYP6_BOVIN & 26 & IGK protein & 100 & 2 & 15 & 100 & 3 & 15 & 100 & 5 & 36 \\
\hline A9XTK4_BOVIN & 38 & 17-beta hydroxysteroid dehydrogenase & 100 & 5 & 26 & 99 & 2 & 13 & & & \\
\hline YKT6_BOVIN & 22 & Synaptobrevin homolog YKT6 & 35 & 1 & 4 & 100 & 2 & 12 & & & \\
\hline ARL15_BOVIN & 23 & ADP-ribosylation factor-like protein 15 & 98 & 1 & 6 & 97 & 2 & 10 & & & \\
\hline Q8MKB7_BOVIN (+1) & 73 & $\mathrm{Na}+/$ glucose cotransporter & 73 & 1 & 4 & 83 & 1 & 4 & & & \\
\hline B6VAP7_BOVIN (+1) & 21 & CDC42 protein & 100 & 3 & 22 & 100 & 2 & 17 & & & \\
\hline Q17QL7_BOVIN & 49 & KRT15 protein & 73 & 1 & 7 & 100 & 2 & 11 & & & \\
\hline 5NTD_BOVIN & 63 & 5'-nucleotidase & 19 & 1 & 2 & 71 & 1 & 3 & & & \\
\hline NSDHL_BOVIN & 40 & Sterol-4-alpha-carboxylate 3-dehydrogenase, decarboxylating & 73 & 1 & 5 & & & & & & \\
\hline D5HSX1_BOVIN & 87 & cGMP-dependant type II protein kinase & 100 & 2 & 3 & 64 & 1 & 2 & & & \\
\hline Q6QRN7_BOVIN & 34 & PP1201 protein & 73 & 1 & 4 & 100 & 2 & 8 & & & \\
\hline Q2TBH2_BOVIN & 24 & Related RAS viral (R-ras) oncogene homolog & 100 & 2 & 11 & 99 & 2 & 11 & & & \\
\hline CHP1_BOVIN & 22 & Calcium-binding protein p22 & 73 & 1 & 8 & 100 & 2 & 13 & & & \\
\hline ARF1_BOVIN (+2) & 21 & ADP-ribosylation factor 1 & 100 & 4 & 29 & 73 & 1 & 6 & & & \\
\hline A6QLH3_BOVIN & 33 & STX3 protein & 100 & 2 & 15 & 51 & 1 & 3 & & & \\
\hline ANXA1_BOVIN & 39 & Annexin A1 & 73 & 1 & 5 & & & & & & \\
\hline A5PKG9_BOVIN & 59 & FGR protein & 73 & 1 & 6 & & & & & & \\
\hline GIPC2_BOVIN & 35 & PDZ domain-containing protein GIPC2 & 100 & 2 & 9 & & & & & & \\
\hline Q2KIS4_BOVIN & 34 & Dehydrogenase/reductase (SDR family) member 1 & 97 & 1 & 5 & & & & & & \\
\hline RHOC_BOVIN & 22 & Rho-related GTP-binding protein RhoC & 73 & 1 & 6 & & & & & & \\
\hline
\end{tabular}




\begin{tabular}{|c|c|c|c|c|c|c|c|c|c|c|c|}
\hline \multirow[t]{2}{*}{ Accession Number } & \multirow[t]{2}{*}{ MW } & \multirow[t]{2}{*}{ Identified Proteins* } & \multicolumn{3}{|c|}{ Fresh } & \multicolumn{3}{|c|}{$4^{\circ} \mathrm{C}$} & \multicolumn{3}{|c|}{ Batch } \\
\hline & & & Pro & Pep & $\% \mathrm{C}$ & Pro & Pep & $\% \mathrm{C}$ & Pro & Pep & $\% \mathrm{C}$ \\
\hline HSP7C_BOVIN & 71 & Heat shock cognate $71 \mathrm{kDa}$ protein & 100 & 4 & 5 & & & & & & \\
\hline RAB13_BOVIN & 23 & Ras-related protein Rab-13 & 73 & 1 & 12 & & & & & & \\
\hline Q3ZC65_BOVIN (+1) & 46 & Ancient ubiquitous protein 1 & 30 & 1 & 3 & & & & & & \\
\hline ERG7_BOVIN & 83 & Lanosterol synthase & 58 & 1 & 2 & & & & 74 & 1 & 1.4 \\
\hline ANXA2_BOVIN & 39 & Annexin A2 & 73 & 1 & 5 & 83 & 1 & 5 & & & \\
\hline Q99BK3_9ALPH & 88 & Ribonucleotide reductase large subunit & 61 & 1 & 1 & 100 & 2 & 3 & 79 & 1 & 1 \\
\hline GNAI1_BOVIN & 40 & Guanine nucleotide-binding protein G(i) subunit alpha-1 & 99 & 2 & 8 & & & & & & \\
\hline RAB5C_BOVIN & 23 & Ras-related protein Rab-5C & 73 & 1 & 7 & 100 & 2 & 13 & & & \\
\hline A6H7G0_BOVIN (+1) & 34 & CYB5R3 protein & & & & 83 & 1 & 6 & 83 & 1 & 6 \\
\hline A5D7E0_BOVIN & 23 & RAB35 protein & & & & 100 & 2 & 21 & & & \\
\hline GLCM1_BOVIN & 17 & Glycosylation-dependent cell adhesion molecule 1 & & & & 100 & 3 & 18 & 100 & 2 & 17 \\
\hline A6QNL0_BOVIN (+2) & 40 & Monocyte differentiation antigen CD14 & & & & 63 & 1 & 3 & 100 & 3 & 17 \\
\hline Q1RMN8_BOVIN & 25 & Immunoglobulin light chain, lambda gene cluster & & & & 100 & 2 & 41 & 100 & 2 & 30 \\
\hline A6QM09_BOVIN & 25 & Putative uncharacterized protein & & & & 100 & 2 & 38 & 100 & 2 & 26 \\
\hline PERL_BOVIN & 81 & Lactoperoxidase & & & & 63 & 1 & 3 & & & \\
\hline Q9TRB9_BOVIN & 2 & Enterotoxin-binding glycoprotein PP20K (Fragment) & & & & & & & 28 & 1 & 40 \\
\hline ANXA5_BOVIN & 36 & Annexin A5 & & & & & & & 38 & 1 & 3 \\
\hline LACB_BOVIN & 20 & Beta-lactoglobulin & & & & & & & 73 & 1 & 78 \\
\hline B3VTM3_BOVIN (+4) & 78 & Lactoferrin & & & & & & & 100 & 4 & 6 \\
\hline A6H7D4_BOVIN (+1) & 52 & $\begin{array}{l}\text { 1-acylglycerol-3-phosphate O-acyltransferase } 6 \\
\text { (Lysophosphatidic acid acyltransferase, zeta) }\end{array}$ & & & & & & & 83 & 1 & 3 \\
\hline A7YWR0_BOVIN (+2) & 36 & Apolipoprotein E & & & & & & & 83 & 1 & 5 \\
\hline A5D7R9_BOVIN & 21 & NRAS protein & & & & & & & 97 & 2 & 12 \\
\hline A5D7N2_BOVIN (+7) & 14 & HIST2H2BE protein & & & & 99 & 2 & 21 & & & \\
\hline A2VDV1_BOVIN & 22 & Ankyrin repeat domain 22 & & & & 73 & 1 & 7 & & & \\
\hline Q28049_BOVIN & 14 & Alpha lactalbumin (Fragment) & & & & & & & & & \\
\hline
\end{tabular}




\begin{tabular}{|c|c|c|c|c|c|c|c|c|c|c|c|}
\hline \multirow[t]{2}{*}{ Accession Number } & \multirow[t]{2}{*}{ MW } & \multirow[t]{2}{*}{ Identified Proteins* } & \multicolumn{3}{|c|}{ Fresh } & \multicolumn{3}{|c|}{$4^{\circ} \mathrm{C}$} & \multicolumn{3}{|c|}{ Batch } \\
\hline & & & Pro & Pep & $\% \mathrm{C}$ & Pro & Pep & $\% \mathrm{C}$ & Pro & Pep & $\% \mathrm{C}$ \\
\hline ALBU_BOVIN & 69 & Serum albumin & & & & & & & & & \\
\hline LIPL_BOVIN & 53 & Lipoprotein lipase & & & & & & & & & \\
\hline RAB8A_BOVIN & 24 & Ras-related protein Rab-8A & 99 & 2 & 21 & & & & & & \\
\hline EF1A1_BOVIN & 50 & Elongation factor 1-alpha 1 & 100 & 2 & 9 & & & & & & \\
\hline ACOC_BOVIN & 98 & Cytoplasmic aconitate hydratase & 100 & 2 & 3 & & & & & & \\
\hline FABP7_BOVIN & 15 & Fatty acid-binding protein, brain & & & & & & & 100 & 2 & 22 \\
\hline D4QGC1_BOVIN (+1) & 59 & Tyrosine-protein kinase Lyn & & & & & & & & & \\
\hline PPBT_BOVIN & 57 & Alkaline phosphatase, tissue-nonspecific isozyme & & & & & & & & & \\
\hline A4FUH8_BOVIN (+1) & 21 & Chromosome 1 open reading frame 93 ortholog & & & & & & & & & \\
\hline B5T263_9CETA (+6) & 90 & Toll-like receptor 2 OS=Bos indicus $x$ Bos taurus GN=TLR2 $P E=4 \mathrm{SV}=1$ & & & & & & & & & \\
\hline A5D792_BOVIN (+5) & 18 & DCK protein & & & & & & & & & \\
\hline
\end{tabular}

\section{Table 37.B. LC/MS results for HTST, UHT, and UV treatment}

\begin{tabular}{|c|c|c|c|c|c|c|c|c|c|c|c|}
\hline \multirow{2}{*}{ Accession Number } & \multirow{2}{*}{ MW } & \multirow{2}{*}{ Identified Proteins* } & \multicolumn{3}{|c|}{ HTST } & \multicolumn{3}{|c|}{ UHT } & \multicolumn{3}{|c|}{$\mathbf{U V}$} \\
\hline & & & Pro & Pep & $\% \mathrm{C}$ & Pro & Pep & $\% \mathrm{C}$ & Pro & Pep & $\% \mathrm{C}$ \\
\hline BT1A1_BOVIN & 59 & Butyrophilin subfamily 1 member A1 & 100 & 83 & 82 & 100 & 53 & 65 & 100 & 51 & 65 \\
\hline PLIN2_BOVIN & 49 & Perilipin-2 & 100 & 84 & 88 & 100 & 42 & 77 & 100 & 51 & 76 \\
\hline XDH_BOVIN & 147 & Xanthine dehydrogenase/oxidase & 100 & 118 & 70 & 100 & 67 & 52 & 100 & 73 & 57 \\
\hline Q3T0K7_BOVIN & 48 & MFGE8 protein & 100 & 32 & 53 & 100 & 18 & 35 & 100 & 21 & 44 \\
\hline ABCG2_BOVIN & 73 & ATP-binding cassette sub-family $G$ member 2 & 100 & 23 & 29 & 100 & 16 & 23 & 100 & 10 & 10 \\
\hline PIGR_BOVIN & 82 & Polymeric immunoglobulin receptor & 100 & 29 & 43 & 100 & 22 & 24 & 100 & 6 & 13 \\
\hline
\end{tabular}




\begin{tabular}{|c|c|c|c|c|c|c|c|c|c|c|c|}
\hline \multirow{2}{*}{ Accession Number } & \multirow{2}{*}{ MW } & \multirow{2}{*}{ Identified Proteins* } & \multicolumn{3}{|c|}{ HTST } & \multicolumn{3}{|c|}{ UHT } & \multicolumn{3}{|c|}{$\mathbf{U V}$} \\
\hline & & & Pro & Pep & $\% \mathrm{C}$ & Pro & Pep & $\% \mathrm{C}$ & Pro & Pep & $\% \mathrm{C}$ \\
\hline FABPH_BOVIN & 15 & Fatty acid-binding protein, heart & 100 & 17 & 90 & 100 & 6 & 37 & 100 & 9 & 64 \\
\hline CD36_BOVIN & 53 & Platelet glycoprotein 4 & 100 & 15 & 26 & 100 & 8 & 13 & 100 & 5 & 9 \\
\hline RAB18_BOVIN & 23 & Ras-related protein Rab-18 & 100 & 17 & 79 & 100 & 5 & 19 & 100 & 13 & 64 \\
\hline CASK_BOVIN & 21 & Kappa-casein & 100 & 7 & 33 & 100 & 12 & 56 & 100 & 3 & 24 \\
\hline Q0VCZ8_BOVIN & 78 & Acyl-CoA synthetase long-chain family member 1 & 100 & 16 & 28 & 100 & 9 & 12 & 100 & 7 & 8 \\
\hline CASA1_BOVIN & 25 & Alpha-S1-casein & 100 & 8 & 37 & 100 & 3 & 19 & 100 & 4 & 22 \\
\hline A1L528_BOVIN & 23 & RAB1A, member RAS oncogene family & 100 & 8 & 47 & 100 & 3 & 11 & 100 & 5 & 32 \\
\hline Q3T101_BOVIN & 25 & IGL@ protein & 100 & 5 & 20 & 100 & 4 & 20 & 100 & 7 & 37 \\
\hline ACACA_BOVIN (+1) & 265 & Acetyl-CoA carboxylase 1 & 100 & 18 & 11 & 100 & 3 & 2 & 100 & 3 & 2 \\
\hline Q861V9_BOVIN & 16 & $\begin{array}{l}\text { Similar to peptidylprolyl isomerase A (Cyclophilin A) } \\
\text { (Fragment) }\end{array}$ & 100 & 9 & 69 & 43 & 1 & 7 & 100 & 4 & 24 \\
\hline GBB2_BOVIN & 37 & $\begin{array}{l}\text { Guanine nucleotide-binding protein } \mathrm{G}(\mathrm{I}) / \mathrm{G}(\mathrm{S}) / \mathrm{G}(\mathrm{T}) \\
\text { subunit beta- } 2\end{array}$ & 100 & 5 & 20 & 100 & 5 & 19 & 100 & 2 & 8 \\
\hline ENPP3_BOVIN & 100 & $\begin{array}{l}\text { Ectonucleotide pyrophosphatase/phosphodiesterase } \\
\text { family member } 3\end{array}$ & 100 & 6 & 9 & 100 & 5 & 7 & 100 & 5 & 8 \\
\hline FAS_BOVIN & 275 & Fatty acid synthase & 100 & 5 & 3 & 98 & 1 & 0.5 & 98 & 1 & 0.3 \\
\hline B5B0D4_BOVIN & 20 & Major allergen beta-lactoglobulin & 100 & 32 & 87 & 100 & 39 & 89 & 100 & 4 & 27 \\
\hline NPT2B_BOVIN & 76 & Sodium-dependent phosphate transport protein $2 \mathrm{~B}$ & 100 & 11 & 12 & 100 & 9 & 16 & & & \\
\hline A6QNZ7_BOVIN (+1) & 55 & $\begin{array}{l}\text { Keratin } 10 \text { (Epidermolytic hyperkeratosis; } \\
\text { keratosis palmaris et plantaris) }\end{array}$ & 100 & 7 & 7 & 100 & 7 & 7 & 98 & 1 & 2 \\
\hline A4FV94_BOVIN & 61 & KRT6A protein & 100 & 2 & 5 & 100 & 2 & 5 & 74 & 1 & 4 \\
\hline CASA2_BOVIN & 26 & Alpha-S2-casein & 100 & 8 & 26 & 100 & 4 & 10 & 100 & 3 & 13 \\
\hline GBB1_BOVIN (+1) & 37 & $\begin{array}{l}\text { Guanine nucleotide-binding protein } \mathrm{G}(\mathrm{I}) / \mathrm{G}(\mathrm{S}) / \mathrm{G}(\mathrm{T}) \\
\text { subunit beta-1 }\end{array}$ & 100 & 5 & 21 & 100 & 2 & 11 & 99 & 3 & 11 \\
\hline A5D7M6_BOVIN (+2) & 63 & KRT5 protein & 99 & 2 & 4 & 100 & 2 & 4 & 20 & 1 & 4 \\
\hline A7E340_BOVIN (+2) & 36 & Mucin 15 , cell surface associated & 99 & 2 & 4 & 98 & 2 & 3 & 51 & 1 & 3 \\
\hline RB11A_BOVIN (+1) & 24 & Ras-related protein Rab-11A & 100 & 5 & 31 & 70 & 1 & 6 & 100 & 4 & 20 \\
\hline A6H7J7_BOVIN & 25 & Putative uncharacterized protein & 71 & 1 & 23 & 58 & 1 & 20 & 74 & 1 & 36 \\
\hline
\end{tabular}




\begin{tabular}{|c|c|c|c|c|c|c|c|c|c|c|c|}
\hline \multirow{2}{*}{ Accession Number } & \multirow{2}{*}{ MW } & \multirow{2}{*}{ Identified Proteins* } & \multicolumn{3}{|c|}{ HTST } & \multicolumn{3}{|c|}{ UHT } & \multicolumn{3}{|c|}{$\mathbf{U V}$} \\
\hline & & & Pro & Pep & $\% \mathrm{C}$ & Pro & Pep & $\% \mathrm{C}$ & Pro & Pep & $\% \mathrm{C}$ \\
\hline ACTB_BOVIN (+3) & 42 & Actin, cytoplasmic 1 & 100 & 4 & 15 & 58 & 1 & 3 & 100 & 5 & 12 \\
\hline A8E4P3_BOVIN & 31 & STOM protein & 100 & 3 & 10 & 50 & 1 & 6 & 100 & 5 & 24 \\
\hline A4FUX1_BOVIN & 25 & CIDEA protein & 100 & 6 & 32 & 16 & 1 & 8 & 100 & 5 & 27 \\
\hline Q9TSF1_BOVIN & 14 & Butyrophilin (Fragment) & 100 & 3 & 80 & & & & & & \\
\hline GNAS2_BOVIN & 46 & $\begin{array}{l}\text { Guanine nucleotide-binding protein } \mathrm{G}(\mathrm{s}) \text { subunit alpha } \\
\text { isoforms short }\end{array}$ & 100 & 5 & 19 & 32 & 1 & 4 & & & \\
\hline Q2T9M8_BOVIN & 23 & Synaptosomal-associated protein 23 isoform SNAP23A & 100 & 5 & 42 & & & & 100 & 5 & 32 \\
\hline Q0IIA4_BOVIN & 59 & Glycoprotein 2 (Zymogen granule membrane) & 100 & 2 & 6 & & & & 100 & 6 & 9 \\
\hline CTHL1_BOVIN & 18 & Cathelicidin-1 & 100 & 2 & 23 & & & & 100 & 5 & 40 \\
\hline A5D7Q2_BOVIN & 52 & Putative uncharacterized protein & 100 & 4 & 9 & & & & 100 & 2 & 5 \\
\hline SAR1A_BOVIN & 22 & GTP-binding protein SAR1a & 100 & 2 & 19 & & & & 100 & 4 & 30 \\
\hline RAB7A_BOVIN & 24 & Ras-related protein Rab-7a & 100 & 3 & 19 & & & & 74 & 1 & 5 \\
\hline MUC1_BOVIN & 58 & Mucin-1 & 50 & 1 & 2 & & & & 100 & 4 & 5 \\
\hline Q3SYR8_BOVIN & 18 & Immunoglobulin $\mathrm{J}$ chain & 71 & 1 & 10 & & & & 74 & 1 & 10 \\
\hline RAC1_BOVIN & 21 & Ras-related $\mathrm{C} 3$ botulinum toxin substrate 1 & 100 & 4 & 33 & & & & 99 & 2 & 9 \\
\hline Q3SX32_BOVIN & 48 & Mannose 6 phosphate receptor binding protein 1 & 100 & 7 & 24 & & & & 100 & 3 & 8 \\
\hline RAP1A_BOVIN (+1) & 21 & Ras-related protein Rap-1A & 99 & 2 & 14 & & & & 98 & 1 & 8 \\
\hline SEP15_BOVIN & 18 & $15 \mathrm{kDa}$ selenoprotein & 100 & 2 & 17 & & & & 74 & 1 & 10 \\
\hline B0JYL8_BOVIN (+2) & 19 & Cofilin 1 (Non-muscle) & 71 & 1 & 7 & & & & 100 & 2 & 24 \\
\hline B0JYP6_BOVIN & 26 & IGK protein & & & & & & & 100 & 2 & 15 \\
\hline A9XTK4_BOVIN & 38 & 17-beta hydroxysteroid dehydrogenase & 100 & 5 & 22 & & & & 41 & 1 & 5 \\
\hline YKT6_BOVIN & 22 & Synaptobrevin homolog YKT6 & 71 & 1 & 5 & & & & 100 & 3 & 16 \\
\hline ARL15_BOVIN & 23 & ADP-ribosylation factor-like protein 15 & 100 & 3 & 19 & & & & 74 & 1 & 6 \\
\hline Q8MKB7_BOVIN (+1) & 73 & $\mathrm{Na}+$ glucose cotransporter & & & & 100 & 2 & 6 & 51 & 1 & 4 \\
\hline B6VAP7_BOVIN (+1) & 21 & $\mathrm{CDC} 42$ protein & 99 & 2 & 16 & & & & & & \\
\hline Q17QL7_BOVIN & 49 & KRT15 protein & & & & 50 & 1 & 7 & & & \\
\hline
\end{tabular}




\begin{tabular}{|c|c|c|c|c|c|c|c|c|c|c|c|}
\hline \multirow{2}{*}{ Accession Number } & \multirow{2}{*}{ MW } & \multirow{2}{*}{ Identified Proteins* } & \multicolumn{3}{|c|}{ HTST } & \multicolumn{3}{|c|}{ UHT } & \multicolumn{3}{|c|}{$\mathbf{U V}$} \\
\hline & & & Pro & Pep & $\% \mathrm{C}$ & Pro & Pep & $\% \mathrm{C}$ & Pro & Pep & $\% \mathrm{C}$ \\
\hline 5NTD_BOVIN & 63 & 5'-nucleotidase & 100 & 3 & 10 & 100 & 3 & 10 & & & \\
\hline NSDHL_BOVIN & 40 & Sterol-4-alpha-carboxylate 3-dehydrogenase, decarboxylating & 100 & 3 & 12 & 58 & 1 & 5 & 100 & 2 & 8 \\
\hline D5HSX1_BOVIN & 87 & cGMP-dependant type II protein kinase & 100 & 2 & 3 & & & & 66 & 1 & 2 \\
\hline Q6QRN7_BOVIN & 34 & PP1201 protein & 71 & 1 & 4 & & & & 100 & 2 & 5 \\
\hline Q2TBH2_BOVIN & 24 & Related RAS viral (R-ras) oncogene homolog & & & & & & & 100 & 2 & 17 \\
\hline CHP1_BOVIN & 22 & Calcium-binding protein $\mathrm{p} 22$ & & & & & & & 100 & 2 & 14 \\
\hline ARF1_BOVIN (+2) & 21 & ADP-ribosylation factor 1 & & & & & & & 74 & 1 & 12 \\
\hline A6QLH3_BOVIN & 33 & STX3 protein & 50 & 1 & 5 & & & & 71 & 1 & 5 \\
\hline ANXA1_BOVIN & 39 & Annexin A1 & 50 & 1 & 5 & & & & 100 & 3 & 10 \\
\hline A5PKG9_BOVIN & 59 & FGR protein & 100 & 3 & 9 & & & & & & \\
\hline GIPC2_BOVIN & 35 & PDZ domain-containing protein GIPC2 & 100 & 2 & 9 & & & & & & \\
\hline Q2KIS4_BOVIN & 34 & Dehydrogenase/reductase (SDR family) member 1 & 100 & 4 & 15 & & & & & & \\
\hline RHOC_BOVIN & 22 & Rho-related GTP-binding protein RhoC & 100 & 3 & 23 & & & & & & \\
\hline HSP7C_BOVIN & 71 & Heat shock cognate $71 \mathrm{kDa}$ protein & 50 & 1 & 2 & & & & & & \\
\hline RAB13_BOVIN & 23 & Ras-related protein Rab-13 & 100 & 2 & 17 & & & & & & \\
\hline Q3ZC65_BOVIN (+1) & 46 & Ancient ubiquitous protein 1 & 99 & 2 & 9 & & & & & & \\
\hline ERG7_BOVIN & 83 & Lanosterol synthase & 100 & 2 & 4 & 100 & 3 & 5 & & & \\
\hline ANXA2_BOVIN & 39 & Annexin A2 & 99 & 2 & 8 & 45 & 1 & 5 & & & \\
\hline Q99BK3_9ALPH & 88 & Ribonucleotide reductase large subunit & & & & & & & & & \\
\hline GNAI1_BOVIN & 40 & Guanine nucleotide-binding protein G(i) subunit alpha-1 & & & & 31 & 1 & 5 & & & \\
\hline RAB5C_BOVIN & 23 & Ras-related protein $\mathrm{Rab}-5 \mathrm{C}$ & & & & & & & & & \\
\hline A6H7G0_BOVIN (+1) & 34 & CYB5R3 protein & 100 & 5 & 23 & 100 & 2 & 8 & 74 & 1 & 6 \\
\hline A5D7E0_BOVIN & 23 & RAB35 protein & 71 & 1 & 17 & 39 & 1 & 16 & 74 & 1 & 18 \\
\hline GLCM1_BOVIN & 17 & Glycosylation-dependent cell adhesion molecule 1 & 100 & 6 & 44 & 80 & 1 & 7 & & & \\
\hline A6QNL0_BOVIN (+2) & 40 & Monocyte differentiation antigen CD14 & 100 & 6 & 31 & 98 & 1 & 9 & & & \\
\hline Q1RMN8_BOVIN & 25 & Immunoglobulin light chain, lambda gene cluster & & & & 75 & 1 & 23 & & & \\
\hline
\end{tabular}




\begin{tabular}{|c|c|c|c|c|c|c|c|c|c|c|c|}
\hline \multirow{2}{*}{ Accession Number } & \multirow{2}{*}{ MW } & \multirow{2}{*}{ Identified Proteins* } & \multicolumn{3}{|c|}{ HTST } & \multicolumn{3}{|c|}{ UHT } & \multicolumn{3}{|c|}{$\mathbf{U V}$} \\
\hline & & & Pro & Pep & $\% \mathrm{C}$ & Pro & Pep & $\% \mathrm{C}$ & Pro & Pep & $\% \mathrm{C}$ \\
\hline A6QM09_BOVIN & 25 & Putative uncharacterized protein & 100 & 2 & 19 & & & & & & \\
\hline PERL_BOVIN & 81 & Lactoperoxidase & 50 & 2 & 1.3 & 99 & 3 & 3 & & & \\
\hline Q9TRB9_BOVIN & 2 & Enterotoxin-binding glycoprotein PP20K (Fragment) & 100 & 2 & 70 & 100 & 2 & 70 & & & \\
\hline ANXA5_BOVIN & 36 & Annexin A5 & 100 & 3 & 14 & & & & & & \\
\hline LACB_BOVIN & 20 & Beta-lactoglobulin & 100 & 6 & 87 & 100 & 5 & 85 & & & \\
\hline B3VTM3_BOVIN (+4) & 78 & Lactoferrin & 100 & 10 & 19 & 100 & 10 & 13 & & & \\
\hline A6H7D4_BOVIN (+1) & 52 & $\begin{array}{l}\text { 1-acylglycerol-3-phosphate O-acyltransferase } 6 \\
\text { (Lysophosphatidic acid acyltransferase, zeta) }\end{array}$ & 100 & 3 & 9 & 40 & 1 & 3 & 71 & 1 & 3 \\
\hline A7YWR0_BOVIN (+2) & 36 & Apolipoprotein E & 100 & 3 & 14 & & & & 53 & 1 & 3 \\
\hline A5D7R9_BOVIN & 21 & NRAS protein & & & & & & & 100 & 2 & 12 \\
\hline A5D7N2_BOVIN (+7) & 14 & HIST2H2BE protein & & & & & & & 98 & 1 & 12 \\
\hline A2VDV1_BOVIN & 22 & Ankyrin repeat domain 22 & 99 & 2 & 13 & & & & 74 & 1 & 6 \\
\hline Q28049_BOVIN & 14 & Alpha lactalbumin (Fragment) & 100 & 2 & 20 & 100 & 5 & 37 & & & \\
\hline ALBU_BOVIN & 69 & Serum albumin & 100 & 22 & 49 & 100 & 18 & 29 & & & \\
\hline LIPL_BOVIN & 53 & Lipoprotein lipase & 100 & 2 & 5 & 21 & 1 & 4 & & & \\
\hline RAB8A_BOVIN & 24 & Ras-related protein Rab-8A & & & & & & & & & \\
\hline EF1A1_BOVIN & 50 & Elongation factor 1 -alpha 1 & & & & & & & 28 & 1 & 5 \\
\hline ACOC_BOVIN & 98 & Cytoplasmic aconitate hydratase & & & & & & & & & \\
\hline FABP7_BOVIN & 15 & Fatty acid-binding protein, brain & & & & & & & & & \\
\hline D4QGC1_BOVIN (+1) & 59 & Tyrosine-protein kinase Lyn & 100 & 2 & 6 & & & & & & \\
\hline PPBT_BOVIN & 57 & Alkaline phosphatase, tissue-nonspecific isozyme & 99 & 2 & 4 & & & & & & \\
\hline A4FUH8_BOVIN (+1) & 21 & Chromosome 1 open reading frame 93 ortholog & 99 & 2 & 25 & & & & & & \\
\hline B5T263_9CETA (+6) & 90 & Toll-like receptor $2 \mathrm{OS}=\mathrm{Bos}$ indicus $\mathrm{x}$ Bos taurus GN=TLR2 $\mathrm{PE}=4 \mathrm{SV}=1$ & 97 & 2 & 5 & & & & & & \\
\hline A5D792_BOVIN (+5) & 18 & DCK protein & & & & & & & 100 & 2 & 12 \\
\hline
\end{tabular}

Pro, probability of protein; Pep, peptides identified; \%C, percent peptide coverage 
Table 38. Functional classification of MFGM proteins

\begin{tabular}{|c|c|c|c|c|c|}
\hline MW & $\begin{array}{c}\text { Accession } \\
\text { Number }\end{array}$ & Uniprot & Identified Proteins & Function & $\begin{array}{c}\text { Functional } \\
\text { Classification }\end{array}$ \\
\hline 275 & $\begin{array}{l}\text { FAS_BOVI } \\
\mathrm{N}\end{array}$ & Q71SP7 & Fatty acid synthase & $\begin{array}{l}\text { A multifunctional protein with } 7 \text { catalytic activities. It catalyzes } \\
\text { the formation of long-chain fatty acids from acetyl-CoA, } \\
\text { malonyl-CoA and NADPH. }\end{array}$ & $\begin{array}{l}\text { Lipid } \\
\text { transport/metabolism }\end{array}$ \\
\hline 265 & $\begin{array}{l}\text { ACACA_BO } \\
\text { VIN }\end{array}$ & Q9TTS3 & Acetyl-CoA carboxylase 1 & $\begin{array}{l}\text { Catalyzes the rate-limiting reaction in the biogenesis of long- } \\
\text { chain fatty acids. It also carries out three functions: biotin } \\
\text { carboxyl carrier protein, biotin carboxylase and } \\
\text { carboxyltransferase }\end{array}$ & $\begin{array}{l}\text { Lipid } \\
\text { transport/metabolism }\end{array}$ \\
\hline 147 & $\begin{array}{l}\text { XDH_BOVI } \\
\mathrm{N}\end{array}$ & P80457 & Xanthine dehydrogenase/oxidase & $\begin{array}{l}\text { Complexes with butyrophilin and adipholipin in fat globule } \\
\text { secretion. Also, it plays a role in purine degradation, oxidation } \\
\text { of hypoxanthine to xanthine, oxidation of xanthine to uric acid, } \\
\text { and contributes to the generation of reactive oxygen species }\end{array}$ & $\begin{array}{l}\text { Lipid } \\
\text { transport/metabolism/ } \\
\text { secretion }\end{array}$ \\
\hline 100 & $\begin{array}{l}\text { ENPP3_BO } \\
\text { VIN }\end{array}$ & P15396 & $\begin{array}{l}\text { Ectonucleotide } \\
\text { pyrophosphatase/phosphodiesterase } \\
\text { family member } 3\end{array}$ & $\begin{array}{l}\text { Hydrolyzes extracellular nucleotide and cleaves a variety of } \\
\text { phosphodiester and phosphosulfate bonds including } \\
\text { deoxynucleotides, nucleotide sugars, and NAD. }\end{array}$ & Unknown \\
\hline 98 & $\begin{array}{l}\text { ACOC_BOV } \\
\text { IN }\end{array}$ & Q0VCU1 & Cytoplasmic 9 aconitate hydratase & $\begin{array}{l}\text { Iron sensor. It functions as mRNA binding protein that } \\
\text { regulates uptake, sequestration and utilization of iron when } \\
\text { cellular iron levels are low. }\end{array}$ & Homeostatic regulator \\
\hline 90 & $\begin{array}{l}\text { B5T263_9C } \\
\text { ETA }\end{array}$ & B5T263 & Toll-like receptor 2 (TLR2) & $\begin{array}{l}\text { Mediates recognition of microbial patterns to eliminate } \\
\text { pathogens }\end{array}$ & Immunity \& Defense \\
\hline 88 & $\begin{array}{l}\text { Q99BK3_9A } \\
\text { LPH }\end{array}$ & Q99BK3 & $\begin{array}{l}\text { Ribonucleotide reductase large } \\
\text { subunit }\end{array}$ & $\begin{array}{l}\text { Catalyzes the biosynthesis of deoxyribonucleotides from the } \\
\text { corresponding ribonucleotides }\end{array}$ & $\begin{array}{l}\text { Protein synthesis, } \\
\text { binding, and/or } \\
\text { folding }\end{array}$ \\
\hline 87 & $\begin{array}{l}\text { D5HSX1_B } \\
\text { OVIN }\end{array}$ & D5HSX1 & $\begin{array}{l}\text { cGMP-dependant type II protein } \\
\text { kinase }\end{array}$ & Phosphorylates proteins for up or down regulation & Homeostatic regulator \\
\hline 83 & $\begin{array}{l}\text { ERG7_BOV } \\
\text { IN }\end{array}$ & P84466 & Lanosterol synthase & $\begin{array}{l}\text { Catalyzes the cyclization of }(\mathrm{S})-2,3 \text { oxidosqualene to lanosterol, } \\
\text { a reaction that forms the sterol nucleus. }\end{array}$ & $\begin{array}{l}\text { Lipid } \\
\text { transport/metabolism }\end{array}$ \\
\hline 82 & $\begin{array}{l}\text { PIGR_BOVI } \\
\mathrm{N}\end{array}$ & P81265 & $\begin{array}{l}\text { Polymeric immunoglobulin } \\
\text { receptor }\end{array}$ & $\begin{array}{l}\text { Binds polymeric } \operatorname{IgA} \text { and } \operatorname{IgM} \text { at the basolateral surface of } \\
\text { epithelial cells. }\end{array}$ & Immunity \& Defense \\
\hline 81 & $\begin{array}{l}\text { PERL_BOVI } \\
\mathrm{N}\end{array}$ & P80025 & Lactoperoxidase & $\begin{array}{l}\text { Antimicrobial agent that might protect cow's udder from } \\
\text { infection and promote growth in newborn calves. }\end{array}$ & Immunity \& Defense \\
\hline 78 & $\begin{array}{l}\text { Q0VCZ8_B } \\
\text { OVIN }\end{array}$ & Q0VCZ8 & $\begin{array}{l}\text { Acyl-CoA synthetase long-chain } \\
\text { family member } 1\end{array}$ & Catalytic activity & $\begin{array}{l}\text { Lipid } \\
\text { transport/metabolism }\end{array}$ \\
\hline 78 & B3VTM3_B & B3VTM3 & Lactoferrin & Maintains cellular iron homeostasis, transports iron, and & Homeostatic regulator \\
\hline
\end{tabular}




\begin{tabular}{|c|c|c|c|c|c|}
\hline MW & $\begin{array}{c}\text { Accession } \\
\text { Number }\end{array}$ & Uniprot & Identified Proteins & Function & $\begin{array}{l}\text { Functional } \\
\text { Classification }\end{array}$ \\
\hline 76 & $\begin{array}{l}\text { OVIN } \\
\text { NPT2B_BO } \\
\text { VIN }\end{array}$ & Q27960 & $\begin{array}{l}\text { Sodium-dependent phosphate } \\
\text { transport protein } 2 \mathrm{~B}\end{array}$ & $\begin{array}{l}\text { peptidase activity } \\
\text { Involved in actively transporting phosphate into cells via } \mathrm{Na}^{+} \\
\text {cotransport }\end{array}$ & General transporter \\
\hline 73 & $\begin{array}{l}\text { ABCG2_BO } \\
\text { VIN }\end{array}$ & Q4GZT4 & $\begin{array}{l}\text { ATP-binding cassette sub-family G } \\
\text { member } 2\end{array}$ & $\begin{array}{l}\text { Plays an important role in the exclusion of xenobiotics from the } \\
\text { brain. May be involved in brain-to-blood efflux }\end{array}$ & General transporter \\
\hline 73 & $\begin{array}{l}\text { Q8MKB7_B } \\
\text { OVIN }\end{array}$ & Q8MKB7 & $\mathrm{Na}+$ glucose cotransporter & Transport sodium ion/glucose membrane & General transporter \\
\hline 71 & $\begin{array}{l}\text { HSP7C_BO } \\
\text { VIN }\end{array}$ & P19120 & Heat shock cognate $71 \mathrm{kDa}$ protein & $\begin{array}{l}\text { Acts as a repressor of transcriptional activation and as a } \\
\text { chaperone }\end{array}$ & $\begin{array}{l}\text { Protein synthesis, } \\
\text { binding, and/or } \\
\text { folding }\end{array}$ \\
\hline 69 & $\begin{array}{l}\text { ALBU_BOV } \\
\text { IN }\end{array}$ & P02769 & Serum albumin & $\begin{array}{l}\text { The main protein of plasma, also present in milk, with a good } \\
\text { binding capacity for water, } \mathrm{Ca}^{2+}, \mathrm{Na}^{+}, \mathrm{K}^{+} \text {, fatty acids, hormones, } \\
\text { bilirubin and drugs. }\end{array}$ & Homeostatic regulator \\
\hline 63 & $\begin{array}{l}\text { A5D7M6_B } \\
\text { OVIN }\end{array}$ & A5D7M6 & KRT5 protein & Structure molecule activity & Cell structure \\
\hline 63 & $\begin{array}{l}\text { 5NTD_BOV } \\
\text { IN }\end{array}$ & Q05927 & 5'-nucleotidase & $\begin{array}{l}\text { Hydrolyzes extracellular nucleotides into membrane permeable } \\
\text { nucleosides. }\end{array}$ & General transporter \\
\hline 61 & $\begin{array}{l}\text { A4FV94_BO } \\
\text { VIN }\end{array}$ & A4FV94 & KRT6A protein & Intermediate filament provides structure molecule activity & Cell Structure \\
\hline 59 & $\begin{array}{l}\text { BT1A1_BO } \\
\text { VIN }\end{array}$ & A4FV94 & $\begin{array}{l}\text { Butyrophilin subfamily } 1 \text { member } \\
\text { A1 }\end{array}$ & $\begin{array}{l}\text { Complexes with xanthine oxidase for fat globule secretion \& } \\
\text { MFGM function }\end{array}$ & $\begin{array}{l}\text { Lipid } \\
\text { transport/metabolism }\end{array}$ \\
\hline 59 & $\begin{array}{l}\text { Q0IIA4_BO } \\
\text { VIN }\end{array}$ & Q0IIA4 & $\begin{array}{l}\text { Glycoprotein } 2 \text { (Zymogen granule } \\
\text { membrane) }\end{array}$ & $\begin{array}{l}\text { A major membrane protein in the pancreatic zymogen granule, } \\
\text { which is cleaved and released into the pancreatic duct along } \\
\text { with exocrine secretions. Its function is unknown (Dittie and } \\
\text { Kern, 1992). }\end{array}$ & Unknown/secretion \\
\hline 59 & $\begin{array}{l}\text { A5PKG9_B } \\
\text { OVIN }\end{array}$ & A5PKG9 & FGR protein & $\begin{array}{l}\text { Also known as Gardner-Rasheed feline sarcoma viral (v-fgr) } \\
\text { oncogene homolog. It is involved in protein phosphorylation, } \\
\text { defense response to Gram (+) bacteria, nucleotide binding, } \\
\text { protein kinase activity, ATP binding; transferase activity; } \\
\text { transferring phosphorous-containing groups }\end{array}$ & $\begin{array}{l}\text { Cell surface receptor } \\
\text { mediated signal } \\
\text { transduction }\end{array}$ \\
\hline 59 & $\begin{array}{l}\text { D4QGC1_B } \\
\text { OVIN }\end{array}$ & D4QGC1 & Tyrosine-protein kinase Lyn & $\begin{array}{l}\text { Protein phosphorylation; response to DNA damage stimulus; + } \\
\text { regulation of cell proliferation; response to hormone stimulus; } \\
\text { phosphorylation; erythrocyte differentiation; intracellular signal } \\
\text { transduction; }\end{array}$ & $\begin{array}{l}\text { Cell surface receptor } \\
\text { mediated signal } \\
\text { transduction }\end{array}$ \\
\hline 58 & $\begin{array}{l}\text { MUC1_BOV } \\
\text { IN }\end{array}$ & Q8WML4 & Mucin-1 & Provides a protective layer on epithelial cells against bacterial. & Immunity \& Defense \\
\hline
\end{tabular}




\begin{tabular}{|c|c|c|c|c|c|}
\hline MW & $\begin{array}{l}\text { Accession } \\
\text { Number }\end{array}$ & Uniprot & Identified Proteins & Function & $\begin{array}{l}\text { Functional } \\
\text { Classification }\end{array}$ \\
\hline 57 & $\begin{array}{l}\text { PPBT_BOVI } \\
\mathrm{N}\end{array}$ & P09487 & $\begin{array}{l}\text { Alkaline phosphatase, tissue- } \\
\text { nonspecific isozyme }\end{array}$ & $\begin{array}{l}\text { Catalytic activity: A phosphate monoester }+\mathrm{H}_{2} \mathrm{O}=\text { an alcohol }+ \\
\text { phosphate. }\end{array}$ & Unknown/indicator \\
\hline 55 & $\begin{array}{l}\text { A6QNZ7_B } \\
\text { OVIN }\end{array}$ & A6QNZ7 & $\begin{array}{l}\text { Keratin } 10 \text { (Epidermolytic } \\
\text { hyperkeratosis; keratosis palmaris } \\
\text { et plantaris) }\end{array}$ & Intermediate filament, provides structural activity & Cell structure \\
\hline 53 & $\begin{array}{l}\text { CD36_BOVI } \\
\mathrm{N}\end{array}$ & P26201 & Platelet glycoprotein 4 & $\begin{array}{l}\text { Binds to collagen, thrombospondin, anionic phospholipids and } \\
\text { oxidized LDL. Binds long chain fatty acids and may function in } \\
\text { the transport and/or as a regulator of fatty acid transport. }\end{array}$ & $\begin{array}{l}\text { Lipid } \\
\text { transport/metabolism }\end{array}$ \\
\hline 53 & $\begin{array}{l}\text { LIPL_BOVI } \\
\mathrm{N}\end{array}$ & P11151 & Lipoprotein lipase & $\begin{array}{l}\text { Hydrolyzes triglycerides of circulating chylomicrons and very } \\
\text { low density lipoproteins (VLDL). }\end{array}$ & $\begin{array}{l}\text { Lipid } \\
\text { transport/metabolism }\end{array}$ \\
\hline 52 & $\begin{array}{l}\text { A6H7D4_B } \\
\text { OVIN }\end{array}$ & A6H7D4 & $\begin{array}{l}\text { 1-acylglycerol-3-phosphate } \mathrm{O} \text { - } \\
\text { acyltransferase } 6 \text { (Lysophosphatidic } \\
\text { acid acyltransferase, zeta) }\end{array}$ & $\begin{array}{l}\text { Involved in actyl-CoA metabolic process, lipid biosynthetic } \\
\text { process, regulation of multicelular organism growth, and } \\
\text { transferase activity }\end{array}$ & $\begin{array}{l}\text { Lipid } \\
\text { transport/metabolism }\end{array}$ \\
\hline 50 & $\begin{array}{l}\text { EF1A1_BO } \\
\text { VIN }\end{array}$ & P68103 & Elongation factor 1 -alpha 1 & $\begin{array}{l}\text { Promotes the GTP-dependent binding of aminoacyl-tRNA to } \\
\text { the A-site of ribosomes during protein biosynthesis. }\end{array}$ & $\begin{array}{l}\text { Protein synthesis, } \\
\text { binding, and/or } \\
\text { folding }\end{array}$ \\
\hline 49 & $\begin{array}{l}\text { PLIN2_BOV } \\
\text { IN }\end{array}$ & Q9TUM6 & Perilipin-2 & $\begin{array}{l}\text { May be involved in development and maintenance of adipose } \\
\text { tissue }\end{array}$ & $\begin{array}{l}\text { Lipid } \\
\text { transport/metabolism }\end{array}$ \\
\hline 49 & $\begin{array}{l}\text { Q17QL7_B } \\
\text { OVIN }\end{array}$ & Q17QL7 & KRT15 protein & Intermediate filament & Cell structure \\
\hline 48 & $\begin{array}{l}\text { Q3T0K7_B } \\
\text { OVIN }\end{array}$ & Q3T0K7 & MFGE8 protein & $\begin{array}{l}\text { Involved in cell adhesion, phagocytosis, engulfment, integrin } \\
\text { binding, and phosphatidylethanolamine binding. }\end{array}$ & Immunity \& Defense \\
\hline 48 & $\begin{array}{l}\text { Q3SX32_BO } \\
\text { VIN }\end{array}$ & Q3SX32 & $\begin{array}{l}\text { Mannose } 6 \text { phosphate receptor } \\
\text { binding protein } 1\end{array}$ & $\begin{array}{l}\text { Coat protein for lipid droplets. Shares homology with perilipin } \\
\text { and adipophilin }\end{array}$ & $\begin{array}{l}\text { Lipid } \\
\text { transport/metabolism }\end{array}$ \\
\hline 46 & $\begin{array}{l}\text { GNAS2_BO } \\
\text { VIN }\end{array}$ & P04896 & $\begin{array}{l}\text { Guanine nucleotide-binding protein } \\
G(s) \text { subunit alpha isoforms short }\end{array}$ & $\begin{array}{l}\text { Involved as modulators or transducers in various } \\
\text { transmembrane signaling systems. The } \mathrm{G}(\mathrm{s}) \text { protein is involved } \\
\text { in hormonal regulation of adenylate cyclase: it activates the } \\
\text { cyclase in response to beta-adrenergic stimuli. }\end{array}$ & $\begin{array}{l}\text { G-protein mediated } \\
\text { cell signaling }\end{array}$ \\
\hline 46 & $\begin{array}{l}\text { Q3ZC65_BO } \\
\text { VIN }\end{array}$ & Q3ZC65 & Ancient ubiquitous protein 1 & Involved in acyltransferase activity and metabolic process & $\begin{array}{l}\text { Lipid } \\
\text { transport/metabolism }\end{array}$ \\
\hline 42 & $\begin{array}{l}\text { ACTB_BOV } \\
\text { IN }\end{array}$ & P60712 & Actin, cytoplasmic 1 & $\begin{array}{l}\text { Involved in various types of cell motility and are ubiquitously } \\
\text { expressed in all eukaryotic cells. }\end{array}$ & Cell structure \\
\hline 40 & $\begin{array}{l}\text { NSDHL_BO } \\
\text { VIN }\end{array}$ & Q3ZBE9 & $\begin{array}{l}\text { Sterol-4-alpha-carboxylate } 3 \text { - } \\
\text { dehydrogenase, decarboxylating }\end{array}$ & $\begin{array}{l}\text { Catalyzes following reaction: 3-beta-hydroxy-4-beta-methyl-5- } \\
\text { alpha-cholest-7-ene-4-alpha-carboxylate }+\mathrm{NAD}(\mathrm{P})^{+}=4 \text {-alpha- } \\
\text { methyl-5-alpha-cholest-7-en-3-one }+\mathrm{CO}_{2}+\mathrm{NAD}(\mathrm{P}) \mathrm{H} \text {. }\end{array}$ & $\begin{array}{l}\text { Lipid } \\
\text { transport/metabolism }\end{array}$ \\
\hline
\end{tabular}




\begin{tabular}{|c|c|c|c|c|c|}
\hline MW & $\begin{array}{l}\text { Accession } \\
\text { Number }\end{array}$ & Uniprot & Identified Proteins & Function & $\begin{array}{c}\text { Functional } \\
\text { Classification }\end{array}$ \\
\hline 40 & $\begin{array}{l}\text { GNAI1_BO } \\
\text { VIN }\end{array}$ & P63097 & $\begin{array}{l}\text { Guanine nucleotide-binding protein } \\
\text { G(i) subunit alpha-1 }\end{array}$ & $\begin{array}{l}\text { Involved as modulators or transducers in various } \\
\text { transmembrane signaling systems. }\end{array}$ & $\begin{array}{l}\text { G-protein mediated } \\
\text { cell signaling }\end{array}$ \\
\hline 40 & $\begin{array}{l}\text { A6QNL0_B } \\
\text { OVIN }\end{array}$ & A6QNL0 & $\begin{array}{l}\text { Monocyte differentiation antigen } \\
\text { CD14 }\end{array}$ & $\begin{array}{l}\text { Cooperates with MD- } 2 \text { and TLR4 to mediate the innate immune } \\
\text { response to bacterial lipopolysaccharide (LPS). }\end{array}$ & Immunity \& Defense \\
\hline 39 & $\begin{array}{l}\text { ANXA1_BO } \\
\text { VIN }\end{array}$ & P46193 & Annexin A1 & $\begin{array}{l}\text { It is a calcium/phospholipid-binding protein, which promotes } \\
\text { membrane fusion and is involved in exocytosis. Annexin A1 is } \\
\text { released from apoptotic neutrophils and acts on macrophages to } \\
\text { promote phagocytosis and removal of apoptotic cells (Perretti } \\
\text { and D'Acquisto, 2009). }\end{array}$ & Immunity \& defense \\
\hline 39 & $\begin{array}{l}\text { ANXA2_BO } \\
\text { VIN }\end{array}$ & P04272 & Annexin A2 & $\begin{array}{l}\text { It is a calcium-regulated membrane-binding protein, which } \\
\text { binds two } \mathrm{Ca}^{+2} \text { ions and whose affinity for calcium is greatly } \\
\text { enhanced by anionic phospholipids. It is a cell surface receptor } \\
\text { that induces the expression cell adhesion molecules } \\
\text { (Yoder; Lennon } \text { et al.; Zhang and McCrae). }\end{array}$ & $\begin{array}{l}\text { Cell surface receptor } \\
\text { mediated signal } \\
\text { transduction }\end{array}$ \\
\hline 38 & $\begin{array}{l}\text { A9XTK4_B } \\
\text { OVIN }\end{array}$ & A9XTK4 & $\begin{array}{l}\text { 17-beta hydroxysteroid } \\
\text { dehydrogenase }\end{array}$ & $\begin{array}{l}\text { Enzyme involved in oxidation-reduction process, binding, and } \\
\text { metabolic process }\end{array}$ & $\begin{array}{l}\text { Lipid } \\
\text { transport/metabolism }\end{array}$ \\
\hline 37 & $\begin{array}{l}\text { GBB2_BOV } \\
\text { IN }\end{array}$ & P11017 & $\begin{array}{l}\text { Guanine nucleotide-binding protein } \\
\mathrm{G}(\mathrm{I}) / \mathrm{G}(\mathrm{S}) / \mathrm{G}(\mathrm{T}) \text { subunit beta- } 2\end{array}$ & $\begin{array}{l}\text { Involved as a modulator or transducer in various } \\
\text { transmembrane signaling systems. The beta and gamma chains } \\
\text { are required for the GTPase activity, for replacement of GDP } \\
\text { by GTP, and for G protein-effector interaction. }\end{array}$ & $\begin{array}{l}\text { G-protein mediated } \\
\text { cell signaling }\end{array}$ \\
\hline 37 & $\begin{array}{l}\text { GBB1_BOV } \\
\text { IN }\end{array}$ & P62871 & $\begin{array}{l}\text { Guanine nucleotide-binding protein } \\
\mathrm{G}(\mathrm{I}) / \mathrm{G}(\mathrm{S}) / \mathrm{G}(\mathrm{T}) \text { subunit beta-1 }\end{array}$ & $\begin{array}{l}\text { Modulator or transducer in various transmembrane signaling } \\
\text { systems. }\end{array}$ & $\begin{array}{l}\text { G-protein mediated } \\
\text { cell signaling }\end{array}$ \\
\hline 36 & $\begin{array}{l}\text { A7E340_BO } \\
\text { VIN }\end{array}$ & A7E340 & Mucin 15 , cell surface associated & Provides protection to neonate by binding to bacteria & Immunity \& Defense \\
\hline 36 & $\begin{array}{l}\text { ANXA5_BO } \\
\text { VIN }\end{array}$ & P81287 & Annexin A5 & $\begin{array}{l}\text { An anticoagulant protein that acts as an indirect inhibitor of the } \\
\text { thromboplastin-specific complex. Recently, it was demonstrate } \\
\text { to contribute to membrane repair (Bouter } \text { et al., 2011). }\end{array}$ & Homeostatic regulator \\
\hline 36 & $\begin{array}{l}\text { A7YWR0_B } \\
\text { OVIN }\end{array}$ & A7YWR0 & Apolipoprotein E & $\begin{array}{l}\text { Involved in negatively regulation of endothelial cell } \\
\text { proliferation, lipid metabolic process, cholesterol catabolic } \\
\text { process, lipid transport, induction of apoptosis, and anti- } \\
\text { apoptosis; }\end{array}$ & $\begin{array}{l}\text { Lipid } \\
\text { transport/metabolism }\end{array}$ \\
\hline 35 & $\begin{array}{l}\text { GIPC2_BOV } \\
\text { IN }\end{array}$ & Q1JQD4 & $\begin{array}{l}\text { PDZ domain-containing protein } \\
\text { GIPC2 }\end{array}$ & Found in cytoplasm, provides structure & Cell structure \\
\hline 34 & $\begin{array}{l}\text { Q6QRN7_B } \\
\text { OVIN }\end{array}$ & Q6QRN7 & PP1201 protein & $\begin{array}{l}\text { Also known as RECS1 is expressed in higher levels in response } \\
\text { to laminar shear stress (Shukla } \text { et al.) }\end{array}$ & Homeostatic regulator \\
\hline
\end{tabular}




\begin{tabular}{|c|c|c|c|c|c|}
\hline MW & $\begin{array}{c}\text { Accession } \\
\text { Number } \\
\end{array}$ & Uniprot & Identified Proteins & Function & $\begin{array}{c}\text { Functional } \\
\text { Classification }\end{array}$ \\
\hline 34 & $\begin{array}{l}\text { Q2KIS4_BO } \\
\text { VIN }\end{array}$ & Q2KIS4 & $\begin{array}{l}\text { Dehydrogenase/reductase (SDR } \\
\text { family) member } 1\end{array}$ & $\begin{array}{l}\text { Involved in oxidation-reduction process, binding, and } \\
\text { metabolic process }\end{array}$ & Homeostatic regulator \\
\hline 34 & $\begin{array}{l}\text { A6H7G0_B } \\
\text { OVIN }\end{array}$ & P07514 & CYB5R3 protein & $\begin{array}{l}\text { Involved in desaturation and elongation of fatty acids, } \\
\text { cholesterol biosynthesis, drug metabolism, and, in erythrocyte, } \\
\text { methemoglobin reduction. }\end{array}$ & $\begin{array}{l}\text { Lipid } \\
\text { transport/metabolism }\end{array}$ \\
\hline 33 & $\begin{array}{l}\text { A6QLH3_B } \\
\text { OVIN }\end{array}$ & A6QLH3 & STX3 protein & $\begin{array}{l}\text { Involved in intracellular protein transport, neurotransmitter } \\
\text { transport, SNAP receptor activity, exocytosis; cell-cell } \\
\text { junction; }\end{array}$ & $\begin{array}{l}\text { Membrane/protein } \\
\text { trafficking }\end{array}$ \\
\hline 31 & $\begin{array}{l}\text { A8E4P3_BO } \\
\text { VIN }\end{array}$ & A8E4P3 & STOM protein & Associates with membrane and involved in cation conductance & General transporter \\
\hline 26 & $\begin{array}{l}\text { CASA2_BO } \\
\text { VIN }\end{array}$ & P02663 & Alpha-S2-casein & $\begin{array}{l}\text { Important role in the capacity of milk to transport calcium } \\
\text { phosphate. Casocidin-I inhibits the growth of E.coli and } \\
\text { S.carnosus. }\end{array}$ & Milk protein \\
\hline 26 & $\begin{array}{l}\text { B0JYP6_BO } \\
\text { VIN }\end{array}$ & B0JYP6 & IGK protein & Immunoglobulin light chain kappa v & Immunity \& defense \\
\hline 25 & $\begin{array}{l}\text { CASA1_BO } \\
\text { VIN }\end{array}$ & P02662 & Alpha-S1-casein & $\begin{array}{l}\text { Important role in the capacity of milk to transport calcium } \\
\text { phosphate. Antioxidant peptide has 2,2-diphenyl-1- } \\
\text { picrylhydrazyl (DPPH) radical scavenging activity }\end{array}$ & Milk protein \\
\hline 25 & $\begin{array}{l}\text { Q3T101_BO } \\
\text { VIN }\end{array}$ & Q3T101 & IGL@ protein & Immunoglobulin lambda locus & Immunity \& defense \\
\hline 25 & $\begin{array}{l}\text { A4FUX1_B } \\
\text { OVIN }\end{array}$ & A4FUX1 & CIDEA protein & $\begin{array}{l}\text { A member of CIDE (cell-death-inducing DNA-fragmentation- } \\
\text { factor- } 45 \text {-like effector) family of proteins, which are highly } \\
\text { enriched in brown adipose tissue playing a critical role in } \\
\text { adaptive thermogenesis and fat accumulation (Christianson et } \\
\text { al.). }\end{array}$ & $\begin{array}{l}\text { Lipid } \\
\text { transport/metabolism }\end{array}$ \\
\hline 25 & $\begin{array}{l}\text { Q1RMN8_B } \\
\text { OVIN }\end{array}$ & Q1RMN8 & $\begin{array}{l}\text { Immunoglobulin light chain, } \\
\text { lambda gene cluster }\end{array}$ & Involved in immunity & Immunity \& defense \\
\hline 24 & $\begin{array}{l}\text { RB11A_BO } \\
\text { VIN }\end{array}$ & Q2TA29 & Ras-related protein Rab-11A & $\begin{array}{l}\text { Modulates endosomal trafficking. Acts as a major regulator of } \\
\text { membrane delivery during cytokinesis }\end{array}$ & $\begin{array}{l}\text { Membrane/protein } \\
\text { trafficking }\end{array}$ \\
\hline 24 & $\begin{array}{l}\text { RAB7A_BO } \\
\text { VIN }\end{array}$ & Q3T0F5 & Ras-related protein Rab-7a & $\begin{array}{l}\text { Involved in late endocytic transport. Contributes to the } \\
\text { maturation of phagosomes (acidification) }\end{array}$ & $\begin{array}{l}\text { Membrane/protein } \\
\text { trafficking }\end{array}$ \\
\hline 24 & $\begin{array}{l}\text { Q2TBH2_B } \\
\text { OVIN }\end{array}$ & Q2TBH2 & $\begin{array}{l}\text { Related RAS viral (R-ras) } \\
\text { oncogene homolog }\end{array}$ & $\begin{array}{l}\text { GTP-binding; nucleotide-binding; small GTPase mediated } \\
\text { signal transductitn; intracelleluar; membrane }\end{array}$ & $\begin{array}{l}\text { Membrane/protein } \\
\text { trafficking }\end{array}$ \\
\hline 24 & $\begin{array}{l}\text { RAB8A_BO } \\
\text { VIN }\end{array}$ & A4FV54 & Ras-related protein Rab-8A & $\begin{array}{l}\text { May be involved in vesicular trafficking and neurotransmitter } \\
\text { release }\end{array}$ & $\begin{array}{l}\text { Membrane/protein } \\
\text { trafficking }\end{array}$ \\
\hline
\end{tabular}




\begin{tabular}{|c|c|c|c|c|c|}
\hline MW & $\begin{array}{l}\text { Accession } \\
\text { Number }\end{array}$ & Uniprot & Identified Proteins & $\begin{array}{ll}\text { Function } \\
\end{array}$ & $\begin{array}{c}\text { Functional } \\
\text { Classification }\end{array}$ \\
\hline 23 & $\begin{array}{l}\text { RAB18_BO } \\
\text { VIN }\end{array}$ & Q0IIG8 & Ras-related protein Rab-18 & $\begin{array}{l}\text { Plays a role in apical endocytosis/recycling. May be implicated } \\
\text { in transport between the plasma membrane and early } \\
\text { endosomes }\end{array}$ & $\begin{array}{l}\text { Membrane/protein } \\
\text { trafficking }\end{array}$ \\
\hline 23 & $\begin{array}{l}\text { A1L528_BO } \\
\text { VIN }\end{array}$ & A1L528 & $\begin{array}{l}\text { RAB1A, member RAS oncogene } \\
\text { family }\end{array}$ & $\begin{array}{l}\text { GTP-binding; nucleotide-binding; protein transport; small } \\
\text { GTPase mediated signal transduction }\end{array}$ & $\begin{array}{l}\text { G-protein mediated } \\
\text { cell signaling }\end{array}$ \\
\hline 23 & $\begin{array}{l}\text { Q2T9M8_B } \\
\text { OVIN }\end{array}$ & Q2T9M8 & $\begin{array}{l}\text { Synaptosomal-associated protein } 23 \\
\text { isoform SNAP23A }\end{array}$ & $\begin{array}{l}\text { Forms a complex which serves as a binding site for the general } \\
\text { membrane fusion machinery. Synaptobrevin/VAMP and } \\
\text { syntaxin are believed to be involved in vesicular transport. }\end{array}$ & $\begin{array}{l}\text { Membrane/protein } \\
\text { trafficking }\end{array}$ \\
\hline 23 & $\begin{array}{l}\text { ARL15_BO } \\
\text { VIN }\end{array}$ & Q5EA19 & $\begin{array}{l}\text { ADP-ribosylation factor-like } \\
\text { protein } 15\end{array}$ & A member of the ARF family of GTP-binding proteins & $\begin{array}{l}\text { G-protein mediated } \\
\text { cell signaling }\end{array}$ \\
\hline 23 & $\begin{array}{l}\text { RAB13_BO } \\
\text { VIN }\end{array}$ & Q58DS5 & Ras-related protein Rab-13 & $\begin{array}{l}\text { Could participate in polarized transport, in the assembly and/or } \\
\text { the activity of tight junctions }\end{array}$ & $\begin{array}{l}\text { Membrane/protein } \\
\text { trafficking }\end{array}$ \\
\hline 23 & $\begin{array}{l}\text { RAB5C_BO } \\
\text { VIN }\end{array}$ & Q58DS9 & Ras-related protein Rab-5C & $\begin{array}{l}\text { Involved in protein transport, probably involved in vesicular } \\
\text { traffic. }\end{array}$ & $\begin{array}{l}\text { Membrane/protein } \\
\text { trafficking }\end{array}$ \\
\hline 23 & $\begin{array}{l}\text { A5D7E0_B } \\
\text { OVIN }\end{array}$ & A5D7E0 & RAB35 protein & $\begin{array}{l}\text { GTP-binding; nucleotide binding; protein transport; small } \\
\text { GTPase mediated signal transduction }\end{array}$ & $\begin{array}{l}\text { Membrane/protein } \\
\text { trafficking }\end{array}$ \\
\hline 22 & $\begin{array}{l}\text { SAR1A_BO } \\
\text { VIN }\end{array}$ & Q3T0D7 & GTP-binding protein SAR1a & $\begin{array}{l}\text { Involved in transport from the endoplasmic reticulum to the } \\
\text { Golgi apparatus. SAR1A-GTP-dependent assembly of SEC16A } \\
\text { on the ER membrane forms an organized scaffold defining } \\
\text { endoplasmic reticulum exit sites (ERES). }\end{array}$ & $\begin{array}{l}\text { Membrane/protein } \\
\text { trafficking }\end{array}$ \\
\hline 22 & $\begin{array}{l}\text { YKT6_BOV } \\
\text { IN }\end{array}$ & Q3T000 & Synaptobrevin homolog YKT6 & $\begin{array}{l}\text { It is a vesicular soluble NSF attachment protein receptor (v- } \\
\text { SNARE) mediating vesicle docking and fusion to a specific } \\
\text { acceptor cellular compartment. }\end{array}$ & $\begin{array}{l}\text { Membrane/protein } \\
\text { trafficking }\end{array}$ \\
\hline 22 & $\begin{array}{l}\text { CHP1_BOVI } \\
\text { N }\end{array}$ & Q3SYS6 & Calcium-binding protein $\mathrm{p} 22$ & $\begin{array}{l}\text { Required for constitutive membrane traffic. Inhibits GTPase- } \\
\text { stimulated } \mathrm{Na}^{+} / \mathrm{H}^{+} \text {exchange. Also inhibits calcineurin } \\
\text { phosphatase activity. Required for activity of SLC9A1/NHE1 }\end{array}$ & $\begin{array}{l}\text { General transporter/ } \\
\mathrm{Ca}^{+2} \text { in milk }\end{array}$ \\
\hline 22 & $\begin{array}{l}\text { RHOC_BOV } \\
\text { IN }\end{array}$ & Q1RMJ6 & $\begin{array}{l}\text { Rho-related GTP-binding protein } \\
\text { RhoC }\end{array}$ & $\begin{array}{l}\text { Regulates a signal transduction pathway linking plasma } \\
\text { membrane receptors to the assembly of focal adhesions and } \\
\text { actin stress fibers }\end{array}$ & $\begin{array}{l}\text { G-protein mediated } \\
\text { cell signaling }\end{array}$ \\
\hline 22 & $\begin{array}{l}\text { A2VDV1_B } \\
\text { OVIN }\end{array}$ & A2VDV1 & Ankyrin repeat domain 22 & Assists in protein-protein interaction & Protein interaction \\
\hline 21 & $\begin{array}{l}\text { CASK_BOV } \\
\text { IN }\end{array}$ & P02668 & Kappa-casein & $\begin{array}{l}\text { Kappa-casein stabilizes micelle formation, preventing casein } \\
\text { precipitation in milk. Casoxins A, B and C have opioid } \\
\text { antagonist activity. Casoxin C causes biphasic ileal contractions } \\
\text { through the binding to the complement C3a } \\
\text { receptors.Casoplatelin inhibits platelet aggregation. }\end{array}$ & Milk protein \\
\hline
\end{tabular}




\begin{tabular}{|c|c|c|c|c|c|}
\hline MW & $\begin{array}{l}\text { Accession } \\
\text { Number }\end{array}$ & Uniprot & Identified Proteins & Function & $\begin{array}{c}\text { Functional } \\
\text { Classification }\end{array}$ \\
\hline 21 & $\begin{array}{l}\text { RAC1_BOV } \\
\text { IN }\end{array}$ & P62998 & $\begin{array}{l}\text { Ras-related C3 botulinum toxin } \\
\text { substrate } 1\end{array}$ & $\begin{array}{l}\text { A plasma membrane-associated small GTPase, which cycles } \\
\text { between active GTP-bound and inactive GDP-bound states. In } \\
\text { its active state, binds to a variety of effector proteins to regulate } \\
\text { cellular responses such as secretory processes, phagocytosis of } \\
\text { apoptotic cells, epithelial cell polarization and growth-factor } \\
\text { induced formation of membrane ruffles. }\end{array}$ & $\begin{array}{l}\text { G-protein mediated } \\
\text { cell signaling }\end{array}$ \\
\hline 21 & $\begin{array}{l}\text { RAP1A_BO } \\
\text { VIN }\end{array}$ & P62833 & Ras-related protein Rap-1A & $\begin{array}{l}\text { Induces morphological reversion of a cell line transformed by a } \\
\text { Ras oncogene. }\end{array}$ & $\begin{array}{l}\text { G-protein mediated } \\
\text { cell signaling }\end{array}$ \\
\hline 21 & $\begin{array}{l}\text { B6VAP7_B } \\
\text { OVIN }\end{array}$ & B6VAP7 & CDC42 protein & $\begin{array}{l}\text { Small GTPase mediated signal transduction; cell-cell adhesion; } \\
\text { acin cytoskeleton organization; positive regulation of protein } \\
\text { phosphorylation; }\end{array}$ & $\begin{array}{l}\text { G-protein mediated } \\
\text { cell signaling }\end{array}$ \\
\hline 21 & $\begin{array}{l}\text { ARF1_BOVI } \\
\mathrm{N}\end{array}$ & P84080 & ADP-ribosylation factor 1 & $\begin{array}{l}\text { A GTP-binding protein involved in protein trafficking among } \\
\text { different compartments. It modulates vesicle budding and } \\
\text { uncoating within the Golgi complex. Deactivation induces the } \\
\text { redistribution of the entire Golgi complex to the endoplasmic } \\
\text { reticulum, suggesting a crucial role in protein trafficking. }\end{array}$ & $\begin{array}{l}\text { Membrane/protein } \\
\text { trafficking }\end{array}$ \\
\hline 21 & $\begin{array}{l}\text { A5D7R9_B } \\
\text { OVIN }\end{array}$ & A5D7R9 & NRAS protein & $\begin{array}{l}\text { Neuroblastoma RAS viral (v-ras) oncogene homolog, a small } \\
\text { GTPase mediated signal transduction protein that shuttles } \\
\text { between Golgi apparatus and the plasma membrane }\end{array}$ & $\begin{array}{l}\text { G-protein mediated } \\
\text { cell signaling }\end{array}$ \\
\hline 21 & $\begin{array}{l}\text { A4FUH8_B } \\
\text { OVIN }\end{array}$ & Q58CY6 & $\begin{array}{l}\text { Chromosome } 1 \text { open reading frame } \\
93 \text { ortholog }\end{array}$ & Unsure & Unknown \\
\hline 20 & $\begin{array}{l}\text { B5B0D4_B } \\
\text { OVIN }\end{array}$ & B5B0D4 & Major allergen beta-lactoglobulin & Fractionation in whey protein correlates with allergen & Whey protein \\
\hline 20 & $\begin{array}{l}\text { LACB_BOV } \\
\text { IN }\end{array}$ & $\mathrm{P} 02754$ & Beta-lactoglobulin & Primary component of whey. & Whey protein \\
\hline 19 & $\begin{array}{l}\text { BOJYL8_BO } \\
\text { VIN }\end{array}$ & B0JYL8 & Cofilin 1 (Non-muscle) & $\begin{array}{l}\text { Cofilin causes depolymerization at the minus end of filaments, } \\
\text { which prevents their reassembly. }\end{array}$ & $\begin{array}{l}\text { Protein synthesis, } \\
\text { binding, and/or } \\
\text { folding }\end{array}$ \\
\hline 18 & $\begin{array}{l}\text { CTHL1_BO } \\
\text { VIN }\end{array}$ & P22226 & Cathelicidin-1 & $\begin{array}{l}\text { It has a potent microbicidal activity and is active against } \\
\text { S.aureus and E.coli. }\end{array}$ & Immunity \& defense \\
\hline 18 & $\begin{array}{l}\text { Q3SYR8_B } \\
\text { OVIN }\end{array}$ & Q3SYR8 & Immunoglobulin $\mathrm{J}$ chain & Immunity & Immunity \& defense \\
\hline 18 & $\begin{array}{l}\text { SEP15_BOV } \\
\text { IN }\end{array}$ & A8YXY3 & $15 \mathrm{kDa}$ selenoprotein & $\begin{array}{l}\text { It may contribute to the quality control of protein folding in the } \\
\text { endoplasmic reticulum }\end{array}$ & $\begin{array}{l}\text { Protein synthesis, } \\
\text { binding, and/or } \\
\text { folding }\end{array}$ \\
\hline
\end{tabular}




\begin{tabular}{|c|c|c|c|c|c|}
\hline MW & $\begin{array}{c}\text { Accession } \\
\text { Number }\end{array}$ & Uniprot & Identified Proteins & Function & $\begin{array}{c}\text { Functional } \\
\text { Classification }\end{array}$ \\
\hline 18 & $\begin{array}{l}\text { A5D792_BO } \\
\text { VIN }\end{array}$ & A5D792 & DCK protein & It is a core component of nucleosome. & $\begin{array}{l}\text { Protein synthesis, } \\
\text { binding, and/or } \\
\text { folding }\end{array}$ \\
\hline 17 & $\begin{array}{l}\text { GLCM1_BO } \\
\text { VIN }\end{array}$ & P80195 & $\begin{array}{l}\text { Glycosylation-dependent cell } \\
\text { adhesion molecule } 1\end{array}$ & $\begin{array}{l}\text { It is a mucin-like endothelial glycoprotein that acts as an } \\
\text { adhesive ligand for L selectin, a leukocyte cell surface protein } \\
\text { (Dowbenko } \text { et al., 1993) }\end{array}$ & Immunity \& defense \\
\hline 16 & $\begin{array}{l}\text { Q861V9_BO } \\
\text { VIN }\end{array}$ & Q5EA19 & $\begin{array}{l}\text { Similar to peptidylprolyl isomerase } \\
\text { A (Cyclophilin A) (Fragment) }\end{array}$ & Also known as PPIA accelerates protein folding & $\begin{array}{l}\text { Protein synthesis, } \\
\text { binding, and/or } \\
\text { folding }\end{array}$ \\
\hline 15 & $\begin{array}{l}\text { FABPH_BO } \\
\text { VIN }\end{array}$ & P10790 & Fatty acid-binding protein, heart & $\begin{array}{l}\text { Plays a role in the intracellular transport of long-chain fatty } \\
\text { acids and their acyl-CoA esters.. }\end{array}$ & $\begin{array}{l}\text { Lipid } \\
\text { transport/metabolism }\end{array}$ \\
\hline 15 & $\begin{array}{l}\text { FABP7_BO } \\
\text { VIN }\end{array}$ & Q09139 & Fatty acid-binding protein, brain & $\begin{array}{l}\text { Plays a role in the intracellular transport of long chain fatty } \\
\text { acids and their acyl-CoA esters. }\end{array}$ & $\begin{array}{l}\text { Lipid } \\
\text { transport/metabolism }\end{array}$ \\
\hline 14 & $\begin{array}{l}\text { Q9TSF1_BO } \\
\text { VIN }\end{array}$ & Q9TSF1 & Butyrophilin (Fragment) & $\begin{array}{l}\text { Complexes with xanthine oxydase in fat globule secretion \& } \\
\text { MFGM function }\end{array}$ & $\begin{array}{l}\text { Lipid } \\
\text { transport/metabolism }\end{array}$ \\
\hline 14 & $\begin{array}{l}\text { A5D7N2_B } \\
\text { OVIN }\end{array}$ & A5D7N2 & HIST2H2BE protein & It is a core component of nucleosome. & $\begin{array}{l}\text { Protein synthesis, } \\
\text { binding, and/or } \\
\text { folding }\end{array}$ \\
\hline 14 & $\begin{array}{l}\text { Q28049_BO } \\
\text { VIN }\end{array}$ & Q28049 & Alpha lactalbumin (Fragment) & A whey protein, which binds calcium ions. & Whey protein \\
\hline 2 & $\begin{array}{l}\text { Q9TRB9_B } \\
\text { OVIN }\end{array}$ & Q9TRB9 & $\begin{array}{l}\text { Enterotoxin-binding glycoprotein } \\
\text { PP20K (Fragment) }\end{array}$ & $\begin{array}{l}\text { A E. coli heat-labile enterotoxin that binds to caseins, whey } \\
\text { proteins, and milk fat globule membrane (Shida et al., 1994) }\end{array}$ & Whey protein \\
\hline
\end{tabular}




\section{K. Two-Dimensional Statistical Data from Delta2D}

Table 39. ANOVA-2 results utilizing Delta2D for all treatments against Fresh milk as a control $(\mathrm{p}<0.01)$.

\begin{tabular}{lllllllc}
\hline \multirow{2}{*}{ Parameter } & \multicolumn{2}{c}{ 3 Week_6Treat } & \multicolumn{3}{c}{ 3 Week_5Treat } & \multicolumn{2}{c}{ Fresh/4C/UV } \\
\cline { 2 - 7 } & \multicolumn{2}{c}{$\#$} & \% & $\#$ & \% & $\#$ & \% \\
\hline Temperature significant & 286 & 86 & 199 & 65 & 169 & 52 \\
Week significant & 211 & 64 & 194 & 63 & 168 & 52 \\
Interaction significant & 184 & 55 & 144 & 47 & 94 & 29 \\
Temperature non-significant & 46 & 14 & 109 & 35 & 155 & 48 \\
Week non-significant & 121 & 36 & 114 & 37 & 156 & 48 \\
Interacion non-significant & 148 & 45 & 164 & 53 & 230 & 71 \\
Non-significant for all effects & 18 & 5 & 50 & 16 & 90 & 28 \\
\hline Total Spots & 332 & & 308 & & 324 & \\
\hline
\end{tabular}

\#, Total protein in category; \%, Percent variation

Table 40. ANOVA-2 results utilizing Delta2D for each treatment against Fresh milk as a control $(\mathrm{p}<0.01)$.

\begin{tabular}{|c|c|c|c|c|c|c|c|c|c|c|}
\hline \multirow[t]{2}{*}{ Parameters } & \multicolumn{2}{|c|}{$4 \mathrm{C}$} & \multicolumn{2}{|c|}{ UV } & \multicolumn{2}{|c|}{ Batch } & \multicolumn{2}{|c|}{ HTST } & \multicolumn{2}{|c|}{ UHT } \\
\hline & \# & $\%$ & $\#$ & $\%$ & $\#$ & $\%$ & $\#$ & $\%$ & \# & $\%$ \\
\hline Temperature significant & 104 & 34 & 116 & 37 & 171 & 50 & 128 & 37 & 186 & 67 \\
\hline Week significant & 138 & 45 & 112 & 37 & 145 & 43 & 127 & 36 & 101 & 36 \\
\hline Interaction significant & 54 & 18 & 54 & 17 & 100 & 29 & 83 & 24 & 92 & 33 \\
\hline Temperature non-significant & 201 & 66 & 195 & 63 & 170 & 50 & 222 & 63 & 91 & 33 \\
\hline Week non-significant & 167 & 55 & 199 & 64 & 196 & 57 & 223 & 64 & 176 & 64 \\
\hline Interacion non-significant & 251 & 82 & 257 & 83 & 241 & 71 & 267 & 76 & 185 & 67 \\
\hline Non-significant for all effects & 109 & 36 & 132 & 42 & 102 & 30 & 133 & 38 & 60 & 22 \\
\hline Total Spots & 305 & & 311 & & 341 & & 350 & & 277 & \\
\hline
\end{tabular}

\#, Total protein in category; \%, Percent variation 